Florida International University

FIU Digital Commons

FIU Electronic Theses and Dissertations

University Graduate School

$12-9-2014$

\title{
Experimental and Analytical Methodologies for Predicting Peak Loads on Building Envelopes and Roofing Systems
}

Maryam Asghari Mooneghi

masgh002@fiu.edu

DOI: $10.25148 /$ etd.FI15032179

Follow this and additional works at: https:// digitalcommons.fiu.edu/etd

Part of the Civil Engineering Commons, Computational Engineering Commons, and the Structural Engineering Commons

\section{Recommended Citation}

Asghari Mooneghi, Maryam, "Experimental and Analytical Methodologies for Predicting Peak Loads on Building Envelopes and Roofing Systems" (2014). FIU Electronic Theses and Dissertations. 1846.

https://digitalcommons.fiu.edu/etd/1846 


\title{
FLORIDA INTERNATIONAL UNIVERSITY \\ Miami, Florida
}

\section{EXPERIMENTAL AND ANALYTICAL METHODOLOGIES FOR PREDICTING}

PEAK LOADS ON BUILDING ENVELOPES AND ROOFING SYSTEMS

\author{
A dissertation submitted in partial fulfillment of \\ the requirements for the degree of \\ DOCTOR OF PHILOSOPHY \\ in \\ CIVIL ENGINEERING
}

by

Maryam Asghari Mooneghi 
To: Dean Amir Mirmiran

College of Engineering and Computing

This dissertation, written by Maryam Asghari Mooneghi, and entitled Experimental and Analytical Methodologies for Predicting Peak Loads on Building Envelopes and Roofing Systems, having been approved in respect to style and intellectual content, is referred to you for judgment.

We have read this dissertation and recommend that it be approved.

$\begin{array}{r}\text { Irtishad Ahmad } \\ \hline \text { Atorod Azizinamini } \\ \hline \text { Arindam Gan Chowdhury, Co-Major Professor } \\ \hline \text { Peter Irwin, Co-Major Professor }\end{array}$

Date of Defense: December 9, 2014

The dissertation of Maryam Asghari Mooneghi is approved.

$\begin{array}{r}\text { Dean Amir Mirmiran } \\ \text { College of Engineering and Computing } \\ \hline \begin{array}{r}\text { Dean Lakshmi N. Reddi } \\ \text { University Graduate School }\end{array}\end{array}$

Florida International University, 2014 
C Copyright 2014 by Maryam Asghari Mooneghi

All rights reserved. 


\section{DEDICATION}

This dissertation is dedicated from the bottom of my heart to my husband, Ramtin Kargarmoakhar, for his unconditional love and everlasting support which made this dissertation possible. He has made a lot of sacrifices during my academic career. He has been by my side throughout this entire process providing words of encouragement and giving me a shoulder to lean on when I most needed it, and wiped my tears when I thought I was going into a meltdown. I was fortunate that he was also a PhD candidate in the same major and we could discuss together about our research and help each other with long days of experiments in the Wall of Wind lab at FIU. No one else fully knows what went into this effort, no one else put more into it and no one else can better share with me the joy of the accomplishment.

To my dear parents, Mr. Aboumohammad Asghari Mooneghi and Mrs. Soheila Esmaeeli Tehrani, who have always loved me unconditionally, supported me and taught me to work hard for the things that I aspire to achieve. I will never forget my father's smiles admiring me for my achievements.

To my always encouraging, ever caring and loving sisters, Sarah, Narges and Shiva who have never left my side and are very special to me.

A special feeling of gratitude to my wonderful in-laws, Mr. and Mrs. Kargarmoakhar, Roozbeh and Maral whose words of encouragement and support still ring in my ears. 


\section{ACKNOWLEDGMENTS}

I would like to express my gratitude and appreciation to all who helped me bring this research project to fruition to only some of whom it is possible to give particular mention here.

First and foremost, I would like to thank my major professor Dr. Peter Irwin, one of the most knowledgeable and well-known wind engineers around the world, for his supervision, valuable advice, and crucial contribution, which made him a backbone of this dissertation. After working with him, he has become my role model in my life. His truly scientific intuition, ideas and passions in science has inspired and nourished my intellectual maturity and enriched my growth as a student and as a researcher that I will benefit from, for years to come. There are not enough words to express my deep and sincere appreciation.

I express my deepest gratitude to my other major professor, Dr. Arindam Gan Chowdhury. I am very grateful for his support, valuable guidance, contribution, patience, and providing me with an excellent atmosphere for doing research throughout my entire program of study. He has always been very nice to me and was always willing to help and support me. Without his guidance and persistent help this dissertation would not have been possible.

Sincere thanks to the members of my doctoral committee, Dr. Amir Mirmiran, Dr. Atorod Azizinamini, and Dr. Irtishad Ahmad for their input, valuable discussions and accessibility.

The Wall of Wind research performed was supported by the National Science Foundation (NSF Award No. CMMI-0928740 and CMMI-1151003), Florida Sea Grant 
College Program (Project \# R/C-D-19-FIU), and Center of Excellence in Hurricane Damage Mitigation and Product Development. WOW instrumentation has been supported through the NSF MRI Award No. CMMI-0923365. The support from the International Hurricane Research Center (IHRC) at FIU, Department of Energy, Florida Division of Emergency Management and TileTech Company for providing concrete roof pavers is acknowledged. The help offered by the Wall of Wind manager, Walter Conklin and the research scientists, Roy Liu Marquis and James Erwin, is greatly acknowledged. I would also like to appreciate the help and support from Dr. Girma Bitsuamlak who was the first one introducing "Wind Engineering" research area to me.

My deepest and heartiest appreciation to my husband, Ramtin Kargarmoakhar, whose love and support is always the first reason I am able to do anything of value. I gratefully thank him for all his scientific contribution to my research, help with the experiments, support, unyielding devotion, continuous encouragement and unwavering love.

I can't imagine my current position without the love and support from my family. I truly thank my parents and my loving sisters who have been a source of love and energy ever since. 


\title{
ABSTRACT OF THE DISSERTATION \\ EXPERIMENTAL AND ANALYTICAL METHODOLOGIES FOR PREDICTING \\ PEAK LOADS ON BUILDING ENVELOPES AND ROOFING SYSTEMS
}

\author{
by \\ Maryam Asghari Mooneghi \\ Florida International University, 2014 \\ Miami, Florida \\ Professor Peter Irwin, Co-Major Professor \\ Professor Arindam Gan Chowdhury, Co-Major Professor
}

The performance of building envelopes and roofing systems significantly depends on accurate knowledge of wind loads and the response of envelope components under realistic wind conditions. Wind tunnel testing is a well-established practice to determine wind loads on structures. For small structures much larger model scales are needed than for large structures, to maintain modeling accuracy and minimize Reynolds number effects. In these circumstances the ability to obtain a large enough turbulence integral scale is usually compromised by the limited dimensions of the wind tunnel meaning that it is not possible to simulate the low frequency end of the turbulence spectrum. Such flows are called flows with Partial Turbulence Simulation.

In this dissertation, the test procedure and scaling requirements for tests in partial turbulence simulation are discussed. A theoretical method is proposed for including the effects of low-frequency turbulences in the post-test analysis. In this theory the turbulence spectrum is divided into two distinct statistical processes, one at high frequencies which can be simulated in the wind tunnel, and one at low frequencies which 
can be treated in a quasi-steady manner. The joint probability of load resulting from the two processes is derived from which full-scale equivalent peak pressure coefficients can be obtained. The efficacy of the method is proved by comparing predicted data derived from tests on large-scale models of the Silsoe Cube and Texas-Tech University buildings in Wall of Wind facility at Florida International University with the available full-scale data.

For multi-layer building envelopes such as rain-screen walls, roof pavers, and vented energy efficient walls not only peak wind loads but also their spatial gradients are important. Wind permeable roof claddings like roof pavers are not well dealt with in many existing building codes and standards. Large-scale experiments were carried out to investigate the wind loading on concrete pavers including wind blow-off tests and pressure measurements. Simplified guidelines were developed for design of loose-laid roof pavers against wind uplift. The guidelines are formatted so that use can be made of the existing information in codes and standards such as ASCE 7-10 on pressure coefficients on components and cladding. 


\section{TABLE OF CONTENTS}

CHAPTER

PAGE

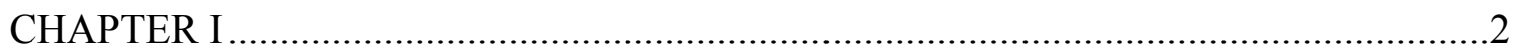

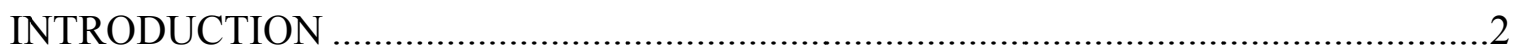

1.1 Wind Induced Damage to Building Envelopes and Roofing Systems ...................2

1.2 Estimating Wind Loads on Low-Rise buildings...................................................

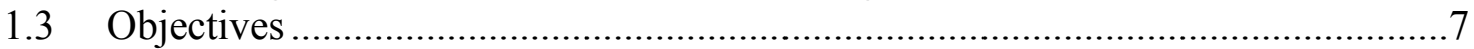

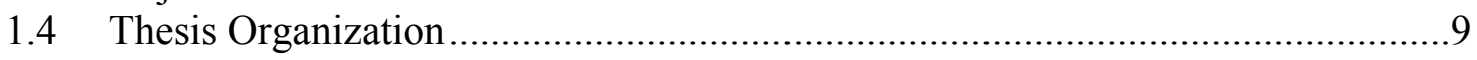

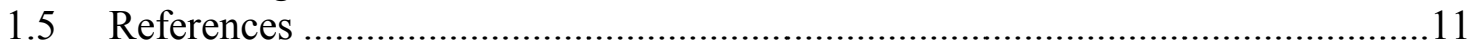

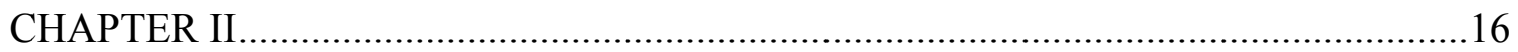

PARTIAL TURBULENCE SIMULATION METHOD FOR PREDICTING PEAK WIND LOADS ON SMALL STRUCTURES AND BUILDING

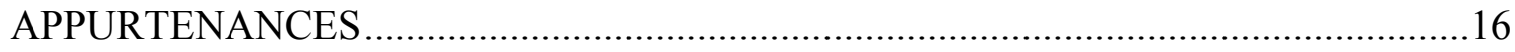

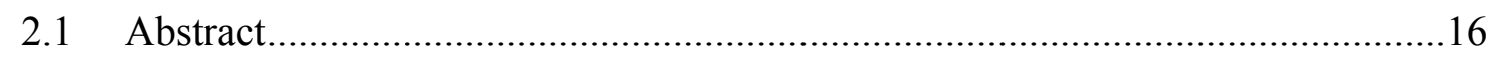

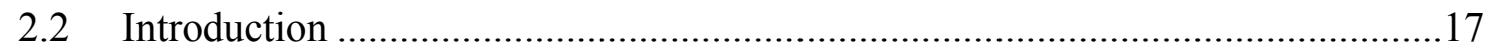

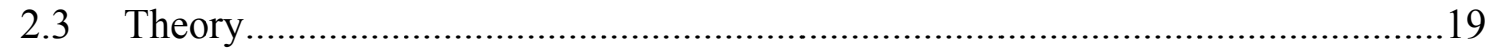

2.3.1 Turbulence scale limitations in wind tunnels .............................................19

2.3.2 Equilibrium of small scale turbulence ..........................................................20

2.3.3 Determination of dividing frequency $n_{c}$ between low and high

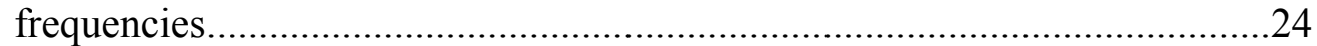

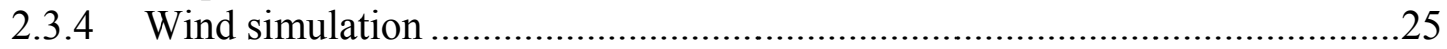

2.3.5 Method for determining the peak pressure coefficients ................................26

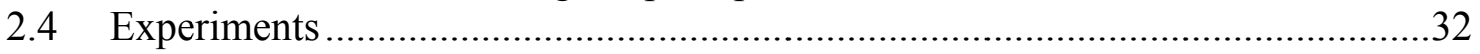

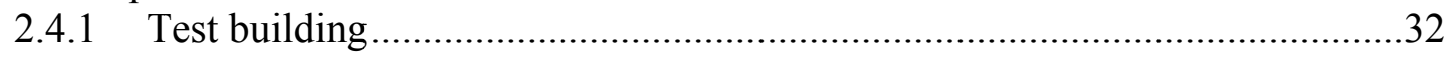

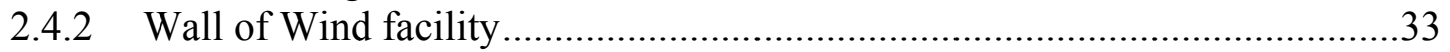

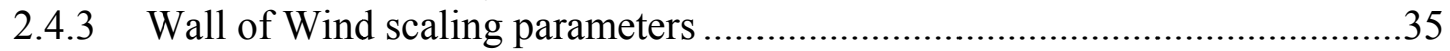

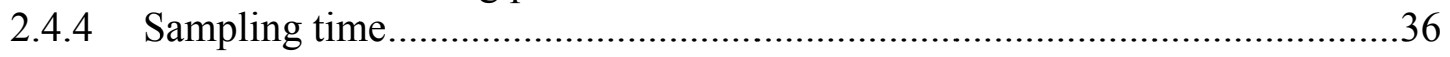

2.4.5 Sample rate and filtering .............................................................................

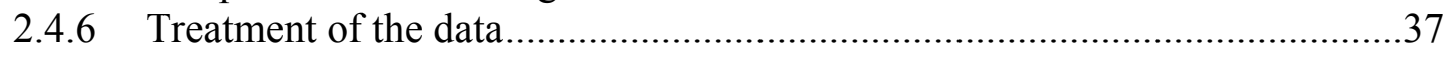

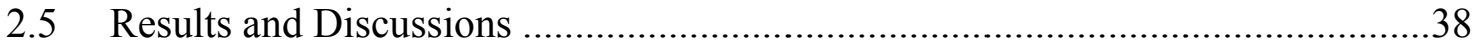

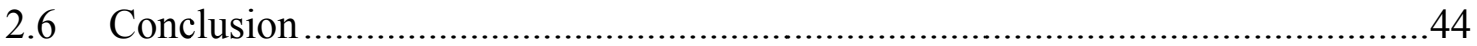

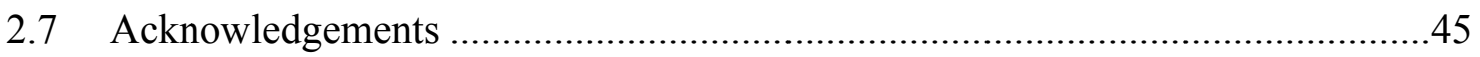

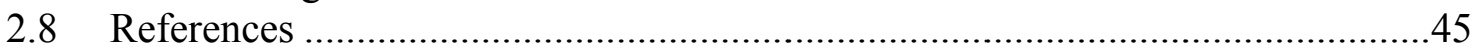

2.9 Appendix A: Effective Filter Frequency for $\Delta \mathrm{t}$ Second Moving Average ............47

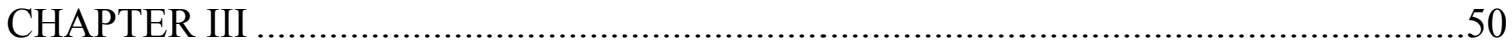

EXTENSION OF PARTIAL TURBULENCE SIMULATION METHOD TO INCLUDE LOW FREQUENCY LATERAL AND VERTICAL TURBULENCE

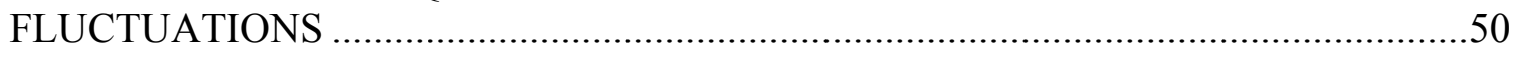

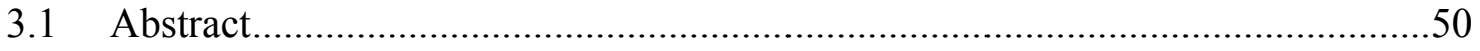

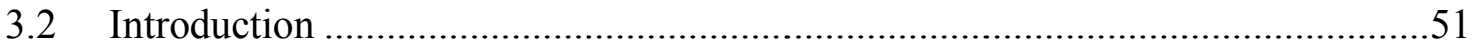

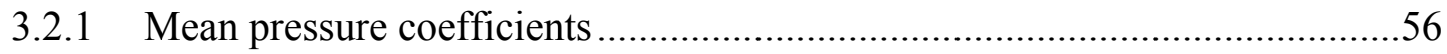

3.2.2 Peak pressure coefficients ........................................................................57 


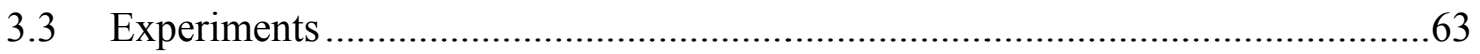

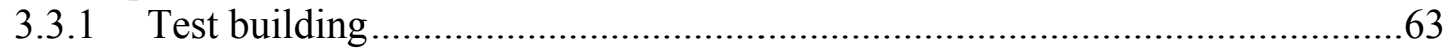

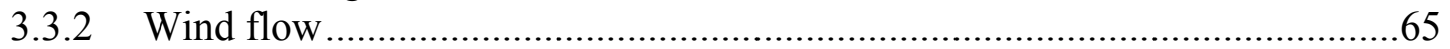

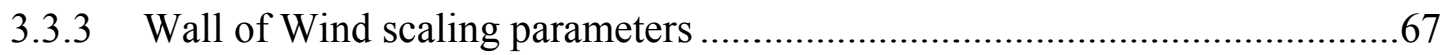

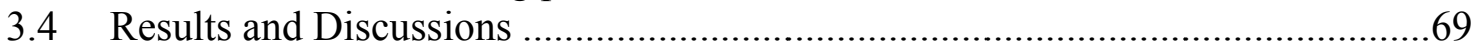

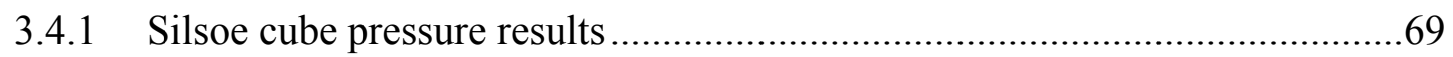

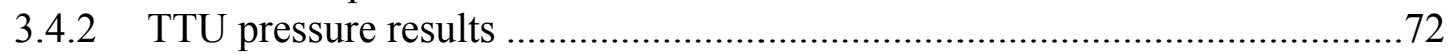

3.4.3 Effects of ignoring wind tilt angle variations ..............................................75

3.4.4 Effects of wind azimuth angle increment size............................................76

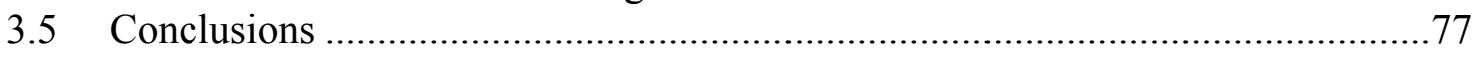

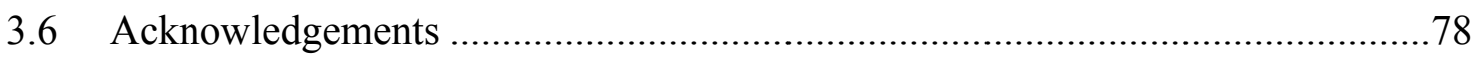

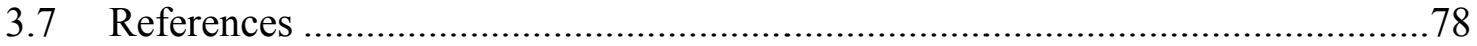

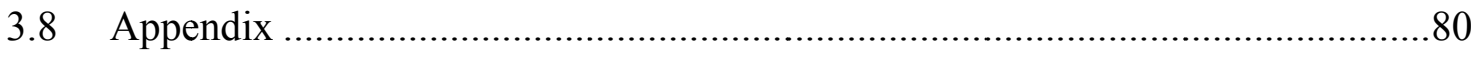

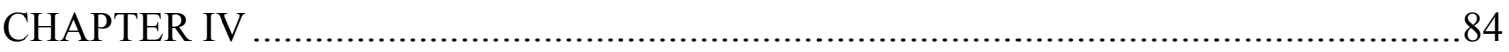

LARGE-SCALE TESTING ON WIND UPLIFT OF ROOF PAVERS …………............84

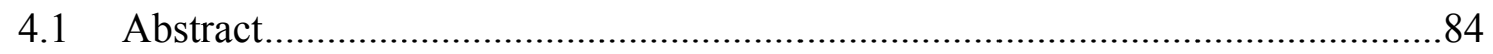

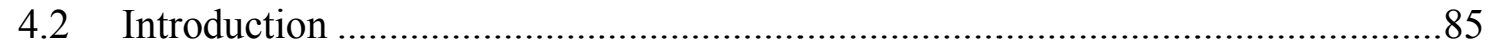

4.3 Wind Loading Mechanism on Permeable Roofing Elements ................................8

4.4 Description of the Experimental Set up and Testing Procedure...........................91

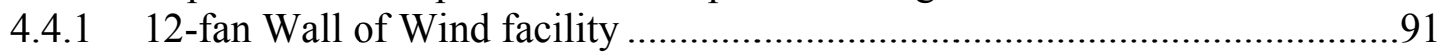

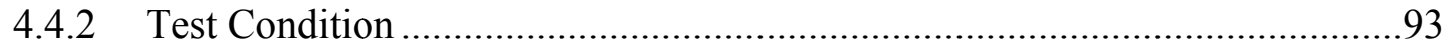

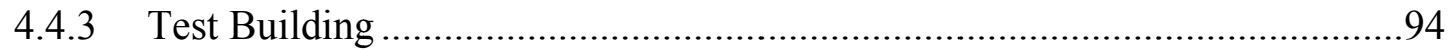

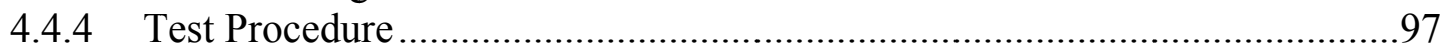

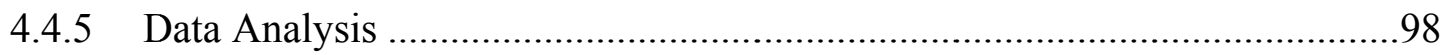

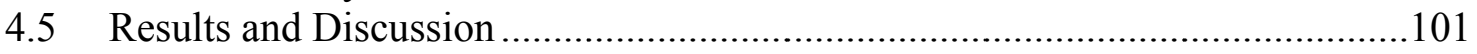

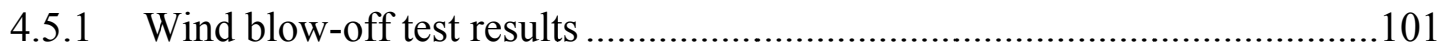

4.5.2 Pressure Measurement Results ................................................................. 102

4.5.3 Comparison with wind blow-off tests and practice based on ASCE 7-

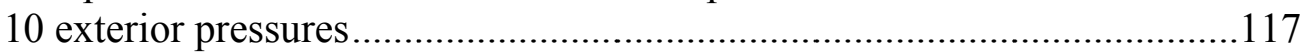

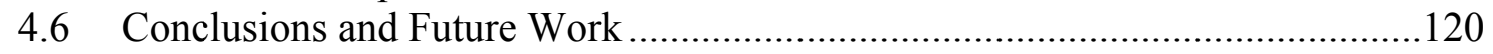

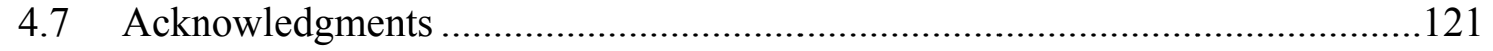

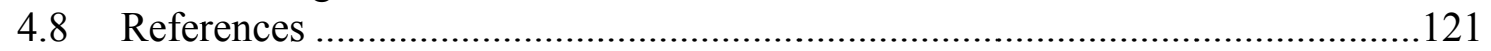

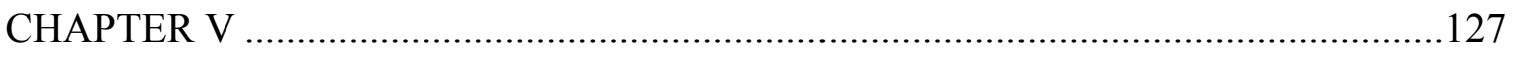

TOWARDS GUIDELINES FOR DESIGN OF LOOSE-LAID ROOF PAVERS

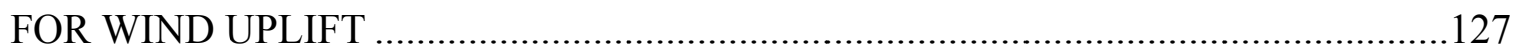

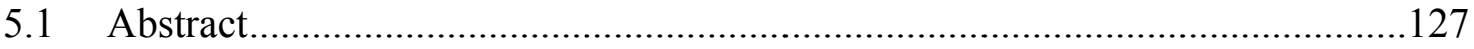

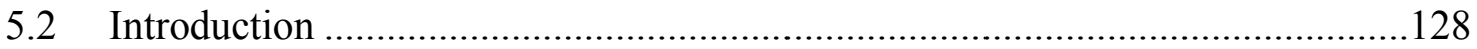

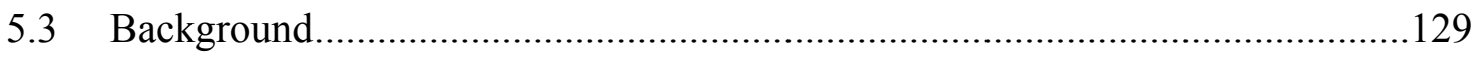

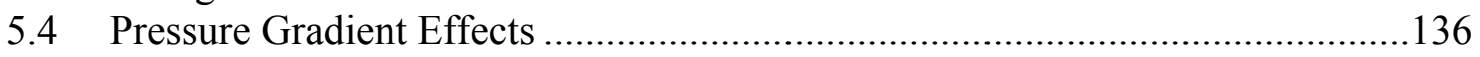

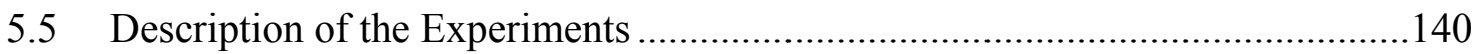

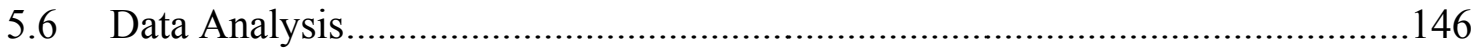

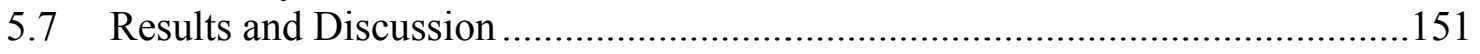

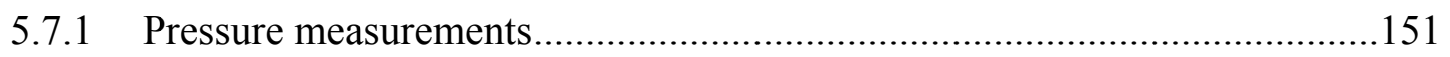




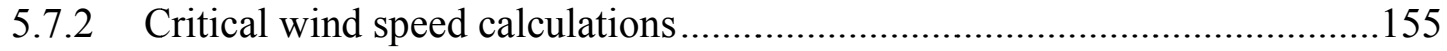

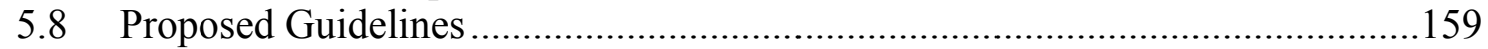

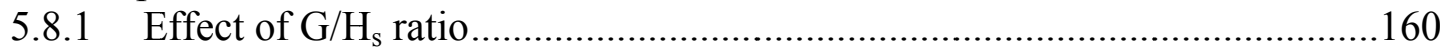

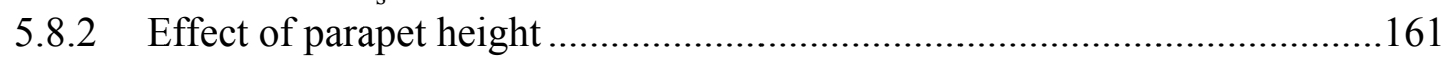

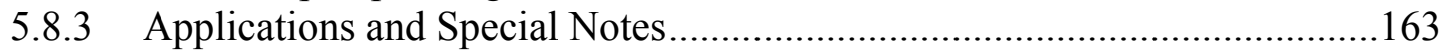

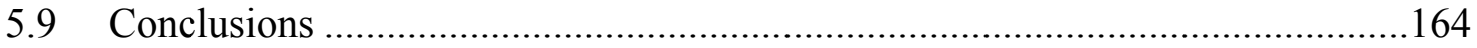

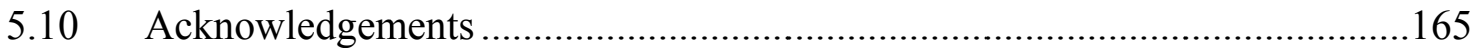

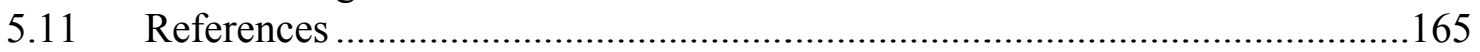

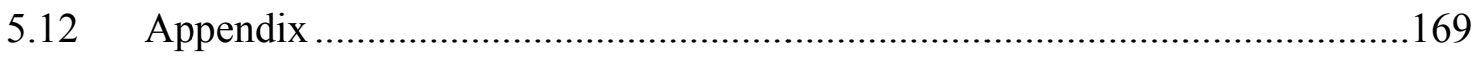

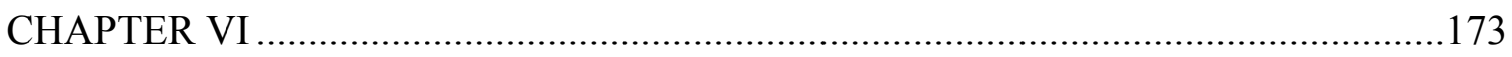

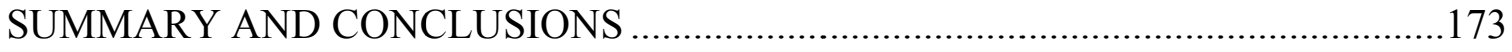

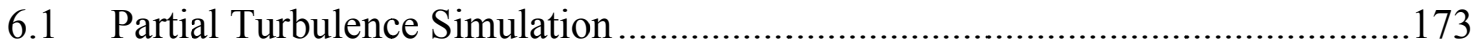

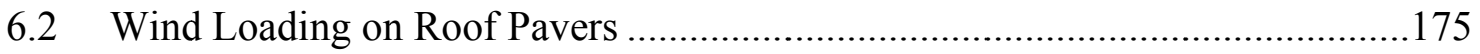

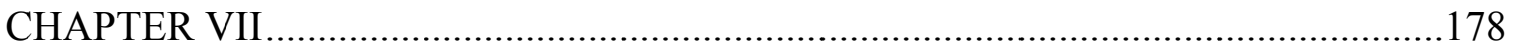

RECOMMENDATIONS FOR FUTURE RESEARCH .......................................... 178

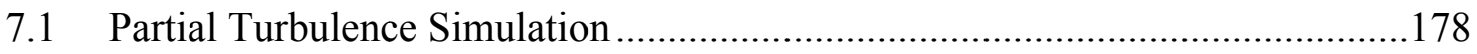

7.2 Non-stationary Gusts and Rapid Wind Directionality Change Effects ..............178

7.3 Design Guidelines for Roof Paving Systems ............................................. 179

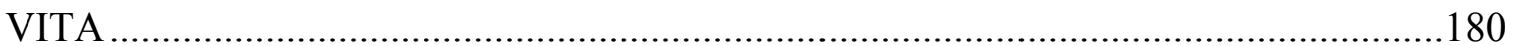




\section{LIST OF TABLES}

TABLE

PAGE

\section{CHAPTER III}

Table 1. Test conditions for Silsoe cube model in WOW and at full-scale.

Table 2. Test conditions for TTU model in WOW and at full-scale

\section{CHAPTER IV}

Table 1.Test number and characteristics.

Table 2. Failure wind speeds and failure mechanisms

Table 3. Characteristics of the experiments used for comparison between external pressure coefficients.

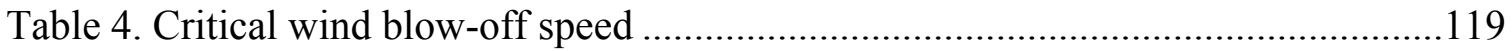

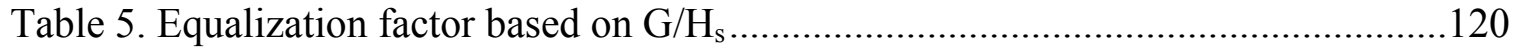

\section{CHAPTER V}

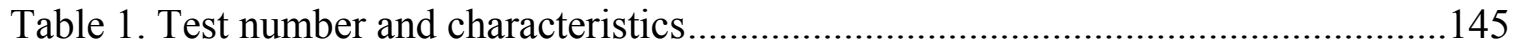

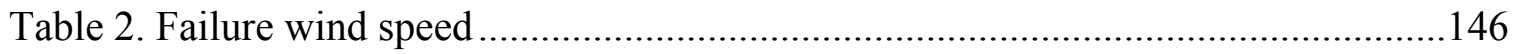

Table 3. Most negative local pressure coefficient $C_{p, e x t}, C_{\text {Lext }}, C_{\text {Lnet }}, C_{M x, \text { net }}$ and $C_{M y, n e t}$ on Paver 21 


\section{LIST OF FIGURES}

FIGURE

PAGE

\section{CHAPTER II}

Figure 1. Illustration of mean flow velocity, low frequency and high frequency

fluctuations.

Figure 2. Probability of exceeding $C p / b$ for $I_{u L}=0.2$ and various $a b$ values, where $C p=$ peak pressure coefficient

Figure 3. (a) Silsoe Cube building model tested in WOW, (b) Tap locations on Silsoe model

Figure 4. (a) Wall of Wind, Florida International University, (b) Spires and floor roughness elements

Figure 5. Comparison between full-scale Silsoe cube full spectrum and WOW partial spectrum.

Figure 6. Open terrain: (a) ABL profile, (b) Turbulence intensity profile .34

Figure 7. Wall Cp values comparisons vs. wind direction

Figure 8. Minimum and maximum of wall $\mathrm{Cp}$ values comparisons considering all directions.

Figure 9. Roof $\mathrm{Cp}$ values comparisons vs. wind direction

Figure 10. Minimum Roof $\mathrm{Cp}$ values comparisons vs. wind direction considering all directions

Figure 11. Filter function for a moving average filter .48

\section{CHAPTER III}

Figure 1. Definition of subintervals, mean flow velocity, low frequency and high frequency fluctuations.

Figure 2. (a) Silsoe Cube building model tested in WOW, (b) Tap locations on Silsoe model

Figure 3. (a) TTU building model tested in WOW, (b) Tap locations on TTU model.

Figure 4. Definition of (a) wind azimuth and (b) tilt angle .65 
Figure 5. (a) Wall of Wind, Florida International University, (b) Spires and floor roughness elements

Figure 6. Comparison between full-scale Silsoe cube with full spectrum and WOW partial spectrum.

Figure 7. Open terrain: (a) ABL profile, (b) Turbulence intensity profile

Figure 8. Illustration of reading the full-scale equivalent peak pressure coefficients from $\mathrm{GCp}$ versus $\mathrm{Cp}$ diagram.

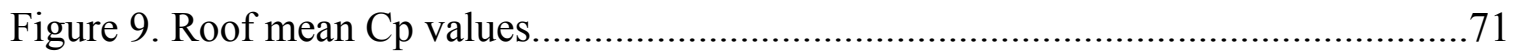

Figure 10. Roof peak Cp values...............................................................................72

Figure 11. (a) Roof mean $\mathrm{Cp}$ values, (b) Roof peak $\mathrm{Cp}$ values ........................................74

Figure 12: Effects of ignoring variations in wind tilt angle on pressure coefficients........75

Figure 12: Effects wind azimuth angle increment size on pressure coefficients................76

Figure 13: Comparison between PTS and 3DPTS methods ...........................................82

\section{CHAPTER IV}

Figure 1. Paths of corner vortices and resulting suction variations on roof

Figure 2. General mechanism of pressure distributions on upper and lower surfaces of a roof paver.

Figure 3. Comparison of ABL full spectrum for suburban terrain simulated in wind tunnel by $\mathrm{Fu}$ (2013), WOW partial spectrum and the dimensionalized Kaimal spectrum

Figure 4. (a) Wall of Wind, Florida International University, (b) Spires and floor roughness Elements

Figure 5. Suburban terrain: (a) ABL profile, (b) Turbulence intensity profile

Figure 6. (a) Geometrical parameter definition, (b) Test building for wind blowoff tests, (c) Roof pavers numbering.

Figure 7. (a) External pressure tap layout, (b) Underneath pressure tap layout, (c) Plexiglas pavers with pressure taps .96

Figure 8. Definition of the point of action of the resultant lift force 100 
Figure 9. Failure of roof pavers during wind blow-off tests: (a) $\mathrm{G} / \mathrm{H}_{\mathrm{s}}=0.25$, (b)

$\mathrm{G} / \mathrm{H}_{\mathrm{s}}=0.083$, (c) $\mathrm{G} / \mathrm{H}_{\mathrm{s}}=0.028$.

Figure 10. External $\mathrm{C} \mathrm{p}_{\text {mean }}$ and $\mathrm{Cp}$ peak $(\mathrm{G} / \mathrm{Hs}=0.083)$

Figure 11. Comparison of external $\mathrm{Cp}_{\text {mean }}\left(\mathrm{h}_{\mathrm{p}} / \mathrm{H}=0.1 ; \mathrm{G} / \mathrm{H}_{\mathrm{s}}=0.083\right)$ with

Stathopoulos (1982)

Figure 12. Comparison of external $\mathrm{Cp}\left(\mathrm{h}_{\mathrm{p}} / \mathrm{H}=0.1 ; \mathrm{G} / \mathrm{H}_{\mathrm{s}}=0.083\right)$ with Kopp et al (2005).....

Figure 13. Net $C \mathrm{p}_{\text {mean }}\left(\mathrm{G} / \mathrm{H}_{\mathrm{s}}=0.083\right)$ 108

Figure 14. Variations of (a) $C_{\text {Lnet }}$ and (b) $C_{\text {Mnet }}$ on Paver 21 with $\mathrm{h}_{\mathrm{p}} / \mathrm{H}$ $\left(\mathrm{G} / \mathrm{H}_{\mathrm{s}}=0.083\right)$

Figure 15. Variation of $\mathrm{L}_{\text {net }}$ point of action on Paver 21 with $\mathrm{h}_{\mathrm{p}} / \mathrm{H}\left(\mathrm{G} / \mathrm{H}_{\mathrm{s}}=0.083\right)$

Figure 16. Underneath $\mathrm{C} \mathrm{p}_{\text {mean }}$ and net $\mathrm{C} \mathrm{p}_{\text {mean }}\left(\mathrm{h}_{\mathrm{p}} / \mathrm{H}=0.05\right)$.

Figure 17. Highest underneath $\mathrm{Cp}\left(\mathrm{h}_{\mathrm{p}} / \mathrm{H}=0.05\right)$

Figure 18. Variation of: (a) $C_{\text {Lnet }}$ and (b) $C_{\text {Mnet }}$ on Paver 21 with $\mathrm{G} / \mathrm{H}_{\mathrm{s}}$ $\left(\mathrm{h}_{\mathrm{p}} / \mathrm{H}=0.05\right)$

Figure 19. Variation of $\mathrm{L}_{\text {net }}$ point of action on Paver 21 with $\mathrm{G} / \mathrm{H}_{\mathrm{s}}\left(\mathrm{h}_{\mathrm{p}} / \mathrm{H}=0.05\right)$

Figure 20. External $\mathrm{Cp}_{\text {mean }}$ on critical pavers $\left(\mathrm{G} / \mathrm{H}_{\mathrm{s}}=0.083, \mathrm{~h}_{\mathrm{p}} / \mathrm{H}=0.05\right)$

Figure 21. Defining vortex core angle.....

Figure 22. External $\mathrm{Cp}_{\text {mean }}$ : (a) High density of pressure taps, (b) Low density of pressure taps $\left(\mathrm{h}_{\mathrm{p}} / \mathrm{H}=0.05, \mathrm{G} / \mathrm{H}_{\mathrm{s}}=0.25\right)$....

Figure 23. Effect of pressure tap layout on external $\mathrm{Cp}_{\text {mean }}\left(\mathrm{h}_{\mathrm{p}} / \mathrm{H}=0.05\right.$ and $\mathrm{G} / \mathrm{H}_{\mathrm{s}}=$ $0.25)$

Figure 24. $C_{\text {Lnet }}$ for different pressure tap layouts $\left(\mathrm{h}_{\mathrm{p}} / \mathrm{H}=0.05 ; \mathrm{G} / \mathrm{H}_{\mathrm{s}}=0.25\right) \ldots \ldots \ldots \ldots \ldots . .116$

Figure 25. $C_{\text {Mnet }}$ for different pressure tap layouts $\left(\mathrm{h}_{\mathrm{p}} / \mathrm{H}=0.05 ; \mathrm{G} / \mathrm{H}_{\mathrm{s}}=0.25\right)$.

\section{CHAPTER V}

Figure 1. Conical vortices; Suction variation on roof under corner vortices.....

Figure 2. Pressure distributions on upper and lower surfaces of a roof paver......

Figure 3. Straps running transverse to the axis of the vortex 
Figure 4. (a) Wall of Wind, Florida International University, (b) Spires and floor roughness elements

Figure 5. Comparison of ABL full spectrum for suburban terrain simulated in wind tunnel by $\mathrm{Fu}$ (2013), WOW partial spectrum and the Kaimal spectrum expressed at full scale

Figure 6. Simulated suburban terrain: (a) Atmospheric boundary layer (ABL) profile, (b) Turbulence intensity profile.

Figure 7. (a) Test building for wind liftoff tests, (b) Roof pavers numbering, (c) Geometrical parameter definition

Figure 8. Definition of the point of action of the resultant lift force

Figure 9. Pressure coefficient contours $\left(\mathrm{G} / \mathrm{H}_{\mathrm{s}}=0.028\right.$ and $\left.\mathrm{h}_{\mathrm{p}} / \mathrm{H}=0\right)$

Figure 10. Highest local suction coefficients on the roof $C_{\text {Lext }}, C_{\text {Lnet }}, C_{M x, \text { net }}$ and $C_{M y, n e t}$ on Paver 21

Figure 11. Reduction factor $r=C_{\text {Lnet }} / C_{\text {Lext }}$

Figure 12. Comparison between wind lift-off speeds from wind blow-off tests and those obtained from pressure measurements

Figure 13. Comparison between wind lift-off speeds from wind blow-off tests and those obtained from a typical practice based on ASCE 7-10 exterior pressures on C\&C and $1 / 3^{\text {rd }}$ Rule

Figure 14. Interlocked pavers in different configurations

Figure 15. Comparison between $C_{\text {Lnet }}$ values for different configurations defined in Fig. 14

Figure 16. Reduction factor for different $\mathrm{G} / \mathrm{H}_{\mathrm{s}}$ ratios 160

Figure 17. Reduction factor for different $\mathrm{h}_{\mathrm{p}} / \mathrm{H}$ ratios 161

Figure 18. Comparison of proposed $R_{2}$ curve with $\mathrm{r}$ as a function of $\mathrm{h}_{\mathrm{p}} / \mathrm{H}$ : (a) $\mathrm{G} / \mathrm{H}_{\mathrm{s}}=0.083$, (b) $\mathrm{G} / \mathrm{H}_{\mathrm{s}}=0.25$

Figure 19. Critical wind speed vs. $\mathrm{G} / \mathrm{H}_{\mathrm{s}}\left(\mathrm{h}_{\mathrm{p}} / \mathrm{H}=0.05\right.$ for wind measurements) 163 
CHAPTER I

INTRODUCTION 


\section{CHAPTER I}

\section{INTRODUCTION}

\subsection{Wind Induced Damage to Building Envelopes and Roofing Systems}

Wind-related disasters are among the most costly natural hazards to occur in the US each year (Simiu and Scanlan, 1996). Between 1986 and 1993, approximately \$41 billion insured catastrophic losses were due to hurricanes and tornadoes while $\$ 6.18$ billion losses were from all the other natural hazards in the U.S (Simiu and Scanlan, 1996). Kikugawa and Bienkiewicz (2005) reported that the contribution of wind-induced losses averaged over 5 years (2000-2004) and 50 years (1955-2004) from the overall hazard damage in the US were about $89 \%$ and $69 \%$, respectively.

The wind damage resistivity of buildings impacted by hurricanes and windstorms is a function of the strength of building envelope components and their connections. It has been stated that about $70 \%$ of the total insured losses in high wind events comes from the damage to the building envelope (Holmes, 2007). Roof systems are most vulnerable to theses extreme wind loads. The regions of worst suctions on the roof comprise only a small fraction of the total roof and have small effects on the total structural load. However, they are critically important for roof cladding and coverings (Kind, 1986; Kind and Wardlaw, 1982). High suction forces on the surface of the roof especially under the conical vortices near roof corners, roof ridges and leading roof edges (Tieleman, 2003) can loosen and lift both roof sheathing and roof claddings, such as tiles, shingles, and roof pavers or gravel ballast. Dislodged roofing elements may become wind-borne debris impacting other structures downwind. Failure of the building envelope components (e.g. breached windows, doors, or sections of the roof itself) allows the wind into the building. 
This generates internal pressures which sometimes are high enough even to separate the roof from the rest of the structure. Even if roof failure does not lead to total structural failure, it dramatically increases losses because of water infiltration and interior damage.

Understanding the mechanism of pressure generation is crucial in order to develop appropriate design guidelines and mitigation techniques to reduce the intensity of pressures in high pressure regions. In static testing of full or model-scales of building envelope systems many important aerodynamic effects of the structure are ignored. As well, for multi-layer building envelopes, such as rain-screen walls, roof pavers, solar panels and vented energy efficient walls not only peak pressures but also the spatial gradients of these pressures are important to loading of the envelope which are ignored in static testing. Accurate modeling of wind-induced effects on building envelopes and roofing systems is required for ascertaining structural safety and reliability under extreme loadings produced by wind.

\subsection{Estimating Wind Loads on Low-Rise buildings}

Low-rise buildings such as residential houses, commercial and industrial structures constitute more than 70 percent of the buildings in the United States and account for the majority of losses due to wind storms. It is therefore of prime importance to enhance our understanding of wind-induced loads on low-rise buildings in order to reduce such damages and to provide reliable guidelines in building codes and standards for wind-resistant design of low-rise buildings.

Boundary layer wind tunnel testing has been long the most effective tool for investigating response of structures due to wind loads (Cermak, 1975). Simulated wind flows should have properties (mean wind profile, turbulence spectrum, turbulence 
intensity, and integral length scale) similar to those of atmospheric boundary layer (ABL) flows (Fu, 2013). The boundary layer ranges in depth between about 1000 and $3000 \mathrm{~m}$ in strong wind conditions. Theoretically, it is required that the model scale be equal to the ratios of the integral scales and the roughness length (Tieleman, 2003). Wind tunnel testing on large structures such as tall buildings, long span bridges, stadiums, arenas etc. is typically done at model scales in the range of 1:300 to 1:600. At these scales a fairly good simulation of the planetary boundary layer can be achieved economically in typical sized wind tunnels (Irwin et al, 2013). However, for small structures like low-rise buildings and building appurtenances often larger model scales in the range of 1:1 to 1:100 are desirable in order to keep Reynolds numbers high enough to avoid adverse scale effects, better replicate the effects of architectural features and to be able to obtain adequate spatial resolution of pressures taps. One of the main challenges of testing at full or large scale is the difficulty of simulating the full-scale wind field including all the scales of turbulence present in the real wind. This is mainly due to the limited dimensions of wind tunnels which prevents obtaining large enough turbulence integral scales (Irwin, 2008). Thus, many of the model tests on these structures have been undertaken with less than ideal simulation of the turbulence integral scale. Extensive research has been conducted during the past few decades on wind loads on low-rise buildings. The availability of full-scale data made comparisons with wind tunnel results possible. Also, they were used as means of verifying techniques for wind tunnel testing for low-rise buildings.

The full-scale Silsoe Experimental Building (6 m cube) was constructed in the late 1990 at the Silsoe Research Institute in South Bedfordshire, UK. It was located in a 
relatively flat terrain imposing "Open terrain" (Richards et al, 2001). Many fundamental studies were performed since then to study the interactions between the wind and structures and to compare data obtained from Computational Fluid Dynamics (CFD) techniques (Irtaza et al, 2013) and/or wind tunnels (Richards et al, 2007) with full-scale Silsoe results. A good agreement between the data obtained from a 1:40 scaled model of the Silsoe cube and field data was found for mean pressures. However, the agreement for the peak and RMS point pressures was found to be less satisfactory at critical locations in the roof corner region (Richards et al, 2007).

In addition, a full-scale test building was constructed at Texas-Tech University (TTU) in Lubbock, Texas. It was a rectangular in plan low-rise building $(9.1$ x 13.7 x 4 m) with a nearly flat roof (Levitan and Mehta, 1992a, b). Full-scale pressure data from TTU has provided high quality data for verification and comparison with results obtained from scaled models tested in wind tunnels. Similar to what was found from comparison between wind tunnel and full-scale results for the Silsoe cube, results from model and/or full-scale experiments on TTU building were generally satisfactory in terms of mean pressure coefficients. However, less than satisfactory agreement existed between the fluctuating pressures in regions of extreme suctions (Cochran and Cermak, 1992; Lin et al, 1995; Okada and Ha, 1992; Surry, 1991; Tieleman et al, 1996).

In addition to the differences observed in fluctuating wind pressures found by comparing full-scale and model-scale research buildings, Fritz et al (2008) showed that peak wind-induced internal forces in structural frames, and pressures at individual taps, can differ from laboratory to laboratory by factors larger than two. 
One of the main reasons for these discrepancies was attributed to mismatches in the turbulence spectrum particularly not having enough low frequency turbulences and too much high frequency turbulences in the simulated wind flow in wind tunnels. Both small-scale and large-scale turbulence play an important role in generating peak wind pressures. Research indicated that small-scale turbulence, i.e. turbulent eddies with similar size to the widths of vortices and shear layers generated at building corners and edges is the most important to be modeled when it comes to the local aerodynamics on a roof or a wall for any given wind direction (Asghari Mooneghi et al, 2014; Banks, 2011; Irwin, 2009; Kopp and Banks, 2013; Kumar and Stathopoulos, 1998; Melbourne, 1980; Richards et al, 2007; Saathoff and Melbourne, 1997; Tieleman, 2003; Yamada and Katsuchi, 2008). As long as sufficient intensity of small-scale turbulence exists in the wind tunnel flow, a good representation of the real aerodynamics and its effects on the building envelope system can be obtained (Irwin et al, 2013). The effect of large-scale turbulence, much larger than the structure itself, on pressures on a building is somewhat like the effect of changes in mean wind speed and/or direction. Natural wind is very nonstationary in both speed and direction which can introduce uncertainties into the comparisons. A few authors have made brief statements about the possible effects of wind non-stationarity on the mismatch between model-scale and full-scale results (Lin et al, 1995; Surry, 1989). Moreover, recent studies suggest that in addition to properly simulating the longitudinal turbulence intensity (Hillier and Cherry, 1981; Melbourne, 1980, 1993; Saathoff and Melbourne, 1989), the simulation of lateral turbulence intensity is also very important for prediction of peak pressures (Letchford and Mehta, 1993; Tieleman, 2003; Tieleman et al, 1996; Zhao, 1997). Other than the longitudinal and 
lateral wind turbulence, the vertical wind angle of attack also has a significant role in accurate simulation of the peak-suction pressures near the roof corner (Wu et al, 2001).

The requirements for wind flow simulation in wind tunnels for predicting the extreme suction pressures are still not fully established. To the author's knowledge, to date, no simple technique is available to simulate the large and the small scales of the wind velocity turbulences along with the mean wind velocity profile in a wind tunnel when using large scale models. This problem is more pronounced when duplicating large lateral turbulence intensities usually observed in full-scale under convective conditions and over complex terrain (Tieleman, 2003).

\subsection{Objectives}

In order to improve the wind performance of building envelope and roofing systems, and thus reduce the losses inflicted by severe wind storms, two steps need to be followed: (1) understanding the wind loading mechanism on structures with the ultimate goal of developing flow simulation techniques for wind testing facilities for low-rise buildings and small building appurtenances from which reliable wind load data can be obtained, and (2) implementing the technical knowledge achieved from experiments into engineering practices by developing design guidelines to be used in codes and standards. The objective of this dissertation is to address persuasively and definitively the aforementioned steps as follows:

1- A technique for testing and analyzing data from large-scale models is developed. The method is called "Partial Turbulence Simulation". In this method tests are performed in flows in which only the high frequency end of the turbulence spectrum is simulated and low frequency velocity fluctuations are missing. The low frequency 
velocity fluctuations are missing because typically, for low rise building tests at large model scale, the wind tunnel working section is too small to permit simulation of the larger scales. The effects of missing low frequency turbulence are included in post-test analysis. In this approach the turbulence is divided into two distinct statistical processes, one at high frequencies which can be simulated in the wind tunnel, and one at low frequencies which can be treated in a quasi-steady manner. The joint probability of load resulting from the two processes is derived, with one part coming from the wind tunnel data and the remainder from the assumed Gaussian behavior of the missing low frequency component. The efficacy of the method is assessed by comparing the predicted mean and peak pressure coefficients derived from tests on large-scale models of the Silsoe cube and Texas-Tech University (TTU) research buildings in the Wall of Wind (WOW), a large-scale hurricane testing facility at Florida International University (FIU), with the corresponding available full-scale data. Generally good agreement was found between the model results and full-scale, particularly when comparing the highest overall peak pressure coefficients. The method is first applied by only accounting for the missing low frequency longitudinal component of turbulence (longitudinal being in the direction of the mean wind). It is then extended to include the effects of missing lateral and vertical low frequency turbulence intensities. This method is called in the rest of the paper " 3 Dimensional Partial Turbulence Simulation (3DPTS)" and it needs a number of tests at small angle increments around a main wind direction. This method is also verified through comparisons made between results from large-scale models of the Silsoe cube and TTU buildings with available full-scale data on each building. The PTS methods allow the use of considerably larger model scales than are possible in conventional 
testing by eliminating restrictions imposed by achievable integral turbulence length scales in laboratories. It allows for high Reynolds number testing, using greater spatial resolution of the pressure taps in critical regions and enabling more accurate modeling of architectural features. It can also be used in conventional wind tunnels (Cermak, 1995) and open jet wind testing facilities (Bitsuamlak et al, 2010; Chowdhury et al, 2009; Huang et al, 2009) in order to obtain benchmark aerodynamic data needed to validate or correct results of tests conducted in conventional facilities and thus advance the state of the art in low-rise buildings aerodynamics.

2- To address the second step, wind loading mechanisms on roof pavers were investigated thoroughly in this dissertation. Roof pavers are one type of multi-layered building envelope systems which are susceptible to wind pressure gradients. Large-scale wind blow-off and pressure measurements were performed on the flat roof of a low-rise building in the Wall of Wind at Florida International University with partial flow simulation. Design guidelines were then proposed for design of roof pavers against wind uplift.

\subsection{Thesis Organization}

This dissertation is written in the format of 'Thesis Containing Journal Papers'. The dissertation contains four manuscripts for scholarly journals, of which one is published, two are under review, and the last one will be submitted shortly. In addition, a general introduction chapter is provided at the beginning and a general conclusion chapter appears at the end of the dissertation.

The first paper, under review in the "Journal of Wind Engineering and Industrial Aerodynamics" describes the proposed test procedures for large-scale testing in facilities 
with partial turbulence simulation. A theoretical method is also developed and described in detail on how to include the effects of missing low frequency longitudinal turbulence in post-test analysis, based on quasi steady assumptions. The method is verified through comparing results obtained from large-scale experiments on 1:5 scale model of Silsoe cube building in the WOW at FIU with the available full-scale data. The new technique can be used to standardize flow simulation techniques and is applicable to large-scale open jet facilities and conventional wind tunnels.

The second paper, under review in the "Journal of Wind Engineering and Industrial Aerodynamics" is an extension of the first paper in which the effects of low frequency lateral and vertical turbulence intensities are also included in addition to the effects of missing low frequency longitudinal turbulence intensity. The method effectively uses the data from a few tests at different wind azimuth and tilt angle increments around a main wind direction and predicts the full-scale equivalent pressures. The efficacy of the method was investigated by comparing aerodynamic pressures on large-scale models of the Silsoe cube and TTU experimental building obtained from the WOW with partial flow simulation and the corresponding full-scale values.

The third paper, published in the "Journal of Wind Engineering and Industrial Aerodynamics", describes the wind loading mechanisms on concrete roof pavers. Wind lift-off tests and detailed pressure measurements were performed on half-scale roof pavers on a square portion of a flat roof of a low-rise building. The aim of the study was to investigate the external and underneath pressure distributions over loose-laid roof pavers in order to develop more effective protections against wind damage. The effects of 
the pavers' edge-gap to spacer height ratio, the relative parapet height and the resolution of the pressure taps on the wind performance of roof pavers were also investigated.

The forth paper, to be submitted to the journal of "Wind and Structures" is an extension of the third paper in which more experimental results were analyzed and presented with the ultimate goal of proposing design guidelines for roof pavers against wind uplift, to be proposed for codes and standards. Based on the experimental results and review of other data a simplified yet reasonably accurate method is proposed for calculating the net uplift force on roof paving systems from the existing external pressure coefficients in the current ASCE 7-10 standard. The effects of the paver's edge-gap to spacer height ratio and parapet height as a fraction of the building height on the wind performance of roof pavers were investigated and are included in the guidelines as adjustment factors.

\subsection{References}

Asghari Mooneghi, M., Irwin, P., Gan Chowdhury, A., 2014. Large-scale testing on wind uplift of roof pavers. Journal of wind engineering and industrial aerodynamics $128,22-$ 36.

Banks, D., 2011. Measuring peak wind loads on solar power assemblies, in: Proceedings of the The 13th International Conference on Wind Engineering.

Bitsuamlak, G., Dagnew, A., Chowdhury, A.G., 2010. Computational blockage and wind sources proximity assessment for a new full-scale testing facility. Wind and Structures $13,21-36$.

Cermak, J.E., 1975. Applications of Fluid Mechanics to Wind Engineering-A Freeman Scholar Lecture. Journal of Fluids Engineering 97, 9-38.

Cermak, J.E., 1995. Development of wind tunnels for physical modeling of the atmospheric boundary layer (ABL). A state of the art in wind engineering, Proceedings of the 9th International Conference on Wind Engineering. New Age International Publishers Limited, London, U.K., pp. 1-25. 
Chowdhury, A.G., Simiu, E., Leatherman, S.P., 2009. Destructive testing under simulated hurricane effects to promote hazard mitigation. Natural Hazards Review (ASCE) 10, 110.

Cochran, L.S., Cermak, J.E., 1992. Full- and model-scale cladding pressures on the texas tech experiment building. Journal of wind engineering and industrial aerodynamics 43 , 1616-1617.

Fritz, W.P., Bienkiewicz, B., Cui, B., Flamand, O., Ho, T.C.E., Kikitsu, H., Letchford, C.W., Simiu, E., 2008. International Comparison of Wind Tunnel Estimates of Wind Effects on Low-Rise Buildings: Test-Related Uncertainties. Journal of Structural Engineering 134, 1887-1890.

Fu, T.-C., 2013. Development of effective approaches to the large-scale aerodynamic testing of low-rise building, FIU Electronic Theses and Dissertations. Paper 986.

Hillier, R., Cherry, N.J., 1981. The effects of stream turbulence on separation bubbles. Journal of wind engineering and industrial aerodynamics 8, 49-58.

Holmes, J.D., 2007. Wind loading of structures. Taylor \& Francis.

Huang, P., Chowdhury, A.G., G, G.B., Liu, R., 2009. Development of devices and methods for simulation of hurricane winds in a full-scale testing facility. Wind and Structures 12, 151-177.

Irtaza, H., Beale, R.G., Godley, M.H.R., Jameel, A., 2013. Comparison of wind pressure measurements on Silsoe experimental building from full-scale observation, wind-tunnel experiments and various CFD techniques. International Journal of Engineering, Science and Technology 5, 28-41.

Irwin, P., 2009. Wind engineering research needs, building codes and project specific studies, in: Proceedings of the 11th Americas Conference on Wind Engineering.

Irwin, P., Chowdhury, A.G., Fu, T.-C., Liu-Marques, R., Zisis, I., 2013. Developments in wind testing of building envelope systems. Proceedings of the RCI 2013 Building Envelope Technology Symposium, Minneapolis, MN

Irwin, P.A., 2008. Bluff body aerodynamics in wind engineering. Journal of wind engineering and industrial aerodynamics 96, 701-712.

Kikugawa, H., Bienkiewicz, B., 2005. Wind damages and prospects for accelerated wind damage reduction in Japan and in the United States. Proceedings of 37th Joint Meeting Panel on Wind and Seismic Effects, Tsukuba, Japan.

Kind, R.J., 1986. Worst suctions near edges of flat rooftops on low-rise buildings. Journal of wind engineering and industrial aerodynamics $25,31-47$. 
Kind, R.J., Wardlaw, R.L., 1982. Failure mechanisms of loose laid roof insulation systems. Journal of wind engineering and industrial aerodynamics 9, 325-341.

Kopp, G.A., Banks, D., 2013. Use of the wind tunnel test method for obtaining design wind loads on roof-mounted solar arrays. Journal of structural engineering 139, 284-287.

Kumar, K.S., Stathopoulos, T., 1998. Spectral density functions of wind pressures on various low building roof geometries. Wind and Structures 1, 203-223.

Letchford, C.W., Mehta, K.C., 1993. The distribution and correlation of fluctuating pressures on the Texas Tech Building. Journal of wind engineering and industrial aerodynamics $50,225-234$.

Levitan, M.L., Mehta, K.C., 1992a. Texas Tech field experiments for wind loads part 1: building and pressure measuring system. Journal of wind engineering and industrial aerodynamics $43,1565-1576$.

Levitan, M.L., Mehta, K.C., 1992b. Texas tech field experiments for wind loads part II: meteorological instrumentation and terrain parameters. Journal of wind engineering and industrial aerodynamics 43, 1577-1588.

Lin, J.X., Surry, D., Tieleman, H.W., 1995. The distribution of pressure near roof corners of flat roof low buildings. Journal of wind engineering and industrial aerodynamics 56, 235-265.

Melbourne, W.H., 1980. Turbulence effects on maximum surface pressures - a mechanism and possibility of reduction. Wind Engineering, 541-551.

Melbourne, W.H., 1993. Turbulence and the leading edge phenomenon. Journal of wind engineering and industrial aerodynamics 49, 45-63.

Okada, H., Ha, Y.-C., 1992. Comparison of wind tunnel and full-scale pressure measurement tests on the Texas Texh Building. Journal of wind engineering and industrial aerodynamics 43, 1601-1612.

Richards, P.J., Hoxey, R.P., Connell, B.D., Lander, D.P., 2007. Wind-tunnel modelling of the Silsoe Cube. Journal of wind engineering and industrial aerodynamics 95, 1384-1399.

Richards, P.J., Hoxey, R.P., Short, L.J., 2001. Wind pressures on a 6\&\#xa0;m cube. Journal of wind engineering and industrial aerodynamics 89, 1553-1564.

Saathoff, P.J., Melbourne, W.H., 1989. The generation of peak pressures in separated/reattaching flows. Journal of wind engineering and industrial aerodynamics 32 , 121-134.

Saathoff, P.J., Melbourne, W.H., 1997. Effects of free-stream turbulence on surface pressure fluctuation in a separation bubble. Journal Of Fluid Mechanics 337, 1-24. 
Simiu, E., Scanlan, R.H., 1996. Wind effects on structures, Third edition ed. John Wiley \& Sons, Inc. .

Surry, D., 1989. Pressure Measurements on the Texas Tech Building-II: Wind tunnel measurements and comparison with full scale. Proceedings of the 8th Colloquium on Industrial Aerodynamics, Aachen, West Germany, pp. 25-35.

Surry, D., 1991. Pressure measurements on the Texas tech building: Wind tunnel measurements and comparisons with full scale. Journal of wind engineering and industrial aerodynamics 38, 235-247.

Tieleman, H.W., 2003. Wind tunnel simulation of wind loading on low-rise structures: a review. Journal of wind engineering and industrial aerodynamics 91, 1627-1649.

Tieleman, H.W., Surry, D., Mehta, K.C., 1996. Full/model-scale comparison of surface pressures on the Texas Tech experimental building. Journal of wind engineering and industrial aerodynamics $61,1-23$.

Wu, F., Sarkar, P.P., Mehta, K.C., Zhao, Z., 2001. Influence of incident wind turbulence on pressure fluctuations near flat-roof corners. Journal of wind engineering and industrial aerodynamics $89,403-420$.

Yamada, H., Katsuchi, H., 2008. Wind-tunnel study on effects of small-scale turbulence on flow patterns around rectangular cylinder, 4th International Colloquium on Bluff Bodies Aerodynamics \& Applications, Italy.

Zhao, Z., 1997. Wind flow characteristics and their effects on low-rise buildings, Doctor of Philosophy Dissertation. Texas Tech University, Lubbock, Texas. 


\section{CHAPTER II}

PARTIAL TURBULENCE SIMULATION METHOD FOR PREDICTING PEAK WIND LOADS ON SMALL STRUCTURES AND BUILDING APPURTENANCES

(A paper under review in The Journal of Wind Engineering and Industrial Aerodynamics) 


\section{CHAPTER II}

PARTIAL TURBULENCE SIMULATION METHOD FOR PREDICTING PEAK

WIND LOADS ON SMALL STRUCTURES AND BUILDING APPURTENACES

Maryam Asghari Mooneghi ${ }^{\mathrm{a}}$, Peter $\operatorname{Irwin}^{\mathrm{b}},{ }^{*}$ Arindam Gan Chowdhury ${ }^{\mathrm{c}}$

\subsection{Abstract}

Large-scale wind tunnel testing is preferred for small structures and building appurtenances for maintaining modeling accuracy and minimizing Reynolds number effects. In these circumstances the ability to obtain a large enough turbulence integral scale is usually compromised by the limited dimensions of the wind tunnel. So, it is not normally possible to simulate the low frequency end of the turbulence spectrum. In this paper the approach is taken of dividing the turbulence into two distinct statistical processes, one at high frequencies which can be simulated in the wind tunnel, and one at low frequencies which can be treated in a quasi-steady manner. In this Partial Turbulence Simulation (PTS) method the joint probability of load from the two processes is derived, with part coming from the wind tunnel data and the remainder from the assumed Gaussian behavior of the missing low frequency component. The efficacy of the method is assessed by comparing predicted pressure coefficients from tests on a 1:5 model of the Silsoe Cube in the Wall of Wind facility at Florida International University with the corresponding full-scale data. Generally good agreement was found between the model

\footnotetext{
${ }^{a} \mathrm{PhD}$ candidate, Civil and Environmental Engineering/International Hurricane Research Center, Florida International University, Miami, FL, USA, masgh002@,fiu.edu

${ }^{\mathrm{b}}$ Professor of Practice, Civil and Environmental Engineering/International Hurricane Research Center, Florida International University, Miami, FL, USA, peairwi@fiu.edu

${ }^{c}$ Corresponding Author. Associate Professor, chowdhur@fiu.edu, Tel: (305) 348-0518
} 
results and full scale, particularly when comparing the highest overall peak pressure coefficients.

Keywords: Partial Turbulence Simulation, Wind Load, Pressure Coefficient, Low-rise Building

\subsection{Introduction}

Boundary layer wind tunnel testing has been generally accepted as a useful tool for evaluating wind loads on structures. For tall buildings the model scales used are typically in the range of 1:300 to 1:600. At these scales it is possible in typical sized wind tunnels to simulate the wind velocity profile, turbulence intensity and turbulence integral scale such that all represent well the corresponding values at full scale. However, for small structures like low-rise buildings, and for building appurtenances, the model scales used are often larger, in the range of 1:10 to 1:100 in order to keep Reynolds numbers high enough to avoid adverse scale effects, better replicate the effects of architectural features and to be able to obtain adequate spatial resolution of pressures taps. For some tests even larger scales are desirable. At these large model scales the ability to obtain a large enough turbulence integral scale in the wind tunnel is compromised by the limited dimensions of the wind tunnel. As a result many of the model tests on these structures have been undertaken with less than ideal simulation of the turbulence integral scale (Stathopoulos and Surry, 1983). Often the turbulence intensity is matched but not the integral scale and this has meant that that the turbulence spectrum in the wind tunnel has too much energy at high frequencies (i.e. in the smaller eddies) (Richards et al, 2007). This can affect the local flows over the building surfaces where the turbulence interacts in important ways with the shear layers coming off the wall corners and roof edges. 
It has been noted by a number of researchers (Banks, 2011; Irwin, 2009; Kopp and Banks, 2013; Kumar and Stathopoulos, 1998; Melbourne, 1980; Mooneghi et al, 2014; Richards et al, 2007; Saathoff and Melbourne, 1997; Tieleman, 2003; Yamada and Katsuchi, 2008) that accurate simulation of high frequency turbulence is necessary in order to correctly model flow separation and reattachment. The effect of large-scale turbulence, much larger than the structure itself, on pressures on a building is somewhat like the effect of changes in wind speed and/or direction but the small scale turbulence changes the local aerodynamics in significant ways. In wind tunnel studies on the Texas Tech University (TTU) test building (Lin et al, 1995; Okada and Ha, 1992; Surry, 1991; Tieleman et al, 1996) good agreement between the laboratory and field data was found for mean pressures. However, the agreement for the peak and RMS point pressures was found to be less satisfactory at critical locations in the roof corner region. Fritz et al (2008) showed that peak wind-induced internal forces in structural frames, and pressures at individual taps, can differ from laboratory to laboratory by factors larger than two. A similar result was obtained by Richards et al (2007) when comparing 1:40 scale wind tunnel results with full scale on the Silsoe Cube. One of the main reasons of this discrepancy was attributed to mismatches in the turbulence spectrum, i.e. not enough content at low frequencies and too much at high frequencies. If the longitudinal and transverse turbulence intensities are matched on the model then the high frequency part of the spectrum has too much power due to the model integral scale being too small. To correctly match the spectrum at high frequencies it is required that the model turbulence intensity be smaller than at full scale but then the question arises as to how to account for the missing low frequency content. 
This paper presents a theoretical approach to account for the effects of the low frequency fluctuations in the wind flow assuming that all the effects of the high frequency fluctuations are captured by measurements in a wind flow that has the high frequency part of the turbulence spectrum at the right energy level. The advantage of this approach is that it allows larger model scales to be employed without having to match the turbulence integral scale. It is called here the Partial Turbulence Simulation (PTS) method. To test the theory a somewhat extreme case has been used. Pressures on a large 1:5 scale model of the Silsoe cube were measured in the 12-Fan Wall of Wind (WOW) facility at Florida International University with only the high frequency part of the turbulence spectrum simulated. The PTS method is then assessed by comparing its predictions with the full scale data for the Cube.

\subsection{Theory}

\subsubsection{Turbulence scale limitations in wind tunnels}

The aerodynamic behavior of a bluff structure such as a building is governed by the state of flow separation around it which is greatly affected by the oncoming flow turbulence. It is known that small-scale turbulence interacts in important ways with the shear layers and vortices cast off from a body immersed in turbulent air flow. On the other hand very large-scale turbulent eddies, much bigger than the body, can be expected to have a similar effect to a change in the mean flow velocity vector. This suggests that if a sufficient range of the small-scale turbulence can be simulated in a wind tunnel then it might be possible to include the effects of the large-scales later in post-test analysis, by treating the changes in flow due to large-scales the same as changes in the steady flow. 


\subsubsection{Equilibrium of small scale turbulence}

A feature of small scale turbulence is that it rapidly adjusts to changes caused by large-scale turbulence. It reaches a new equilibrium state quite quickly, particularly near to a solid surface such as the ground. Close to the ground the non-dimensional Reynolds stresses and mean velocity profile converge to universal values consistent with the universal law of the wall, provided that the averaging time over which they are determined corresponds to a wave length large compared to the height above ground. This feature has been exploited by measurement devices such as the Irwin Sensor (Irwin, 1981) that rely on the existence of the universal law of the wall for their calibration. These devices can measure not only mean flow velocities but also velocity fluctuations caused by turbulent eddies provided these eddies are much larger than the height of the sensor or probe. Wave length may be expressed roughly as $U t$, where $U=$ mean velocity and $t=$ characteristic time for the passage of one wave. Thus, at $10 \mathrm{~m}$ height, if the wave length is to be 10 times the height then $U t / H$ should be greater than 10 . For a height of $10 \mathrm{~m}$ with $U=50 \mathrm{~m} / \mathrm{s}$ the characteristic time is about 2 seconds and disturbances taking longer than this to pass by can be approximated as quasi-steady variations.

When testing in a partial simulation of turbulence, where we only include the high frequency end of the turbulence spectrum, we suppose that a similar assumption can be applied, i.e., the small scales of turbulence rapidly reach an equilibrium state when changes are imposed by large scale turbulence. For convenience we therefore consider the total turbulence velocity as being made up of two parts, a low frequency part and a high frequency part. The question of where the dividing line occurs will be deferred to the next section. It is acknowledged that in reality there is no sharp dividing line between 
low and high frequencies but it is nonetheless of interest to see where this theoretical division into two distinct parts leads and how well it approximates the real flow behavior. Thus, we express the total velocity $\widetilde{U}$ at any given instant as:

$$
\widetilde{U}=U+u_{L}+u_{H}
$$

where $U$ is the mean flow velocity, $u_{L}$ is the part of the fluctuating velocity contributed by the low frequency end of the spectrum and $u_{H}$ is the part contributed by the high frequency end. It is to be noted that in the current treatment the possible effects of low frequency changes in flow angle are ignored, it being assumed that if we test at enough wind directions we will capture peak responses due to low frequency variations in direction. The present approach can in fact be extended to include low frequency lateral and vertical fluctuations but this will be deferred to a subsequent paper. In a partial turbulence simulation test where we only include the high frequency part of the spectrum the mean velocity of the test $U_{p s}$ effectively is the mean speed $U$ that would be present with full spectrum plus whatever the low frequency gust component $u_{L}$ that would occur at the time, as illustrated in Fig. 1.

$$
U_{p s}=U+u_{L}
$$

The overall variance of the turbulence when the full spectrum is present is:

$$
\sigma_{u}^{2}=\overline{\overline{\left(u_{L}+u_{H}\right)^{2}}}
$$

where the double over-bar denotes the mean value over a long enough time to attain statistical stability of the low frequency turbulence quantities such as $\sigma_{u L}$. 


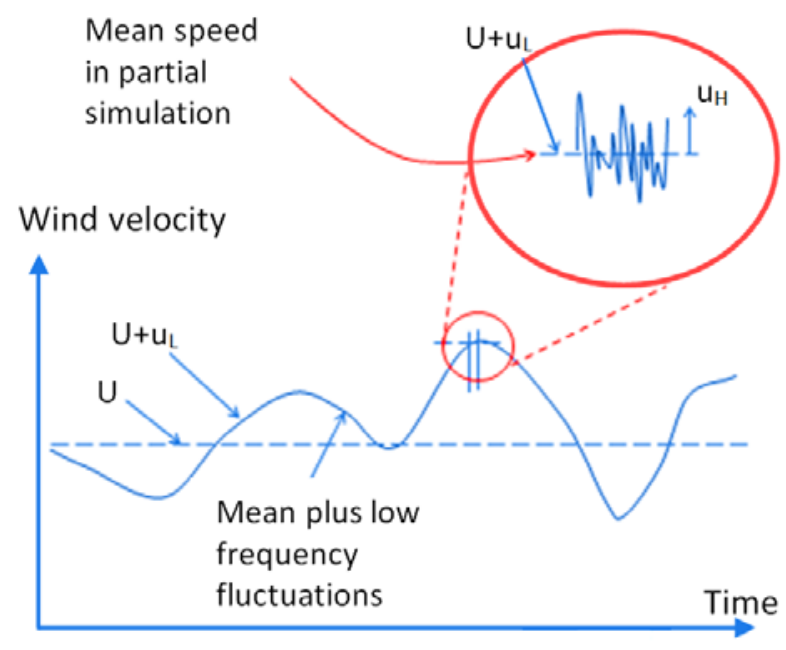

Figure 1. Illustration of mean flow velocity, low frequency and high frequency fluctuations

Since in the partial simulation the mean velocity is $U+u_{L}$, our measured partial simulation turbulence intensity, called $I_{u H}$ here, is:

$$
I_{u H}=\frac{\sqrt{\overline{u_{H}^{2}}}}{U+u_{L}}=\frac{\sigma_{u H}}{U+u_{L}}
$$

where the single over-bar denotes mean values over a long enough time to attain statistical stability of high frequency quantities such as $\sigma_{u H}$. At this point we bring in the rapid equilibrium assumption, which is that $I_{u H}$ is a constant as far as the low frequency flow variations are concerned. If a low frequency gust occurs, i.e. $u_{L}$ increases, then $\sigma_{u H}$ adjusts quickly to the new amount of energy being fed in from the large scale turbulence. In other words the high frequency turbulence rapidly attains a new equilibrium with increased energy. We may express $u_{H}$ in the following form.

$$
u_{H}=\frac{u_{H}}{\sigma_{u H}}\left(U+u_{L}\right) I_{u H}
$$


In this equation the ratio $\frac{u_{H}}{\sigma_{u H}}$ is a variable that fluctuates rapidly at high frequency but the fluctuations are not correlated with the low frequency fluctuations of $u_{L}$. The only link with low frequency fluctuations is through the term $\left(U+u_{L}\right)$ which is independent of high frequency fluctuations of $\frac{u_{H}}{\sigma_{u H}}$. Then Eq. (3) becomes:

$$
\begin{gathered}
\sigma_{u}^{2}=\overline{\overline{\left(u_{L}+\left(U+u_{L}\right) I_{u H} \frac{u_{H}}{\sigma_{u H}}\right)^{2}}} \\
=\overline{u_{L}^{2}+\left(U^{2}+2 U u_{L}+u_{L}^{2}\right) I_{u H}^{2} \frac{u_{H}^{2}}{\sigma_{u H}^{2}}+2 u_{L}\left(U+u_{L}\right) I_{u H} \frac{u_{H}}{\sigma_{u H}}}
\end{gathered}
$$

Since the high frequency fluctuations of $\frac{u_{H}}{\sigma_{u H}}$ are assumed to be uncorrelated with the low frequency fluctuations of $u_{L}$, the mean values of cross-products $u_{L}\left(\frac{u_{H}}{\sigma_{u H}}\right), u_{L}^{2}\left(\frac{u_{H}}{\sigma_{u H}}\right)$ and $u_{L}\left(\frac{u_{H}}{\sigma_{u H}}\right)^{2}$ are zero. Also we can ignore the higher order term $\overline{I_{u H}^{2} u_{L}^{2}\left(\frac{u_{H}}{\sigma_{u H}}\right)^{2}}$ as being very small compared to the other terms. Then, noting that the mean of $\left(\frac{u_{H}}{\sigma_{u H}}\right)^{2}$ is 1 , Eq. (3) becomes:

$$
\sigma_{u}^{2}=\overline{u_{L}^{2}}+U^{2} I_{u H}^{2}
$$

Therefore, in terms of turbulence intensities, the total turbulence intensity $I_{u}$ is given by:

$$
I_{u}=\frac{\sigma_{u}}{U}=\sqrt{I_{u L}^{2}+I_{u H}^{2}}
$$

where $I_{u L}=\frac{\sigma_{u L}}{U}$.

From Eq. (8) it is observed that if we have done a partial turbulence simulation with turbulence intensity $I_{u H}$ then the intensity of the missing low frequency intensity is given by: 


$$
I_{u L}=\sqrt{I_{u}^{2}-I_{u H}^{2}}
$$

\subsubsection{Determination of dividing frequency $n_{c}$ between low and high frequencies}

When we do a partial simulation we know our turbulence intensity is $I_{u H}$ and that our missing low frequency turbulence intensity is $I_{u L}$, as given by Eq. (9). We also know that:

$$
\left(\frac{I_{u H}}{I_{u}}\right)^{2}=\int_{n_{c}}^{\infty} \frac{S_{u}(n)}{\sigma_{u}^{2}} d n=\frac{U}{{ }^{2} L_{u}} \int_{\frac{n_{c}{ }^{x} L_{u}}{U}}^{\infty} \frac{S_{u}\left(\frac{n^{\times} L_{u}}{U}\right)}{\sigma_{u}^{2}} d\left(\frac{n^{\times} L_{u}}{U}\right)
$$

where $n=$ frequency, $S_{u}(n)=$ average power spectrum of $u$ over a long enough time to attain statistical stability, and $n_{c}$ is the "critical frequency" dividing the high and low frequency parts of the spectrum. Note that the longitudinal integral scale of the turbulence ${ }^{\mathrm{x}} L_{u}$ is here introduced as a convenient length to use, along with the velocity $U$ for converting frequency to non-dimensional form $\frac{n^{\mathrm{x}} L_{u}}{U}$. The von Karman spectrum, which gives a good description of $S_{u}$, is:

$$
\frac{n S_{u}}{\sigma_{u}^{2}}=\frac{4 \frac{n^{\times} L_{u}}{U}}{\left(1+70.78\left(\frac{n^{\times} L_{u}}{U}\right)^{2}\right)^{5 / 6}}
$$

Using Eq. (11) in Eq. (10) gives:

$$
\left(\frac{I_{u H}}{I_{u}}\right)^{2}=\int_{\eta_{c}}^{\infty} \frac{4}{\left(1+70.78 \eta^{2}\right)^{5 / 6}} d \eta
$$

where $\eta_{c}=\frac{n_{c}{ }^{\mathrm{x}} L_{u}}{U}$. In general, with the partial simulation approach we expect that we will be integrating over a range of frequencies where the second term in the denominator dominates. Thus we may simplify Eq. (12) to: 


$$
\left(\frac{I_{u H}}{I_{u}}\right)^{2}=\int_{\eta_{c}}^{\infty} \frac{4}{70.78^{5 / 6} \eta^{5 / 3}} d \eta=\frac{6}{70.78^{5 / 6}} \eta_{c}{ }^{-2 / 3}
$$

Thus an expression for $n_{c}$ is obtained:

$$
n_{c}=\eta_{c} \frac{U}{{ }^{{ } L_{u}}}=\frac{U}{{ }^{\mathrm{x}} L_{u}}\left(\frac{6^{3 / 2}}{70.78^{5 / 4}} \frac{I_{u}^{3}}{I_{u H}^{3}}\right)=0.0716 \frac{U}{{ }^{\mathrm{x}} L_{u}}\left(\frac{I_{u}}{I_{u H}}\right)^{3}
$$

Note that this relationship uses the full spectrum value of ${ }^{\mathrm{x}} L_{u}$ and $U=$ mean velocity with full spectrum present.

\subsubsection{Wind simulation}

In wind simulation with missing low frequency turbulence the goal is to have the kinetic energy of the high frequency turbulence per unit frequency in the right ratio to the kinetic energy of the mean wind. This can be achieved if, at high frequencies in the scale-

model tests the non-dimensional power spectrum, $\frac{n S_{u}}{U^{2}}$, is the same in the full scale or prototype wind. This implies that at high frequencies:

$$
\frac{n_{m} S_{u m}}{U_{m}^{2}}=\frac{n_{p} S_{u p}}{U_{p}^{2}}
$$

where subscripts $m$ and $p$ denote model scale and prototype (i.e. full-scale) quantities respectively. At high frequencies the von Karman model of the power spectrum (Eq. 11) may be written as:

$$
\frac{n S_{u}}{U^{2}}=\frac{4 I_{u}^{2}}{70.78^{5 / 6}\left(\frac{n^{x} L u}{U}\right)^{2 / 3}}
$$

Also the non-dimensional frequency $n b / U$, where $b$ is a reference dimension, must match at model and prototype scale. This implies that:

$$
\frac{n_{m} b_{m}}{U_{m}}=\frac{n_{p} b_{p}}{U_{p}}
$$


Combining Eqs. (15), (16) and (17) we find that $I_{u m} /\left(\frac{{ }^{\mathrm{x}} L_{u m}}{b_{m}}\right)^{1 / 3}=I_{u p} /\left(\frac{{ }^{\mathrm{x}} L_{u p}}{b_{p}}\right)^{1 / 3}$ which leads to the requirement that the ratio of model turbulence intensity to prototype turbulence intensity should be governed by:

$$
\frac{I_{u m}}{I_{u p}}=\left(\frac{{ }^{\mathrm{x}} L_{u m}}{{ }^{\mathrm{x}} L_{u p}}\right)^{1 / 3}\left(\frac{b_{p}}{b_{m}}\right)^{1 / 3}
$$

In a full turbulence simulation $\left(\frac{{ }^{\mathrm{x}}{ }{ }_{u m}}{{ }^{\mathrm{x}}{ }_{L_{u p}}}\right)=\left(\frac{b_{p}}{b_{m}}\right)$ and it is required to have $I_{u m}=I_{u p}$. However, in a partial turbulence simulation, where $\left(\frac{{ }^{\mathrm{x}} L_{u m}}{{ }^{{ } L_{u p}}}\right)<\left(\frac{b_{p}}{b_{m}}\right)$, it is required to have $I_{u m}<I_{u p}$ in accordance with Equation 18.

In reality there are other integral scales similar to ${ }^{\mathrm{x}} L_{u}$ that are linked with the other turbulence velocity components, $v$ and $w$, in the lateral and vertical directions. Therefore, there are similar relationships for those components which should also be adhered to. However, typically it is found that if Eq. (18) is used to set the ratio $I_{u m} / I_{u p}$ then the equivalent ratios for the other turbulence velocity components fall into line fairly well.

\subsubsection{Method for determining the peak pressure coefficients}

In a partial turbulence simulation the sample period can be divided into subintervals of sufficient duration that they may be treated as independent events. The peak pressure $\hat{p}$ in any one subinterval may be written as:

$$
\hat{p}=\frac{1}{2} \rho Q^{2} \hat{C}
$$

where $\hat{C}$ is the peak pressure coefficient that occurred during the subinterval. Strictly $\hat{C}$ is a function of flow angle (which would make it a function of low frequency lateral and 
vertical turbulence fluctuations) but as explained earlier we are ignoring these effects in the present paper. The resultant wind speed $Q$ for the subinterval is given by:

$$
Q^{2}=\left(U+u_{L}\right)^{2}+v_{L}^{2}+w_{L}^{2}
$$

where each of the low frequency turbulent velocity components $u_{L}, v_{L}, w_{L}$, may be regarded as constant during the subinterval. Therefore in each subinterval:

$$
\hat{p}=\frac{1}{2} \rho\left(\left(U+u_{L}\right)^{2}+v_{L}^{2}+w_{L}^{2}\right) \hat{C}
$$

In Eq. (21) the terms $v_{L}^{2}$ and $w_{L}^{2}$ are very small relative to $\left(U+u_{L}\right)^{2}$. Therefore, to simplify the analysis they will be ignored. Also, we will define $\zeta \equiv \frac{u_{L}}{U}$. Then Eq. (21) may be expressed as:

$$
\hat{C}_{p}=\frac{\hat{p}}{\frac{1}{2} \rho U^{2}}=(1+\zeta)^{2} \hat{C}
$$

Equation (22) may be regarded as the expression for the peak pressure coefficient for a single subinterval based on the mean velocity of the full sample period with full spectrum turbulence present. The peak over all subintervals may be written:

$$
\hat{C}_{p M A X}=\left\langle(1+\zeta)^{2} \hat{C}\right\rangle_{M A X}
$$

where we have used the notation \langle\rangle$_{M A X}$ to denote the maximum value out of all the subintervals that make up the full sample period. For each subinterval there will be a combination of $\zeta$ and subinterval peak coefficient $\hat{C}$.

In the partial turbulence simulation we can measure the probability that the peak pressure coefficient will not exceed a value $\hat{C}$ in a subinterval. This probability is in general described well by the Fisher Tippet Type I distribution.

$$
F(\hat{C})=\exp (-\exp (-a(\hat{C}-b)))
$$


where $a$ and $b$ are constants that can be determined experimentally. The probability that the pressure coefficient will exceed $\hat{C}$ in a subinterval is $G=1-F(\hat{C})$. From Eq. (22) we may replace $\hat{C}$ in Eq. (24) by $\frac{\hat{C}_{p}}{(1+\zeta)^{2}}$. Therefore, the probability that $\hat{C}_{p}$ will be exceeded for a given value of $\zeta$ is:

$$
G\left(\hat{C}_{p} / b, \zeta\right)=1-\exp \left(-\exp \left(-a b\left(\frac{\hat{C}_{p} / b}{(1+\zeta)^{2}}-1\right)\right)\right)
$$

For a given subinterval the probability of $\zeta$ being in the range $\zeta$ to $\zeta+\delta \zeta$ is $f_{\zeta}(\zeta) \delta \zeta$, in which $f_{\zeta}$ is the probability density of $\zeta$. Therefore, the probability of $\hat{C}_{p}$ being exceeded for all values of $\zeta$ is:

$$
G\left(\hat{C}_{p} / b\right)=\int_{-\infty}^{\infty} f_{\zeta}(\zeta)\left[1-\exp \left(-\exp \left(-a b\left(\frac{\hat{C}_{p} / b}{(1+\zeta)^{2}}-1\right)\right)\right)\right] d \zeta
$$

The probability distribution of wind turbulence in a generic boundary layer (i.e. one free from local aerodynamic effects of upwind structures) is generally Gaussian. So it is assumed that:

$$
f_{\zeta}(\zeta)=\frac{1}{\sqrt{2 \pi} I_{u L}} e^{-\frac{1}{2}\left(\frac{\zeta}{I_{u L}}\right)^{2}}
$$

Therefore, we deduce that the probability of $\hat{C}_{p}$ being exceeded for all values of $\zeta$ is:

$$
G\left(\hat{C}_{p} / b\right)=\int_{-\infty}^{\infty} \frac{1}{\sqrt{2 \pi} I_{u L}} e^{-\frac{1}{2}\left(\frac{\zeta}{I_{u L}}\right)^{2}}\left[1-\exp \left(-\exp \left(-a b\left(\frac{\hat{C}_{p} / b}{(1+\zeta)^{2}}-1\right)\right)\right)\right] d \zeta
$$

Note that if we define:

$$
\xi \equiv \frac{\zeta}{I_{u L}}
$$

Then Equation 30 can be written as: 


$$
G\left(\frac{\hat{C}_{p}}{b}\right)=\int_{-\infty}^{\infty} \frac{1}{\sqrt{2 \pi}} e^{-\frac{1}{2} \xi^{2}}\left[1-\exp \left(-\exp \left(-a b\left(\frac{\frac{\widehat{C}_{p}}{b}}{\left(1+I_{u L} \xi\right)^{2}}-1\right)\right)\right)\right] d \xi
$$

The parameters $a$ and $b$ can be measured from time histories of pressures in partial simulations. Then, given the turbulence intensity of the low frequency fluctuations, $I_{u L}$, the probability of exceeding a given value of $\hat{C}_{p} / b$ in a single subinterval can be computed by numerical integration using Eq. (30). If our full sample period is one hour of wind in which we have $N$ subintervals then the highest pressure coefficient will have probability $1 / N$ of being exceeded (note that in the partial turbulence test we typically do not need to sample for as many as $N$ sub-intervals, because statistical stability of the parameters $a$ and $b$ can be obtained with fewer). For example, if our subintervals on the model scale up to be 1.5 seconds at full scale then we need to determine the value of $\hat{C}_{p} / b$ that has $1.5 / 3600=0.00042$ probability of being exceeded in one hour.

The probability of not being exceeded in any one subinterval is then $P=1-\frac{1}{N}$. The probability of this highest value not being exceeded during the whole hour is therefore: $P_{N}=\left(1-\frac{1}{N}\right)^{N}$. As $N$ increases above about 10 this rapidly asymptotes to $P_{N}=0.3679$. So the mode of the distribution has about $37 \%$ probability of not being exceeded in the hour of wind. If we want to set the probability of non-exceedance in $N$ subintervals to some other value such as 0.85 then this is equivalent to changing the target probability per subinterval $P_{t a r}$ to some value such that $P_{t a r}^{N}=0.85$. Since the corresponding probability of exceedance is $G=1-P_{\text {tar }}$, this implies that we should evaluate the peak $\frac{C_{p}}{b}$ value at: 


$$
G=1-0.85^{1 / N}
$$

Figure 2 illustrates the results of the numerical integration for various values of $a b$ in the typical range with low frequency turbulence intensity $I_{u L}=0.2$. It can be seen that the peak value of $\hat{C}_{p} / b$ corresponding to the selected target probability of 0.00042 depends on the value of $a b$.

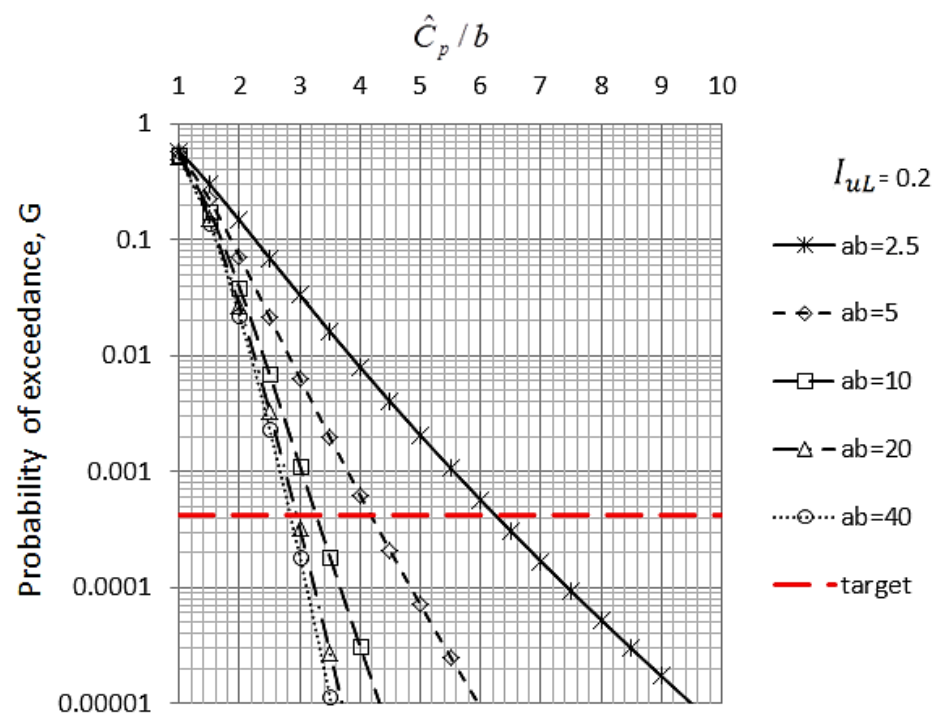

Figure 2. Probability of exceeding $\hat{C}_{p} / b$ for $I_{u L}=0.2$ and various $a b$ values, where $\hat{C}_{p}=$ peak pressure coefficient

The above procedure can be simplified by using an empirical fit to the integral relationship of Eq. (30) which allows $\hat{C}_{p}$ to be computed directly for any selected probability $G$. A reasonably accurate fit has been found to be:

$$
\hat{C}_{p}=\left(\alpha \log _{10} G+\beta\right) b
$$

where

$$
\alpha=\left[-\left(2.5+\frac{14}{(a b)^{1.4}}\right) I_{u L}+0.06-\frac{2.1}{(a b)^{1.15}}\right]\left(0.93+4.44\left(I_{u L}-0.15\right)^{2}\right)
$$

and 


$$
\beta=\left(1.7-\frac{20.7}{(a b)^{1.1}}\right) I_{u L}+1+\frac{1}{(a b)^{1.5}}
$$

Equations (32) through (34) have been found to give acceptable engineering accuracy in the range $10^{-2} \leq G \leq 10^{-6}, 2.5 \leq a b \leq 40$, and $0.05 \leq I_{u L} \leq 0.3$.

It has been assumed above that the sub-interval peaks measured in the Partial Turbulence tests follow a Fisher Tippet Type I probability distribution. The hourly peak values of $\hat{C}_{p} / b$ can also themselves be expected to follow a Fisher-Tippet type I distribution, but the parameters $a$ and $b$ are now replaced by the parameters $\alpha$ and $\beta$. Equations (29) and (32) determine the mode of the hourly peak values of $\hat{C}_{p} / b$ and it can be shown that the mean, or expected value, of the hourly peaks is given by:

$$
\frac{\hat{\hat{C}}_{p}}{b}=\left(\alpha \log _{10} G+\beta\right)-0.5772157 \times \alpha / \ln 10
$$

It can be shown that the mean, or expected value, of the Fisher Tippet Type I distribution is at probability

$$
P(\overline{\hat{C}})=e^{-e^{-\gamma}}=e^{-e^{-0.5772}}=0.5704
$$

where $\gamma$ is Euler's constant.

The peak pressure coefficients calculated using the procedure described above are based on mean hourly dynamic pressure. The pressure coefficient $\hat{C}_{p, 3 \text { sec }}$ based on 3second gust dynamic pressure, for example, can be obtained by re-scaling using:

$$
\hat{C}_{p, 3 \text { sec }}=\hat{C}_{p}\left(\frac{U}{\widehat{U}_{3 s e c}}\right)^{2}
$$

The above analysis has been in the context of pressure coefficient. However, the same procedure can be applied to any other quantity such as a force or moment coefficient, just so long as the behavior of the pressure, force or moment that is involved varies as 
velocity squared. When predicting the most probable peak in a single hour (or some other selected full sample period) of wind the relationships for the mode would be the most applicable (Eqs. 29 and 32). When comparing with the average of many events such as the records for the Silsoe Cube in this paper, the mean or expected peak prediction (Eq. $35)$ is the most applicable.

\subsection{Experiments}

\subsubsection{Test building}

As indicated earlier, to check the efficacy of the PTS method described above the full-scale pressure coefficient data obtained by Richards and Hoxey (2012) on the Silsoe Cube were used as a benchmark for comparison. A1:5 model of the Cube was constructed, resulting in a $1.2 \mathrm{~m}$ cube at model scale. Figure 3 shows the test model in the WOW and the pressure tap locations matching the full-scale tap locations. The wind directions considered were $0^{\circ}$ to $90^{\circ}$ at $15^{\circ}$ intervals.
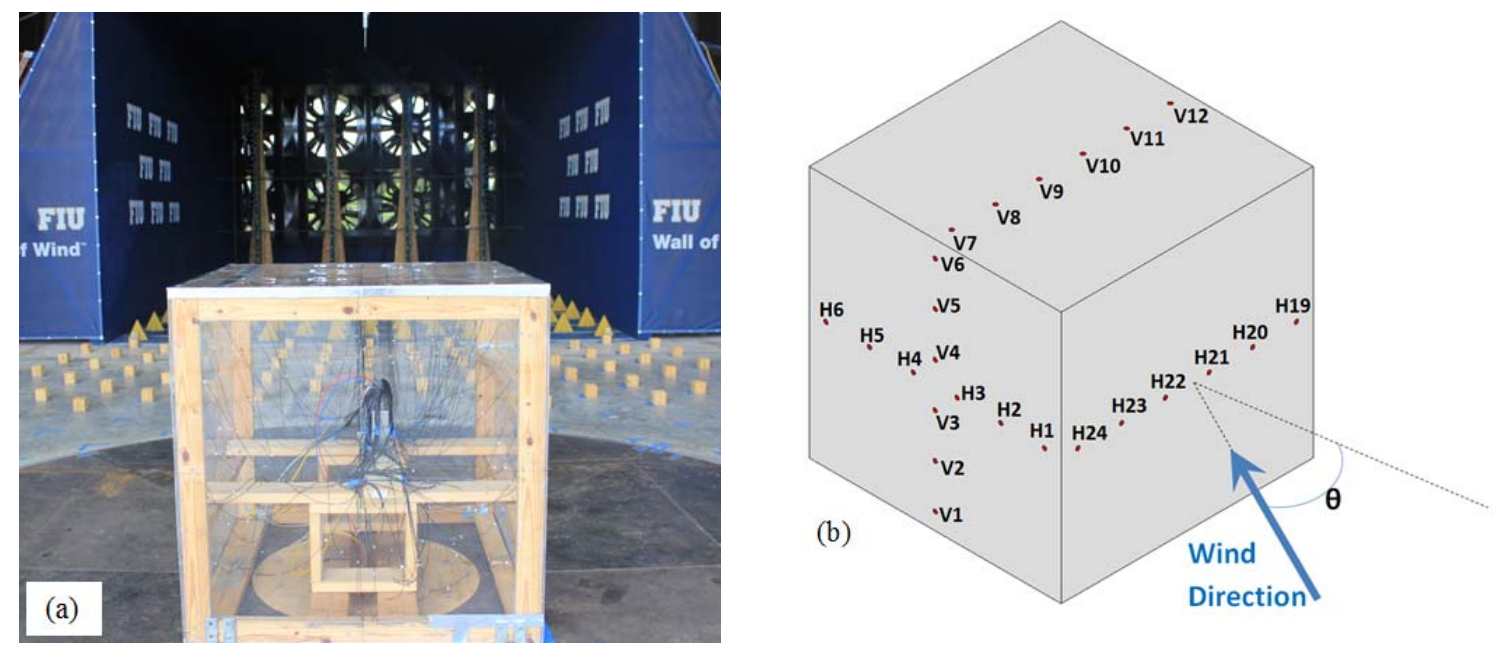

Figure 3. (a) Silsoe Cube building model tested in WOW, (b) Tap locations on Silsoe model 
A 512 channel Scanivalve Corporation pressure scanning system was used for pressure measurements. Pressure data were acquired at a sampling frequency of $512 \mathrm{~Hz}$ for a period of 90 seconds. A transfer function designed for the tubing (Irwin et al, 1979) was used to correct for tubing effects.

\subsubsection{Wall of Wind facility}

Testing was performed in the 12-fan Wall of Wind (WOW) open jet facility at FIU. This facility can generate a $6.1 \mathrm{~m}$ wide and $4.3 \mathrm{~m}$ high wind field and speeds as high as $70 \mathrm{~m} / \mathrm{s}$. A set of triangular spires and floor roughness elements was used to generate the turbulence and boundary layer characteristics (Fig. 4).
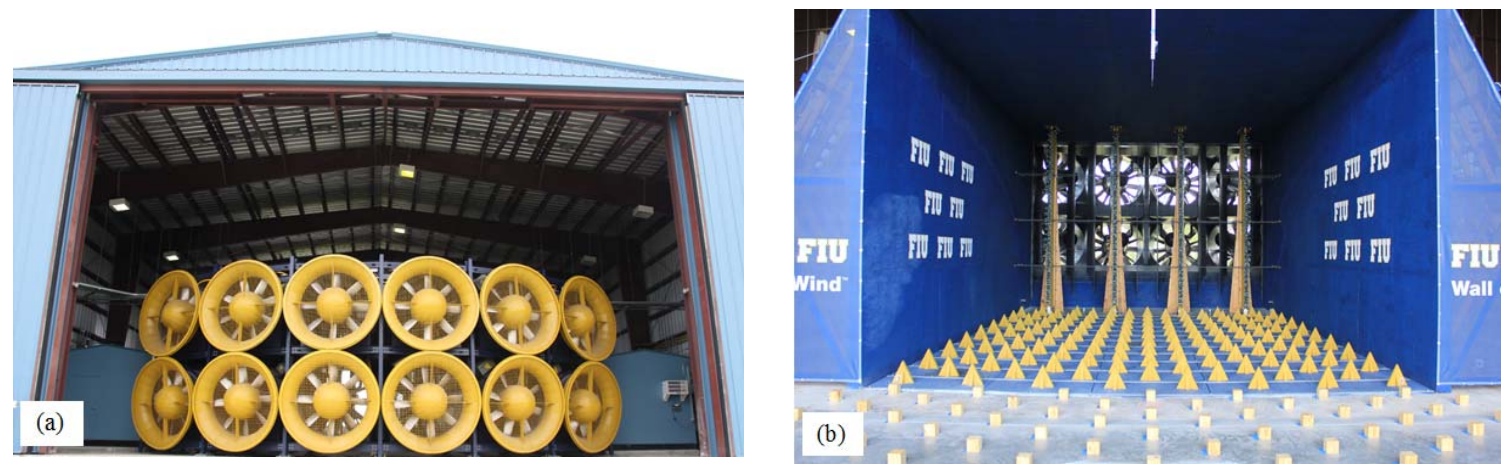

Figure 4. (a) Wall of Wind, Florida International University, (b) Spires and floor roughness elements

Figure 5 shows the comparison of the non-dimensional longitudinal turbulence power spectra for the full scale cube and the model as measured at the level of the top of the cube. All spectra were plotted in non-dimensional terms of $n S(n) / U^{2}$ versus $n B / U$, as suggested by Irwin (1988) and Richards et al (2007), where $B$ is a reference length taken here as height $z$. The atmospheric boundary layer (ABL) full spectrum and the WOW prototype high frequency spectrum approximately match for non-dimensional 
frequencies higher than 0.2 , but if anything the WOW spectrum had a little more power present at high frequencies.

The mean wind speed and turbulence intensity profiles for WOW open terrain are shown in Fig. 6 for $20.69 \mathrm{~m} / \mathrm{s}$ mean wind speed at $\mathrm{z}=1.22 \mathrm{~m}$ elevation (achieved power law coefficient for the mean velocity profile was 0.185 ). It should be noted that in the tests in partial turbulence simulation the turbulence intensity is significantly lower than that for the ABL flow containing the low full spectrum of fluctuations.

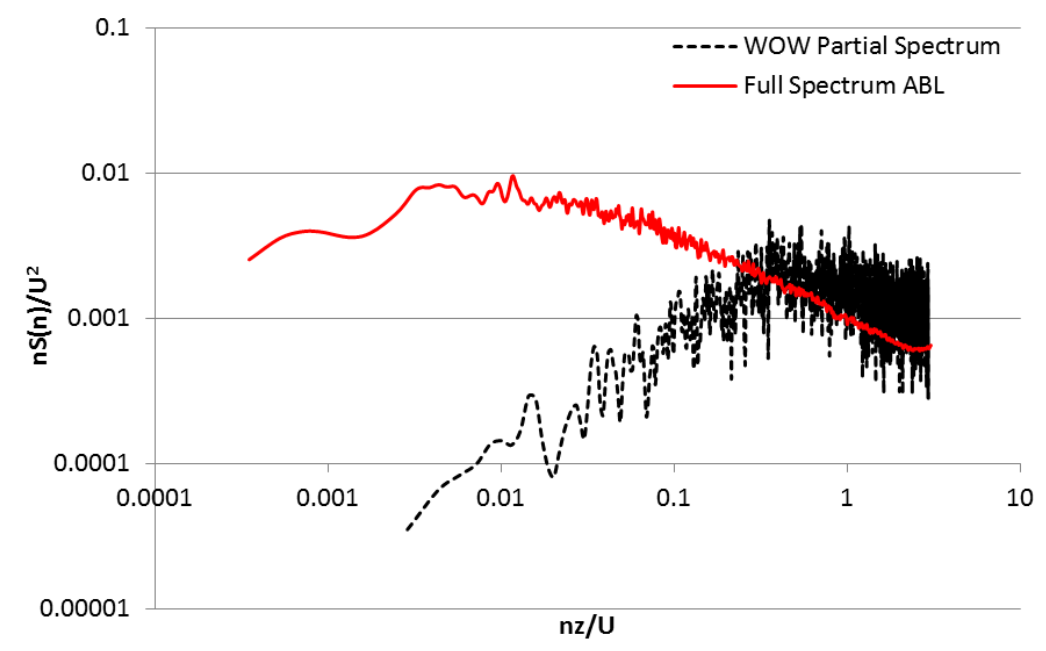

Figure 5. Comparison between full-scale Silsoe cube full spectrum and WOW partial spectrum
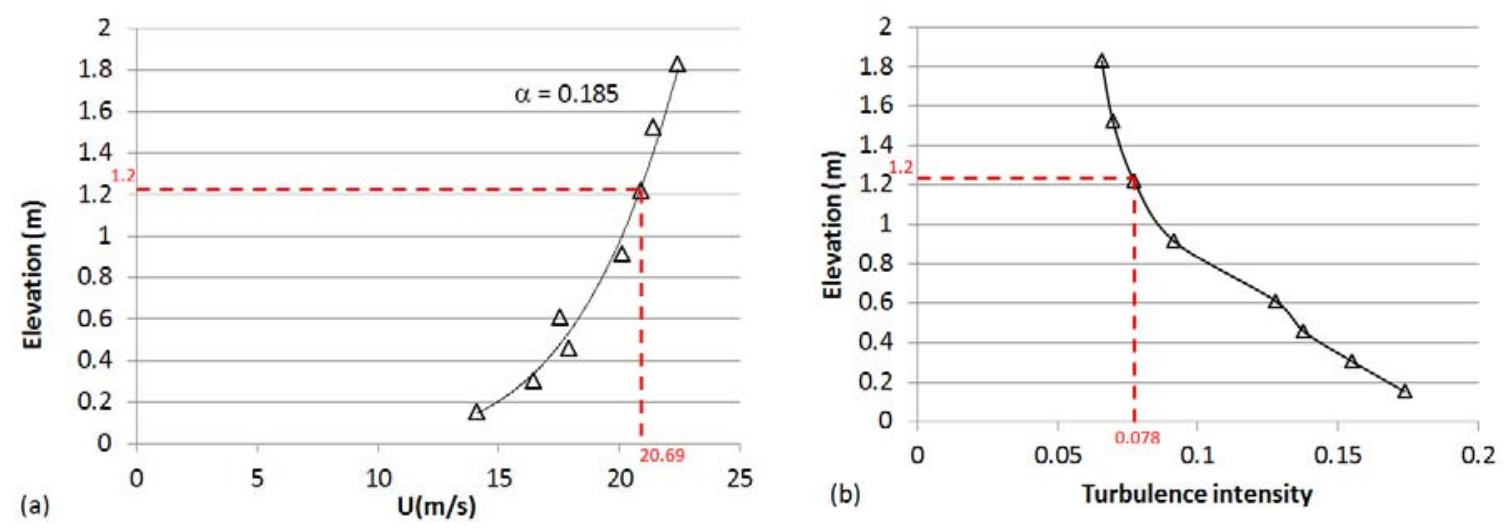

Figure 6. Open terrain: (a) ABL profile, (b) Turbulence intensity profile 


\subsubsection{Wall of Wind scaling parameters}

The most recent wind measurements at the Silsoe Research Institute site, with southwest to west winds, resulted in longitudinal turbulence intensity $I_{u}$ values of $19.3 \%$ at Silsoe cube roof height $(6 \mathrm{~m})$ and roughness length $z_{0}=0.006-0.01 \mathrm{~m}$ (Richards and Hoxey, 2012). The mean wind speed was $U_{p}=9.52 \mathrm{~m} / \mathrm{s}$ at roof height, the test duration was $t_{p}=12$ min., the sampling frequency was $8 \mathrm{~Hz}$ and the integral length scale was ${ }^{\mathrm{x}} L_{u}=53 \mathrm{~m}$. In the current model tests the scale was 1:5, the mean wind speed was 20.69 $\mathrm{m} / \mathrm{s}$ at roof height $(1.2 \mathrm{~m})$, which was expected to put the measurements of pressures in the right range for the WOW instrumentation, and the integral scale was found to be ${ }^{\mathrm{x}} L_{u}=0.48 \mathrm{~m}$ at roof height. Therefore, from Eq. (18) we calculate the desired turbulence intensity on the model

$$
I_{u H}=0.193\left(\frac{0.48}{53}\right)^{1 / 3}(5)^{1 / 3}=0.069
$$

In the model tests the achieved turbulence intensity was close to this with a value of $I_{u H}=0.078$. The missing low frequency turbulence intensity was therefore, from Eq. (9):

$$
I_{u L}=\sqrt{I_{u}^{2}-I_{u H}^{2}}=\sqrt{0.193^{2}-0.078^{2}}=0.1765
$$

The full scale gust due to the missing low frequency turbulence was estimated using the peak factor of 3.4 used in ASCE 7 for background turbulence and is therefore:

$$
\widehat{U}_{L p}=U_{p}\left(1+3.4 I_{u L}\right)=15.23 \mathrm{~m} / \mathrm{s}
$$

As discussed above, the mean speed in the Wall of Wind was $20.69 \mathrm{~m} / \mathrm{s}$. Since the corresponding full scale speed varies from subinterval to subinterval there is a question as how to fix the speed scaling, since strictly speaking it will also vary from subinterval to 
subinterval. However, the most probable situation causing the highest wind load or local pressure is where a particularly high large scale gust blows through. Therefore, by far the largest contribution to probability of exceedance comes when the low frequency gust fluctuations are at high positive values. With this in mind the speed scaling for the present study was set such that the mean speed of the PTS tests corresponded to the low frequency gust speed calculated above in Eq. (40). Hence:

$$
\frac{U_{m}}{U_{p}}=\frac{20.69}{15.23}=1.36
$$

Since the length scaling was $b_{m} / b_{p}=1 / 5$, the frequency scale was:

$$
\frac{n_{m}}{n_{p}}=\frac{b_{p}}{b_{m}} \frac{U_{m}}{U_{p}}=5 \times 1.36=6.79
$$

The time scale was therefore:

$$
\frac{t_{m}}{t_{p}}=\frac{n_{p}}{n_{m}}=0.147
$$

\subsubsection{Sampling time}

At full scale, with the full turbulence spectrum present, it is widely recognized that $T_{S}=1$ hour is sufficient sample time to achieve stable statistics when measuring fluctuating wind loads. However, full scale sample times as short as 10 minutes are sometimes used. The sample time for the full scale Silsoe cube was $12 \mathrm{~min}$. The representative characteristic time for the turbulence is $\frac{{ }^{{ }} L_{u}}{U}$ which at full scale is calculated to be:

$$
\frac{{ }^{\mathrm{x}}{ }_{L_{u}}}{U}=\frac{53}{9.52}=5.57 \mathrm{~s}
$$

Therefore, the ratio of a one hour sample time $T_{s}$ to turbulence characteristic time in the Silsoe situation was 


$$
\frac{T_{s} U}{{ }^{\mathrm{x}} L_{u}}=\frac{3600}{5.57}=646
$$

If we can achieve the same ratio of sample time to turbulence characteristic time on the model then we should also have stable statistics. So, on the model we require:

$$
T_{s}=646 \times \frac{{ }^{\mathrm{x}} L_{u m}}{U_{m}}=646 \times \frac{0.48}{20.69}=15 \mathrm{~s}
$$

This implies that we should sample for at least 15 seconds on the model. In the current experiments, sampling time was 90 seconds, well in excess of the minimum needed according to the above estimate. Note that according to Eq. (43), 90 seconds model sampling time corresponds to $90 / 0.147=612.24$ seconds, or about 10 minutes at full scale.

\subsubsection{Sample rate and filtering}

Measurements in the WOW were sampled at a rate of $512 \mathrm{~Hz}$. Since the low pass cut of frequency for full scale data was $8 \mathrm{~Hz}$, all pressure readings were low pass filtered at the corresponding frequency at model scale, $55 \mathrm{~Hz}$.

\subsubsection{Treatment of the data}

In the Wall of Wind we simulated turbulence fluctuations at frequencies above the cut-off frequency provided by Eq. (14). As described above, at full scale the mean velocity was $U_{p}=9.52 \mathrm{~m} / \mathrm{s}$ and the integral scale was ${ }^{\mathrm{x}} L_{u}=53 \mathrm{~m}$. Also the turbulence intensity ratio was $I_{u} / I_{u H}=0.193 / 0.078=2.47$. Therefore, from Eq. (14),

$$
n_{c}=0.0716 \frac{9.52}{53} 2.47^{3}=0.194 \mathrm{~Hz}
$$

The relationship between gust duration and cut-off frequency is discussed in Appendix A and it leads to the equivalent gust-duration at full scale being about $0.45 / 0.194=2.32$ seconds. This implies that in the Wall of Wind the sample period could be regarded as 
being made up of a sequence of 2.32 second duration gusts. Therefore, in dividing the test sample period into sub-intervals the length of each subinterval needed to be in excess of 2.32 seconds to avoid excessive correlation between events in adjacent sub-intervals. The pressure coefficient for each sub-interval based on the mean speed in the WOW was

$$
\hat{C}_{p}=\frac{\hat{p}-p_{\text {ref }}}{\frac{1}{2} \rho U_{\text {wow }}^{2}}
$$

where $\hat{p}=$ peak pressure in the sub-interval, $p_{\text {ref }}=$ reference static pressure, and $U_{\text {wow }}=$ mean velocity measured in the Wall of Wind. Then as explained in Section 2.4, the collection of sub-interval peak coefficients was analyzed to determine the $a$ and $b$ parameters and hence the expected peak pressure coefficient based on the mean hourly speed (Eqs. 30, 32 and 35). This analysis takes into account the joint probability of low frequency gust velocity and peak coefficient, i.e. the fact that the highest peak pressure in one hour can be due to an exceptionally strong gust combined with a less than maximum peak pressure coefficient, or due to an exceptionally high peak pressure coefficient combined with a gust speed lower than the maximum. In the current experiments the number of sub-intervals was set at 100 , which corresponded to a sub-interval length of 6.12 seconds, well in excess of the minimum set above of 2.32 seconds.

\subsection{Results and Discussions}

The pressure coefficient comparisons shown in this section are based on full-scale Silsoe measurement results given in Richards and Hoxey (2012) in which the pressure coefficients are defined in terms of the mean dynamic pressure as follows:

$$
C p_{\text {mean }}=\frac{P_{\text {mean }}}{q_{\text {mean }}}
$$




$$
C p_{\text {peak }}=\frac{P_{\text {peak }}}{\left(3 q_{\text {mean }}\right)}
$$

where $P_{\text {mean }}$ is the mean surface pressure, $P_{\text {peak }}$ is the highest positive or lowest negative pressure observed during the test duration at the Silsoe site and $q_{\text {mean }}$ is the mean dynamic pressure defined as $0.5 \rho U^{2}(\rho=$ air density). The WOW pressure data were obtained using the method described in Sec. 2.4 and normalized in the same way as in Eqs. (49) and (50).

Figure 7 Shows comparisons of wall pressure coefficients obtained in WOW using the above procedures and at full scale (see Figure 3 for the pressure tap notation). Expected peak pressure coefficients were obtained with the WOW sample time divided into 100 sub-intervals. This means that each subinterval in model scale is equivalent $90 / 100=0.9$ sec. Based on the time scale, each subinterval at full scale is equivalent to $0.9 / 0.147=6.12$ sec. So the targeted probability for $12 \mathrm{~min}$ full spectrum is $G=$ $6.12 /(12 \times 60)=0.0085$ and the expected peak pressure coefficient was evaluated using Eq. (35). The results show generally good agreement with full scale for both the mean and expected peak coefficients. The best agreement tends to be obtained when the highest pressure coefficients occur.
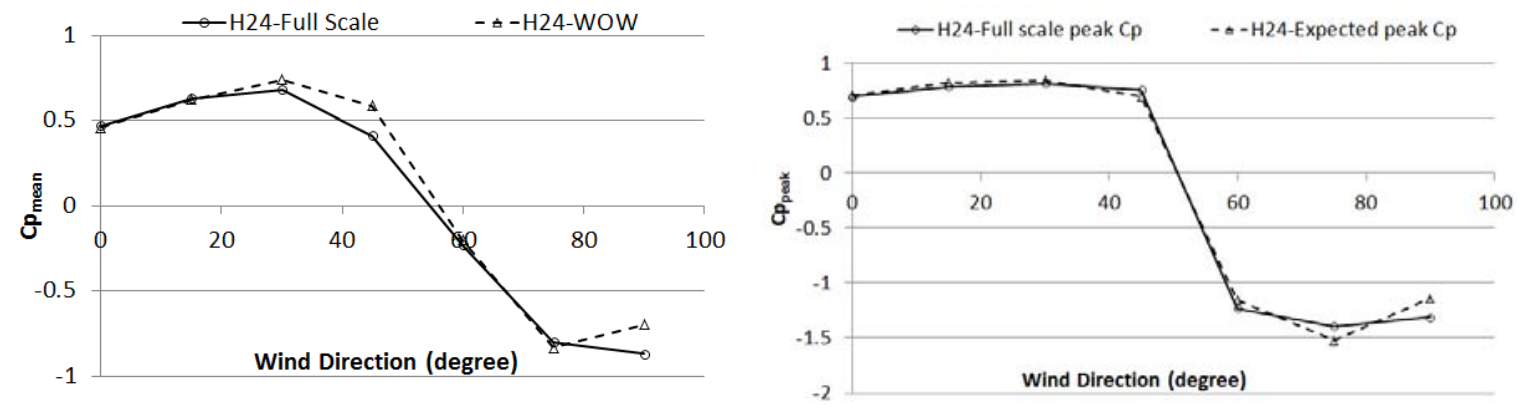

Figure 7. Wall Cp values comparisons vs. wind direction 

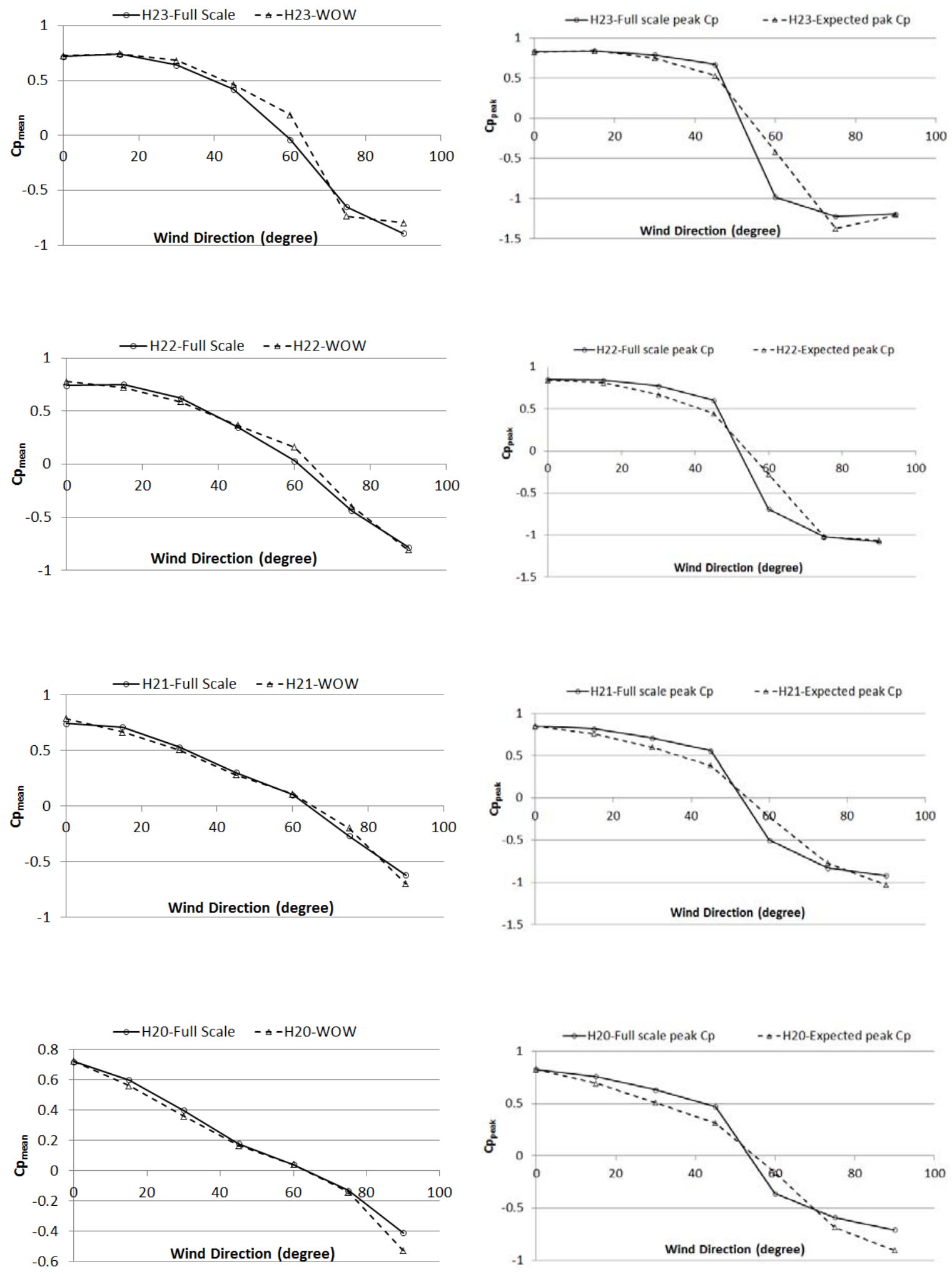

Figure 7 (Cont.). Wall Cp values comparisons vs. wind direction 

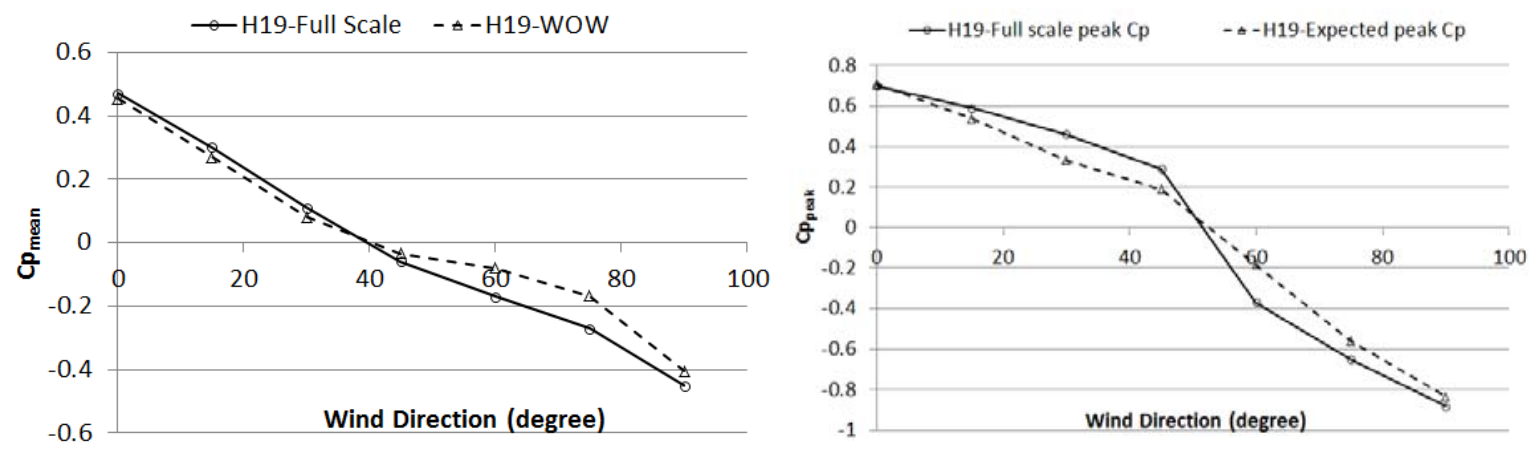

Figure 7 (Cont.). Wall Cp values comparisons vs. wind direction

Figure 8 shows the overall minimum and maximum of peak pressure coefficients on the walls considering all directions. Again the agreement is generally good.
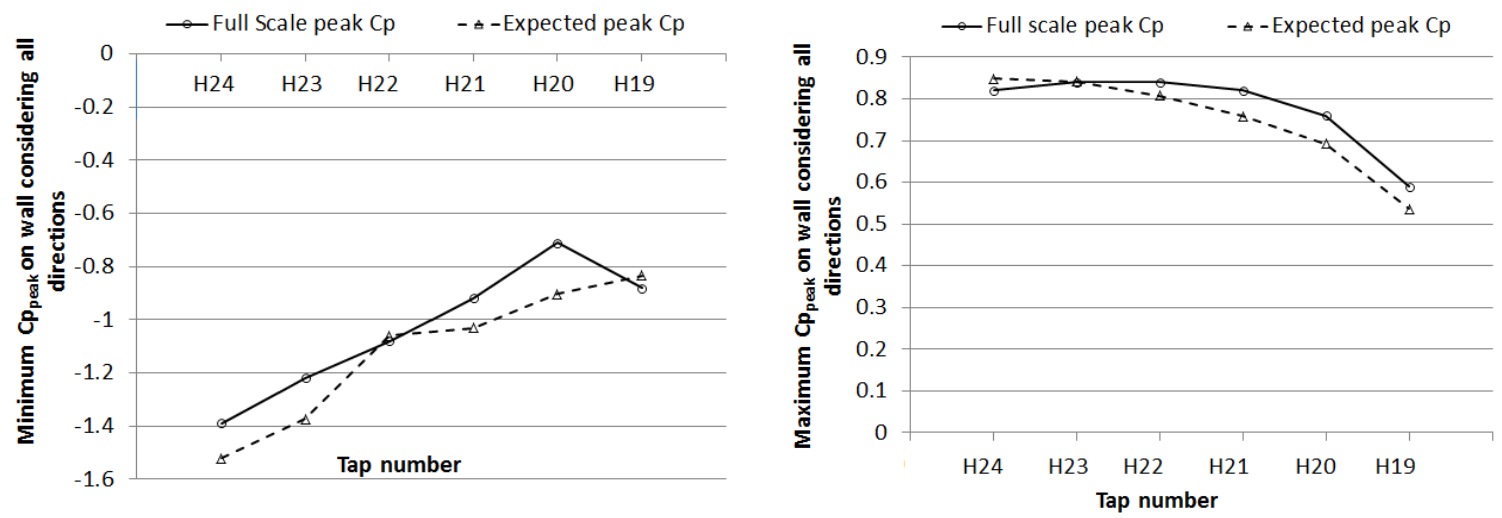

Figure 8. Minimum and maximum of wall $\mathrm{Cp}$ values comparisons considering all directions

Similar comparisons are shown in Fig. 9 for the roof taps. The agreement is not as good as for the wall taps but it is noteworthy that the highest values are well predicted. 

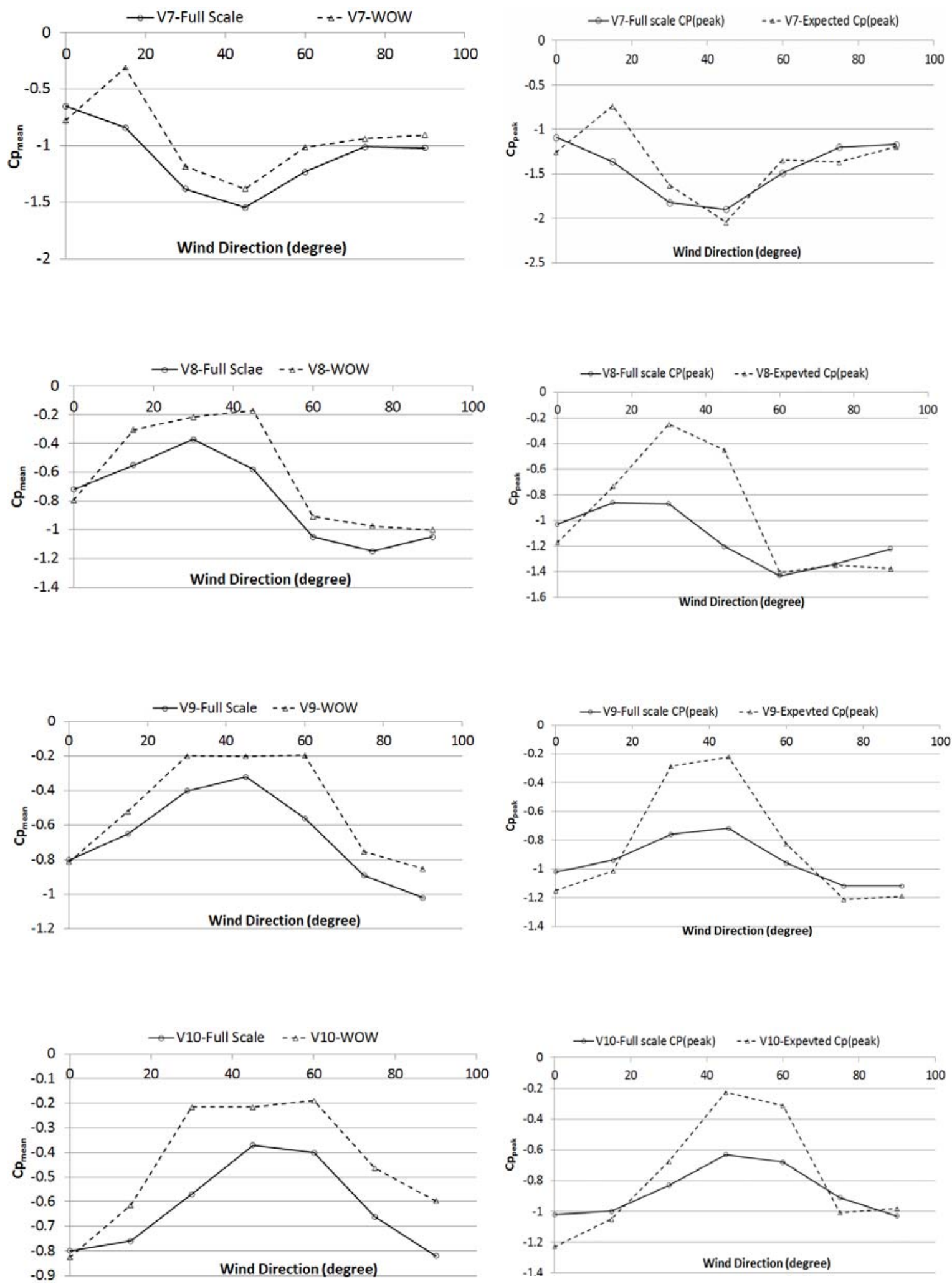

Figure 9. Roof $\mathrm{Cp}$ values comparisons vs. wind direction 

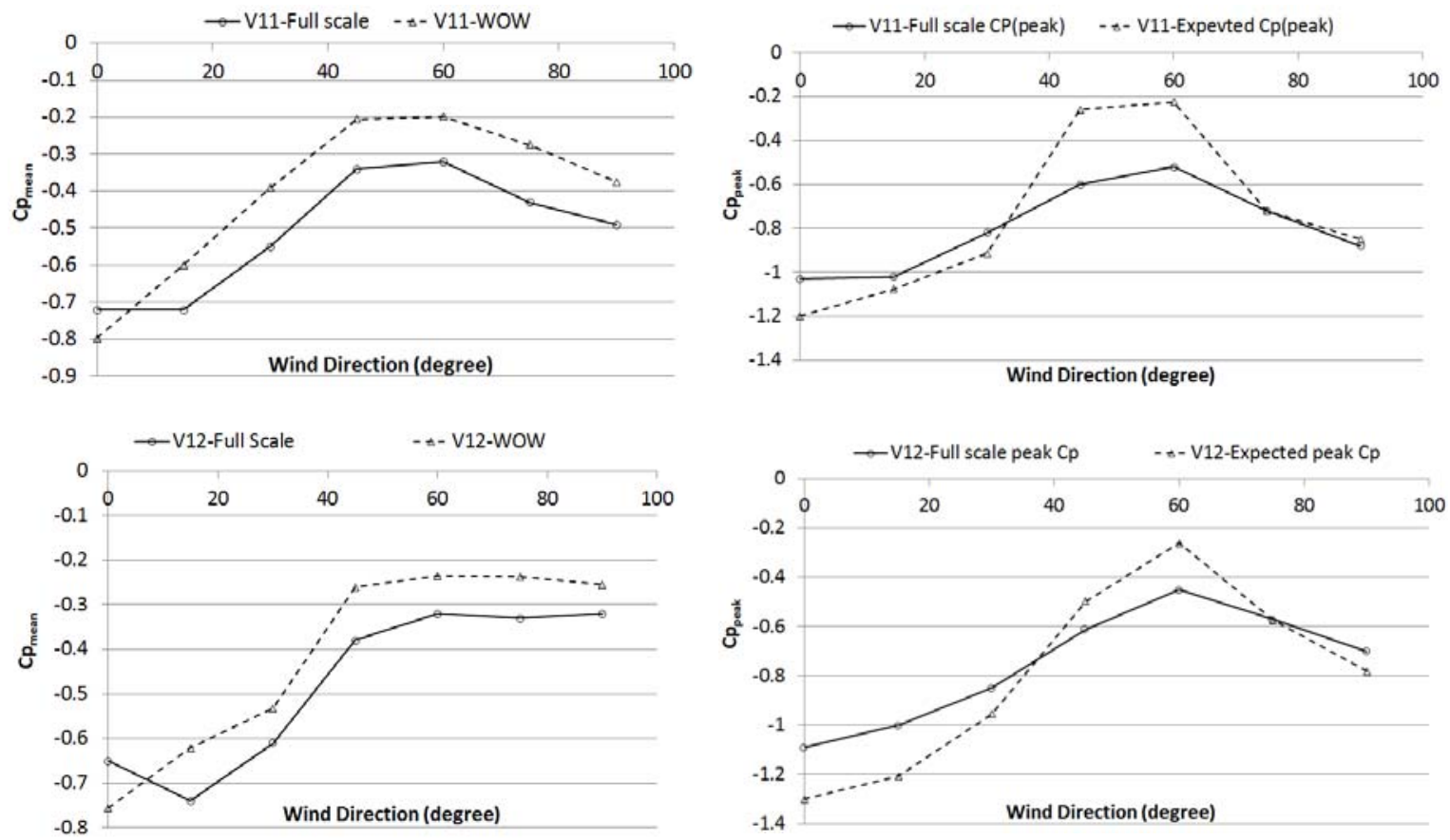

Figure 9 (cont.). Roof $\mathrm{Cp}$ values comparisons vs. wind direction

The results show that where the mean Cps are well-reproduced the PTS method works well. The differences in mean $\mathrm{Cp}$ values may be due to three causes: 1) as shown in Fig. 5 the WOW turbulence spectrum was slightly higher than ideal at high frequencies which could have affected the flow separation and re-attachment on the roof for some wind directions; 2) the gradient of turbulence intensity on the model was steeper on the model than at full scale; and 3) the effects of low frequency lateral turbulence fluctuations were ignored in the theory. The effect of the low frequency lateral turbulence would be expected to smooth out some of the variations of pressure coefficient with wind direction. However, as shown in Fig. 10 the overall worst case peak roof Cps (all directions considered) are in quite good agreement. 


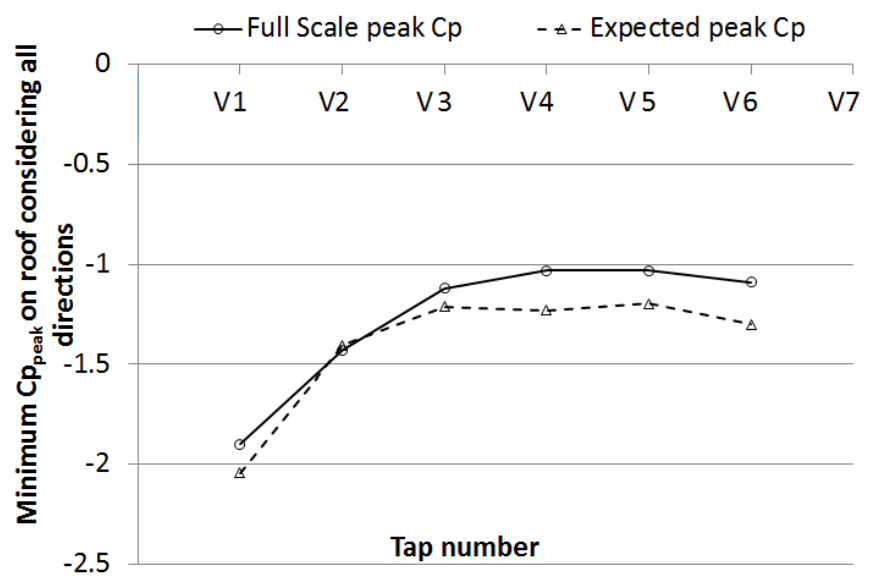

Figure 10. Minimum Roof Cp values comparisons vs. wind direction considering all directions

\subsection{Conclusion}

This paper describes a technique for testing and analyzing data from large scale models when only the high frequency end of the turbulence spectrum is simulated and for including low frequency effects using theoretical quasi-steady assumptions. The proposed test procedure and theoretical method for including the effects of low frequency turbulence in post-test analysis have been assessed by comparing 1:5 scale model results obtained in the Wall of Wind facility at Florida International University for mean and peak pressure coefficients with the full scale data from the Silsoe Cube. This represents a fairly severe test of the methodology because of the large model scale. The results are very encouraging, with generally good agreement being obtained, particularly when the highest loads out of all wind directions are compared. On the walls good agreement was also found for all individual wind directions. On the roof some differences were noted in the central area for non-governing wind directions, primarily quartering angles. This could have been due to the turbulence spectrum being slightly higher on the model at roof 
height and having a steeper vertical gradient, but is also attributed to the simplification in the present paper that low frequency fluctuations of lateral turbulence were ignored. A second paper is in preparation in which methodology for including the effects of low frequency lateral and vertical turbulence is described. It should be noted that while the present method was applied in the Wall of Wind facility, it is not limited in its application to this type of facility. It is equally applicable to boundary layer wind tunnels in general.

\subsection{Acknowledgements}

The 12-fan Wall of Wind flow simulation and large-scale testing for this research was supported by the National Science Foundation (NSF) (NSF Award No. CMMI1151003). We also acknowledge NSF support for Wall of Wind instrumentation (NSF Award No. CMMI-0923365). The Wall of Wind facility was partially funded by the Center of Excellence in Hurricane Damage Mitigation and Production Development through the FIU International Hurricane Research Center. We would like to acknowledge the help received from the $\mathrm{PhD}$ candidate, Ramtin Kargarmoakhar. The help offered by the Wall of Wind manager, Walter Conklin and research scientist Roy Liu Marquis is greatly acknowledged.

\subsection{References}

Banks, D., 2011. Measuring peak wind loads on solar power assemblies, in: Proceedings of the The 13th International Conference on Wind Engineering.

Fritz, W.P., Bienkiewicz, B., Cui, B., Flamand, O., Ho, T.C.E., Kikitsu, H., Letchford, C.W., Simiu, E., 2008. International comparison of wind tunnel estimates of wind effects on low-rise buildings: Test-Related Uncertainties. Journal of Structural Engineering 134, 1887-1890.

Irwin, P., 2009. Wind engineering research needs, building codes and project specific studies, in: Proceedings of the 11th Americas Conference on Wind Engineering. 
Irwin, P., Cooper, K., Girard, R., 1979. Correction of distortion effects caused by tubing systems in measurements of fluctuating pressures. Journal of Wind Engineering and Industrial Aerodynamics 5, 93-107.

Irwin, P.A., 1981. A Simple Omnidirectional sensor for wind tunnel studies of pedestrian level winds. Journal of Wind Engineering and Industrial Aerodynamics 7, 219-239.

Irwin, P.A., 1988. The role of wind tunnel modeling in the prediction of wind effects on bridges, International Symposium on Advances in Bridge Aerodynamics. Balkema, Copenhagen, pp. 99-117.

Kopp, G.A., Banks, D., 2013. Use of the wind tunnel test method for obtaining design wind loads on roof-mounted solar arrays. Journal of structural engineering 139, 284-287.

Kumar, K.S., Stathopoulos, T., 1998. spectral density functions of wind pressures on various low building roof geometries. Wind and Structures 1, 203-223.

Lin, J.X., Surry, D., Tieleman, H.W., 1995. The distribution of pressure near roof corners of flat roof low buildings. Journal of wind engineering and industrial aerodynamics 56, 235-265.

Melbourne, W.H., 1980. Turbulence effects on maximum surface pressures - a mechanism and possibility of reduction. Wind Engineering, 541-551.

Mooneghi, M.A., Irwin, P., Chowdhury, A.G., 2014. Large-scale testing on wind uplift of roof pavers. Journal of Wind Engineering and Industrial Aerodynamics 128, 22-36.

Okada, H., Ha, Y.-C., 1992. Comparison of wind tunnel and full-scale pressure measurement tests on the Texas Texh Building. Journal of wind engineering and industrial aerodynamics 43, 1601-1612.

Richards, P.J., Hoxey, R.P., 2012. Pressures on a cubic building-Part 1: Full-scale results. Journal of wind engineering and industrial aerodynamics 102, 72-86.

Richards, P.J., Hoxey, R.P., Connell, B.D., Lander, D.P., 2007. Wind-tunnel modelling of the Silsoe Cube. Journal of wind engineering and industrial aerodynamics 95, 1384-1399.

Saathoff, P.J., Melbourne, W.H., 1997. Effects of free-stream turbulence on surface pressure fluctuation in a separation bubble. Journal Of Fluid Mechanics 337, 1-24.

Stathopoulos, T., Surry, D., 1983. Scale effects in wind tunnel testing of low buildings. Journal of wind engineering and industrial aerodynamics 13,313-326.

Surry, D., 1991. Pressure measurements on the Texas tech building: Wind tunnel measurements and comparisons with full scale. Journal of wind engineering and industrial aerodynamics 38, 235-247. 
Tieleman, H.W., 2003. Wind tunnel simulation of wind loading on low-rise structures: a review. Journal of wind engineering and industrial aerodynamics 91, 1627-1649.

Tieleman, H.W., Surry, D., Mehta, K.C., 1996. Full/model-scale comparison of surface pressures on the Texas Tech experimental building. Journal of wind engineering and industrial aerodynamics $61,1-23$.

Yamada, H., Katsuchi, H., 2008. Wind-tunnel study on effects of small-scale turbulence on flow patterns around rectangular cylinder, 4th International Colloquium on Bluff Bodies Aerodynamics \& Applications, Italy.

\subsection{Appendix A}

\section{Effective Filter Frequency for $\Delta t$ Second Moving Average}

A variable $y$ that is fluctuating in the form of a sine wave obeys the relationship

$$
y=a \sin 2 \pi f t
$$

where $a=$ amplitude of the sinusoidal variations, $f=$ frequency of the wave in $\mathrm{Hz}$, and $t=$ time in seconds. If we sample the signal at rate $f_{s}$ then the $n^{\text {th }}$ sample will correspond to a time $=\frac{n}{f_{s}}$, and so

$$
y=a \sin 2 \pi \frac{f}{f_{s}} n
$$

It is shown in standard texts that the magnitude of the filter function corresponding to a moving average of $\mathrm{N}$ points of the sine wave is

$$
|H(f)|=\frac{\sin \pi \frac{f}{f_{S}} N}{N \sin \pi \frac{f}{f_{S}}}
$$

Since a time interval of $\Delta t$ corresponds to $N=\Delta \boldsymbol{t} \times f_{s}$, then

$$
|H(f)|=\frac{\sin \pi f \Delta t}{f_{s} \Delta t \sin \left(\pi \frac{f}{f_{s}}\right)}
$$


If the sample rate $f_{s}$ is very high compared to the frequency of the sine wave, which would be true for the limiting the case of a continuous analogue signal, then this reduces to:

$$
|H(f)|=\frac{\sin \pi f \Delta t}{\pi f \Delta t}
$$

In terms of the power spectrum the filter would be $|H|^{2}$. Figure 11 shows $|H|^{2}$ plotted against $f \Delta t$. It can be seen that the filter function is down to about a 0.5 value at $f \Delta t=$ 0.45. So, if we choose the half power level as being at our effective cut-off frequency, the effective cut off frequency is $f_{c}=\frac{0.45}{\Delta t}$. Or, viewing it the other way round, if $f_{c}=$ the cut-off frequency then the duration of the corresponding moving average is $\Delta t=\frac{0.45}{f_{c}}$. From this we see that a 3-second moving average corresponds to a cut-off frequency of about $0.15 \mathrm{~Hz}$. Or a $1 \mathrm{~Hz}$ cut-off frequency corresponds to a moving 0.45 second average.

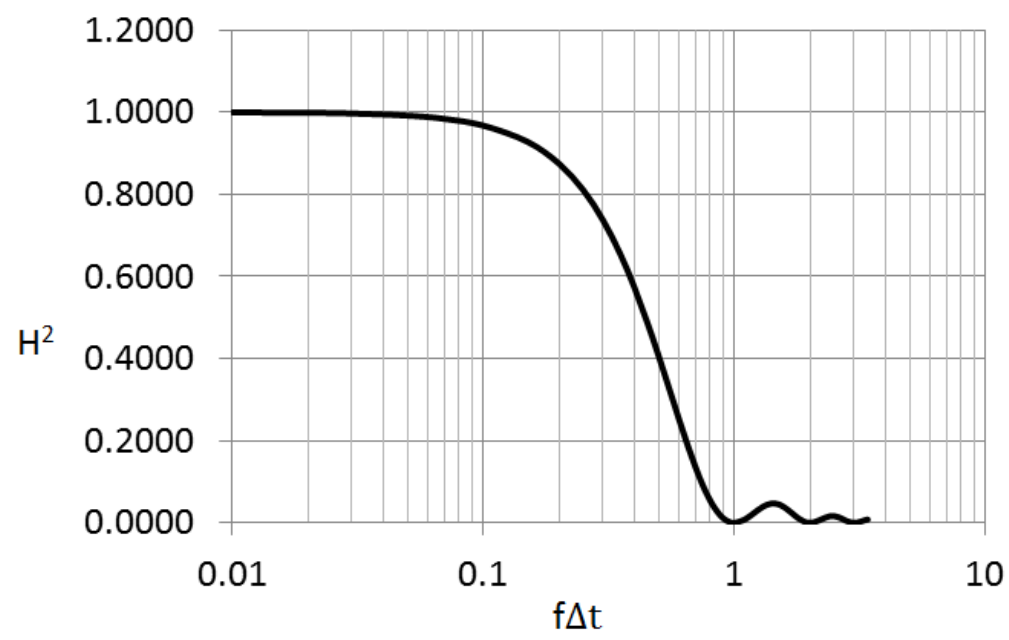

Figure 11. Filter function for a moving average filter 


\section{CHAPTER III}

EXTENSION OF PARTIAL TURBULENCE SIMULATION METHOD TO INCLUDE LOW FREQUENCY LATERAL AND VERTICAL TURBULENCE FLUCTUATIONS

(A paper under review in The Journal of Wind Engineering and Industrial Aerodynamics) 


\section{CHAPTER III}

EXTENSION OF PARTIAL TURBULENCE SIMULATION METHOD TO INCLUDE LOW FREQUENCY LATERAL AND VERTICAL TURBULENCE FLUCTUATIONS Maryam Asghari Mooneghi ${ }^{\mathrm{b}}$, Peter Irwin $^{\mathrm{b}},{ }^{*}$ Arindam Gan Chowdhury ${ }^{\mathrm{c}}$

\subsection{Abstract}

This paper is the extension of a method called partial turbulence simulation proposed by authors for predicting peak wind loads on low-rise buildings and small structures. In partial turbulence simulation, the flow reproduces only the high frequency portion of the atmospheric boundary layer turbulence spectrum. The low frequency fluctuations are missing mainly due to the limited size of wind tunnels. Thus, the turbulence intensities are less than in full-scale. This affects the mean and mainly the peak pressure coefficients for a particular wind direction by decreasing the band of wind directions occurring during that run. The proposed method is based on quasi-steady assumption and is able to simulate the effect of the missing low frequency lateral and vertical fluctuations in addition to the missing longitudinal low frequency turbulence fluctuations which was discussed in the earlier version of this theory. The current method requires a number of tests over a range of wind azimuth and tilt angles in small increments. Pressures on large-scale models of the Silsoe cube and Texas Tech University research buildings were measured in Wall of Wind facility at Florida

\footnotetext{
${ }^{\mathrm{b}} \mathrm{PhD}$ candidate, Civil and Environmental Engineering/International Hurricane Research Center, Florida International University, Miami, FL, USA, masgh002@,fiu.edu

${ }^{\mathrm{b}}$ Professor of Practice, Civil and Environmental Engineering/International Hurricane Research Center, Florida International University, Miami, FL, USA, peairwi@fiu.edu

${ }^{c}$ Corresponding Author. Associate Professor, chowdhur@fiu.edu, Tel: (305) 348-0518
} 
International University with partial flow simulation. The predicted full-scale pressures from the theory were compared with the pressures measured on the respective prototypes in flow with full turbulence spectrum. Results were in good agreement.

Keywords: Partial Turbulence Simulation; Wind; Lateral and Vertical Turbulence; Lowrise buildings; Wind Tunnel

\subsection{Introduction}

Damage to the building envelope from windstorms accounts for about $70 \%$ of the total insured losses in the United States (Holmes, 2007). Model-scale testing in boundary layer wind tunnels has long been the main means to determine wind loads on buildings and other structures. Wind tunnel flows should have properties such as mean wind velocity profile, turbulence intensity, turbulence spectrum and turbulence integral scale such that all represent well the corresponding values at full scale. This is generally possible at scales of about 1:300 to 1:600. These scales are suitable for large structures such as tall buildings but are too small for structures such as low-rise buildings, signs, appurtenances, solar panels and building components. For the latter applications, largescale testing (e.g. 1:1 to 1:100) is desirable to reduce Reynolds number effects, better replicate the effects of architectural features and achieve adequate spatial resolution of pressures taps. At these larger scales though, it is not possible in wind tunnels to correctly simulate the low-frequency content of the turbulence spectrum. In particular it is difficult to simulate the integral length scale parameter, this being mainly due to the limited size of the wind testing facility. One way around this is to artificially introduce low frequency velocity fluctuations through the tunnel drive system but this is a complex and costly approach and there remain some questions as to how realistically one can duplicate real 
turbulence through such mechanical means. The present method aims to account for the effects of low frequency turbulence using a quasi-steady theoretical analysis that incorporates the effects of low frequency turbulence into test data through post-test analysis.

Both small-scale and large-scale turbulence play an important role in the development of the peak pressures. The small scale turbulence interacts directly with the turbulent shear layers and vortices that originate at the roof edge and then pass over the roof surface. The paths and strengths of these shear layers and vortices, which directly affect the suctions on the roof surface, can be significantly altered by the small scale turbulence. As a matter of fact, accurate simulation of high frequency turbulence is necessary in order to correctly model flow separation and reattachment (Asghari Mooneghi et al, 2014; Banks, 2011; Irwin, 2009; Kopp and Banks, 2013; Kumar and Stathopoulos, 1998; Melbourne, 1980; Mooneghi et al, 2014; Richards et al, 2007; Saathoff and Melbourne, 1997; Tieleman, 2003; Yamada and Katsuchi, 2008). The large scale turbulence tends to cause low frequency fluctuations in the oncoming wind speed and direction, which then cause low frequency movements and changes in strength of the shear layers and vortices. In principle these low frequency fluctuations are similar to what would be caused by changes in mean wind speed and direction.

The availability of full-scale data enables the ability of scale model test to predict full scale behavior to be assessed. The comparisons of a number of researchers of mean pressure coefficients from model tests with full-scale data have demonstrated good agreement in many cases. However, discrepancies have been observed for the peak suction pressures, mainly in regions of flow separation and vortex development like near 
the leading edges of the roof and roof corners for oblique wind azimuth angles (Cheung et al, 1997; Cochran and Cermak, 1992; Okada and Ha, 1992; Surry, 1991). One of the reasons for these discrepancies has been the inability to model properly the full turbulence spectrum at all frequencies Often the high frequency end of the spectrum of all turbulence components had too much power and the low frequency end had too little power. In the present approach the intent of the physical testing is to obtain a good simulation of the high frequency end of the spectrum and accept that the low frequency part will be missing. Wind tunnel flows in which the low frequency turbulence fluctuations are missing but the high frequency fluctuations are present are called flows with partial turbulence simulation (PTS). Asghari Mooneghi et al (2015), proposed a theoretical partial turbulence simulation approach and the corresponding analytical procedures to account for the effects of the missing low frequency longitudinal fluctuations in wind flows with partial turbulence simulation. The theory was validated by comparing the predicted pressure coefficients on a large 1:5 scale model of the Silsoe cube with the full-scale data for the Cube. Generally good agreement was found between the results. However, some discrepancies were observed for pressures on the roof at oblique wind directions. One of the reasons for this was discussed as ignoring the effects of low frequency fluctuations of lateral and vertical turbulence. Recent studies suggest that in addition to properly simulating the longitudinal turbulence intensity (Hillier and Cherry, 1981; Melbourne, 1980, 1993; Saathoff and Melbourne, 1989), the simulation of lateral turbulence intensity is also important for prediction of peak pressures (Letchford and Mehta, 1993; Tieleman, 2003; Tieleman et al, 1996; Zhao, 1997). Other than the longitudinal and lateral wind turbulence, the vertical wind angle of attack also plays a 
role in accurate simulation of the peak-suction pressures near the roof corner (Wu et al, 2001).

In this paper, the approach proposed by authors (Asghari Mooneghi et al, 2015) is extended to include the effects of low frequency lateral and vertical turbulence as well as the longitudinal turbulence. The earlier version of this theory (Asghari Mooneghi et al, 2015) was called "Partial turbulence Simulation (PTS)" method in which just the effects of missing longitudinal turbulence were considered. The extended version of PTS which is proposed in this paper is called "3 Dimensional Partial Turbulence Simulation (3DPTS)". The method requires a number of tests at different wind azimuth and tilt angles at small angle increments. To validate the theory, pressures on large-scale models of the Silsoe cube and Texas Tech University building were measured in the Wall of Wind (WOW) facility at Florida International University (FIU). The flow represented a flow with partial turbulence simulation in which only the high frequency end of the turbulence spectrum was scaled and the low frequency fluctuations were missing. Analysis of the results was undertaken using the presently proposed 3DPTS approach and they were compared with full scale. Theory

The partial turbulence simulation method proposed in this paper is based on the assumption of "Equilibrium of Small-scale Turbulence" which was proposed by authors in Asghari Mooneghi et al (2015). It is assumed that the small scales of turbulence rapidly reach an equilibrium state when changes are imposed by large-scale turbulence. The total turbulence velocity is considered as being made up of two parts, a low frequency part and a high frequency part. The high frequency turbulence can be simulated in a typical sized wind tunnel, and the low frequency turbulence can be treated 
in a quasi-steady manner. Although in reality there is not any sharp dividing line between the low and high frequency turbulences, it can be theoretically shown that Eq. (1) can be used to estimate an "effective" cut-off frequency between the high-frequency and lowfrequency turbulence (Asghari Mooneghi et. al):

$$
n_{c}=0.0716 \frac{U}{{ }^{{ }_{L}} L_{u}}\left(\frac{I_{u}}{I_{u H}}\right)^{3}
$$

where the ${ }^{\mathrm{x}} L_{u}$ and $U$ are the full spectrum values of longitudinal integral scale and the mean velocity respectively. $I_{u}$ is the full-spectrum longitudinal turbulence intensity and $I_{u H}$ is the longitudinal turbulence intensity in a flow with partial turbulence simulation. This means that in partial turbulence simulation, turbulence fluctuations at frequencies above $n_{c}$ are simulated in the tests and those at frequencies less than $n_{c}$ are treated as quasi-steady. It should be acknowledged that similar formulas can be written for lateral and vertical components of the wind velocity spectrums. However, the formula in this paper is presented just for the longitudinal component which is believed to be the most important component. It can also be shown that in a partial turbulence simulation with turbulence intensity $I_{u H}$, the intensity of the missing low frequency $I_{u L}$ can be calculated from (Asghari Mooneghi et. al, 2015):

$$
I_{(u, \mathrm{v}, \mathrm{w}) L}=\sqrt{I_{(u, \mathrm{v}, \mathrm{w})}^{2}-I_{(u, \mathrm{v}, \mathrm{w}) H}^{2}}
$$

where $I_{u, v, w}$ are the full-spectrum longitudinal, lateral and vertical turbulence intensities respectively. In a partial turbulence simulation, matching of the non-dimensional spectrum to full-scale at high frequencies requires that the ratio of model turbulence 
intensity to prototype turbulence intensity be governed by (Asghari Mooneghi et. al, 2015):

$$
\frac{I_{u m}}{I_{u p}}=\left(\frac{{ }^{\mathrm{x}} L_{u m}}{{ }^{\mathrm{x}} L_{u p}}\right)^{1 / 3}\left(\frac{b_{p}}{b_{m}}\right)^{1 / 3}
$$

where ${ }^{\mathrm{x}} L_{u}$ is the longitudinal integral length scale, $b$ is a representative building dimension and the subscripts $m$ and $p$ denote prototype and model respectively.

The proper simulation of wind flow properties in a facility with partial turbulence simulation and the test procedures was explained in detail in Asghari Mooneghi et al (2015). In this paper just a brief description of the main assumptions is presented and for details the reader is referred to the previous paper by the authors. The focus of this paper is on the method for predicting mean, and peak pressure coefficients taking into account the effects of missing longitudinal, lateral and vertical low frequency fluctuations.

\subsubsection{Mean pressure coefficients}

As far as the low frequency fluctuations in wind speed, direction and wind inclination to the horizontal are concerned, the "instantaneous" pressure $p$ at a point on the structure can be expressed as:

$$
\begin{gathered}
p=\frac{1}{2} \rho Q^{2} C_{p}(\varphi, \theta) \\
Q=\left((U+u)^{2}+v^{2}+w^{2}\right)^{1 / 2}
\end{gathered}
$$

where $Q$ is the resultant wind speed, $U$ is the mean wind speed in the direction of the mean wind over a sample time long enough to include all the low frequency turbulence fluctuations, e.g. one hour at full scale. $u, v, w$ are low frequency turbulence velocities in the longitudinal, lateral and vertical directions, respectively. $\varphi$ is low frequency yaw angle of wind vector away from the mean direction. $\theta$ is low frequency pitch angle of the 
wind vector relative to horizontal. $C_{p}(\varphi, \theta)$ is the mean pressure coefficient measured in the partial turbulence simulation at angles $(\varphi, \theta)$. By "instantaneous" we mean of short duration equal to the sampling time in the partial turbulence simulation, which is much less, perhaps by a factor as high as 100 , than one hour at full scale. The duration of the sampling time in the partial turbulence simulation is assumed to be long enough to achieve a stable value of mean pressure coefficient $C_{p}$ at each of the angle combinations $(\varphi, \theta)$.

The equivalent mean pressure coefficient at full scale $\left(\left.C_{p}\right|_{\text {mean }}\right)$ can be obtained from the mean pressure coefficient obtained in a partial turbulence simulation using the following equation:

$$
\left.C_{p}\right|_{\text {mean }}=\iint C_{p, \text { mean }}(\varphi, \theta) f_{\theta}(\theta) f_{\varphi}(\varphi) d \varphi d \theta
$$

where $f_{\varphi}(\varphi)$ and $f_{\theta}(\theta)$ are the probability density function of $\varphi$ and $\theta$ assumed to have a Gaussian distribution:

$$
\begin{aligned}
& f_{\theta}(\theta)=\frac{1}{\sqrt{2 \pi} I_{w L}} e^{-\frac{1}{2}\left(\frac{\theta}{I_{w L}}\right)^{2}} \\
& f_{\varphi}(\varphi)=\frac{1}{\sqrt{2 \pi} I_{v L}} e^{-\frac{1}{2}\left(\frac{\varphi}{I_{v L}}\right)^{2}}
\end{aligned}
$$

where $I_{v L}$ and $I_{w L}$ are the intensity of the missing low frequency fluctuations given by Eq. (2).

\subsubsection{Peak pressure coefficients}

The evaluation of peak pressure coefficients is more complex than mean pressure coefficients because the peak varies with length of sample period, tending to increase as the sample period increases. In the partial simulation the sample period is relatively short 
compared with the sample time for a full turbulence simulation. This short sample period is called here a subinterval within the sample period for a full simulation (Fig. 1).

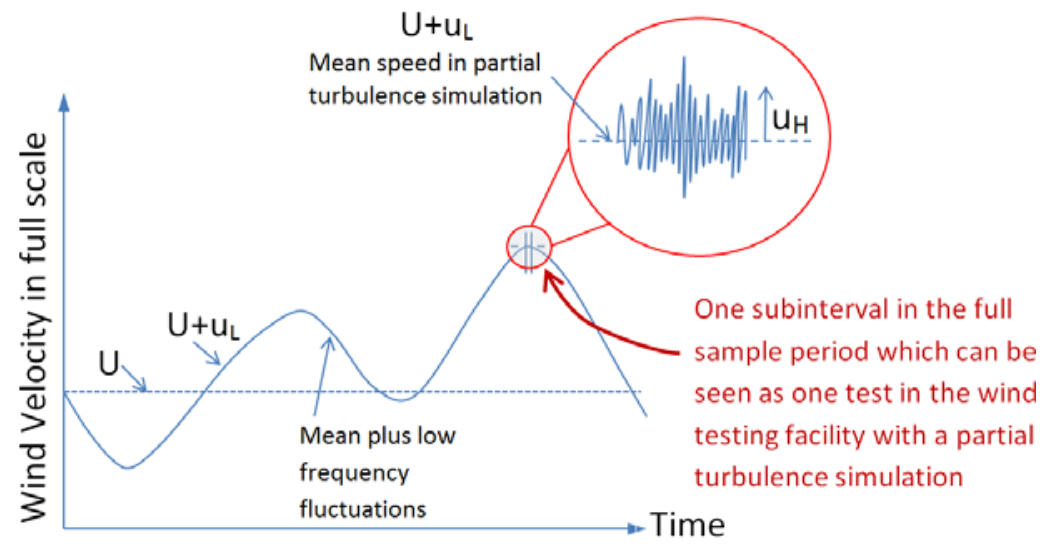

Figure 1. Definition of subintervals, mean flow velocity, low frequency and high frequency fluctuations

We can expect the peak pressure and peak pressure coefficient to increase when comparing peaks over, say, 50 or 100 subintervals to those over only one. However, the situation is made more complex by the fact that the low frequency turbulence causes variations in the flow azimuthal angle $\varphi$ and pitch angle $\theta$ from subinterval to subinterval, and the behavior of peak pressure coefficients will be different for different angles. The peak pressure $\hat{p}$ in any one subinterval may be written as:

$$
\hat{p}=\frac{1}{2} \rho Q^{2} C(\varphi, \theta)
$$

where $C(\varphi, \theta)$ is the peak pressure coefficient that occurred during the subinterval and the angles $\varphi, \theta$ may be regarded as a constant within the subinterval. The resultant wind speed $Q$ for the subinterval is given by:

$$
Q^{2}=(U+u)^{2}+v^{2}+w^{2}
$$


where each of the low frequency turbulent velocity components $u, v, w$, like the flow angles, may be regarded as constant during the subinterval. Therefore in each subinterval:

$$
\begin{gathered}
\hat{p}=\frac{1}{2} \rho\left((U+u)^{2}+v^{2}+w^{2}\right) C(\varphi, \theta) \\
=\frac{1}{2} \rho\left(U^{2} C(\varphi, \theta)+2 U u C(\varphi, \theta)+q^{2} C(\varphi, \theta)\right)
\end{gathered}
$$

where $q^{2}=u^{2}+v^{2}+w^{2}$. The last term in Eq. 11 is ignored as being a couple of orders of magnitude below the first. We also note that for practical ranges of turbulence intensity $\varphi=\frac{v}{U}$ and $\theta=\frac{w}{U}$, and we define $\eta=\frac{u}{U}$. Then Eq. 11 may be simplified and expressed as:

$$
\frac{\hat{p}}{\frac{1}{2} \rho U^{2}}=(1+2 \eta) C(\varphi, \theta)
$$

Equation 12 may be regarded as the expression for the peak pressure coefficient for a single subinterval based on the mean velocity over the full sample period. The peak over all subintervals may be written as:

$$
\hat{C}_{p}=\langle(1+2 \eta) C(\varphi, \theta)\rangle_{M A X}
$$

where we have used the notation \langle\rangle$_{M A X}$ to denote the maximum value out of all the subintervals that make up the full sample period. For each subinterval there will be a combination of $\eta, \varphi, \theta$ and also some random variations in the value of subinterval peak coefficient $C$. To proceed any further we need to adopt a probabilistic methodology. In the partial turbulence simulation we can set up the angles $\varphi, \theta$ and measure the probability that the peak pressure coefficient will not exceed a value $C$ in a subinterval. This probability is in general described well by the Fisher Tippet Type I distribution.

$$
F_{\varphi, \theta}(C, \varphi, \theta)=\exp \left(-\exp \left(-a_{\varphi \theta}\left(C-b_{\varphi \theta}\right)\right)\right)
$$


where $a_{\varphi \theta}$ and $b_{\varphi \theta}$ are constants that can be determined experimentally as functions of the flow angles $\varphi, \theta$. From the probability of $C$ given in Eq. 14 the probability density of $C$ is:

$$
f_{c}(C, \varphi, \theta)=a_{\varphi \theta} e^{-a_{\varphi \theta}\left(C-b_{\varphi \theta}\right)} e^{-e^{-a_{\varphi \theta}\left(c-b_{\varphi \theta}\right)}}
$$

For a given subinterval the probability of $C$ being in the range $C$ to $C+\delta C$ is $f_{c} \delta C$. The probability that the angle $\varphi$ is in the range $\varphi$ to $\varphi+\delta \varphi$ is $f_{\varphi}(\varphi) \delta \varphi$ and the probability that the angle $\theta$ is in the range $\theta$ to $\theta+\delta \theta$ is $f_{\theta}(\theta) \delta \theta$, where $f_{\varphi}$ and $f_{\theta}$ are probability densities of $\varphi$ and $\theta$ respectively. Therefore, the probability of all three occurring is $f_{c}(C, \varphi, \theta) f_{\varphi}(\varphi) f_{\theta}(\theta) \delta C \delta \varphi \delta \theta$. In boundary layer flow there is correlation between $\eta$ and $\theta$. Therefore, if we want the probability of $\eta$ also being in the range $\eta$ to $\eta+\delta \eta$ it must be expressed as $f_{C}(C, \varphi, \theta) f_{\varphi}(\varphi) f_{\eta \theta}(\eta, \theta) \delta C \delta \eta \delta \varphi \delta \theta$, where $f_{\eta \theta}$ is the joint probability density of $\eta$ and $\theta$. We want the probability $G_{\hat{C}_{p}}\left(\hat{C}_{p}\right)$, of $\hat{C}_{p}$ in Eq. 13 exceeding a certain value ( $G$ is the probability of exceedance and is related to the probability of non-exceedance $F$ by $G=1-F$ ). We could initially ask for the probability of $\hat{C}_{p}$ being exceeded while $\eta$ is at a certain value. This can be obtained by integrating over all values of $\varphi$ and $\theta$, and from $C=\frac{\hat{C}_{p}}{(1+2 \eta)}$ to infinity:

$$
G_{\hat{C}_{p}, \eta}\left(\hat{C}_{p}, \eta\right)=\int_{\frac{\widehat{C}_{p}}{(1+2 \eta)}}^{\infty} \int_{-\pi}^{+\pi} \int_{-\pi}^{+\pi} f_{C}(C, \varphi, \theta) f_{\varphi}(\varphi) f_{\eta \theta}(\eta, \theta) d \varphi d \theta d C
$$

Then we need to do the integration over all $\eta$ to obtain the total probability of exceeding $\hat{C}_{p}:$

$$
G_{\hat{C}_{p}}\left(\hat{C}_{p}\right)=\int_{-\infty}^{\infty} \int_{\frac{\hat{C}_{p}}{(1+2 \eta)}}^{\infty} \int_{-\pi}^{+\pi} \int_{-\pi}^{+\pi} f_{c}(C, \varphi, \theta) f_{\varphi}(\varphi) f_{\eta \theta}(\eta, \theta) d \varphi d \theta d C d \eta
$$


The integration with respect to $\varphi$ can be done first:

$$
G_{\hat{C}_{p}}\left(\hat{C}_{p}\right)=\int_{-\infty}^{\infty} \int_{\frac{\widehat{C}_{p}}{(1+2 \eta)}}^{\infty} \int_{-\pi}^{+\pi}\left(\int_{-\pi}^{+\pi} f_{c}(C, \varphi, \theta) f_{\varphi}(\varphi) d \varphi\right) f_{\eta \theta}(\eta, \theta) d \theta d C d \eta
$$

Calling this inner integral $I_{1}$, we have:

$$
\begin{gathered}
I_{1}(C, \theta)=\int_{-\pi}^{+\pi} f_{c}(C, \varphi, \theta) f_{\varphi}(\varphi) d \varphi= \\
\int_{-\pi}^{+\pi} a_{\varphi \theta} e^{-a_{\varphi \theta}\left(C-b_{\varphi \theta}\right)} e^{-e^{-a_{\varphi \theta}\left(c-b_{\varphi \theta}\right)}} \frac{1}{\sqrt{2 \pi} \sigma_{\varphi}} e^{-\frac{1}{2}\left(\frac{\varphi^{2}}{\sigma_{\varphi}^{2}}\right)} d \varphi \\
=\frac{1}{\sqrt{2 \pi} \sigma_{\varphi}} \int_{-\pi}^{+\pi} a_{\varphi \theta} e^{-\left(a_{\varphi \theta}\left(C-b_{\varphi \theta}\right)+e^{-a_{\varphi \theta}\left(c-b_{\varphi \theta}\right)}+\frac{1}{2}\left(\frac{\varphi^{2}}{\sigma_{\varphi}^{2}}\right)\right)} d \varphi
\end{gathered}
$$

This is best evaluated numerically and it needs to be done for a range of values of $C$ and $\theta$. Probably about 20 values of $C$ and say 11 values of $\theta$. So, we would have about 220 values of $I_{1}(C, \theta)$. Equation 18 then becomes:

$$
G_{\hat{C}_{p}}\left(\hat{C}_{p}\right)=\int_{-\infty}^{\infty} \int_{\frac{\hat{C}_{p}}{(1+2 \eta)}}^{\infty} \int_{-\pi}^{+\pi} I_{1}(C, \theta) f_{\eta \theta}(\eta, \theta) d \theta d C d \eta
$$

To evaluate this integral we need the joint probability density $f_{\eta \theta}(\eta, \theta)$. The probabilities of $\eta$ and $\theta$ tend to follow a Gaussian form. Using the Gaussian form for two correlated variables, with correlation coefficient $r$, the joint probability density is expressed as:

$$
f_{\eta \theta}(\eta, \theta)=\frac{1}{2 \pi \sigma_{\eta} \sigma_{\theta}\left(1-r^{2}\right)^{1 / 2}} \exp \left[-\frac{1}{2\left(1-r^{2}\right)}\left(\frac{\eta^{2}}{\sigma_{\eta}^{2}}-\frac{2 r \eta \theta}{\sigma_{\eta} \sigma_{\theta}}+\frac{\theta^{2}}{\sigma_{\theta}^{2}}\right)\right]
$$

Therefore our next step is to evaluate

$$
\begin{gathered}
I_{2}(C, \eta)=\int_{-\pi}^{+\pi} I_{1}(C, \theta) f_{\eta \theta}(\eta, \theta) d \theta \\
=\frac{1}{2 \pi \sigma_{\eta} \sigma_{\theta}\left(1-r^{2}\right)^{1 / 2}} \int_{-\pi}^{+\pi} I_{1}(C, \theta) \exp \left[-\frac{1}{2\left(1-r^{2}\right)}\left(\frac{\eta^{2}}{\sigma_{\eta}^{2}}-\frac{2 r \eta \theta}{\sigma_{\eta} \sigma_{\theta}}+\frac{\theta^{2}}{\sigma_{\theta}^{2}}\right)\right] d \theta
\end{gathered}
$$

This needs to be done for our 20 or so values of $C$ and for a number of values, say 11, of $\eta$. Again, the integration is best done numerically. 
The next step after obtaining the function $I_{2}(C, \eta)$ is to evaluate:

$$
G_{\hat{C}_{p}}\left(\hat{C}_{p}\right)=\int_{-\infty}^{\infty} \int_{\frac{\widehat{C}_{p}}{(1+2 \eta)}}^{\infty} I_{2}(C, \eta) d C d \eta
$$

This is achieved by first evaluating:

$$
I_{3}\left(\hat{C}_{p}, \eta\right)=\int_{\frac{\widehat{C}_{p}}{(1+2 \eta)}}^{\infty} I_{2}(C, \eta) d C
$$

where $\hat{C}_{p}$ is a selected value of peak pressure coefficient. The integration is again done numerically. Then the final step is to evaluate:

$$
G_{\hat{C}_{p}}\left(\hat{C}_{p}\right)=\int_{-\infty}^{\infty} I_{3}(\eta) d \eta
$$

Equation 25 gives us the probability that a given value of $\hat{C}_{p}$ will be exceeded in a particular subinterval in the full turbulence. The computations need to be repeated for a range of values of $\hat{C}_{p}$.

To summarize, the procedure is:

1. $a$ and $b$ are determined from tests which measure $\hat{C}_{p}$ for each of $N$ subintervals using the usual ranking method of fitting to extremes.

2. Step 1 is repeated for several azimuth $\varphi$ and pitch $\theta$ angles (In this paper 11 azimuth angles at 3 degree intervals and 6 pitch angles at 2 degree intervals were tested).

3. $I_{1}$ is evaluated using numerical integration over $\varphi$ for each value of $\theta$ and 20 or more selected values of peak pressure coefficient $C$.

4. $I_{2}$ is evaluated using numerical integration over $\theta$ for each of value of $\eta$ and $C$.

5. $I_{3}$ is evaluated using numerical integration over $C$ for each value of $\eta$ and $\hat{C}_{p}$.

6. $G_{\hat{C}_{p}}$ is evaluated using numerical integration over $\eta$ for each of the selected values of $\hat{C}_{p}$ 
7. From the graph of $G_{\hat{C}_{p}}$ versus $\hat{C}_{p}$, the expected value of peak pressure coefficient for the full turbulence sample period is interpolated.

8. The peak pressure coefficients calculated using the procedure described above are based on mean hourly dynamic pressure. The pressure coefficient based on 3 -second gust dynamic pressure $\hat{C}_{p, 3 \text { sec }}$, for example, can be obtained by re-scaling using:

$$
\hat{C}_{p, 3 \text { sec }}=\hat{C}_{p}\left(\frac{U}{\widehat{U}_{3 s e c}}\right)^{2}
$$

9. Note that in evaluating the $I_{1}(C, \theta)$ in Eq. (19) and $I_{2}(C, \eta)$ in Eq. (22), the limits of the integral is from $-\pi: \pi$, theoretically. However, when doing experiments the variations in $\varphi$ and $\theta$ does not need to be this wide since very little contribution to the integral arises for angles greater than about 30 degrees.

\subsection{Experiments}

\subsubsection{Test building}

In order to check the efficacy of the 3DPTS method described above the full-scale pressure coefficient data obtained by Richards and Hoxey (2012) on the Silsoe Cube and by Levitan and Mehta (1992a,b) on the Texas Tech University (TTU) Building (Levitan and Mehta, 1992a, b) were used as benchmarks for comparison. Figures 2 and 3 show the building models in WOW and the pressure tap locations matching the full-scale tap locations. The Silsoe cube model was 1:5 scale and TTU model was 1:6 scale. As explained before, each test requires a number of tests at different azimuth and tilt angles at small angle increments around the main wind direction. In this paper, only one main wind direction was tested which was $45^{\circ}$. Based on past studies this wind direction was selected as the most critical orientation for generating high uplifts under conical vortices 
on flat rectangular roofs (Holmes, 2007). The range of azimuth angles was 15 degrees on either side of the desired wind direction in 3 degree intervals. This means that tests needed to be performed from 30 to 60 degrees wind directions in 3 degrees intervals resulting in 11 azimuth angles. In addition, models were tilted from -6 to +6 degrees in 2 degree intervals (a total of 7 tilt angles) (Fig. 4). To do so, a platform was designed and built for the building models. The pressure coefficients on the roof of each model were measured and compared for the cases of building model with and without the platform to make sure that the platform did not have any significant effect on the pressure results. The differences were very minimal. A 512 channel Scanivalve Corporation pressure scanning system was used for pressure measurements. Pressure data were acquired at a sampling frequency of $512 \mathrm{~Hz}$ for a period of 90 seconds. A transfer function designed for the tubing (Irwin et al, 1979) was used to correct for tubing effects. All pressure readings were low pass filtered at frequencies corresponding to the "low pass filter" frequency at full scale.
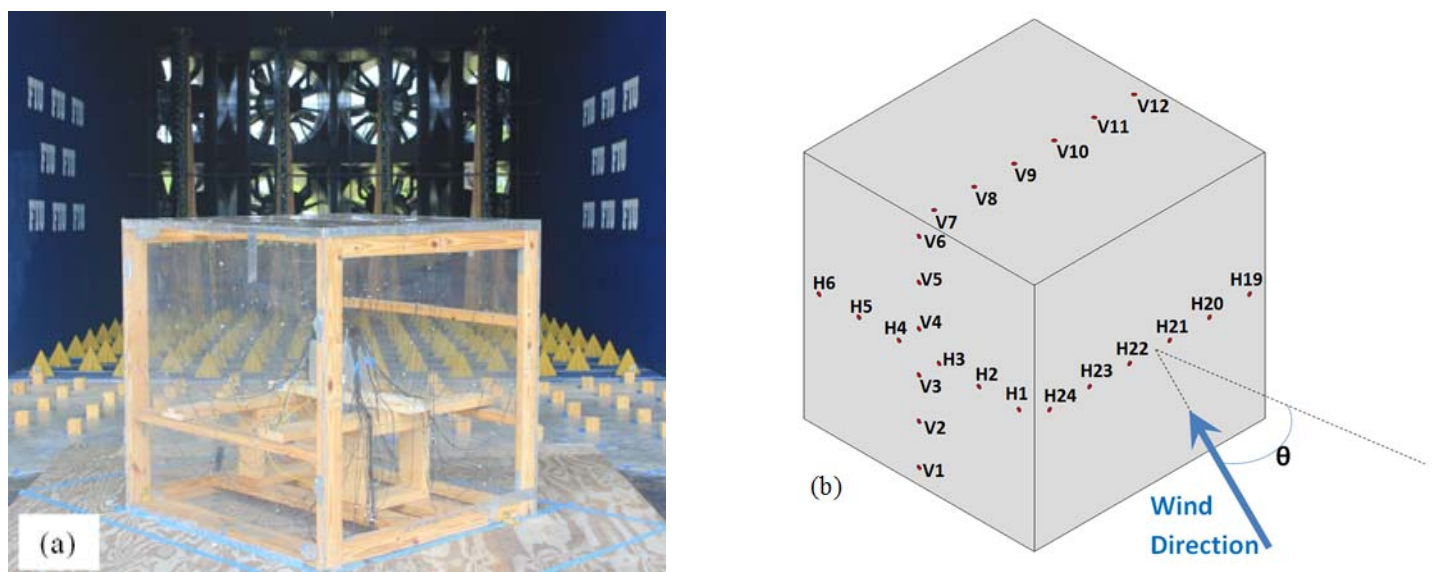

Figure 2. (a) Silsoe Cube building model tested in WOW, (b) Tap locations on Silsoe model 

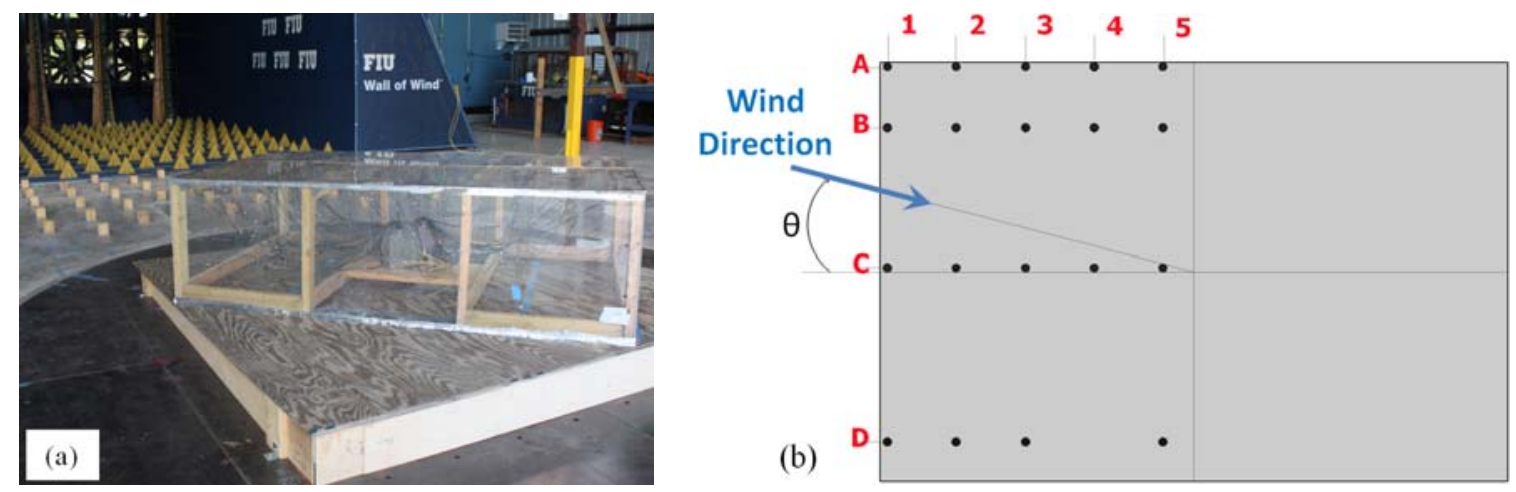

Figure 3. (a) TTU building model tested in WOW, (b) Tap locations on TTU model

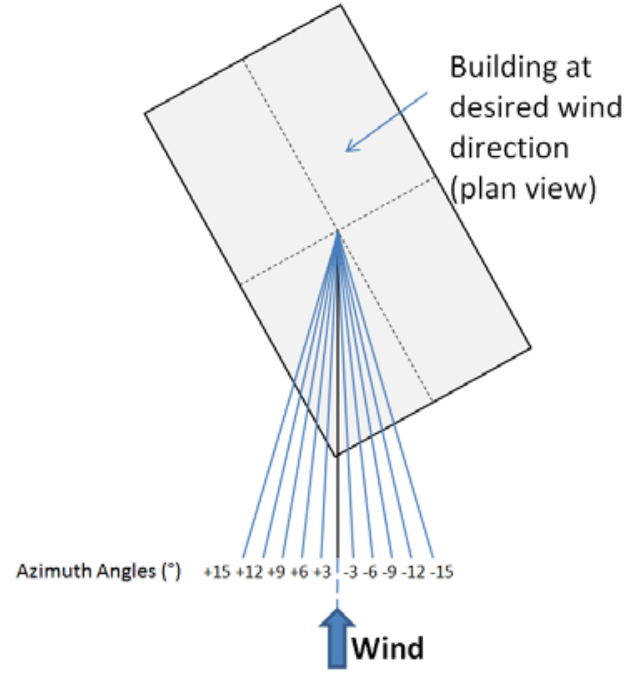

(a)

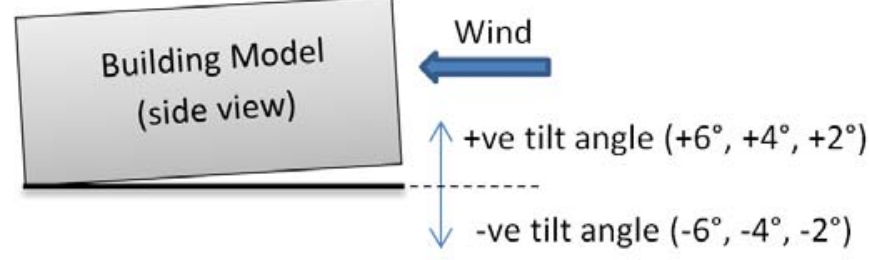

(b)

Figure 4. Definition of (a)wind azimuth and (b) tilt angle

\subsubsection{Wind flow}

Testing was performed in the 12-fan Wall of Wind (WOW) open jet facility at FIU. This facility can generate a $6.1 \mathrm{~m}$ wide and $4.3 \mathrm{~m}$ high wind field and speeds as high as $70 \mathrm{~m} / \mathrm{s}$. A set of triangular spires and floor roughness elements was used to generate the turbulence and boundary layer characteristics (Fig. 5). 

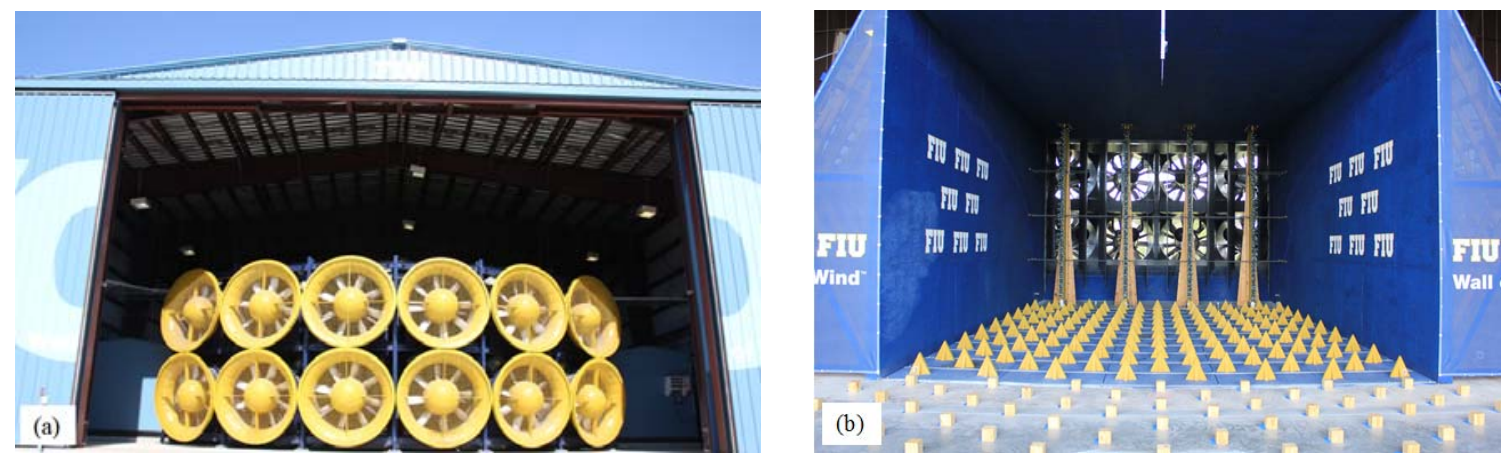

Figure 5. (a) Wall of Wind, Florida International University, (b) Spires and floor roughness elements

Figure 6 shows the comparison of the non-dimensional longitudinal turbulence power spectra for the full scale Silsoe cube and the WOW measured flow at the level of the model. All spectra were plotted in non-dimensional terms of $n S(n) / U^{2}$ versus $n B / U$, as suggested by Irwin (1988) and Richards et al (2007), where $B$ is a reference length taken here as height $z$. The atmospheric boundary layer (ABL) full spectrum and the WOW prototype high frequency spectrum approximately match for non-dimensional frequencies higher than 0.2 , but if anything the WOW spectrum had a little more power present at high frequencies.

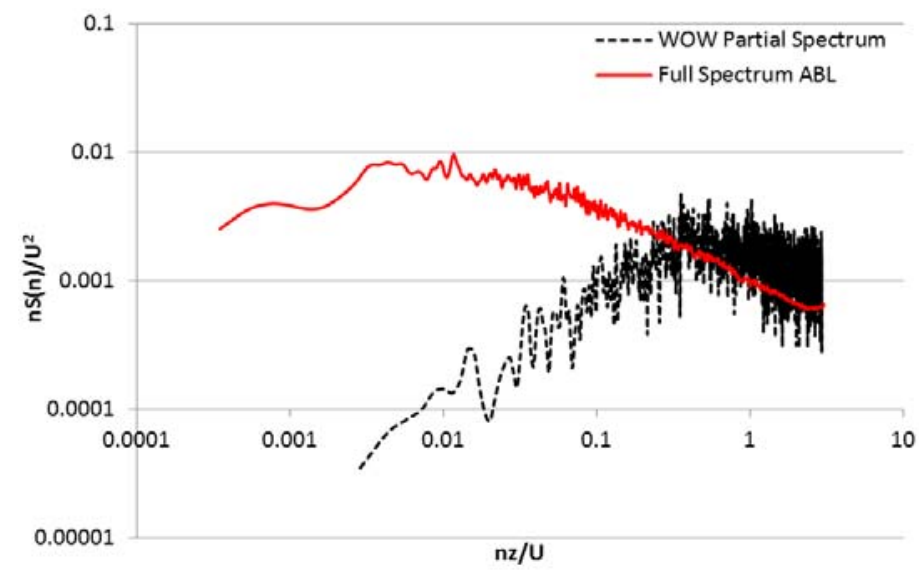

Figure 6. Comparison between full-scale Silsoe cube with full spectrum and WOW partial spectrum 
The mean wind speed and turbulence intensity profiles for WOW open terrain are shown in Fig. 7 (achieved power law coefficient for the mean velocity profile was 0.185 ). It should be noted that in the tests in partial turbulence simulation the turbulence intensity is significantly lower than that for the ABL flow containing the full spectrum of fluctuations.
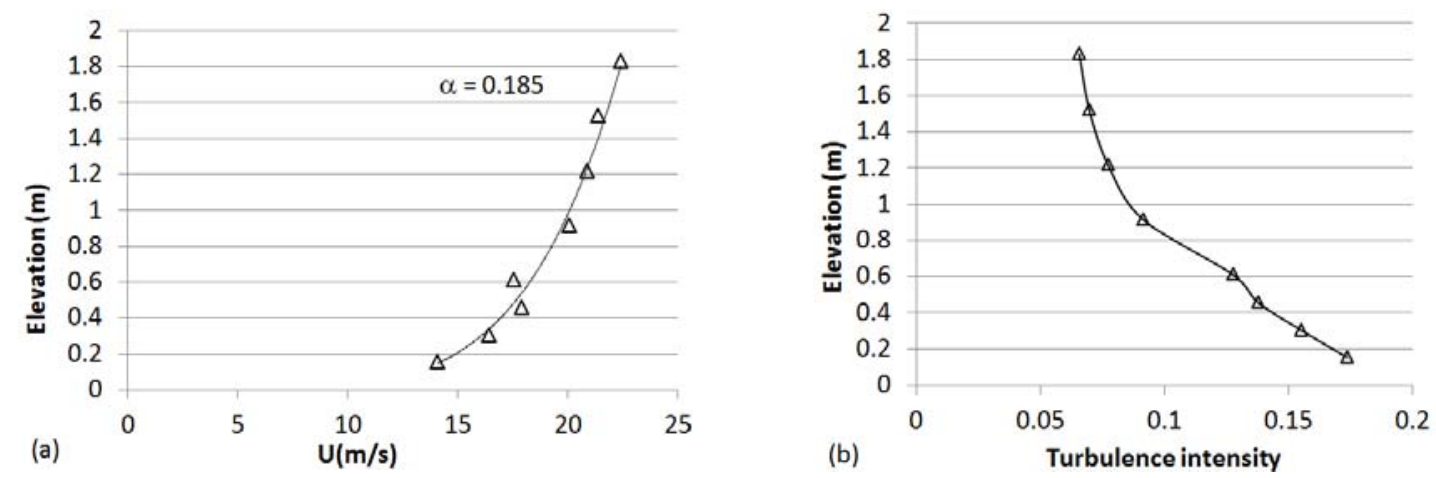

Figure 7. Open terrain: (a) ABL profile, (b) Turbulence intensity profile

\subsubsection{Wall of Wind scaling parameters}

In this paper, the same method as explained by authors Asghari Mooneghi et al (2015) for the simplified version of 3DPTS (PTS: in which the effects of low lateral and vertical turbulence intensity was ignored) is used for calculating WOW scaling parameters which were then used for calculating the required probability level at which peak pressures were determined. The reader is referred to Asghari Mooneghi et al (2015) for a full description of all the equations and procedures. The following steps were followed:

1. The missing low frequency turbulence intensities were calculated using Eq. (2).

2. The full scale gust due to the missing low frequency turbulence was estimated using the peak factor of 3.4 used in ASCE 7 for background turbulence using: 


$$
\widehat{U}_{L p}=U_{p}\left(1+3.4 I_{u L}\right)
$$

In which $U_{p}$ is the mean wind speed at full scale.

3. The speed scaling for the present study was set such that the mean speed of the tests in partial turbulence simulation correspond to the low frequency gust speed calculated above in Eq. (27). This means that:

$$
\lambda_{U}=\frac{U_{m}}{\widehat{U}_{L p}}
$$

4. From length scale $\lambda_{L}=\frac{b_{m}}{b_{p}}$, the frequency scale is calculated as:

$$
\lambda_{n}=\frac{n_{m}}{n_{p}}=\lambda_{U} / \lambda_{L}
$$

5. The time scale is therefore:

$$
\lambda_{t}=\frac{t_{m}}{t_{p}}=1 / \lambda_{n}
$$

6. Equivalent gust-duration at full scale was calculated using Eq. (1):

$$
t_{\text {Gust }}=0.45 / n_{c}
$$

This implies that in the Wall of Wind the sample period could be regarded as being made up of a sequence of $t_{\text {Gust }}$ second duration gusts. Therefore, in dividing the test sample period into subintervals the length of each subinterval needed to be in excess of $t_{\text {Gust }}$ seconds to avoid excessive correlation between events in adjacent subintervals.

7. Number of subintervals $(N)$ is chosen such that the length of each subinterval in partial simulation $\left(t_{\text {subinterval,PS }}=\frac{\text { test duration }}{N}\right)$ be in excess of $t_{\text {Gust }}$ seconds. The equivalent gust-duration at full scale is then $t_{\text {subinterval,FS }}=t_{\text {subinterval,PS }} / \lambda_{t}$. So, the required $G$ at which pressure coefficients are calculated can be obtained using: 


$$
G=\frac{t_{\text {subinterval,FS }}}{\text { Full Scale time }(\text { e.g.1 hour })}
$$

In other words, the full-scale equivalent peak pressure coefficient is obtained from intersecting the graph of $G_{\hat{C}_{p}}$ versus $\hat{C}_{p}$ which is obtained from Eq. (25) at $G$ (Fig .8).

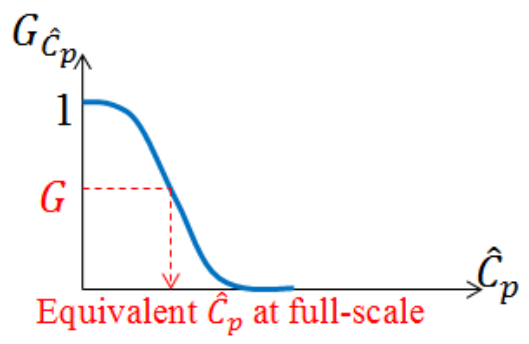

Figure 8. Illustration of reading the full-scale equivalent peak pressure coefficients from $\mathrm{G}_{\widehat{\mathrm{C}}_{\mathrm{p}}}$ versus $\widehat{\mathrm{C}}_{\mathrm{p}}$ diagram

8. The pressure coefficients calculated from the above analysis are representative of the most probable peak (mode of the distribution) which has about $37 \%$ probability of not being exceeded in the hour of wind (or other selected full sample period). To set the probability of non-exceedance to some other value such as $P_{t a r}=0.85$ we should evaluate the peak value at:

$$
G=1-P_{t a r}^{G(f r o m ~ E q .29)}
$$

When comparing with the average of many events such as the results presented in this paper, the mean or expected peak prediction with $57 \%$ probability of not being exceeded in the hour of wind is most suitable.

\subsection{Results and Discussions}

\subsubsection{Silsoe cube pressure results}

The pressure coefficient comparisons shown in this section are based on full-scale Silsoe measurement results given in Richards and Hoxey (2012). The full-scale pressure 
coefficients in Richards and Hoxey (2012) are defined in terms of the mean dynamic pressure as follows:

$$
\begin{gathered}
C p_{\text {mean }}=\frac{P_{\text {mean }}}{q_{\text {mean }}} \\
C p_{\text {peak }}=\frac{P_{\text {peak }}}{\left(3 q_{\text {mean }}\right)}
\end{gathered}
$$

where $P_{\text {mean }}$ is the mean surface pressure, $P_{\text {peak }}$ is the highest positive or lowest negative pressure observed during the test duration at the Silsoe site and $q_{\text {mean }}$ is the mean dynamic pressure defined as $0.5 \rho U^{2}(\rho=$ air density). The WOW mean and peak pressure data were obtained using the method described in Sec. 3.3.1 and 3.3.2 respectively and normalized in the same way as in Eqs. (34) and (35). Table 1 shows the test conditions for Silsoe model in WOW and at Full-scale.

Table 1. Test conditions for Silsoe cube model in WOW and at full-scale

\begin{tabular}{lll}
\hline Test Characteristics & Full Scale & Model scale $\left(\boldsymbol{\lambda}_{\boldsymbol{L}}=\frac{\mathbf{1}}{\mathbf{5}}\right)$ \\
\hline & $I_{u}=0.1955$ & $I_{u H}=0.074$ \\
Turbulence intensity & $I_{v}=0.15$ & $I_{v H}=0.073$ \\
& $I_{w}=0.078$ & $I_{w H}=0.063$ \\
Integral length scale & $L_{u}^{x}=53 \mathrm{~m}$ & $L_{u}^{x}=0.46 \mathrm{~m}$ \\
Reference height & $Z_{r e f}=6 \mathrm{~m}$ & $Z_{r e f}=1.2 \mathrm{~m}$ \\
Mean wind speed & $U_{F S}=9.52 \mathrm{~m} / \mathrm{s}$ & $U_{P S}=21.05 \mathrm{~m} / \mathrm{s}$ \\
Test duration & $T_{F S}=12 \mathrm{~min}$ & $T_{P S}=2 \mathrm{~min}$ \\
low pass filter frequency & $8 \mathrm{~Hz}$ & $55 \mathrm{~Hz}$ \\
\hline
\end{tabular}

Expected peak pressure coefficients using 3DPTS method were obtained with the WOW sample time divided into 100 subintervals. This means that each subinterval in model scale is equivalent to $120 / 100=1.2 \mathrm{sec}$. Based on the time scale, each subinterval at full scale is equivalent to $1.2 / 0.145=8.28 \mathrm{sec}$. So, the targeted probability for $12 \mathrm{~min}$ full spectrum is $G=8.28 /(12 \times 60)=0.011$. For peak pressure coefficients, the expected 
value with $57 \%$ probability of non-exceedance is reported. To do so, $G=1-$ $0.57^{0.011}=0.0062($ Eq. (33)) was used in the analysis.

Figures 9 and 10 show comparisons of the mean and peak pressure coefficients on roof of the Silsoe cube model obtained in WOW using the above procedures and at fullscale (see Figure 2 for the pressure tap notation). The mean pressure coefficients, Fig. 9, shows similar trends to the full-scale but tends to have a consistent bias towards being a little less negative ( $\mathrm{Cp}$ difference of about 0.15 to 0.2 ) at all roof taps. The application of the weighted average process to account for low frequency angle fluctuations improved agreement marginally. The peak pressure coefficient comparison in Fig. 10 shows that the application of the 3DPTS process produced results in generally good agreement with full-scale. It was a significant improvement over the results based on observed peaks and the simple PTS procedure.

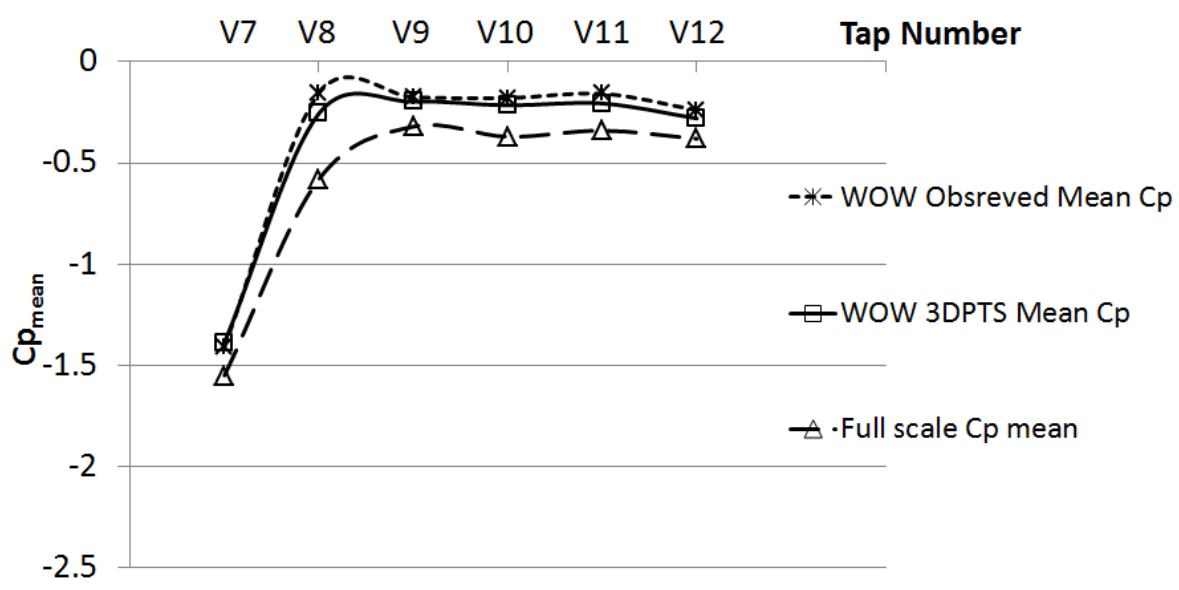

Figure 9. Roof mean $\mathrm{Cp}$ values 


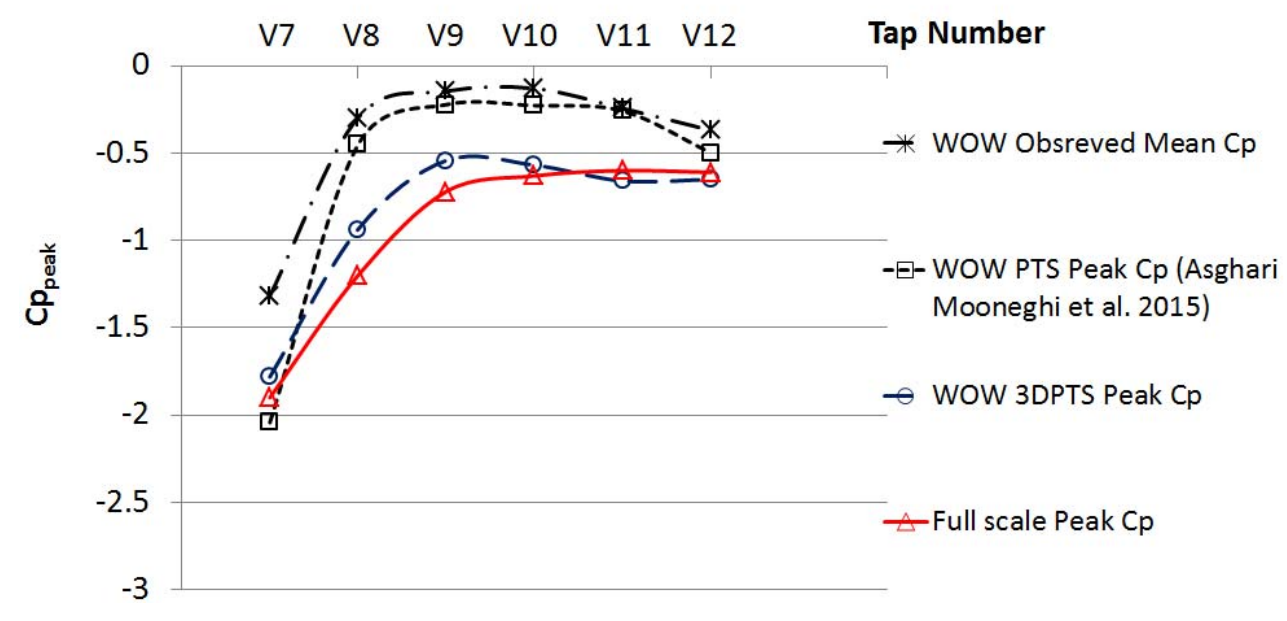

Figure 10. Roof peak Cp values

\subsection{2 $\underline{\text { TTU pressure results }}$}

The pressure coefficient comparisons presented in this section are based on fullscale TTU measurement results in which the pressure coefficients are defined in terms of the mean dynamic pressure as follows:

$$
\begin{gathered}
C p_{\text {mean }}=\frac{P_{\text {mean }}}{q_{\text {mean }}} \\
C p_{\text {peak }}=\frac{P_{\text {peak }}}{q_{\text {mean }}}
\end{gathered}
$$

where $P_{\text {mean }}$ is the mean surface pressure, $P_{\text {peak }}$ is the highest positive or lowest negative pressure observed during the test duration at the TTU site and $q_{\text {mean }}$ is the mean dynamic pressure defined as $0.5 \rho U^{2}$ ( $\rho=$ air density). The WOW mean and peak pressure data were obtained using the method described in Sec. 3.3.1 and 3.3.2 respectively and normalized in the same way as in Eqs. (36) and (37). Table 2 shows the test conditions for TTU model in WOW and at full-scale. 
Table 2. Test conditions for TTU model in WOW and at full-scale

\begin{tabular}{lll}
\hline Test Characteristics & Full Scale & Model scale $\left(\boldsymbol{\lambda}_{L}=\mathbf{1} / \mathbf{6}\right)$ \\
\hline Turbulence intensity & $I_{u}=0.216$ & $I_{u H}=0.1$ \\
& $I_{v}=0.207$ & $I_{v H}=0.084$ \\
& $I_{w}=0.12$ & $I_{w H}=0.082$ \\
Integral length scale & $L_{u}^{x}=146 \mathrm{~m}$ & $L_{u}^{x}=0.43 \mathrm{~m}$ \\
Reference height & $Z_{r e f}=2.96 \mathrm{~m}$ & $Z_{r e f}=0.66 \mathrm{~m}$ \\
Mean wind speed & $U_{F S}=7.66 \mathrm{~m} / \mathrm{s}$ & $U_{P S}=19.48$ \\
Test duration & $T_{F S}=15 \mathrm{~min}$ & $T_{P S}=2 \mathrm{~min}$ \\
Low pass filter frequency & $30 \mathrm{~Hz}$ & $141 \mathrm{~Hz}$ \\
\hline
\end{tabular}

Expected peak pressure coefficients were obtained with the WOW sample time divided into 80 subintervals. This means that each subinterval in model scale is equivalent to $120 / 80=1.5 \mathrm{sec}$. Based on the time scale, each subinterval at full scale is equivalent to $1.5 / 0.11=13.64 \mathrm{sec}$. So the targeted probability for $15 \mathrm{~min}$ full spectrum is $G=13.64 /(15 \times 60)=0.015$. For peak pressure coefficients, the expected value with $57 \%$ probability of non-exceedance is reported. To do so, $G=1-0.57^{0.015}=0.0084$ (Eq. (33)) was used.

Figure 11 shows comparisons of mean and peak pressure coefficients on roof of the TTU model obtained in WOW using the above procedures and at full scale (see Figure 3 for the pressure tap notation). The results show generally good agreement with full scale for both the mean and expected peak coefficients. The best agreement in terms of percent difference tends to be obtained where the highest pressure coefficients occur. A comparison of the results obtained from the 3DPTS methodology with that obtained from the earlier version of the theory (Asghari Mooneghi et. al, 2015) in which the effects of low frequency lateral and vertical turbulence is ignored is given in Appendix. 

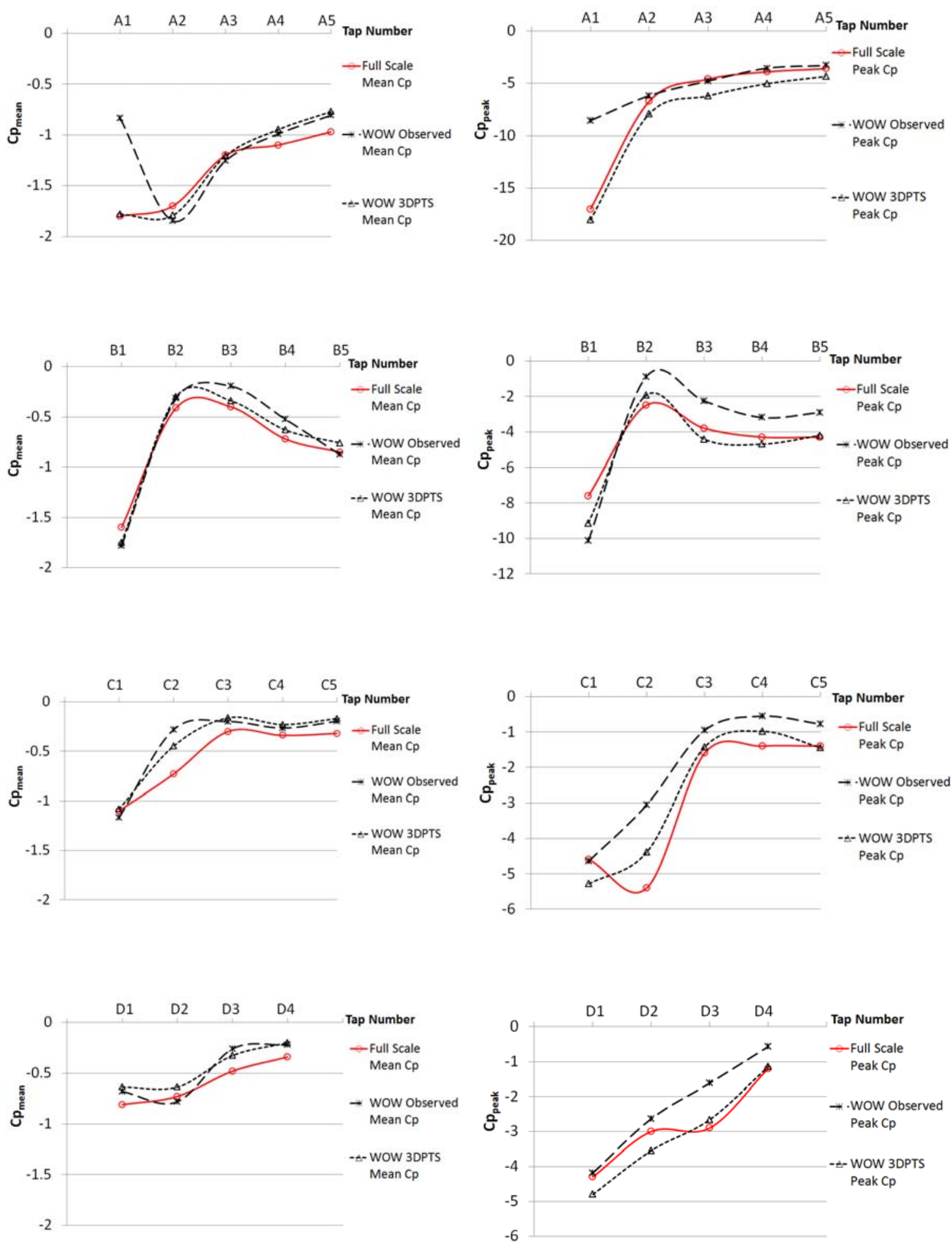

(a)

(b)

Figure 11. (a) Roof mean Cp values, (b) Roof peak Cp values 


\subsubsection{Effects of ignoring wind tilt angle variations}

As explained in previous sections, the 3DPTS method proposed in this paper needs tests in small increment azimuth and tilt angles centered on a main wind direction. It is acknowledged that the use of the 3DPTS approach proposed in this paper in general boundary layer wind tunnels might be demanding when it comes to experiments at different tilt angles. To address the above issues, results are analyzed for the case of ignoring variations in tilt angle. Figure 12 shows comparison of the results between the 3DPTS method proposed in this paper as compared to the case where the variation of tilt angle is ignored for Silsoe cube model. The range of azimuth angle increments considered is -15 to 15 in 3 degrees increments. It can be seen that in most cases, ignoring the variations of the tilt angle was not significant. However, in some cases (e.g. Tap V9), minor effects of changes in wind vertical angle can be seen.

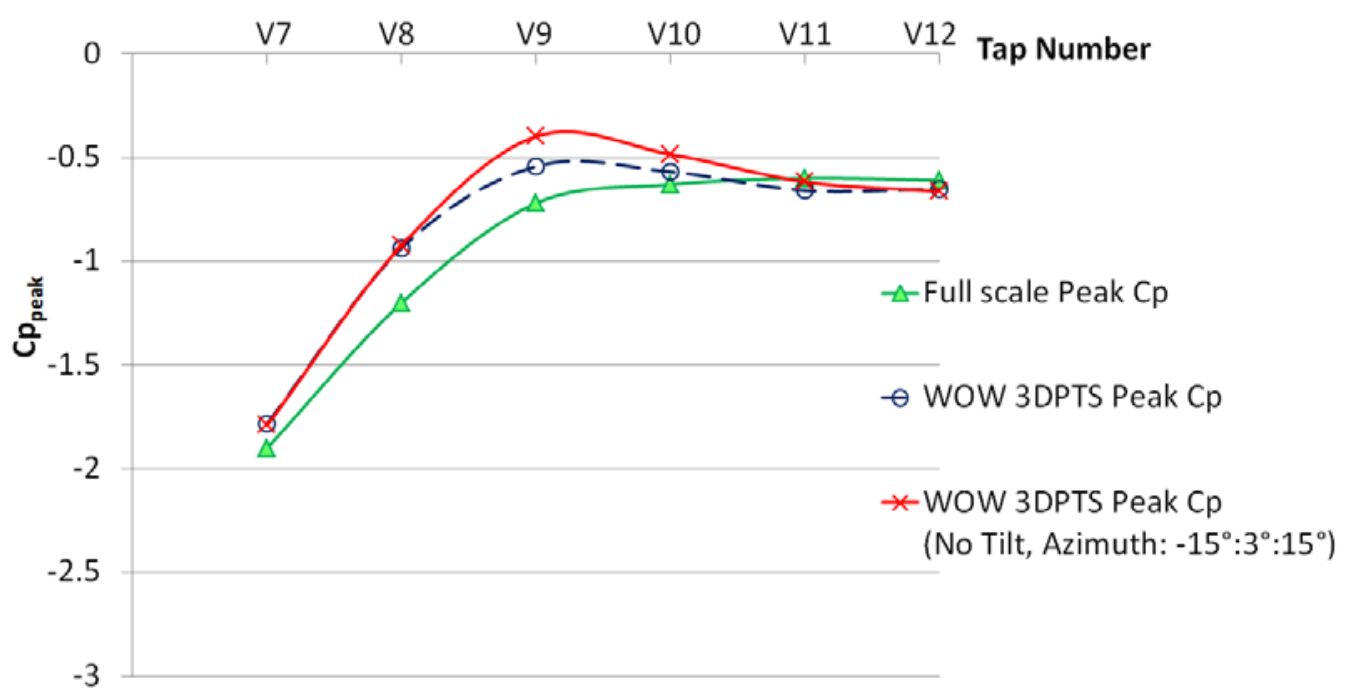

Figure 12: Effects of ignoring variations in wind tilt angle on pressure coefficients 


\subsubsection{Effects of wind azimuth angle increment size}

Another issue which is of importance is the selection of the increments between the angles. Figure 13 shows comparison of the results between the 3DPTS method with no tilt variations for two selected increments of azimuth angles for the Silsoe cube model. In the first case the azimuth angle was varied from -15 to 15 in 3 degrees increments and in the second case the azimuth angles was varied from -15 to 15 degrees in 5 degrees increments.

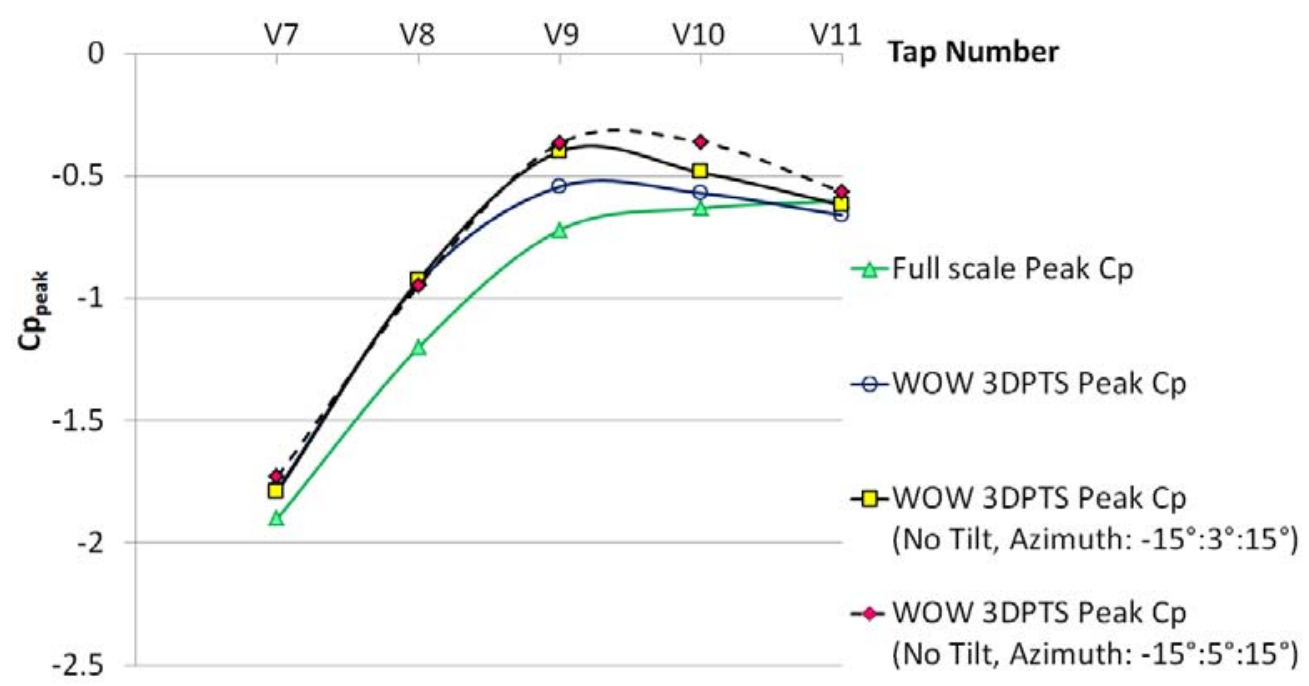

Figure 13: Effects wind azimuth angle increment size on pressure coefficients

Results showed that although for many cases considering 5 degrees increment in the azimuth angle can predict almost the same peak pressure coefficients as obtained using smaller angle increments (3 degrees), on some critical taps (e.g. V10) which are sensitive to slight variations of wind direction, very small angle increments in the range of 3 degrees are needed to resolve the peak pressure coefficents accurately. It is recommended that in case of using the 3DPTS approach in wind tunnels, angle increments in the range of 5 degrees or smaller be used. 


\subsection{Conclusions}

In this paper an extension of the Partial Turbulence Simulation Method was presented which includes the effects of missing low frequency lateral and vertical turbulence intensities in addition to the effects of missing low longitudinal turbulence intensity. In a flow with Partial Turbulence Simulation, only the high frequency end of the turbulence spectrum was simulated and the effects of missing low frequency turbulences were included theoretically using quasi-steady assumptions. A methodology for including the effects of low frequency lateral and vertical turbulence was described for which a number of tests at small angle increments was required in a flow with partial flow simulation. The 3DPTS method was assessed by comparing pressure data obtained on large scale models of the Silsoe cube and Texas Tech University building models for which full-scale data are available. The results show that the 3DPTS approach brings the model scale data into generally good alignment with the full-scale data. Comparison between the results obtained from the presently described 3DPTS method showed improvements over the previous version which only implemented correcting for low frequency longitudinal turbulence. The reason is that wind pressures on some taps in the critical regions are highly sensitive to slight changes in wind direction and the 3DPTS approach allowed these effects to be captured. The proposed 3DPTS method enables larger models to be tested in existing test facilities such as the WOW and conventional boundary layer wind tunnels. This enables improved accuracy of predictions of full-scale behavior on smaller structures and building components through reduction of Reynolds number effects and enhanced spatial resolution of the pressure taps in high pressure zones. 


\subsection{Acknowledgements}

The 12-fan Wall of Wind flow simulation and large-scale testing for this research was supported by the National Science Foundation (NSF) (NSF Award No. CMMI1151003). We also acknowledge NSF support for Wall of Wind instrumentation (NSF Award No. CMMI-0923365). The Wall of Wind facility was partially funded by the Center of Excellence in Hurricane Damage Mitigation and Production Development through the FIU International Hurricane Research Center. We would like to acknowledge the help received from the PhD candidate, Ramtin Kargarmoakhar. The help offered by the Wall of Wind manager, Walter Conklin and research scientist Roy Liu Marquis is greatly acknowledged.

\subsection{References}

Asghari Mooneghi, M., Irwin, P., Gan Chowdhury, A., Partial turbulence simulation method for predicting peak wind loads on small structures and building appurtenances. Journal of Wind Engineering and Industrial Aerodynamics, Under review.

Asghari Mooneghi, M., Irwin, P., Gan Chowdhury, A., 2014. Large-scale testing on wind uplift of roof pavers. Journal of wind engineering and industrial aerodynamics 128, 2236.

Banks, D., 2011. Measuring peak wind loads on solar power assemblies, in: Proceedings of the The 13th International Conference on Wind Engineering.

Cheung, J.C.K., Holmes, J.D., Melbourne, W.H., Lakshmanan, N., Bowditch, P., 1997. Pressures on a 110 scale model of the Texas Tech Building. Journal of wind engineering and industrial aerodynamics 69-71, 529-538.

Cochran, L.S., Cermak, J.E., 1992. Full- and model-scale cladding pressures on the Texas Tech University experimental building. Journal of wind engineering and industrial aerodynamics $43,1589-1600$.

Hillier, R., Cherry, N.J., 1981. The effects of stream turbulence on separation bubbles. Journal of wind engineering and industrial aerodynamics 8, 49-58.

Holmes, J.D., 2007. Wind loading of structures. Taylor \& Francis. 
Irwin, P., 2009. Wind engineering research needs, building codes and project specific studies, in: Proceedings of the 11th Americas Conference on Wind Engineering.

Irwin, P., Cooper, K., Girard, R., 1979. Correction of distortion effects caused by tubing systems in measurements of fluctuating pressures. Journal of Wind Engineering and Industrial Aerodynamics 5, 93-107.

Irwin, P.A., 1988. The role of wind tunnel modeling in the prediction of wind effects on bridges, International Symposium on Advances in Bridge Aerodynamics. Balkema, Copenhagen, pp. 99-117.

Kopp, G.A., Banks, D., 2013. Use of the wind tunnel test method for obtaining design wind loads on roof-mounted solar arrays. Journal of structural engineering 139, 284-287.

Kumar, K.S., Stathopoulos, T., 1998. Spectral density functions of wind pressures on various low building roof geometries. Wind and Structures 1, 203-223.

Letchford, C.W., Mehta, K.C., 1993. The distribution and correlation of fluctuating pressures on the Texas Tech Building. Journal of wind engineering and industrial aerodynamics $50,225-234$.

Levitan, M.L., Mehta, K.C., 1992a. Texas Tech field experiments for wind loads part 1: building and pressure measuring system. Journal of wind engineering and industrial aerodynamics $43,1565-1576$.

Levitan, M.L., Mehta, K.C., 1992b. Texas tech field experiments for wind loads part II: meteorological instrumentation and terrain parameters. Journal of wind engineering and industrial aerodynamics $43,1577-1588$.

Melbourne, W.H., 1980. Turbulence effects on maximum surface pressures - a mechanism and possibility of reduction. Wind Engineering, 541-551.

Melbourne, W.H., 1993. Turbulence and the leading edge phenomenon. Journal of wind engineering and industrial aerodynamics 49, 45-63.

Mooneghi, M.A., Irwin, P., Chowdhury, A.G., 2014. Large-scale testing on wind uplift of roof pavers. Journal of Wind Engineering and Industrial Aerodynamics 128, 22-36.

Okada, H., Ha, Y.-C., 1992. Comparison of wind tunnel and full-scale pressure measurement tests on the Texas Texh Building. Journal of wind engineering and industrial aerodynamics 43, 1601-1612.

Richards, P.J., Hoxey, R.P., 2012. Pressures on a cubic building-Part 1: Full-scale results. Journal of wind engineering and industrial aerodynamics 102, 72-86.

Richards, P.J., Hoxey, R.P., Connell, B.D., Lander, D.P., 2007. Wind-tunnel modelling of the Silsoe Cube. Journal of wind engineering and industrial aerodynamics 95, 1384-1399. 
Saathoff, P.J., Melbourne, W.H., 1989. The generation of peak pressures in separated/reattaching flows. Journal of wind engineering and industrial aerodynamics 32 , 121-134.

Saathoff, P.J., Melbourne, W.H., 1997. Effects of free-stream turbulence on surface pressure fluctuation in a separation bubble. Journal Of Fluid Mechanics 337, 1-24.

Surry, D., 1991. Pressure measurements on the Texas tech building: Wind tunnel measurements and comparisons with full scale. Journal of wind engineering and industrial aerodynamics 38, 235-247.

Tieleman, H.W., 2003. Wind tunnel simulation of wind loading on low-rise structures: a review. Journal of wind engineering and industrial aerodynamics 91, 1627-1649.

Tieleman, H.W., Surry, D., Mehta, K.C., 1996. Full/model-scale comparison of surface pressures on the Texas Tech experimental building. Journal of wind engineering and industrial aerodynamics $61,1-23$.

Wu, F., Sarkar, P.P., Mehta, K.C., Zhao, Z., 2001. Influence of incident wind turbulence on pressure fluctuations near flat-roof corners. Journal of wind engineering and industrial aerodynamics 89, 403-420.

Yamada, H., Katsuchi, H., 2008. Wind-tunnel study on effects of small-scale turbulence on flow patterns around rectangular cylinder, 4th International Colloquium on Bluff Bodies Aerodynamics \& Applications, Italy.

Zhao, Z., 1997. Wind flow characteristics and their effects on low-rise buildings, Doctor of Philosophy Dissertation. Texas Tech University, Lubbock, Texas.

\subsection{Appendix}

\section{Comparison between the PTS and 3DPTS methods}

Figure 14 shows a comparison between the peak pressure coefficients obtained using the PTS method (Asghari Mooneghi et al, 2015), the currently proposed 3DPTS method and full-scale results for TTU building.

The results showed that using the 3DPTS approach better agreement can be obtained with the full-scale data. The difference is more pronounce for taps which are located on the critical regions on the roof which are more sensitive to variations in wind 
direction. 

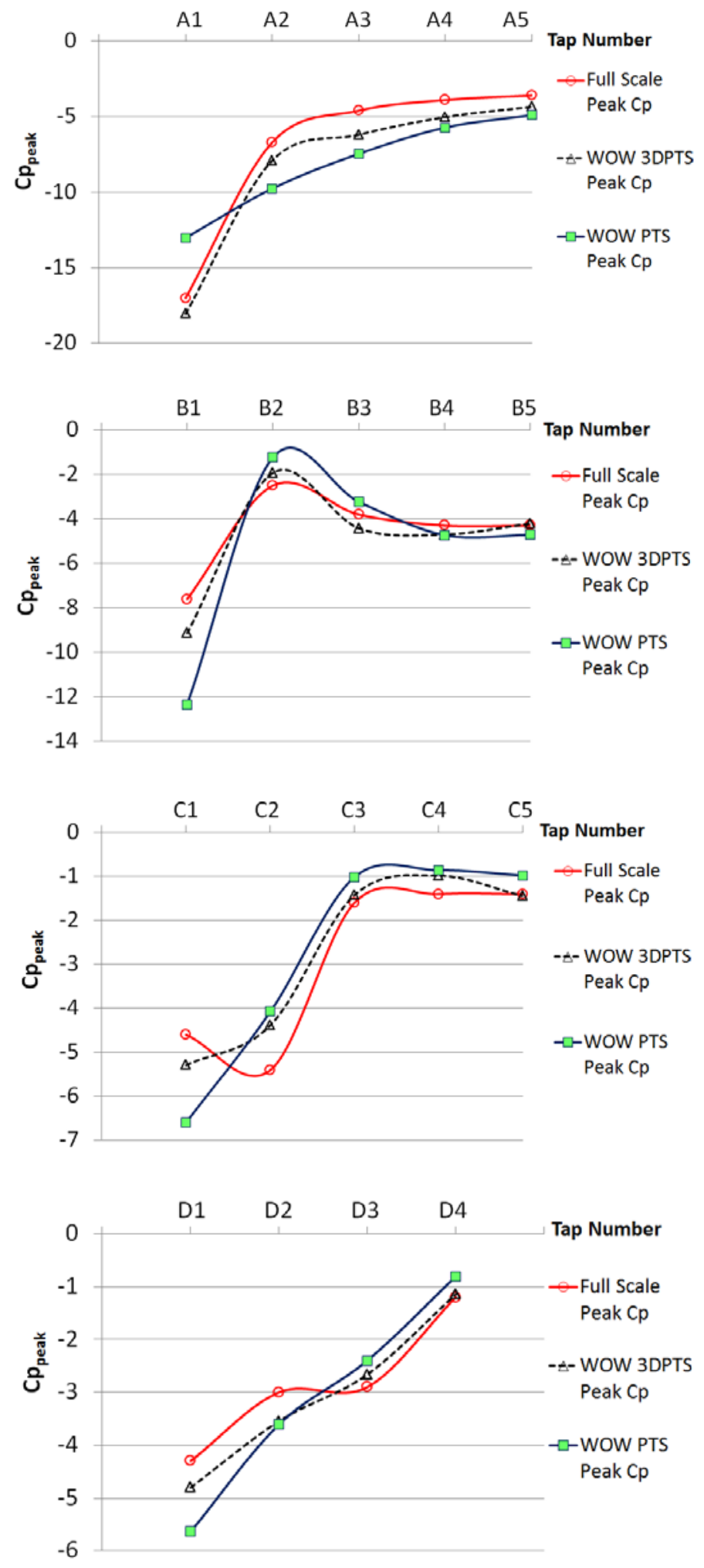

Figure 14: Comparison between PTS and 3DPTS methods 


\section{CHAPTER IV}

\section{LARGE-SCALE TESTING ON WIND UPLIFT OF ROOF PAVERS}

(A paper published in The Journal of Wind Engineering and Industrial Aerodynamics) 


\section{CHAPTER IV}

\section{LARGE-SCALE TESTING ON WIND UPLIFT OF ROOF PAVERS}

Maryam Asghari Mooneghi ${ }^{\mathrm{c}}$, Peter Irwin ${ }^{\mathrm{b}},{ }^{*}$ Arindam Gan Chowdhury ${ }^{\mathrm{c}}$

\subsection{Abstract}

This paper presents a large-scale experimental study to investigate the wind loading on concrete roof pavers on the flat roof of a low rise building. The experiments were performed in Wall of Wind, a large-scale hurricane testing facility at Florida International University. Experiments included both wind blow-off tests and pressure measurements on the top and bottom surfaces of the pavers. The effects of the pavers' edge-gap to spacer height ratio and the relative parapet height on the wind performance of roof pavers were also investigated. The results showed that increasing the edge-gap to spacer height ratio parameter decreases the net pressures by enhancing pressure equalization between top and bottom surfaces. Also, increasing the relative parapet height reduces the worst suctions for the parapet heights considered in this study. The resolution of the pressure taps was found to have significant influence on the test results. Too few taps can result in underestimation of the net uplift and overturning moments that can cause failure under strong winds. Guidelines on the resolution and location of pressure taps were provided for better capturing the effects of conical vortices on wind loads on

\footnotetext{
${ }^{\mathrm{c}} \mathrm{PhD}$ candidate, Civil and Environmental Engineering/International Hurricane Research Center, Florida International University, Miami, FL, USA, masgh002@fiu.edu

${ }^{\mathrm{b}}$ Professor of Practice, Civil and Environmental Engineering/International Hurricane Research Center, Florida International University, Miami, FL, USA, peairwi@fiu.edu

${ }^{\mathrm{c}}$ Corresponding Author. Associate Professor, chowdhur@fiu.edu, Tel: (305) 348-0518
} 
pavers. Results of the wind blow-off tests are compared with those obtained from pressure measurements and typical practice based on ASCE 7-10 exterior pressures.

Keywords: Wind uplift; Roof pavers; Conical vortices; Pressure taps resolution; Lowrise building

\subsection{Introduction}

Due to the rising loss of life and economic losses associated with the frequent occurrence of severe wind storms, wind induced loads are one of the most critical design parameters for coastal construction. Roof systems are exposed to higher loading than any other building element (Smith and McDonnald, 1991). Suction forces on the roof can loosen and lift both roof sheathing and roof coverings, such as tiles, shingles, and roof pavers. Dislodged roofing elements may become wind-borne debris impacting other structures downwind. Internal pressure generated when windows, doors, or sections of the roof are breached can lift and separate the roof from the rest of the structure. This may result in total failure of the building or increased losses because of water infiltration and interior damage.

Loose-laid roof pavers are commonly used on flat roofs and as decorative elements on terraces. Wind uplift of roof pavers is not only the result of the suction on their top surface, but also of the pressure on their underside. Designers of these materials often rely on a significant amount of pressure equalization between top and bottom to help keep them in place. Interlocking and strapping systems are used to improve the resistance of pavers but these typically are not based on true knowledge of the forces involved and failures still occur despite such systems. 
Many studies are reported on wind loading and performance of loose laid roofing systems. The failure mechanisms have been extensively studied (Kind, 1988; Kind and Wardlaw, 1982). Bienkiewicz and Sun (1992) performed wind tunnel experiments to investigate the wind loading of loose-laid roof paving systems on a low-rise building with flat roof. The effects of space under the paver and the parapet height on the pressure correlation were investigated. Kramer and Gerhardt (1983) investigated the critical loading on permeable roofing elements including tiles and paving slabs and presented typical test results for roof tiles and flat roof elements. Bienkiewicz and Endo (2009) carried out a wind tunnel study on wind loads on loose-laid roof pavers and photovoltaic roofing systems. Effects of the edge-gap between pavers, and the space beneath the pavers on the pressures underside the pavers were discussed. Trung et al (2009) conducted wind tunnel tests in order to investigate the effects of parapet height and underside volume on wind loading of porous roof cover sheets. They concluded that the correlation between upper and lower surface pressures decreased with increasing the underside "volume". This means that increasing the underside volume increases the net pressure on porous roofs. Studies of wind effects on full- and large-scale building models have been limited. Fu et al (2012b) performed an experimental study to assess wind induced pressures on full-scale loose concrete roof pavers using the 6-fan Wall of Wind, at Florida International University (FIU). A limited number of numerical simulations of wind loading on roof paver systems have been proposed in the literature (Amano et al, 1988; Bofah et al, 1996; Gerhardt et al, 1990; Kind, 1994; Sun and Bienkiewicz, 1993; Trung et al, 2010). Results from some of the preceding studies have been used for the development of models for design of loose-laid roofing systems e.g. 
roof pavers (Bienkiewicz and Endo, 2009; Cheung and Melbourne, 1986; Cheung and Melbourne, 1988). Some codes and standards address the design of these systems. In the Netherlands code, NEN EN 1991-1-4/NA, a set of values for net pressure coefficients (difference between the external and underneath pressure coefficients; Cpnet=Cpe-Cpi) is proposed for design of roofing tiles and pavers. These values were based on a number of experiments and full-scale studies on roof tiles on pitched roofs and roof pavers on flat roofs including those of Geurts (2000), who proposed equalization factors defined as Ceq=Cpnet/Cpe from full-scale measurements on roof tiles and roof pavers to be applied to the external pressure coefficients given in the Netherlands wind loading code. The proposed value for roof pavers with and without interlock were 0.25 and 0.6 , respectively. In the German Wind Code (DEUTSCHE NORM, 2001-03) design pressure coefficients are provided for building envelopes with permeable facades based on a study by Gerhardt and Janser (1995). In the Australian Standard for wind loads (AS 1170.2, 2011) reduction factors are given for estimating design wind loads on porous claddings. These factors depend on the cladding porosity and the horizontal distance from windward building edge. Other major international codes and standards for wind loads in Canada and USA (ASCE 7-10; NBCC) specify roof wind pressures for typical roof geometries but there are no specific provisions on how to apply such pressures to roofing elements such as tiles, shingles, and pavers.

To better understand the effects of conical vortices on roof pavers under cornering winds, the present work focused on a large-scale experimental study on the wind loading mechanism of concrete roof pavers using the 12-fan Wall of Wind (WOW) facility at FIU. Half scale concrete pavers were installed on a square portion of a flat roof of a low- 
rise building. Tests in which pavers were actually lifted off by the wind were conducted and pressure measurements were performed. The aim of the study was to investigate the external and underneath pressure distribution over loose-laid roof pavers in order to develop more effective protections against wind damage. In the course of the work guidelines were developed for the resolution and location of pressure taps on critical pavers to better resolve the effects of conical vortices. The effects of paver's edge-gap to spacer height ratio and the relative parapet height were also explored. Wind blow-off speeds were compared to those calculated using a typical informal practice based on ASCE 7-10 external pressures and also with the current net-pressure measurements.

\subsection{Wind Loading Mechanism on Permeable Roofing Elements}

Solid pavers are frequently used as ballast and walking surfaces on roofs and it is necessary that they be capable of resisting uplift forces due to wind. Usually concrete pavers are placed on the roof with gaps in between them and with spaces between their under sides and the roof deck. This is necessary to allow for water drainage and for vapor diffusion when using an "inverse roof" in which the principal thermal insulation material is applied on top of the waterproof covering. Since air can readily leak around the edges of pavers, the pressure distribution produced by the wind flow over the outer surface of the roof produces secondary flows through the spaces between and underneath the paver elements. A pressure distribution is generated under the roof pavers which is related to, but different from, that on the outer surface. The pressure equalization occurs very quickly, typically in less than 0.1 of a second, because very small volumes of air exchange are needed to bring the underside pressure into equilibrium with the pressures around the paver perimeter. The pressure equalization effect greatly reduces the net uplift 
force on pavers in most areas of roofs. However, in areas of very high spatial gradients of pressure, such as those which occur under vortices near roof corners, significant net uplift pressures can still occur. Figure 1 illustrates the typical path of the vortices over a flat roof for cornering winds.
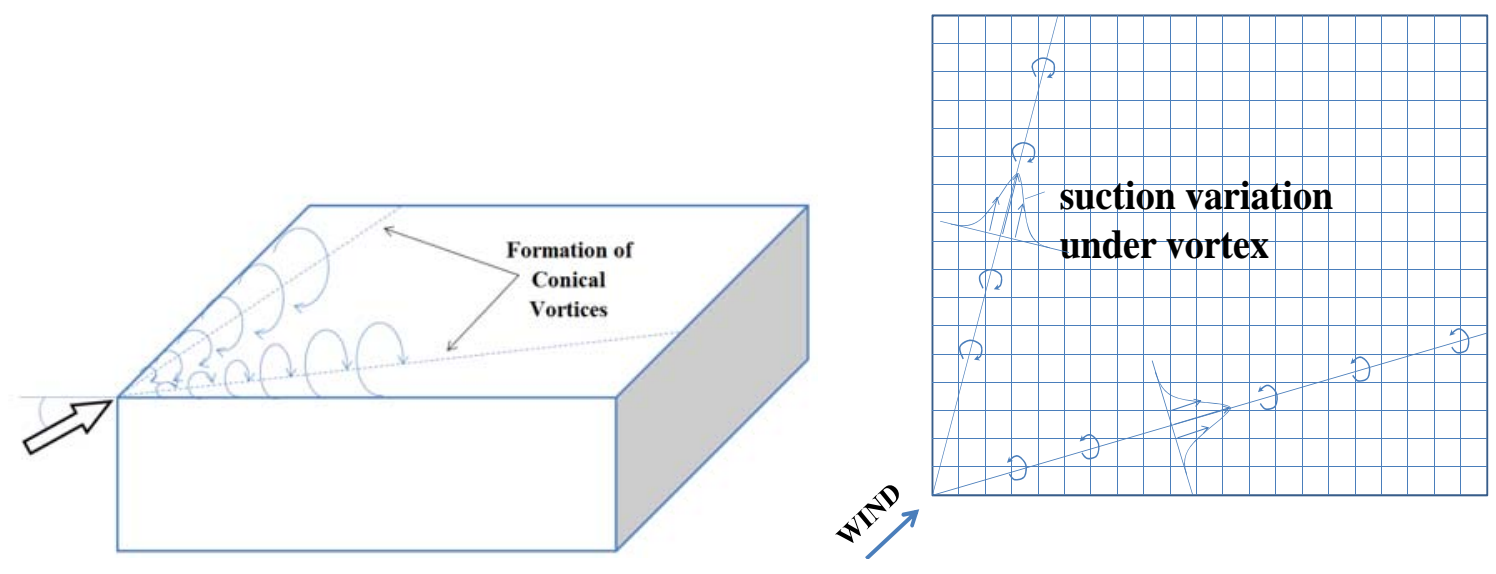

Figure 1. Paths of corner vortices and resulting suction variations on roof

The diagram in Fig. 2 illustrates the general mechanism of uplift on roof pavers. The aerodynamic uplift force is the difference between the pressure on the lower surface of the paver, PL and the pressure on the upper surface, PU (Fig. 2). The pressure on the upper surface due to the presence of a corner vortex (solid curve) is negative (when measured relative to a non-zero baseline, e.g. the static pressure in the surrounding air stream) and has a concentrated peak. The pressure on the lower surface is depicted by the broken curve and it is shown as being equal to that on the top surface at the paver edges. In practice the top and bottom edge pressures do not always match exactly. The underneath pressure depends on the outer pressure distribution and the relative magnitude of the joint resistances compared to the under-element resistance which prevents a complete pressure equilibration between upper and lower surfaces of the element (Bofah 
et al, 1996; Gerhardt et al, 1990; Kind, 1994). Detailed measurements done by (Kind and Wardlaw, 1982) showed that the underneath pressure does tend to vary roughly linearly between the pressures at the paver edges as depicted in Fig. 2 (this is also discussed in Bofah et al (1996)). More precisely, it should satisfy the Laplace equation as explained by (Kind, 1994). It is only due to the sharp peak of the negative pressure under a vortex (between points $\mathrm{A}$ and B) that a net uplift occurs, signified by the large difference between the solid and broken curves. If the upper surface pressure does not have the peak then pressure equalization caused by flow around the edges of the paver results in smaller net uplift as shown by the small differences between the solid and dashed curves on the pavers outside of the zone between points A and B.

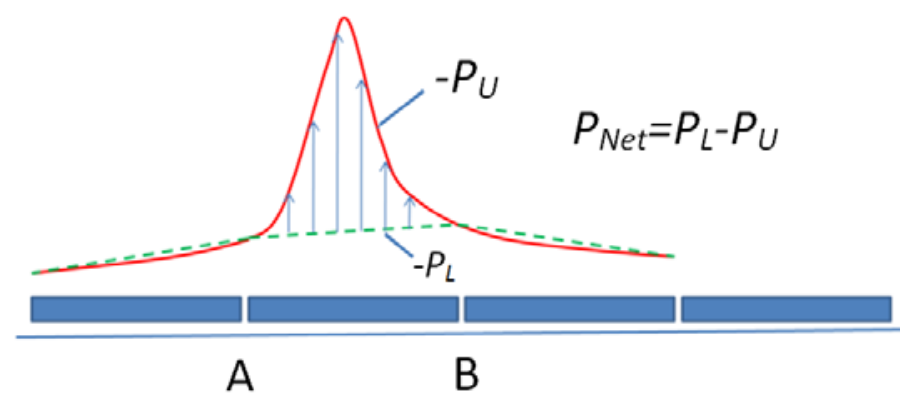

Figure 2. General mechanism of pressure distributions on upper and lower surfaces of a roof paver

The aerodynamic uplift force and/or the overturning moment on the element may become higher than the weight and/or the resisting moment. Parameters influencing the wind loading mechanism of roof pavers in terms of the nonlinear net (i.e., external minus internal) pressure distribution over the paver due to conical vortices include: paver size, paver edge-gap to spacer height ratio, distance of the paver from the roof corner, and height of parapets. Roof external pressures are a function of building height, exposure, 
building orientation, parapet height, and other roof top features such as elevator housings, stairwell cover, and cooling towers (Kramer and Gerhardt, 1983). The internal pressure (i.e. pressure underneath the pavers) depends on the external pressure distribution, the edge-gap to spacer height ratio, and the flow resistance underneath the pavers. A large gap between the pavers has a considerable effect on the reduction of the wind force because it makes the internal pressure approach the external one (Kramer and Gerhardt, 1983).

\subsection{Description of the Experimental Set up and Testing Procedure}

\subsubsection{2-fan Wall of Wind facility}

The full-scale 12-fan Wall of Wind (WOW) open jet facility at FIU was used to generate the wind field for the present study. It can generate up to a Category 5 SaffirSimpson Scale hurricane wind speed that reasonably replicates mean wind speed and partial turbulence characteristics of real hurricane winds. Figure 3 shows the comparison between the atmospheric boundary layer ( $\mathrm{ABL}$ ) full spectrum for suburban terrain as simulated in a boundary layer wind tunnel by (Fu, 2013) and the WOW partial spectrum. The dimensionalized Kaimal spectrum is also shown. Note that the high frequency portions of the WOW and wind tunnel spectra match satisfactorily and show good agreement with the $-5 / 3$ slope corresponding to the inertial subrange of the dimensionalized Kaimal spectrum. As noted by several researchers (Banks, 2011; Irwin, 2009; Kopp and Banks, 2013; Kumar and Stathopoulos, 1998; Melbourne, 1980; Richards et al, 2007; Saathoff and Melbourne, 1997; Tieleman, 2003; Yamada and Katsuchi, 2008), accurate simulation of high frequency turbulence is necessary for an adequate simulation of the separated flows on local aerodynamic effects on low-rise 
structures. A set of triangular spires and floor roughness elements were used to generate the turbulence and the boundary layer characteristics (Fig. 4).

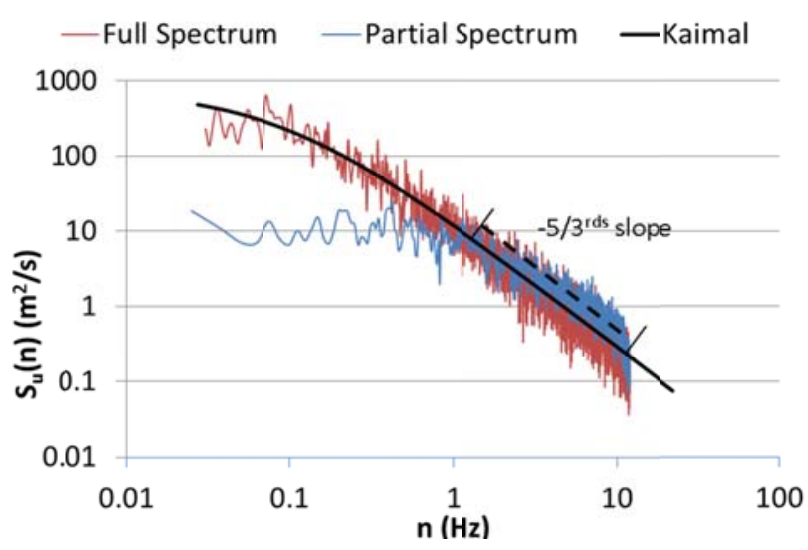

Figure 3. Comparison of ABL full spectrum for suburban terrain simulated in wind tunnel by Fu (2013), WOW partial spectrum and the dimensionalized Kaimal spectrum
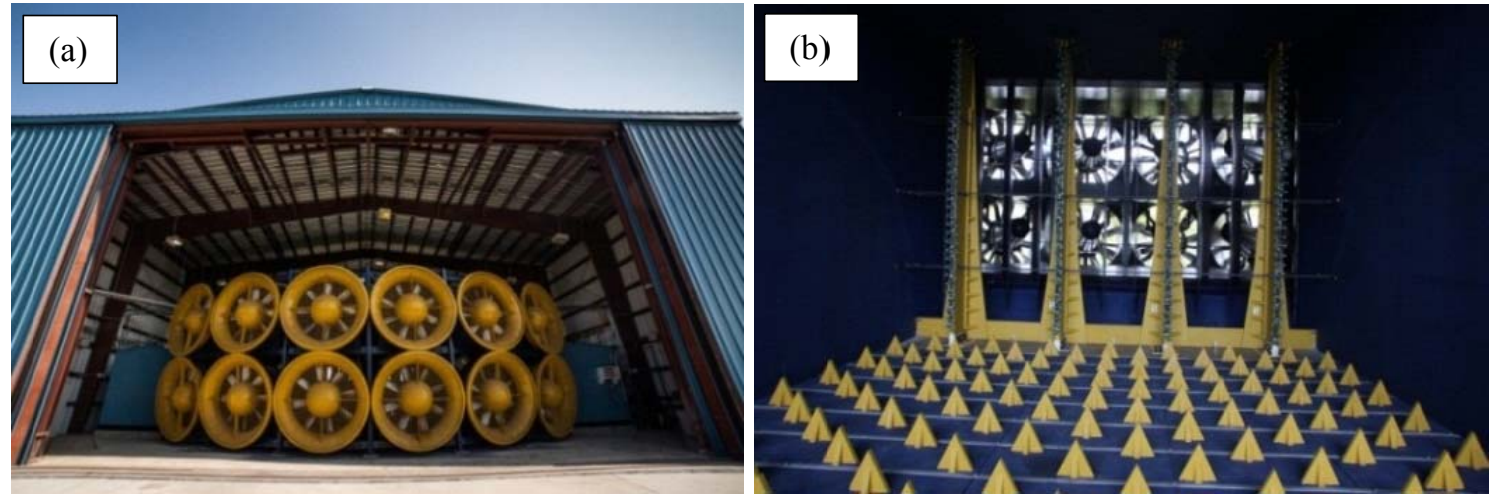

Figure 4. (a) Wall of Wind, Florida International University, (b) Spires and floor roughness elements

The mean wind speed and turbulence intensity profiles for suburban terrain are shown in Fig. 5 for $20.1 \mathrm{~m} / \mathrm{s}$ wind speed at $\mathrm{z}=2.6 \mathrm{~m}$ elevation (target power law coefficient was $\alpha=1 / 4)$. It should be noted that the tests were performed in a partial turbulence simulation in which the turbulence intensity is lower than that for the $\mathrm{ABL}$ flow containing the full spectrum of turbulence. However, using the method proposed by 
Katsuchi and Yamada (2011), the adequacy of the current turbulence intensity was shown.
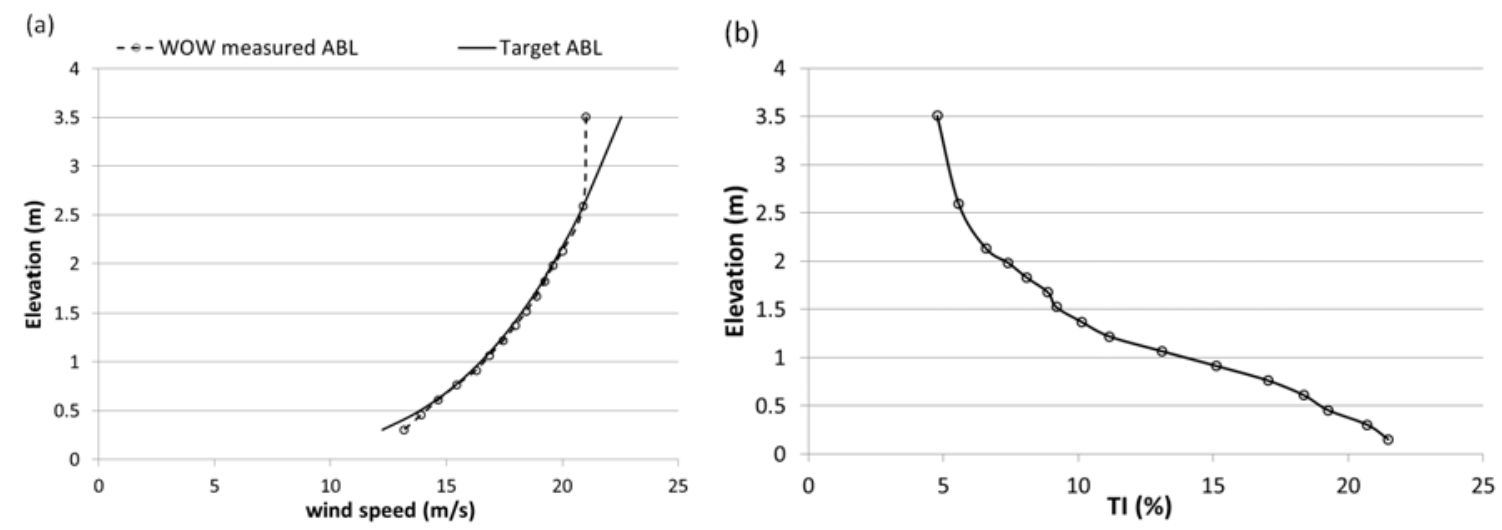

Figure 5. Suburban terrain: (a) ABL profile, (b) Turbulence intensity profile

\subsection{2 $\quad$ Test Condition}

If the tests results are to be meaningful, conditions must be such that the test model behavior is dynamically similar to that of the prototype. The wind approaching the model should satisfactorily simulate the natural wind, and the Reynolds number $(U L / \vartheta)$, the Froude number $\left(U^{2} / L g\right)$, and the density ratio $\left(\rho_{s} / \rho\right)$ should have the same numerical values between the model and the prototype. $U$ is the speed of approaching wind at roof height, $L$ is a reference length, $\vartheta$ is the kinematic viscosity of air, $g$ is the gravitational acceleration, $\rho$ is the density of air, and $\rho_{s}$ is the density of the solid paver. In the case of thin objects, the requirement that the density ratios be matched between the model and the prototype can be relaxed, if the weight per unit area of the model is correctly scaled meaning that $\left(\rho_{s} t\right)_{M} /\left(\rho_{s} t\right)_{P}=L_{M} / L_{P}$ in which symbol $t$ denotes the thickness of the pavers and subscripts $M$ and $P$ denote the model and the prototype, respectively. Except at a scale of 1:1, Froude number and Reynolds number similarity 
cannot be satisfied simultaneously. The flow underneath and through the joints might be somewhat dependent on Reynolds number but it was assumed in the present experiments that being out by a factor of two in Reynolds number would have very minor effect on the results. Kind and Wardlaw (1982) discuss Re effects and accepted a larger mismatch in their experiments. The complete simulation of the atmospheric boundary layer is not possible at $1 / 2$ scale in most wind testing facilities due to their limited size. Typically, the large scale turbulence present at full scale cannot be generated and only the highfrequency part of the power spectrum can be simulated (Fu et al, 2012a; Yeo and Chowdhury, 2013). However, previous experiments have shown that the flow pattern over the upwind corner of the building roof is mainly dependent on the correct simulation of high frequency turbulence, as was done in the present tests, and achieving a Reynolds number of approximately the right order.

\subsubsection{Test Building}

A test building was constructed to install the roof pavers (a total of 100) in a similar way to real roof pavement systems. The size of the 1:2 test building model was $3.35 \mathrm{~m}$ by $3.35 \mathrm{~m}$ in plan by $1.524 \mathrm{~m}$ high, thus it represented a low-rise prototype building with height of $3.48 \mathrm{~m}$. The model was engulfed completely in the $6.1 \mathrm{~m}$ wide and $4.3 \mathrm{~m}$. high wind field generated by the WOW. The roof deck was made from plywood and was completely sealed and rigid. The rectangular sharped edge parapets on the building model were interchangeable which allowed evaluation of the effect of parapet height on the wind effects on pavers. The parapet height was measured from the top of the pavers (Fig. 6a). There were no parapets on the leeward side of the building so that the roof could be representative of the windward corner of a bigger roof structure. 
The justification of this comes from the studies of Lin and Surry (1998) and Lin et al (1995) who found that, for low buildings which are large enough to have reattached flows on the roof, the distribution of pressure coefficients in the corner region is mainly dependent on the eave height, $H$, and not so much on the building plan dimensions as long as terrain conditions are similar. Also, external pressure coefficients measured in wind tunnel by Kopp et al (2005) on roof corners of a nearly flat building model were consistent with those measured on roof corners of flat roof low-rise building models with different plan aspect ratios as reported by Stathopoulos (1982) (Ho et al, 2005; Pierre et al, 2005); Stathopoulos and Baskaran (1988). The experiments included both the wind blow-off testing (i.e. blowing at sufficient speed to dislodge pavers) and pressure measurements. For the wind blow-off tests, concrete pavers with a dimension of $0.305 \mathrm{~m}$ by $0.305 \mathrm{~m}$ by $2.54 \mathrm{~cm}$ thickness and having weight per unit area of $532 \mathrm{~N} / \mathrm{m}^{2}$ were installed on the roof which can be considered as modeling typical $0.61 \mathrm{~m}$ square pavers at half-scale. Figure $6 \mathrm{~b}$ shows the test building for the wind blow-off tests with the concrete roof pavers installed. For pressure measurements, pavers with exactly the same dimensions as the actual concrete pavers were made from Plexiglas. This made it more convenient to install pressure taps on both upper and lower surfaces of the pavers. Adjustable height pedestals were used to change the space between the paver and the roof deck $\left(\mathrm{H}_{\mathrm{s}}\right.$, Fig.6a). Pedestals had top caps which created a constant $\mathrm{G}=3.175 \mathrm{~mm}$ space between the pavers (Fig. 6a). Pavers were numbered from 1 to 100 (Fig. 6c). Pressure taps were installed on Plexiglas roof pavers for simultaneous measurement of the external and the underneath pressures. Fig. 7 shows the external and underneath pressure tap layout (total of 447). 


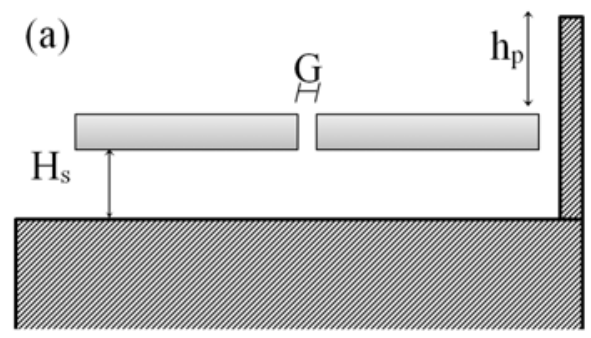

(b)

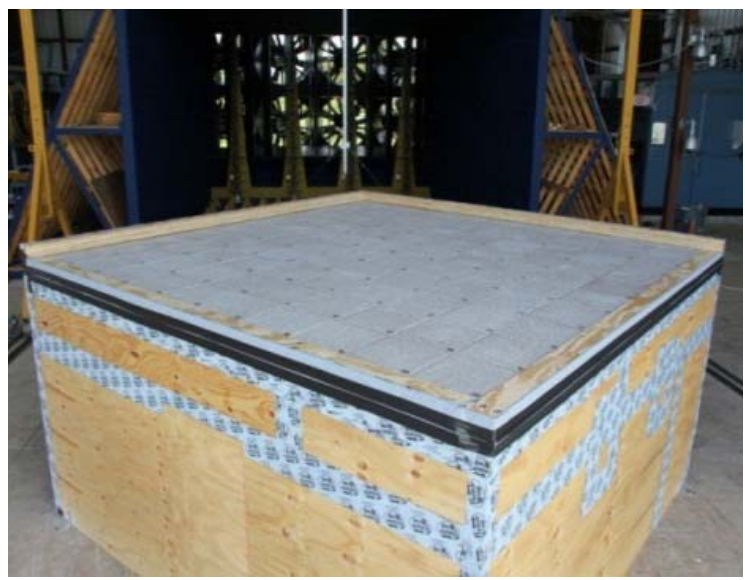

(c)

\begin{tabular}{|l|l|l|l|l|l|l|l|l|l|}
\hline 91 & 81 & 71 & 61 & 51 & 41 & 31 & 21 & 11 & 1 \\
\hline 92 & 82 & 72 & 62 & 52 & 42 & 32 & 22 & 12 & 2 \\
\hline 93 & 83 & 73 & 63 & 53 & 43 & 33 & 23 & 13 & 3 \\
\hline 94 & 84 & 74 & 64 & 54 & 44 & 34 & 24 & 14 & 4 \\
\hline 95 & 85 & 75 & 65 & 55 & 45 & 35 & 25 & 15 & 5 \\
\hline 96 & 86 & 76 & 66 & 56 & 46 & 36 & 26 & 16 & 6 \\
\hline 97 & 87 & 77 & 67 & 57 & 47 & 37 & 27 & 17 & 7 \\
\hline 98 & 88 & 78 & 68 & 58 & 48 & 38 & 28 & 18 & 8 \\
\hline 99 & 89 & 79 & 69 & 59 & 49 & 39 & 29 & 19 & 9 \\
\hline 100 & 90 & 80 & 70 & 60 & 50 & 40 & 30 & 20 & 10 \\
\hline
\end{tabular}

Figure 6. (a) Geometrical parameter definition, (b) Test building for wind blow-off Tests, (c) Roof pavers numbering

(a)

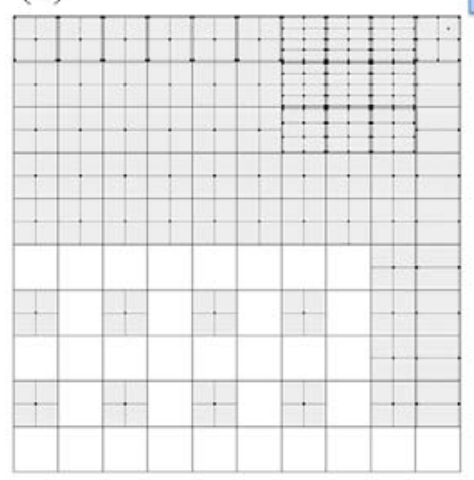

(b)

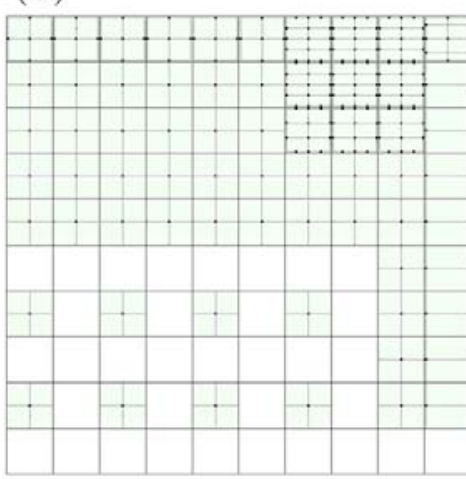

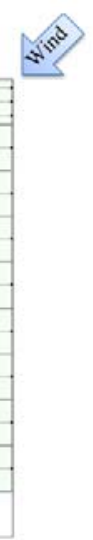

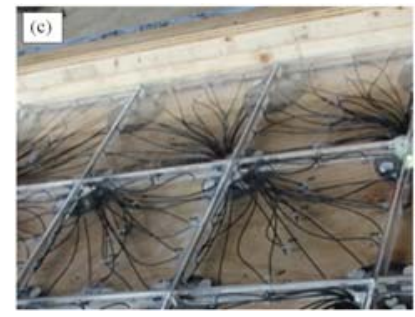

Figure 7. (a) External pressure tap layout, (b) Underneath pressure tap layout, (c) Plexiglas pavers with pressure taps 


\subsubsection{Test Procedure}

A total of 9 experiments were carried out, including three wind blow-off tests and 6 pressure measurement tests. A summary of each test characteristics is given in Table 1 . Only one wind direction was tested which was $45^{\circ}$. Based on past studies this wind direction was selected as the most critical orientation for generating high uplifts under conical vortices on flat rectangular roofs (Holmes, 2007).

Table 1.Test number and characteristics

\begin{tabular}{lcccc}
\hline Wind Test Number & Spacer height $\left(\mathbf{H}_{\mathbf{s}}\right)$ & Windward parapet height & ${ }^{*} \mathbf{G} / \mathbf{H}_{\mathbf{s}}$ & $\mathbf{h}_{\mathbf{p}} / \mathbf{H}$ \\
\hline Wind Uplift 1 & $1.27 \mathrm{~cm}$ & $7.62 \mathrm{~cm}$ & 0.25 & 0.05 \\
Wind Uplift 2 & $3.81 \mathrm{~cm}$ & $7.62 \mathrm{~cm}$ & 0.083 & 0.05 \\
Wind Uplift 3 & $11.43 \mathrm{~cm}$ & $7.62 \mathrm{~cm}$ & 0.028 & 0.05 \\
\hline Pressure 1-1 & $1.27 \mathrm{~cm}$ & $7.62 \mathrm{~cm}$ & 0.25 & 0.05 \\
\hline Pressure 2-1 & $3.81 \mathrm{~cm}$ & $5.08 \mathrm{~cm}$ & 0.083 & 0.033 \\
Pressure 2-2 & $3.81 \mathrm{~cm}$ & $7.62 \mathrm{~cm}$ & 0.083 & 0.05 \\
Pressure 2-3 & $3.81 \mathrm{~cm}$ & $15.24 \mathrm{~cm}$ & 0.083 & 0.1 \\
Pressure 2-4 & $3.81 \mathrm{~cm}$ & $22.86 \mathrm{~cm}$ & 0.083 & 0.15 \\
\hline Pressure 3-2 & $11.43 \mathrm{~cm}$ & $7.62 \mathrm{~cm}$ & 0.028 & 0.05 \\
\hline
\end{tabular}

* Constant $\mathrm{G}=3.175 \mathrm{~mm}$ for all tests

The basic test procedure consisted of first conducting wind blow-off tests. The aim of these tests was to provide guidance on the location where paver blow-off, i.e. failure, first occurs, which could then be used to decide on the pressure tap layout. The test was done by gradually increasing the wind speed in WOW and visually observing the behavior of the roofing system. The most critical pavers which dislodged first were identified. Wind speeds were measured at the roof height of the test model $(1.524 \mathrm{~m}$ height) using a turbulent flow Cobra probe. After identifying the critical pavers and deciding on the pressure tap layout, the original pavers were replaced by the Plexiglas pavers with pressure taps. Pressure measurements were carried out at wind speed $=18.5$ $\mathrm{m} / \mathrm{s}$ which was below the failure speed of concrete pavers (but required some special measures to hold the Plexiglas pavers in place). Nine critical pavers were fitted with total 
of 256 pressure taps to allow accurate measurements of the pressure distribution above and underneath the pavers. A 512 channel Scanivalve Corporation pressure scanning system was used for pressure measurements. Pressure data were acquired at sampling frequency of $512 \mathrm{~Hz}$ for a period of two minutes. Each pressure measurement test was repeated for three times to assure repeatability of the data. A transfer function designed for the tubing (Irwin et al, 1979) was used to correct for tubing effects.

\subsubsection{Data Analysis}

The mean pressure coefficient at any location was obtained from:

$$
C p_{\text {mean }}=\frac{P_{\text {mean }}}{\frac{1}{2} \rho U_{\text {mean }}^{2}}
$$

where $P_{\text {mean }}$ is the mean pressure, $\rho$ is the air density at the time of the test $(1.225$ $\mathrm{kg} / \mathrm{m}^{3}$ ) and $U$ is the mean wind speed measured at the building height of the test model $(1.524 \mathrm{~m})$.

For the proper securing of individual pavers, measured values of $\mathrm{Cp}_{\text {peak }}$ should be considered. Due to the highly fluctuating nature of wind pressures, significant differences might be expected in the peak values of pressure time series obtained from several different tests under nominally identical conditions. The Sadek and Simiu (2002) method was used to obtain statistics of pressure peaks from observed pressure time histories (unless otherwise stated). Because estimates obtained from this approach are based on the entire information contained in the time series, they are more stable than estimates based on single observed peaks. For the evaluation of these estimated values, the peak value with $85 \%$ probability of not being exceeded in one hour of full spectrum wind was 
selected. The peak pressure coefficient was normalized by the three second gust dynamic pressure as follows:

$$
C p_{\text {peak }}=\frac{P_{\text {peak }}}{\frac{1}{2} \rho U_{3 S}^{2}}
$$

where $P_{\text {peak }}$ is the peak pressure, and $U_{3 s}$ is the peak 3-s gust at the reference height. For the WOW the wind speed $U_{3 s}$ was obtained using time scale $\lambda_{\mathrm{t}}=0.7$ $\left(\lambda_{\mathrm{t}}=\frac{\lambda_{\mathrm{L}}=0.5}{\lambda_{\mathrm{V}}=0.71 \text { (based on Froud Number Similarity) }}\right)$, meaning that $512 \times 3 \times 0.7=1075$ data points were required for its determination. The peak value of the $U_{3 s}$ was obtained by performing moving averages. Data were low-pass filtered at $30 \mathrm{~Hz}$ equivalent to $21 \mathrm{~Hz}$ full scale.

To properly design and secure the most critical pavers in place, it is necessary to know the wind-induced loads acting on individual pavers under the design wind speed. It should be noted that the highest suction on the paver does not necessarily occur at the center of the paver. This means that even for cases where the total uplift force is less than the weight of the paver, the weight of the paver might not overcome the corresponding overturning moment. The overall wind uplift load, $L(t)$, and lift coefficient, $C_{L}(t)$, acting on any single paver are obtained as:

$$
\begin{gathered}
L(t)=\frac{1}{2} \rho U^{2} \iint_{A_{\text {paver }}} C p_{\text {net }}(t, x, y) d A \\
C_{L}(t)=\frac{L(t)}{\frac{1}{2} \rho U^{2} A}
\end{gathered}
$$

where $\mathrm{A}$ is the surface area of the paver and $C p_{\text {net }}(t)=C p_{\text {ext }}(t)-C p_{\text {int }}(t)$ is the net total pressure coefficient defined as the instantaneous difference between the external and 
the corresponding underneath pressure coefficient at the same location. The overturning moment and moment coefficient about a selected axis are obtained from:

$$
\begin{gathered}
M(x, y, t)=\frac{1}{2} \rho U^{2} \iint_{A_{\text {paver }}} C p_{\text {net }}(t, x, y) \times d(x, y) \times d A \\
C_{M}(t)=\frac{M(t)}{\frac{1}{2} \rho U^{2} A a}
\end{gathered}
$$

where $a$ is the width of the paver and $d(x, y)$ is the moment arm defined as the distance from the selected axis to each point on the paver (Fig. 8).

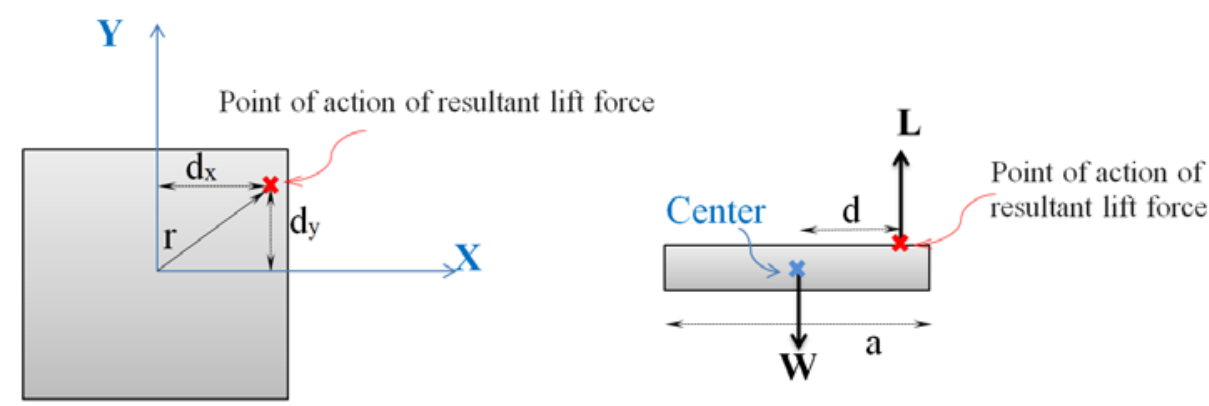

Figure 8. Definition of the point of action of the resultant lift force

Another important parameter is the point of action of the uplift force (Fig. 8). Having the net lift, $L$, and moments $M_{x}$ and $M_{y}$, offsets of point of action of lift from the center are:

$$
d_{y}=M_{x} / L ; d_{x}=M_{y} / L
$$

The blow-off takes place when the moment caused by the uplift force is equal to the moment from the paver weight, $\mathrm{W}$. Therefore, the critical wind velocity $U_{C R I T}$ at which blow-off occurs is calculated from:

$$
\frac{1}{2} \rho U_{C R I T}^{2} C_{L} A\left(d+\frac{a}{2}\right)=W \times \frac{a}{2}
$$

From which it can be deduced that: 


$$
U_{C R I T}=\sqrt{\frac{a}{2\left(d+\frac{a}{2}\right)} \times \frac{W}{\frac{1}{2} \rho C_{L} A}} \quad\left(d \text { is the larger of } d_{x} \text { and } d_{y}\right)
$$

\subsection{Results and Discussion}

\subsubsection{Wind blow-off test results}

Table 2 shows the failure wind speeds and the failure mechanism for wind blowoff tests (see Table 1 for each test characteristics). $1^{\text {st }}$ failure wind speed is defined as the wind speed at which minor displacement and/or limited failure (wobbling of pavers and/or 1 paver lifted off) was observed. $2^{\text {nd }}$ failure wind speed corresponds to the situation when more failure occurred ( 2 or 3 pavers were lifted off). The failure in each case is shown in Fig. 9.

Table 2. Failure wind speeds and failure mechanisms

\begin{tabular}{|c|c|c|}
\hline Test Number & $1^{\text {st }}$ failure wind speed: $\mathrm{m} / \mathrm{s}$ & $2^{\text {nd }}$ failure wind speed: $\mathrm{m} / \mathrm{s}$ \\
\hline Wind Uplift 1 & $\begin{array}{l}37.2 \text { :Pavers } 1 \text { wobbling, Pavers } \\
21 \text { lifted off }\end{array}$ & $\begin{array}{l}\text { 40: Paver } 1 \text { wobbling, Paver } 4 \text { lifted off) } \\
\text { 43: Paver } 1 \text { wobbling, Paver } 31 \text { lifted off) }\end{array}$ \\
\hline Wind Uplift 2 & 34: Pavers 1,11 wobbling & 37.3: Pavers 4, 21 lifted off \\
\hline Wind Uplift 3 & $\begin{array}{l}\text { 28: Pavers } 1,2 \text { wobbling } \\
\text { 30.7: Paver } 1 \text { lifted off }\end{array}$ & $\begin{array}{l}\text { 34: Pavers 3,4 wobbling } \\
\text { 37: Pavers 2, } 21 \text { lifted off }\end{array}$ \\
\hline
\end{tabular}
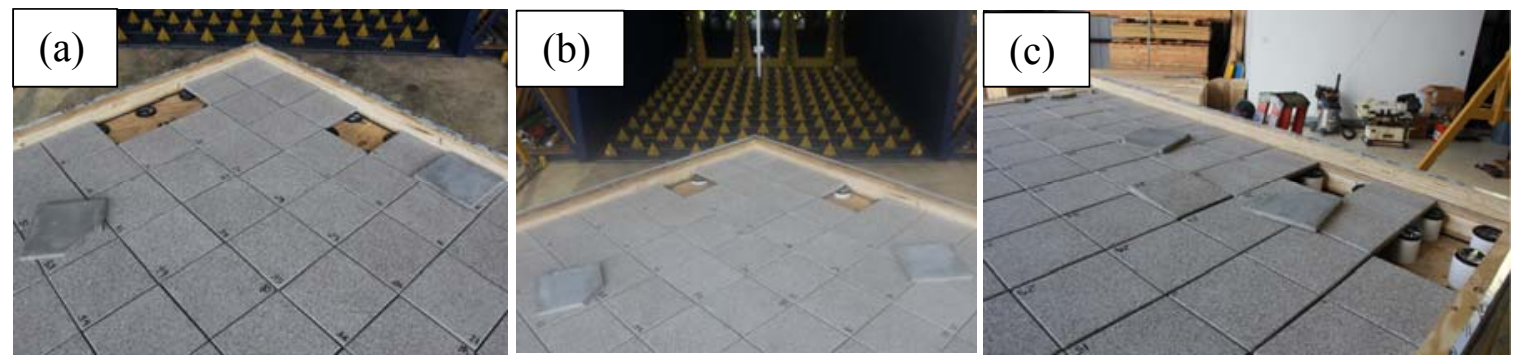

Figure 9. Failure of roof pavers during wind blow-off tests: (a) $\mathrm{G} / \mathrm{H}_{\mathrm{s}}=0.25$, (b)

$$
\mathrm{G} / \mathrm{H}_{\mathrm{s}}=0.083 \text {, (c) } \mathrm{G} / \mathrm{H}_{\mathrm{s}}=0.028
$$

The results showed that by increasing the spacer height $\left(\mathrm{H}_{\mathrm{s}}\right)$, the failure wind speed decreases. This is in agreement with studies of (Bienkiewicz and Endo, 2009) who showed that increasing the height $\mathrm{H}_{\mathrm{s}}$ while having a constant edge-gap between the 
pavers, increases the net pressures on the pavers which may be regarded as lowering the failure wind speed. The location of the failure was in all cases near the edge of the roof (Fig. 9). Pavers 1, 2, 3, 4 and 11, 21, 31 were the most critical pavers. The pressure tap layout (Fig. 7) was decided based on the wind blow-off tests for detailed evaluation of the pressure distribution over the roof and the most critical pavers.

\subsection{2 $\quad$ Pressure Measurement Results}

\subsubsection{Effect of Relative Parapet Height $(\mathrm{hp} / \mathrm{H})$}

\subsection{External Pressure Distribution}

Figure 10 shows the surface plots of the external mean and external peak pressure coefficients for various relative parapet height ratios $\left(\mathrm{h}_{\mathrm{p}} / \mathrm{H}\right)$. The Peak values correspond to the estimated peak value for each tap during the test and do not happen simultaneously on all taps.
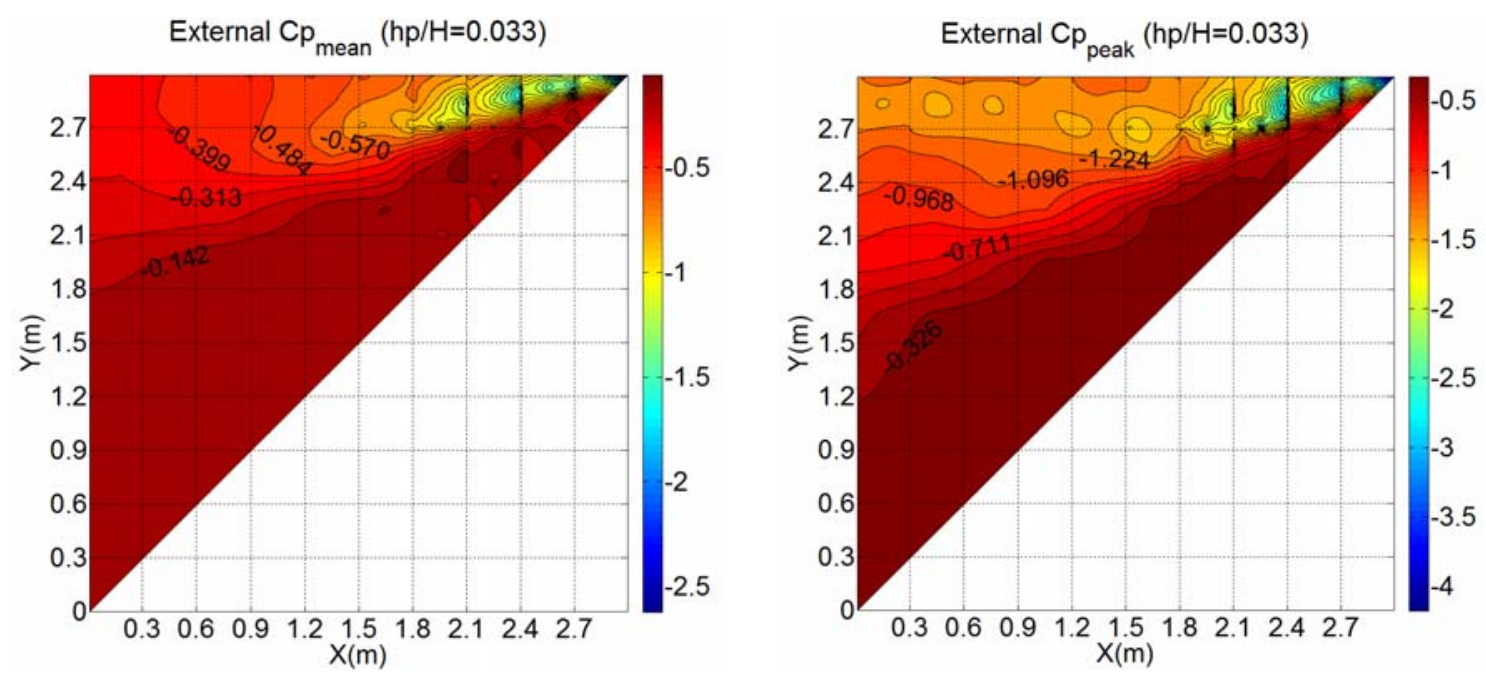

Figure 10. External $\mathrm{Cp}_{\text {mean }}$ and $C \mathrm{p}_{\text {peak }}(\mathrm{G} / \mathrm{Hs}=0.083)$ 

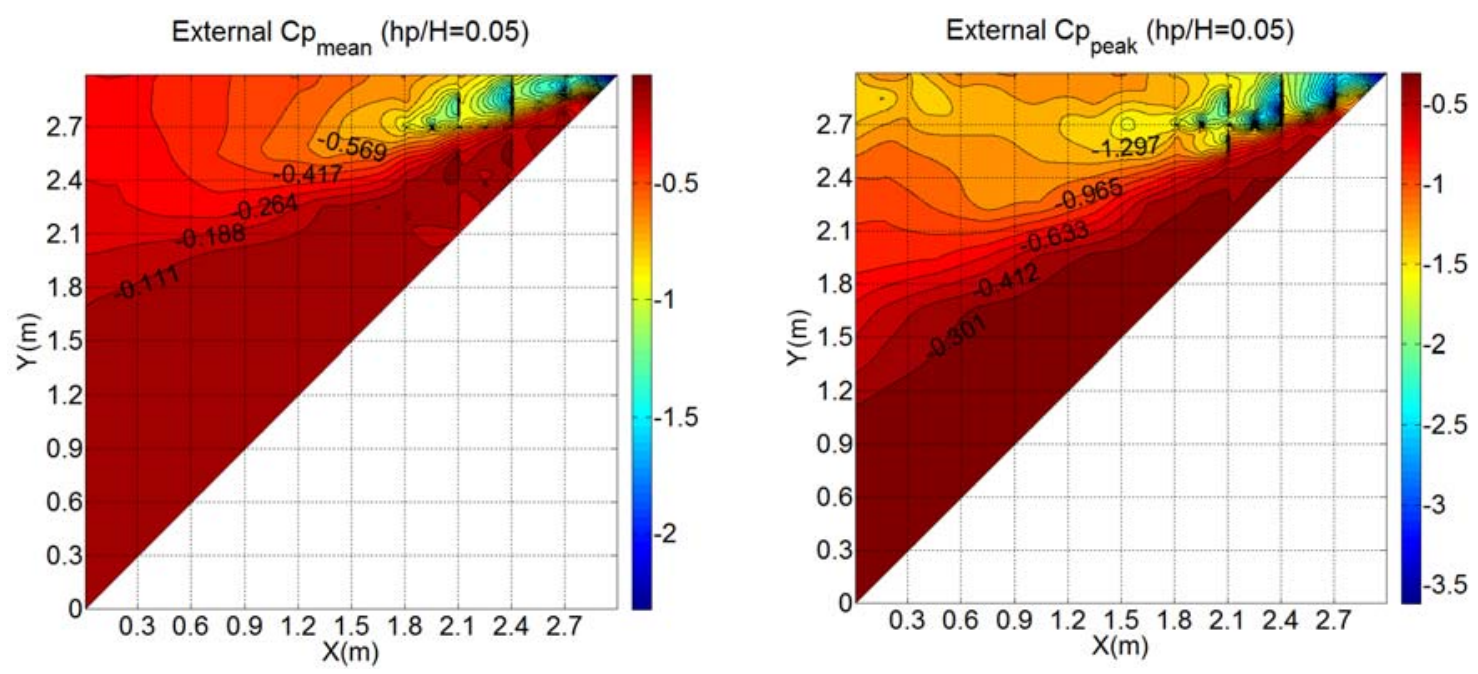

External $\mathrm{Cp}_{\text {mean }}(\mathrm{hp} / \mathrm{H}=0.1)$

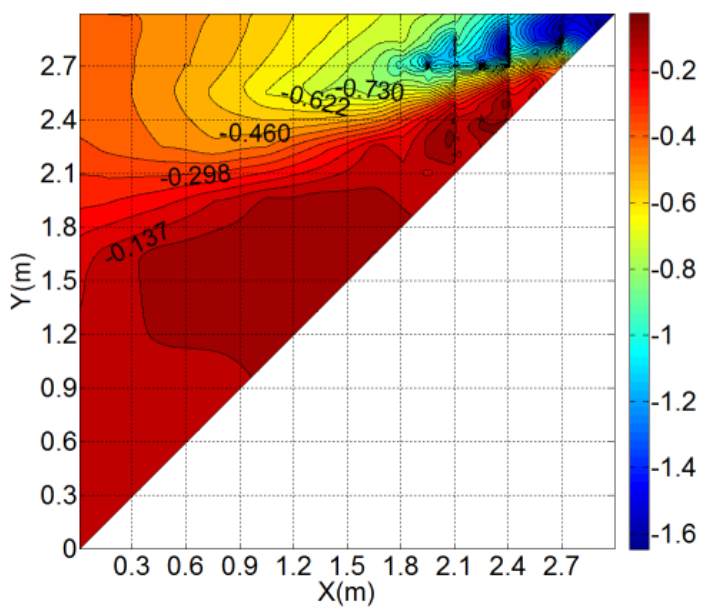

External $\mathrm{Cp}_{\text {peak }}(\mathrm{hp} / \mathrm{H}=0.1)$
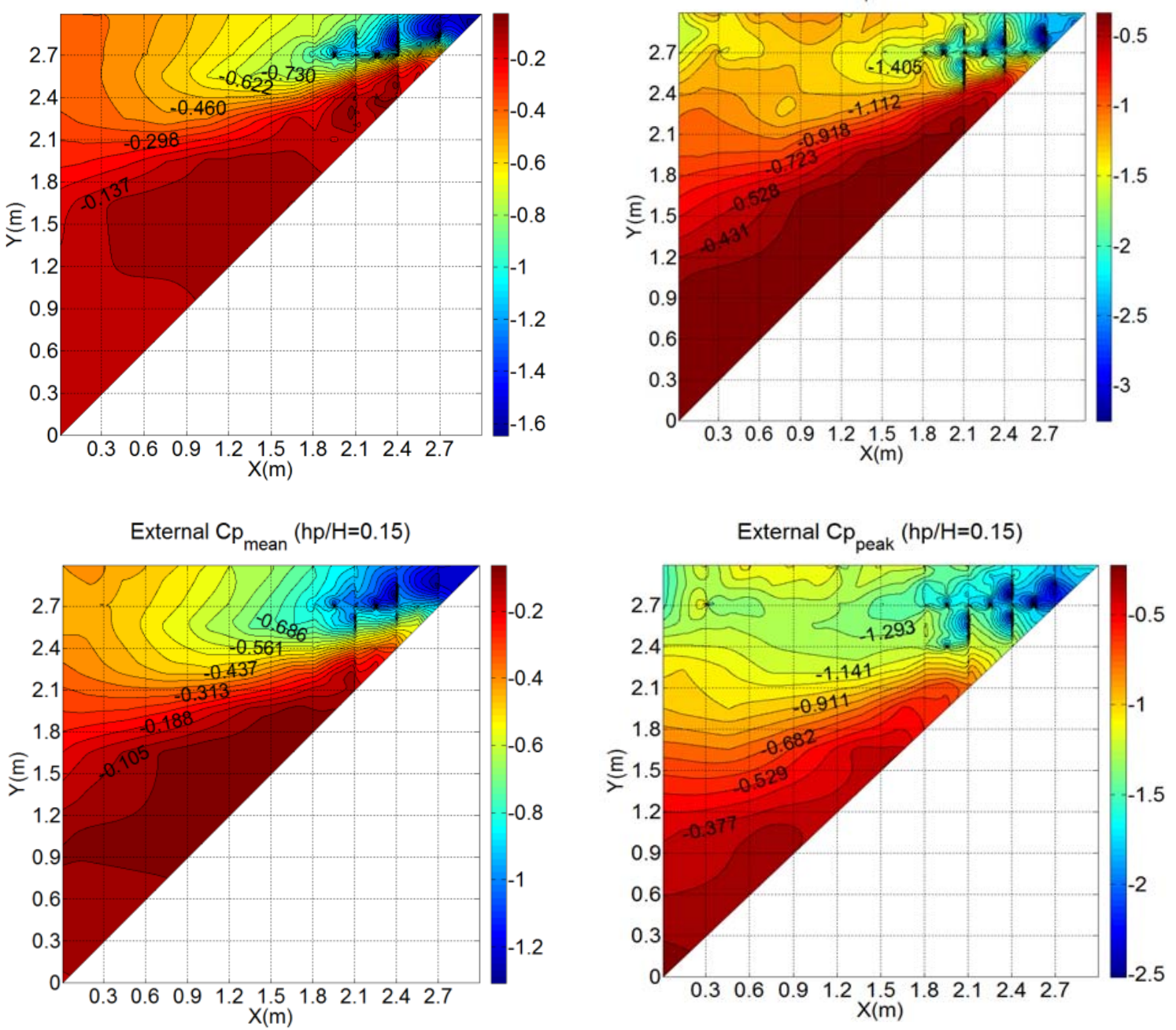

Figure 10 (Cont.) External $\mathrm{Cp}_{\text {mean }}$ and $\mathrm{C} \mathrm{p}_{\text {peak }}\left(\mathrm{G} / \mathrm{H}_{\mathrm{s}}=0.083\right)$ 
Results in Fig. 10 show that pavers close to the edges and corners of the roof are subjected to the highest local negative pressures. It can be seen that the highest local mean suction pressure coefficient is reduced by about $50 \%$ by changing $h_{p} / H$ from 0.033 to 0.15 . The width of the zone of high suctions caused by the conical vortices increases and their strength decreases with taller parapets. This trend is in agreement with the results obtained by Kind (1988) on the effect of parapet height on worst mean suction pressure coefficient for a 1:20 scale low-rise building.

Several studies have been done on the effect of parapets on the external pressure coefficients on flat roofs (Kopp et al, 2005; Stathopoulos, 1982; Stathopoulos and Baskaran, 1987). In order to put the current data in context with the previously published data, it was attempted to compare the external pressure coefficients with those obtained in the literature. Table 3 shows the characteristics of the experiments used for comparison. Note that comparisons pertain to the closest possible match of geometric and exposure configurations as found in the literature and could not be performed for exactly similar test configurations. Comparison was limited to the corner region where the 45 degree wind direction usually dominates the behavior of peak suctions and since 45 degrees was the only angle tested in the present research.

Table 3. Characteristics of the experiments used for comparison between external pressure coefficients

\begin{tabular}{lcccccc}
\hline & H (m) & $\mathbf{h}_{\mathbf{p}} / \mathbf{H}$ & Plan Aspect ratio & Terrain & Scale & Wind Direction \\
\hline Current Study & 3.48 & 0.1 & 1 & Suburban & $1 / 2$ & 45 \\
$\begin{array}{l}\text { Stathopoulos, } \\
\text { 1982 }\end{array}$ & 9.8 & 0.122 & 3 & Suburban & $1 / 250$ & $\begin{array}{c}\text { Most critical, } \\
\text { from tests for 0- } \\
90 \text { is presented }\end{array}$ \\
$\begin{array}{l}\text { Kopp et. al, } \\
\mathbf{2 0 0 5}\end{array}$ & 4.6 & 0.1 & 1.5 & Open & $1 / 50$ & 325 \\
\hline
\end{tabular}




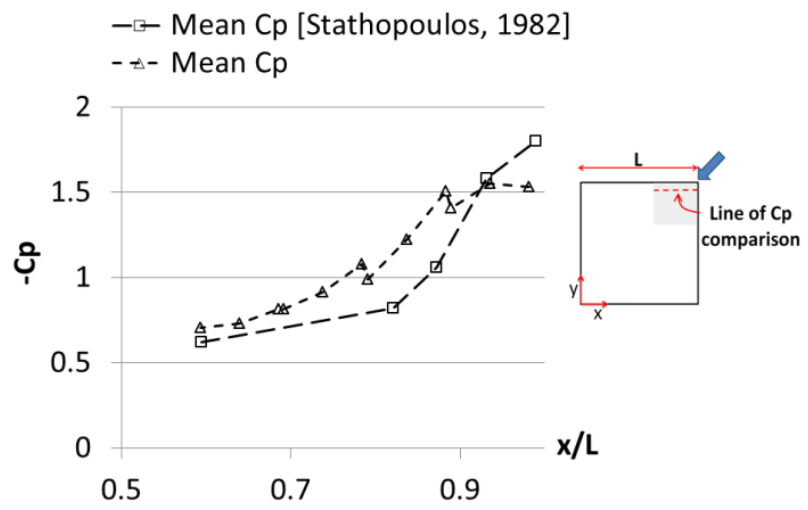

Figure 11. Comparison of external $\mathrm{Cp}_{\text {mean }}\left(\mathrm{h}_{\mathrm{p}} / \mathrm{H}=0.1 ; \mathrm{G} / \mathrm{H}_{\mathrm{s}}=0.083\right)$ with Stathopoulos (1982)

Figure 11 shows the external mean pressure coefficients measured at the edge taps of the building with the corresponding values from literature (Stathopoulos, 1982). Note that in the latter reference the published values are the highest ones as obtained from all the wind directions tested, rather than those at 45 degrees only. However, close to the corner the 45 degree case dominates. It can be seen that the values obtained in the present work are generally in a good agreement with those from the (Stathopoulos, 1982).

As explained previously, the peak values presented in this paper are normalized to the 3-s gust wind speed. In order to be able to compare our peak pressures with those obtained in wind tunnel by Kopp et al (2005) the procedure explained by Pierre et al (2005) was used to calculate the equivalent wind tunnel pressure coefficient:

$$
(G C p)_{e q}=\frac{q_{H} \hat{C} p}{q_{10 m, 3 s} K_{z t} K_{h} K_{d} I}=F_{W T} \hat{C} p
$$

where $\hat{C} p$ is the peak coefficient based on the mean hourly wind speed measured at the eave height in a wind tunnel, $q_{10 m, 3 s}$ and $q_{H}$ are the dynamic wind pressures at heights of $10 \mathrm{~m}$ and $\mathrm{H}$, respectively, as given in the ASCE $7-10, K_{z t}$ is the topographic factor, $K_{h}$ is the exposure factor, $K_{\mathrm{d}}$ is the directionality factor and $I$ is the importance factor. The 
factors $K_{z t}, K_{\mathrm{d}}$ and $I$ were set to unity. The coefficient $F_{\mathrm{WT}}$ was given as 0.38 for $H=4.6 \mathrm{~m}$ in the open country terrain which was used to re-reference the peak pressure coefficients obtained by Kopp et al (2005) for comparison purposes. Figure 12 shows the comparison between the mean and Peak pressure coefficients obtained in the current study with the corresponding values in Kopp et al (2005). The measurement were limited to corner region along the line of $\mathrm{x} / \mathrm{H}=0.42$ from the windward corner of the roof as defined by Kopp et al (2005). Results show that the mean pressure coefficients are in very good agreement with the results in Kopp et al (2005). The differences in the peak pressure coefficients are probably due to different building geometries, different terrains, and Reynolds number effect. Higher peak pressures are generally expected for suburban terrain as compared to open terrain results for similar building configurations.

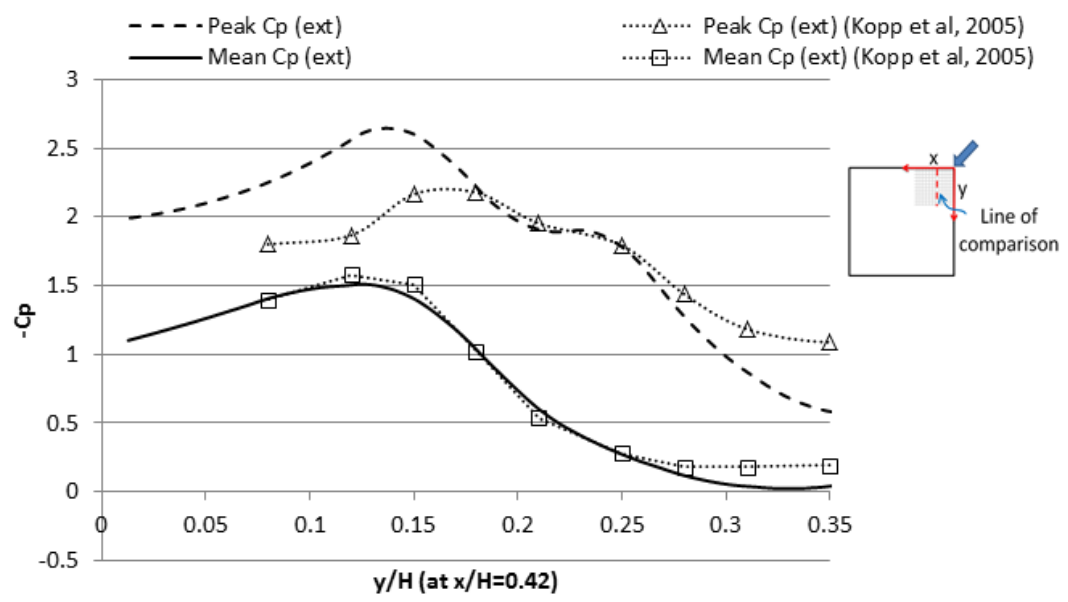

Figure 12. Comparison of external $\mathrm{Cp}\left(\mathrm{h}_{\mathrm{p}} / \mathrm{H}=0.1 ; \mathrm{G} / \mathrm{H}_{\mathrm{s}}=0.083\right)$ with Kopp et al (2005)

External pressure coefficients measured in this paper are in very good agreement with an earlier full-scale study performed in 6-fan Wall of Wind facility at FIU on concrete roof pavers (Fu et al, 2012). It is to be noted that although the 45 degree 
cornering wind is usually considered as the most critical direction for pavers, very localized higher suctions than seen at 45 degrees can occur in small regions near the roof edges for other wind directions ( $\mathrm{Fu}$ et al, 2012), but apparently the size of the effected region is too small to be the most critical case for pavers.

\subsection{Net Pressure Distribution}

Figure 13 shows the variation of Net pressure coefficients for various relative parapet height ratios $\left(\mathrm{h}_{\mathrm{p}} / \mathrm{H}\right)$ showing that taller parapets $\left(\mathrm{h}_{\mathrm{p}} / \mathrm{H}>0.1\right)$ reduce the Net $\mathrm{Cp}_{\text {mean }}$ on the roof. This was mainly due to reductions made on the mean external pressure coefficients. However, results show that low parapets might significantly increase the peak roof corner suctions for oblique wind directions (Bienkiewicz and Meroney, 1988; Stathopoulos and Baskaran, 1987).

Figure 14 shows the variation of the net uplift force coefficient and the net pitching moment coefficient on paver 21 with $\mathrm{h}_{\mathrm{p}} / \mathrm{H}$. Results show that in contrast to local suctions, the net uplift and the net moment on a paver, are both less sensitive to parapet height. For example, in going from $\mathrm{h}_{\mathrm{p}} / \mathrm{H}$ from 0.033 to $\mathrm{h}_{\mathrm{p}} / \mathrm{H}$ in the range of 0.05 to 0.10 ,

the values of both $C_{\text {Lnet }}$ and $C_{M n e t}$ were increased which makes the range $\mathrm{h}_{\mathrm{p}} / \mathrm{H}=0.05$ to 0.10 the worst case scenario among the parapets considered for this study. 

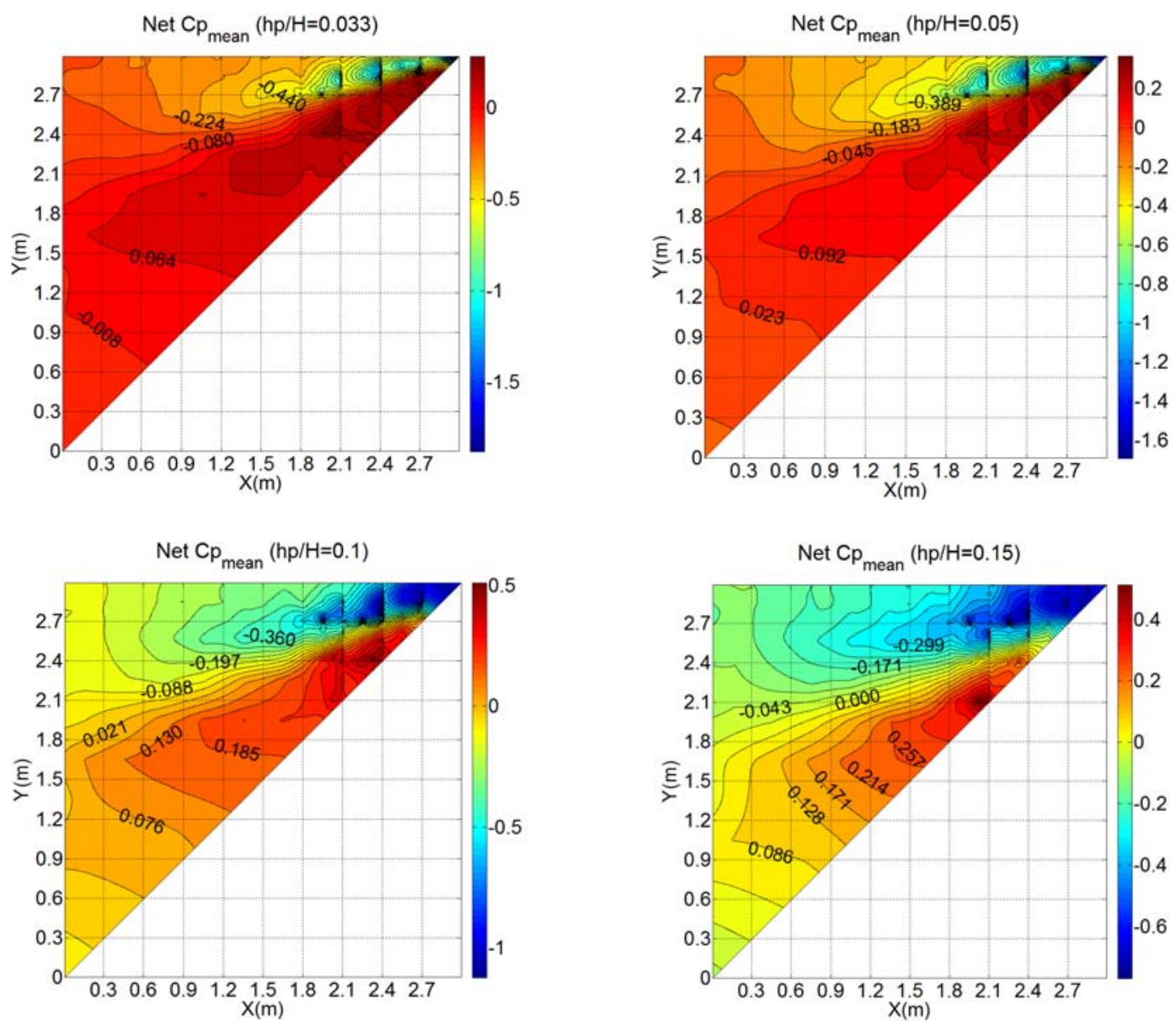

Figure 13. Net $\mathrm{Cp}$ mean $\left(\mathrm{G} / \mathrm{H}_{\mathrm{s}}=0.083\right)$

The variation of the location of the point of action of the net uplift force with relative parapet height $\left(\mathrm{h}_{\mathrm{p}} / \mathrm{H}\right)$ is plotted in Fig. 15. It shows that increasing the parapet height to above $h_{p} / H$ from 0.1 to 0.15 moves the point of action of the net uplift force more towards the center of the paver while the lift coefficient was also decreased. This situation can be interpreted as an improved wind performance for higher parapets. Thus from the current study it was found that a relative parapet height ratio of 0.15 could significantly reduce the suction pressure on pavers under conical vortices. It also reduces the offset distance of the point of action of the lift force from the center of the paver. 

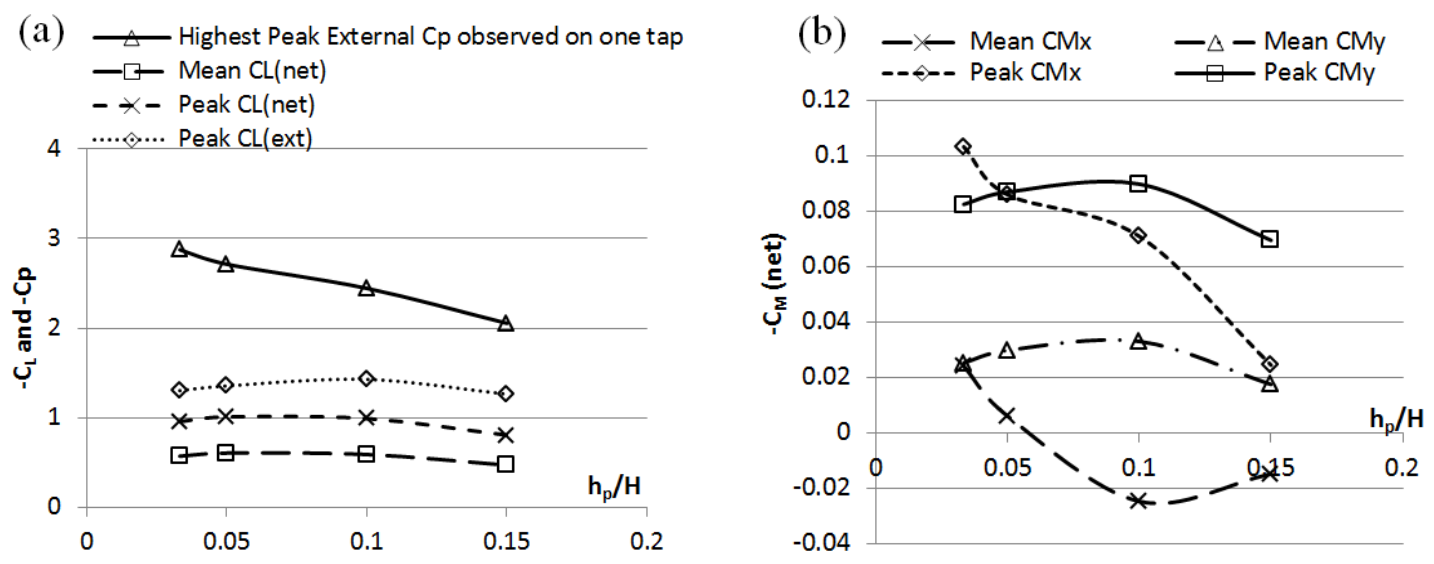

Figure 14. Variations of (a) $C_{\text {Lnet }}$ and (b) $C_{\text {Mnet }}$ on Paver 21 with $\mathrm{h}_{\mathrm{p}} / \mathrm{H}\left(\mathrm{G} / \mathrm{H}_{\mathrm{s}}=0.083\right)$

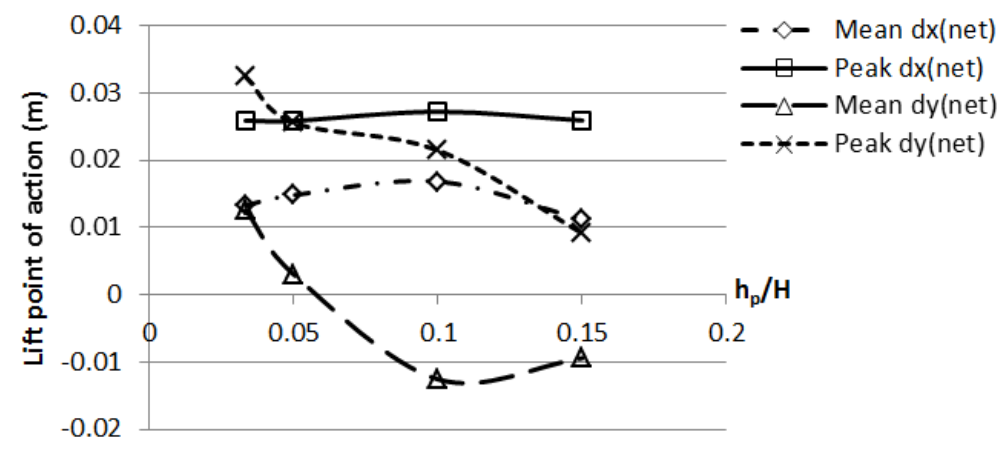

Figure 15. Variation of $L_{n e t}$ point of action on Paver 21 with $h_{p} / H\left(G / H_{s}=0.083\right)$

\subsubsection{Effect of Pavers' Edge-gap to Spacer Height Ratio $\left(\mathrm{G} / \mathrm{H}_{\mathrm{s}}\right)$}

Figure 16 shows the surface plots of the underneath mean and net mean pressure coefficients for various $\mathrm{G} / \mathrm{H}_{\mathrm{s}}$ ratios. Results presented in Fig. 16 show the effect of edgegap to spacer height $\left(\mathrm{G} / \mathrm{H}_{\mathrm{s}}\right)$ ratio on the wind loading of roof pavers. 

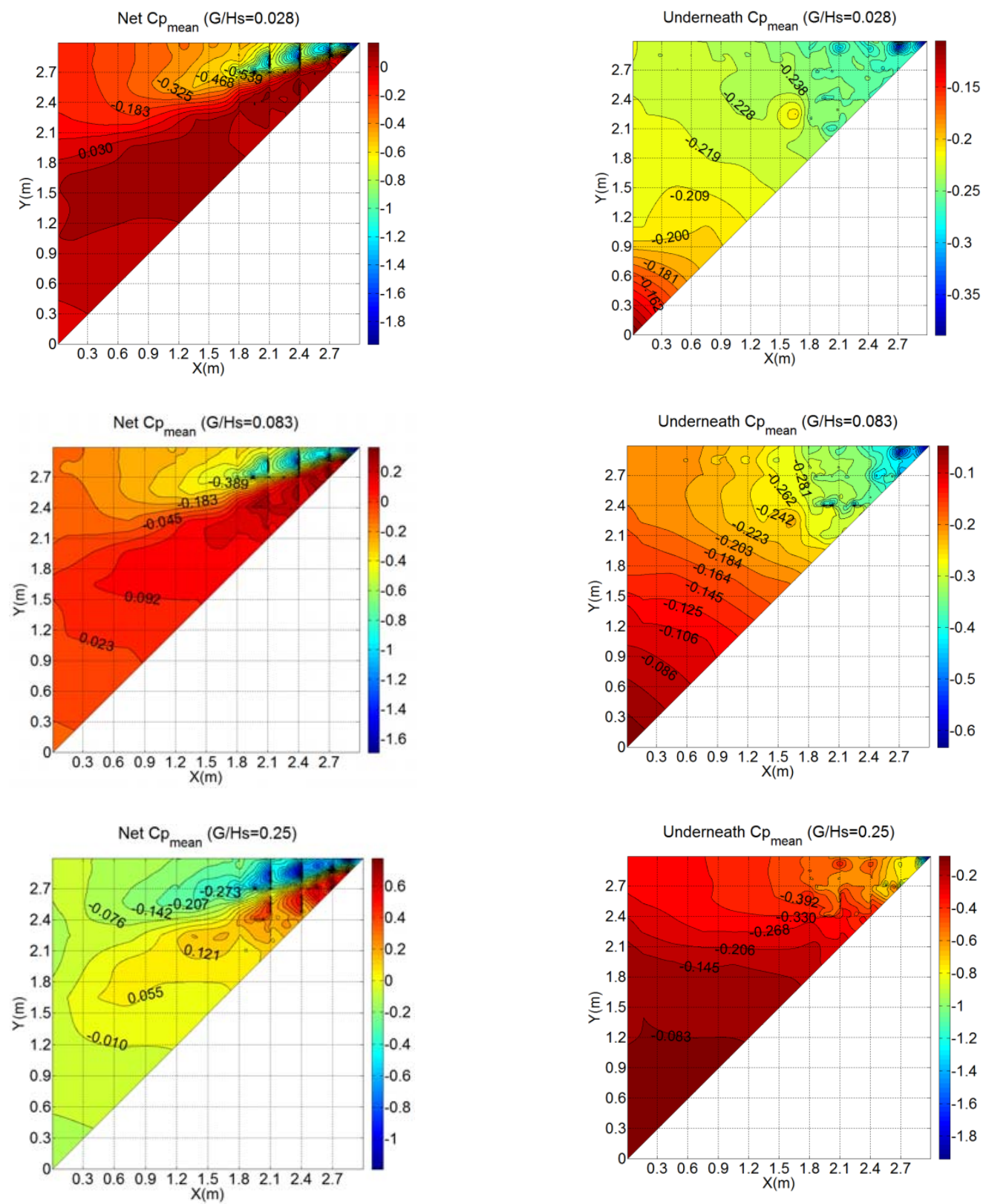

Figure 16. Underneath $\mathrm{Cp}_{\text {mean }}$ and net $C \mathrm{p}_{\text {mean }}\left(\mathrm{h}_{\mathrm{p}} / \mathrm{H}=0.05\right)$

It can be seen in Fig.16 that in these cases also pavers close to the edges and corners of the roof are subjected to the highest negative pressures which is mainly due to the wind-induced conical vortices. Compared to external pressures, the values of underneath pressures acting on the lower surfaces of the pavers are low in magnitude and 
exhibit more uniformity. For lower $\mathrm{G} / \mathrm{H}_{\mathrm{s}}$ ratios (larger height spacers), the underneath pressure becomes nearly uniform, probably due to the lower flow resistance underneath the pavers. As concluded by Bienkiewicz and Endo (2009), the $\mathrm{G} / \mathrm{H}_{\mathrm{s}}$ ratio affects the underside pressures such that the higher the ratio, the less the net pressure on the pavers. Figure 17 clearly shows that increasing the $\mathrm{G} / \mathrm{H}_{\mathrm{s}}$ ratio results in higher suctions underneath the pavers.

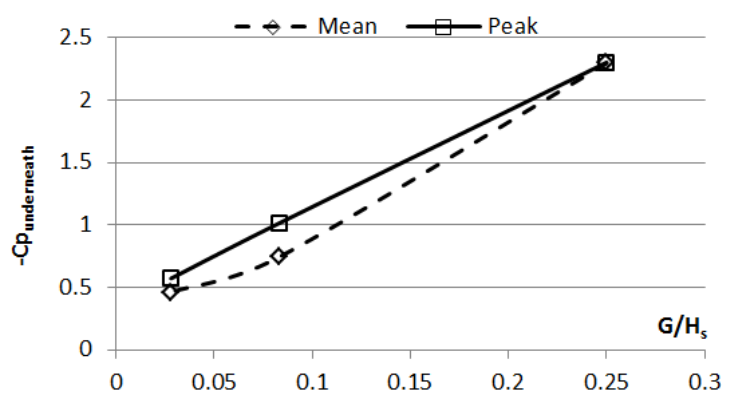

Figure 17. Highest underneath $\mathrm{Cp}\left(\mathrm{h}_{\mathrm{p}} / \mathrm{H}=0.05\right)$

Figure 18 shows the variation of the net uplift force coefficient and the net pitching moment coefficient on paver 21 with $\mathrm{G} / \mathrm{H}_{\mathrm{s}}$. The results show that increasing $\mathrm{G} / \mathrm{H}_{\mathrm{s}}$ ratio reduces the net uplift force coefficient on the paver but the pitching moment is less sensitive to this parameter.

(a)

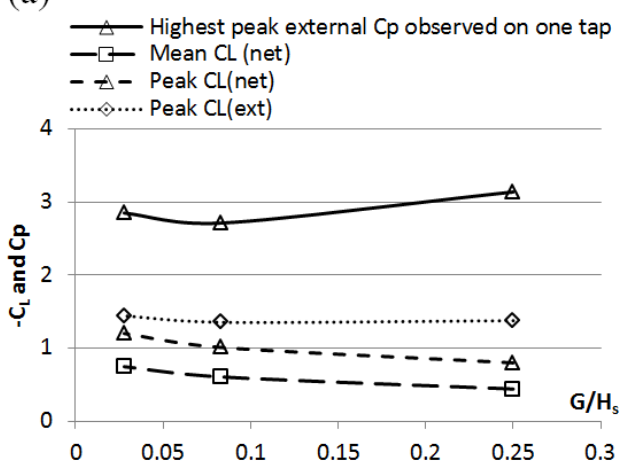

(b)

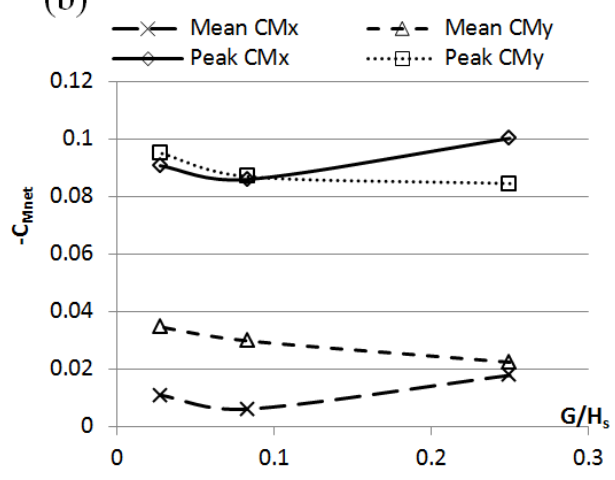

Figure 18. Variation of: (a) $C_{\text {Lnet }}$ and (b) $C_{\text {Mnet }}$ on Paver 21 with $\mathrm{G} / \mathrm{H}_{\mathrm{s}}\left(\mathrm{h}_{\mathrm{p}} / \mathrm{H}=0.05\right)$ 
The variation of the location of the point of action of the net uplift force with $\mathrm{G} / \mathrm{H}_{\mathrm{s}}$ ratio is plotted in Fig. 19. For higher $\mathrm{G} / \mathrm{H}_{\mathrm{s}}$ ratios, the point of action of the lift force is more offset from the center of the paver. Comparing the results presented in Fig 18. and Fig. 19 shows that even though by increasing the $\mathrm{G} / \mathrm{H}_{\mathrm{s}}$ ratio the lift force is more offset from the center of the paver, nonetheless it's value decreases in such a way that an overall better wind performance is observed for higher $\mathrm{G} / \mathrm{H}_{\mathrm{s}}$ ratio.

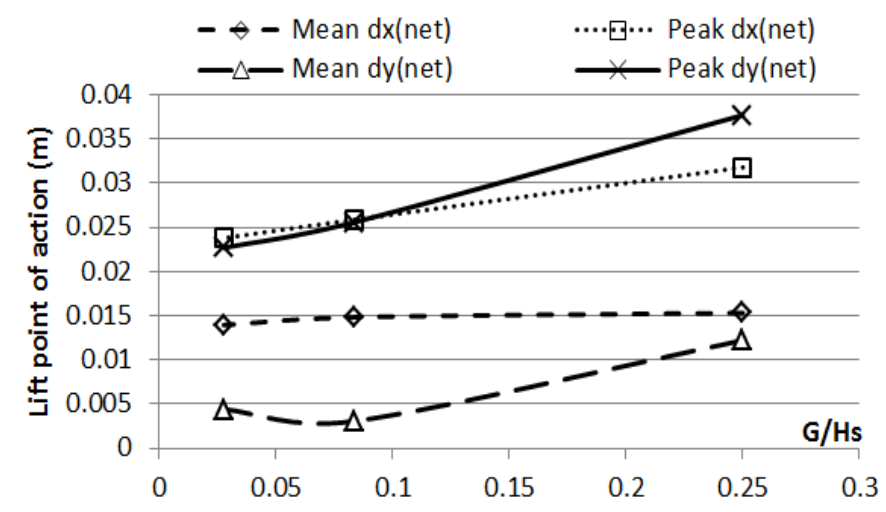

Figure 19. Variation of $\mathrm{L}_{\text {net }}$ point of action on Paver 21 with $\mathrm{G} / \mathrm{H}_{\mathrm{s}}\left(\mathrm{h}_{\mathrm{p}} / \mathrm{H}=0.05\right)$

\subsubsection{Effect of Pressure Tap Resolution on Aerodynamic Lift and Moment Results}

Figure 20 shows the external mean pressure distribution on pavers 1, 11, 21 and 31 and the line indicating the path of the corner vortex. It is noteworthy that the highest suctions are observed at the upwind edge of each paver. It is hypothesized that this is due to the interaction of the high velocity rotating flow caused by the corner vortex with a vertical flow coming out of the upwind end of the paver. Wind lift-off tests showed that paver 1 was wobbling but didn't fail, whereas paver 21 failed (corresponding to Wind Uplift 2 in Table 2). Results showed that the magnitude of the mean and peak uplift coefficients for paver 21 (mean $C_{\text {Lnet }}=-0.6$, peak $C_{\text {Lnet }}=-1.0$ ) were higher than those for paver 1 (mean $C_{\text {Lnet }}=-0.25$, peak $C_{\text {Lnet }}=-0.76$ ). This was because the size of the 
high suction zone relative to the paver size was bigger for paver 21 than for paver 1 (Fig. 20).The aerodynamic mechanisms that cause uplift are quite complex, involving significant interaction between the external flow and the internal flow into and out of the gaps between pavers. This interaction can increase the offset of the lift force from the center of the paver. As pointed out by Gerhardt et al (1990), the impact of vortices on pavers significantly depends on the size of the paver relative to the width of the corner vortex. If the paver is much larger than the width of the vortex then the impact is reduced since only a small fraction of the paver area is affected by the high suction. Also, if the paver is much smaller than the width of the vortex then, even if it is sitting in a high suction zone, the pressure equalization effect of the gaps at its edges substantially reduces the difference in pressure between top and bottom surfaces. However, if the paver and vortex widths are similar the net uplift will tend to be at a maximum.

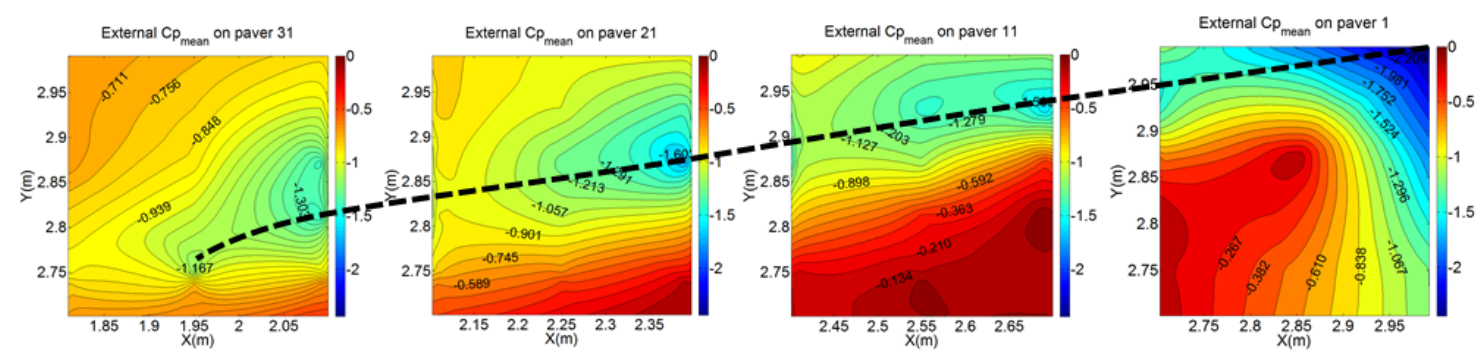

Figure 20. External $\mathrm{C} p_{\text {mean }}$ on critical pavers $\left(\mathrm{G} / \mathrm{H}_{\mathrm{s}}=0.083, \mathrm{~h}_{\mathrm{p}} / \mathrm{H}=0.05\right)$

Banks et al (2000) proposed an empirical equation valid for incident wind angle of $\omega=30^{\circ}-70^{\circ}$ to calculate the vortex core angle: $\varphi_{c}=2.94 e^{0.0297 \omega}$ (Fig. 21). The vortex core angle measured during experiments for $\mathrm{G} / \mathrm{H}_{\mathrm{s}}=0.083 ; \mathrm{h}_{\mathrm{p}} / \mathrm{H}=0.05$ case was $11.31^{\circ}$ which was in a very good agreement with the results obtained from $\varphi_{c}=$ $2.94 e^{0.0297 \times 45^{\circ}}=11.2^{\circ}($ Banks et al, 2000). 


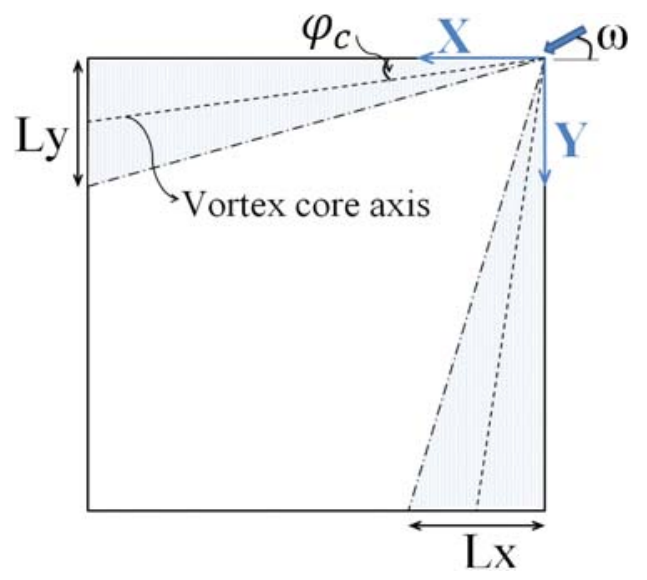

Figure 21. Defining vortex core angle

Figure 22 shows the contour plot for the $\mathrm{h}_{\mathrm{p}} / \mathrm{H}=0.05$ and $\mathrm{G} / \mathrm{H}_{\mathrm{s}}=0.25$ case in which the same pressure tap layouts as for pavers 2,3 , and 4 were considered for paver 11,21 , and 31. This results in loss of detail and the resulting pressure patterns resemble some of the earlier patterns obtained by other workers (Kind and Wardlaw, 1982) who had less density of taps available to them at the time of their experiments. It appears that a fairly high density of taps is required to capture all the detailed aerodynamic effects.
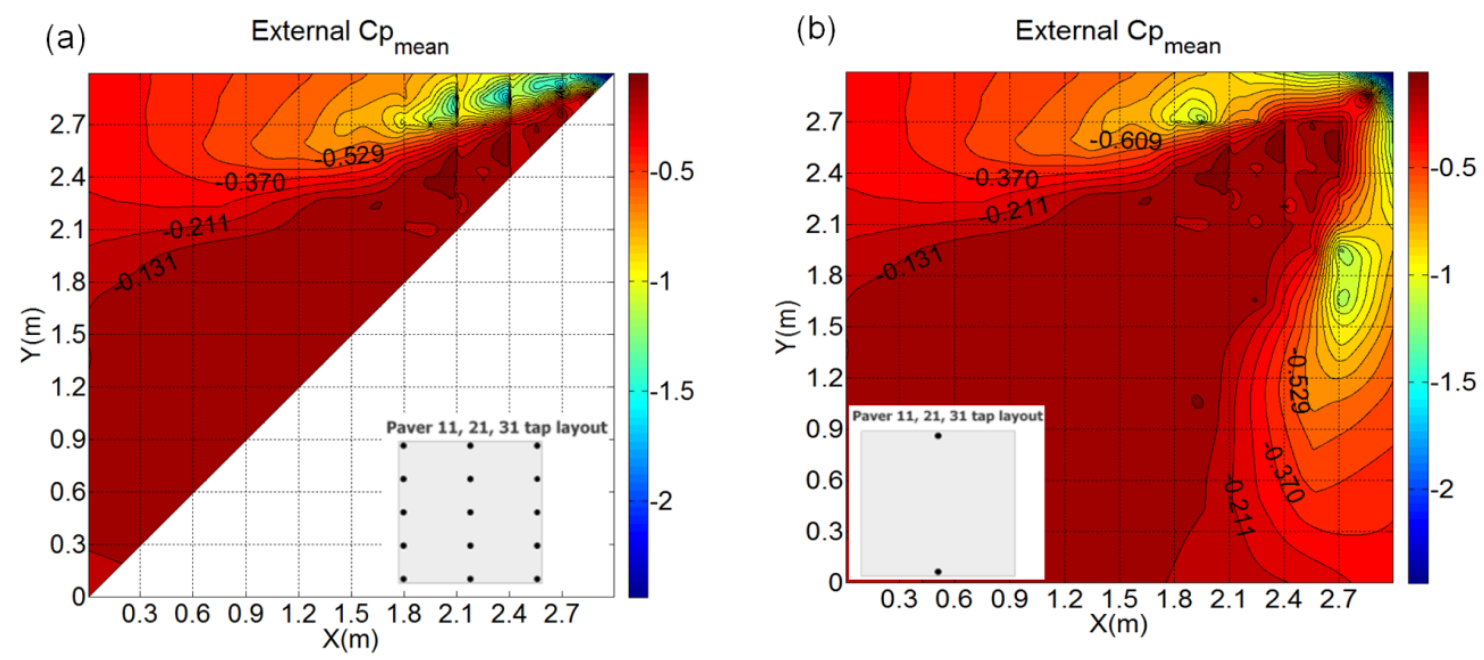

Figure 22. External $\mathrm{Cp}_{\text {mean }}$ : (a) High density of pressure taps, (b) Low density of pressure taps $\left(\mathrm{h}_{\mathrm{p}} / \mathrm{H}=0.05, \mathrm{G} / \mathrm{H}_{\mathrm{s}}=0.25\right)$ 
In order to find the effect of the tap arrangement and required resolution for pressure taps on the critical pavers, six different tap layouts were evaluated, the results of which are plotted in Fig. 23. The results show that having the pressure taps near the edges, especially those edges which are perpendicular to the parapet, is quite necessary for capturing an accurate measurement of high suctions.

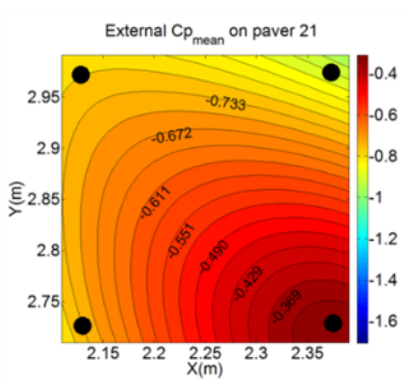

(a)

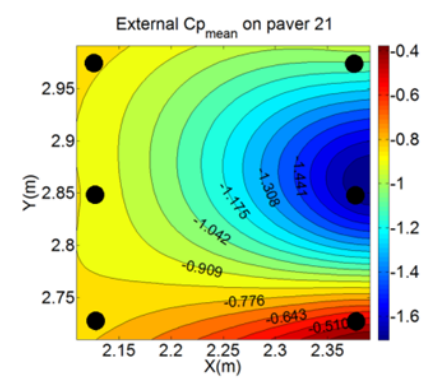

(d)

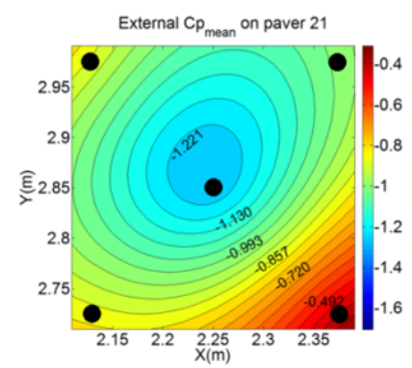

(b)

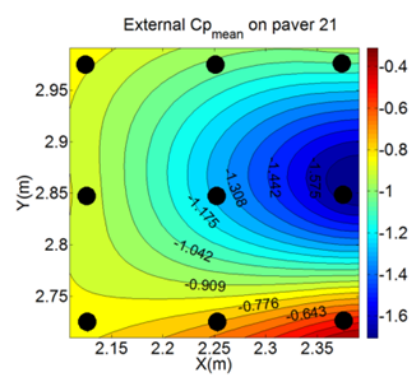

(e)

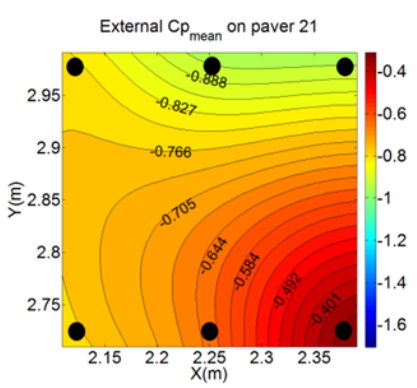

(c)

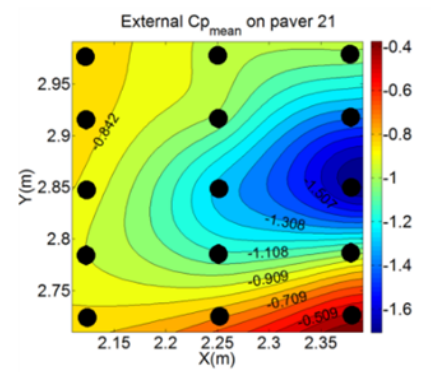

(f)

Figure 23. Effect of pressure tap layout on external $\mathrm{Cp}_{\text {mean }}\left(\mathrm{h}_{\mathrm{p}} / \mathrm{H}=0.05\right.$ and $\left.\mathrm{G} / \mathrm{H}_{\mathrm{s}}=0.25\right)$

Figure 24 and Fig. 25 show the net uplift force and net moment coefficients on paver 21 for different tap layouts defined in Fig. 23.

The results demonstrate that the net uplift force coefficient and net moment coefficient are sensitive to the resolution and arrangement of the pressure taps. Figures 24 and 25 also show there might be significant differences in the calculated lift and overturning moment obtained from a particular layout. Case (f) shows the tap layout used 
in this study on critical pavers with 30 pressure taps (15 taps on top and 15 taps on bottom). The results show that inaccuracies can occur when having low resolution of pressure taps. High suction areas can be missed as is the case of Tap layout a, or lift can be can be overestimated as such as for Tap Layout $\mathrm{d}$. The latter is mainly because one of the taps captured a local very high suction on the paver which was then integrated over too large an area. The results of this study show that to obtain accurate measurements of aerodynamic lift and moment a high density of taps is needed, higher than typically used in the past. If the analysis requires higher degrees of accuracy, it is recommended that additional pressure taps be added evenly on lines perpendicular to the corresponding building edge. Of course vortices do not only occur at roof corners but can also occur at setbacks and next to roof obstructions, and similar detailed pressure patterns can be expected at these discontinuities in building geometry.

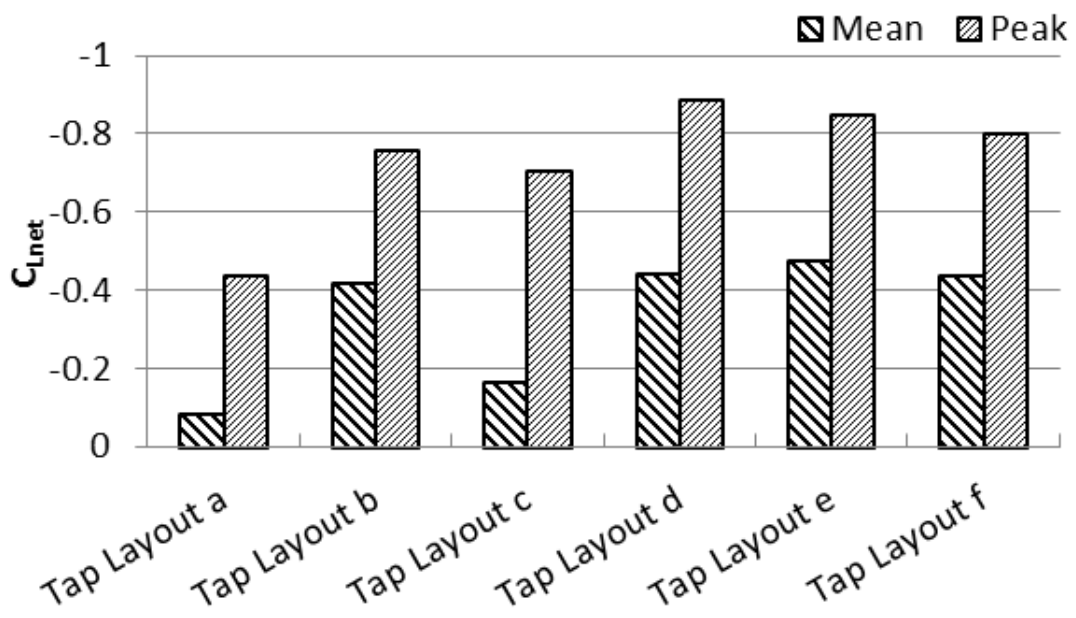

Figure 24. $C_{\text {Lnet }}$ for different pressure tap layouts $\left(\mathrm{h}_{\mathrm{p}} / \mathrm{H}=0.05 ; \mathrm{G} / \mathrm{H}_{\mathrm{s}}=0.25\right)$ 

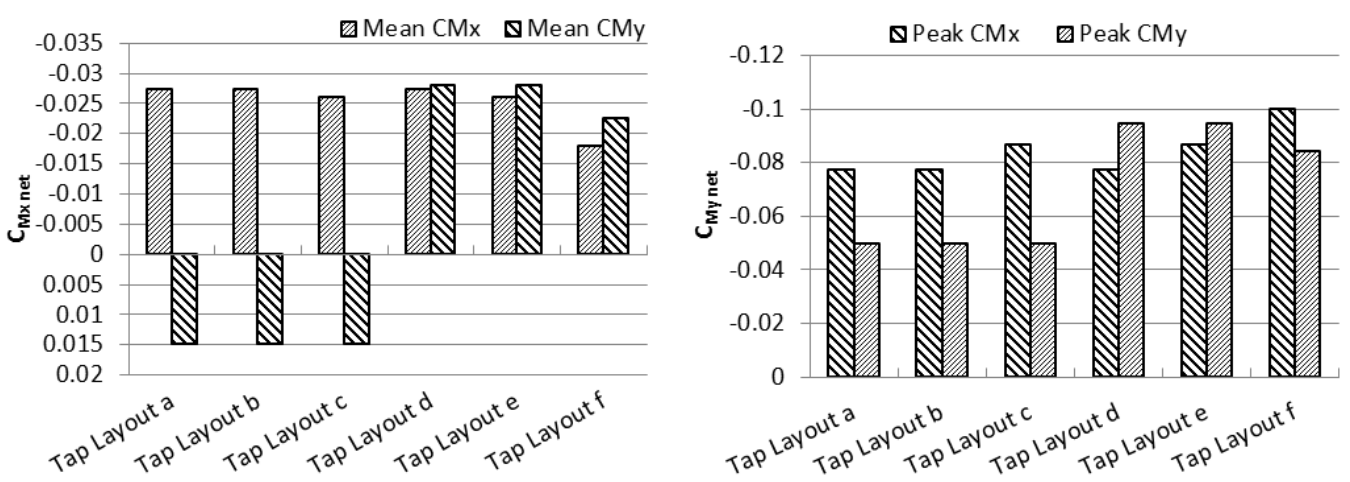

Figure 25. $C_{\text {Mnet }}$ for different pressure tap layouts $\left(\mathrm{h}_{\mathrm{p}} / \mathrm{H}=0.05 ; \mathrm{G} / \mathrm{H}_{\mathrm{s}}=0.25\right)$

\subsubsection{Comparison with wind blow-off tests and practice based on ASCE 7-10 exterior}

pressures

The highest external single tap pressure coefficients and the external area averaged pressure coefficient $\left(C_{\text {Lext }}\right)$ observed on the most critical paver (paver 21) obtained for different cases (Table 1) were also compared to component and cladding external pressure coefficients for roofs as given in ASCE 7-10 (2010). Chapter 30 of ASCE 7-10 provides the peak pressure coefficients for components and claddings. For gable roofs with slope $\theta \leq 7^{\circ}$ the peak external pressure coefficient for corner Zone 3 for tributary areas less than $0.9 \mathrm{~m}^{2}$ is given as -2.8 in Fig. 30.4-2A (ASCE 7-10, 2010). The highest single tap peak suction coefficients observed in the present tests for all cases ranged from -4.1682 for $h_{p} / H=0.033$ and $G / H_{s}=0.083$ to -3.5486 for $h_{p} / H=0.15$ and $\mathrm{G} / \mathrm{H}_{\mathrm{s}}=0.083$ in the corner zone. Being single tap values, they correspond to much smaller tributary area than $0.9 \mathrm{~m}^{2}$ and so would be expected to be somewhat higher in magnitude than the ASCE 7 value. The highest peak external lift coefficients ranged from -1.44 for $h_{p} / H=0.05$ and $\mathrm{G} / \mathrm{H}_{\mathrm{s}}=0.028$ to -1.26 for $\mathrm{h}_{\mathrm{p}} / \mathrm{H}=0.15$ and $\mathrm{G} / \mathrm{H}_{\mathrm{s}}=0.083$. The underneath pressure coefficients required for calculating the net pressure coefficients are not dealt 
with in ASCE 7-10. One informal practice is to assume the underneath pressure coefficient to be zero (FPHLM study on tiles, 2005, Volume II, p. 55) and that the net uplift force acts on the center of the paver.

In order to see the overall effect of high local $\mathrm{Cp}$ values on the failure wind speeds, the critical wind blow-off speeds were calculated from the pressure measurements using Eq. (9) and compared to those obtained from the wind blow-off tests (Table 4) and the wind blow-off speeds calculated from a typical informal practice based on ASCE 7-10 exterior pressures (i.e. using the ASCE 7-10 external pressure coefficients, taking the effective internal pressure as zero and simply assuming that the net uplift acts at the paver's center). Results calculated from pressure measurements are calculated for Paver 21 which was shown to be one of the most critical in all three cases. The values recorded for the wind blow-off tests correspond to the case where both wobbling of pavers and first failure was observed. For the practice based on ASCE 7-10 exterior pressures, wind blow-off speed values are calculated using $\mathrm{GCp}=-2.8$ (external pressure coefficient in Zone 3 for $A_{\text {eff }}=0.09 \mathrm{~m}^{2} \leq 0.9 \mathrm{~m}^{2}$ ).

Results show that quite good agreement exists between the results from wind blow-off tests and those obtained from mean $\mathrm{C}_{\text {Lnet }}$ values. This means that although high peak suctions were observed on critical pavers, which can cause instantaneous wobbling, the fluctuations did not last long enough to actually cause lift off. The best agreement between the blow tests and the pressure measurements would be obtained by calculating the lift based on the mean coefficient plus a small contribution from the fluctuations. The critical wind blow-off value calculated using ASCE 7-10 exterior pressures is clearly conservative in comparison to the current experiments. 
Table 4. Critical wind blow-off speed

\begin{tabular}{|c|c|c|c|}
\hline \multirow{4}{*}{ Test Case } & \multicolumn{3}{|c|}{ Critical wind blow-off speed $(\mathrm{m} / \mathrm{s})$} \\
\hline & \multirow{2}{*}{$\begin{array}{c}\text { Practice based on } \\
\text { ASCE 7-10 exterior } \\
\text { pressures }\end{array}$} & \multirow{3}{*}{$\begin{array}{l}\text { Wind } \\
\text { blow-off } \\
\text { tests }\end{array}$} & Pressure Measurement tests \\
\hline & & & $\left(\mathrm{U}_{\mathrm{CRIT}}=\sqrt{\frac{\mathrm{a}}{2\left(\mathrm{~d}+\frac{\mathrm{a}}{2}\right)} \times \frac{\mathrm{W}}{\frac{1}{2} \mathrm{C}_{\mathrm{L}(\text { mean or peak })} \mathrm{A}}}\right)$ \\
\hline & $\left(\mathrm{U}_{\mathrm{CRIT}}=\sqrt{\frac{\mathrm{W}}{\frac{1}{2} \rho \mathrm{p}_{\mathrm{ext}_{\mathrm{t}} \mathrm{A}}}}\right)$ & & Based on Mean $C_{\text {Lnet }}$ Based on Peak $C_{\text {Lnet }}$ \\
\hline $\mathrm{G} / \mathrm{H}_{\mathrm{s}}=\mathbf{0 . 2 5}$ & \multirow{3}{*}{17.6} & 37.2 & 29.14 \\
\hline$G / H_{s}=0.083$ & & 35.7 & 35.72 \\
\hline $\mathrm{G} / \mathrm{H}_{\mathrm{s}}=\mathbf{0 . 0 2 8}$ & & 30.7 & 32.24 \\
\hline
\end{tabular}

$* 22(\mathrm{~m} / \mathrm{s})$ for $\mathrm{GCp}=-1.8$ (external pressure coefficient in Zone 2 for $\left.\mathrm{A}_{\text {eff }}=0.09 \mathrm{~m}^{2} \leq 0.93 \mathrm{~m}^{2}\right)$

Table 5 shows equalization factors, as defined by Geurts (2000), for different $\mathrm{G} / \mathrm{H}_{\mathrm{s}}$ ratios for the critical paver 21 . A value of 0.6 was proposed by Geurts based on fullscale pressure measurements. Comparison between the results shows the present values ranging around 0.6. The results presented in Geurts (2000) were for a single $\mathrm{G} / \mathrm{H}_{\mathrm{s}}$ ratio. The present results indicate the value 0.6 may underestimate the ratio on pavers with low $\mathrm{G} / \mathrm{H}_{\mathrm{s}}$ ratios. The results presented in this paper are for 45 degree cornering winds only which is the most critical for paver lift-off on a flat roof. The equalization factor may well be a function of wind direction and Geurts' results covered various wind directions. For the purposes of codification the concept of an equalization factor is useful but it needs also to take account of the results in Table 4. These results show that the best correlation with observed blow off speeds is obtained using the mean $\mathrm{C}_{\mathrm{Lnet}}$, not the peak $\mathrm{C}_{\text {Lnet }}$. It appears that most of the fluctuations in $\mathrm{C}_{\mathrm{Lnet}}$ do not last long enough to disturb the paver. Therefore a more meaningful factor for codification purposes is likely to be the ratio of mean $\mathrm{C}_{\mathrm{Lnet}}$ (or perhaps mean plus a small contribution from fluctuations) to the peak $\mathrm{Cp}$ that is provided in codes for cladding design. Future work is in progress to explore this aspect in more detail, as well as the effects of building geometry, paver size, $\mathrm{G} / \mathrm{H}_{\mathrm{s}}$ ratio and $\mathrm{h}_{\mathrm{p}} / \mathrm{H}$. 
Table 5. Equalization factor based on $\mathrm{G} / \mathrm{H}_{\mathrm{s}}$

\begin{tabular}{lccc}
\hline \multirow{2}{*}{$/ \mathbf{H}_{\mathbf{s}}$} & Mean $\boldsymbol{C}_{\text {Lnet }}$ & $\frac{\text { Peak } \boldsymbol{C}_{\text {Lnet }}}{\text { Peak } \boldsymbol{C}_{\text {Lext }}}$ & Geurts (2000) $\frac{\boldsymbol{C} \boldsymbol{p}_{\text {net }}}{\boldsymbol{C} \boldsymbol{p}_{\text {ext }}}$ \\
\hline $\mathbf{0 . 2 5}$ & 0.49 & 0.58 & 0.6 \\
$\mathbf{0 . 0 8 3}$ & 0.68 & 0.75 & 0.6 \\
$\mathbf{0 . 0 2 8}$ & 0.77 & 0.83 & \\
\hline
\end{tabular}

\subsection{Conclusions and Future Work}

The wind loading mechanism of concrete roof pavers was investigated in this project. Wind blow-off tests and pressure measurements were carried out on a square portion of a flat roof for the critical wind direction that generates corner vortices. The experiments were performed in the Wall of Wind, at FIU. The influence of an edge parapet on net uplift pressures was also explored. Increasing the pavers' edge-gap to spacer height ratio improves the system behavior. A certain relative parapet height in the range $h_{p} / H=0.10$ to 0.15 exists in which the uplift loads reach worst case values. The results demonstrated that the net uplift force and moment coefficients are sensitive to the resolution and layout of the pressure taps. The location and spacing of pressure taps needed to accurately resolve the uplift pressures was investigated. A larger number of taps than typically used in the past was found to be needed. Based on the information gathered in the current tests and review of literature, guidelines suitable for codes and standards are being developed for the design of roof pavers. These guidelines will need to incorporate appropriate factors of safety in order to achieve the normal levels of reliability used in the design of building envelopes. Similar phenomena observed for the roof pavers affect roof tiles and shingles, further complicated by the profiles of the particular tile and shingle systems used. The large-scale testing methods used in the present investigation are also applicable to these other roofing systems and provide new 
insights through accurately reproducing critical aerodynamic effects at full scale, or close to full scale Reynolds numbers.

\subsection{Acknowledgments}

We would like to greatly appreciate the Tile Tech Company for providing us with concrete roof pavers and the pedestal system required for the wind blow-off tests. This research was supported by the Florida Division of Emergency Management (DEM) and the National Science Foundation (NSF) (NSF Award No. CMMI-1151003) through the 12-fan Wall of Wind flow simulation and large-scale testing of roof pavers. The help offered by the Wall of Wind manager, Walter Conklin and the Research scientists, Roy Liu Marquis and James Erwin is greatly acknowledged. We would also like to acknowledge the great help received from the graduate research assistant, Ramtin Kargarmoakhar.

\subsection{References}

Amano, T., Fujii, K., Tazaki, S., 1988. Wind loads on permeable roof-blocks in roof insulation systems. Journal of Wind Engineering \& Industrial Aerodynamics 29, 39-48.

AS 1170.2, 2011. Australian/New Zealand standard: structural design actions, Part 2: wind actions, Standards Australia/Standards New Zealand, Sydney, Australia.

ASCE 7-10, 2010. Minimum Design Loads for Buildings and Other Structures, American Society of Civil Engineers, ASCE, Virginia.

Banks, D., 2011. Measuring peak wind loads on solar power assemblies, in: Proceedings of the The 13th International Conference on Wind Engineering.

Banks, D., Meroney, R.N., Sarkar, P.P., Zhao, Z., Wu, F., 2000. Flow visualization of conical vortices on flat roofs with simultaneous surface pressure measurement. Journal of Wind Engineering and Industrial Aerodynamics 84, 65-85.

Bienkiewicz, B., Endo, M., 2009. Wind considerations for loose-laid and photovoltaic roofing systems, Structures Congress, Austin, Texas, pp. 2578-2587. 
Bienkiewicz, B., Meroney, R.N., 1988. Wind effects on roof ballast pavers. Journal of engineering structures 114, 1250-1267.

Bienkiewicz, B., Sun, Y., 1992. Wind-tunnel study of wind loading on loose-laid roofing system. Journal of wind engineering and industrial aerodynamics 43, 1817-1828.

Bofah, K.K., Gerhardt, H.J., Kramer, C., 1996. Calculations of pressure equilibration underneath loose-laid, flow permeable roof insulation boards. Journal of wind engineering and industrial aerodynamics 59, 23-37.

Cheung, J.C.K., Melbourne, W.H., 1986. Wind loads on porous cladding, 9th Australasian Fluid Mechanics conference, Auckland, pp. 308-311.

Cheung, J.C.K., Melbourne, W.H., 1988. Wind Loading on a Porous Roof. Journal of wind engineering and industrial aerodynamics $29,19-28$.

DEUTSCHE NORM, 2001-03. DIN 1055-4, Einwirkungen auf Tragwerke, Teil 4: Windlasten.

Fu, T.-C., 2013. Development of effective approaches to the large-scale aerodynamic testing of low-rise building, FIU Electronic Theses and Dissertations. Paper 986.

Fu, T.-C., Aly, A.M., Chowdhury, A., Bitsuamlak, G., Yeo, D.H., Simiu, E., 2012a. A proposed technique for determining aerodynamic pressures on residential homes. Wind and Structures 15, 27-41.

Fu, T.-C., Aly, A.M., Chowdhury, A.G., Bitsuamlak, G., Yeo, D., Simiu, E., 2012b. A proposed technique for determining aerodynamic pressures on residential homes. Wind and Structures 15, 27-41.

Gerhardt, H.J., Janser, F., 1995. Windbelastung belufteter Fassadensysteme. Bauingenieur 70, 193-201.

Gerhardt, H.J., Kramer, C., Bofah, K.K., 1990. Wind loading on loosely laid pavers and insulation boards for flat roofs. Journal of wind engineering and industrial aerodynamics 36, Part 1, 309-318.

Geurts, C.P.W., 2000. Wind loads on permeable roof covering products, Fourth Colloquium on Bluff Body Aerodynamics and Applications, Ruhr Universität Bochum, pp. 511-514.

Ho, T.C.E., Surry, D., Morrish, D., Kopp, G.A., 2005. The UWO contribution to the NIST aerodynamic database for wind loads on low buildings: Part 1. Archiving format and basic aerodynamic data. Journal of wind engineering and industrial aerodynamics 93 , $1-30$.

Holmes, J.D., 2007. Wind Loading of Structures. Taylor \& Francis. 
Irwin, P., 2009. Wind engineering research needs, building codes and project specific studies, in: Proceedings of the 11th Americas Conference on Wind Engineering.

Irwin, P., Cooper, K., Girard, R., 1979. Correction of distortion effects caused by tubing systems in measurements of fluctuating pressures. Journal of Wind Engineering and Industrial Aerodynamics 5, 93-107.

Katsuchi, H., Yamada, H., 2011. Study on turbulence partial simulation for wind-tunnel testing if bridge deck, 12th International Conference on Web Engineering ICWE 2012, Amsterdam, Netherlands.

Kind, R.J., 1988. Worst suctions near edges of the flat roof tops with parapets. Journal of wind engineering and industrial aerodynamics 31, 251-264.

Kind, R.J., 1994. Predicting pressure distribution underneath loose laid roof cladding systems. Journal of Wind Engineering and Industrial Aerodynamics 51, 371-379.

Kind, R.J., Wardlaw, R.L., 1982. Failure mechanisms of loose laid roof insulation systems. Journal of wind engineering and industrial aerodynamics 9, 325-341.

Kopp, G.A., Banks, D., 2013. Use of the wind tunnel test method for obtaining design wind loads on roof-mounted solar arrays. Journal of structural engineering 139, 284-287.

Kopp, G.A., Surry, D., Mans, C., 2005. Wind effects of parapets on low buildings: Part 1. Basic aerodynamics and local loads. Journal of wind engineering and industrial aerodynamics $93,817-841$.

Kramer, C., Gerhardt, H.J., 1983. Wind loads on permeable roofing systems. Journal of Wind Engineering and Industrial Aerodynamics 13, 347-358.

Kumar, K.S., Stathopoulos, T., 1998. Spectral density functions of wind pressures on various low building roof geometries. Wind and Structures 1, 203-223.

Lin, J.X., Surry, D., 1998. The variation of peak loads with tributary area near corners on flat low building roofs. Journal of wind engineering and industrial aerodynamics $77-78$, 185-196.

Lin, J.X., Surry, D., Tieleman, H.W., 1995. The distribution of pressure near roof corners of flat roof low buildings. Journal of Wind Engineering and Industrial Aerodynamics 56, $235-265$.

Melbourne, W.H., 1980. Turbulence effects on maximum surface pressures - a mechanism and possibility of reduction. Wind Engineering, 541-551.

NBCC, 1995. User's Guide-NBC 1995, Structural Commentaries (Part 4), National Research Council of Canada, Ottawa, Canada. 
NEN EN 1991-1-4/NA, Eurocode: Actions on structures - General actions - Part 1.4: Wind actions.

Pierre, L.M.S., Kopp, G.A., Surry, D., Ho, T.C.E., 2005. The UWO contribution to the NIST aerodynamic database for wind loads on low buildings: Part 2. Comparison of data with wind load provisions. Journal of wind engineering and industrial aerodynamics 93, 31-59.

Richards, P.J., Hoxey, R.P., Connell, B.D., Lander, D.P., 2007. Wind-tunnel modelling of the Silsoe Cube. Journal of wind engineering and industrial aerodynamics 95, 1384-1399.

Saathoff, P.J., Melbourne, W.H., 1997. Effects of free-stream turbulence on surface pressure fluctuation in a separation bubble. Journal Of Fluid Mechanics 337, 1-24.

Sadek, F., Simiu, E., 2002. Peak non-Gaussian wind effects for database-assisted lowrise building design. Journal of engineering Mechanics 128, 530-539.

Smith, T., McDonnald, J., 1991. Roof wind damage mitigation: Lessons from Hugo. American Society of Civil Engineers, New York.

Stathopoulos, T., 1982. Wind pressure on low buildings with parapets. Journal of the Structural Division 108, 2723-2736.

Stathopoulos, T., Baskaran, A., 1987. Wind pressures on flat roofs with parapets. Journal of structural engineering 113, 2166-2180.

Stathopoulos, T., Baskaran, A., 1988. Turbulent wind loading on roofs with parapet configurations. Canadian Journal of Civil Engineering 29, 570-578.

Sun, Y., Bienkiewicz, B., 1993. Numerical simulation of pressure distributions underneath roofing paver systems. Journal of wind engineering and industrial aerodynamics 46-47, 517-526.

Tieleman, H.W., 2003. Wind tunnel simulation of wind loading on low-rise structures: a review. Journal of wind engineering and industrial aerodynamics 91, 1627-1649.

Trung, V., Tamura, Y., Yoshida, A., 2009. Study on wind loading on porous roof cover sheets on a low-rise building: effects of parapet height and underneath volume, 11th Americas Conference on Wind Engineering, San Juan, Puerto Rico.

Trung, V., Tamura, Y., Yoshida, A., 2010. Numerical computation for lower surface pressures on a porous sunshade roof cover sheet, Fifth International Symposium on Computational Wind Engineering (CWE2010), Chapel Hill, North Carolina, USA.

Yamada, H., Katsuchi, H., 2008. Wind-tunnel study on effects of small-scale turbulence on flow patterns around rectangular cylinder, 4th International Colloquium on Bluff Bodies Aerodynamics \& Applications, Italy. 
Yeo, D., Chowdhury, A.G., 2013. Simplified wind flow model for the estimation of Aerodynamic effects on small structures. Journal of Engineering Mechanics 139, 367375. 


\section{CHAPTER V}

TOWARDS GUIDELINES FOR DESIGN OF LOOSE-LAID ROOF PAVERS FOR WIND UPLIFT

(A paper to be submitted to the journal of Wind and Structures) 


\title{
CHAPTER V
}

\section{TOWARDS GUIDELINES FOR DESIGN OF LOOSE-LAID ROOF PAVERS FOR}

\section{WIND UPLIFT}

\author{
Maryam Asghari Mooneghi ${ }^{\mathrm{d}}$, Peter Irwin $^{\mathrm{b}},{ }^{*}$ Arindam Gan Chowdhury ${ }^{\mathrm{c}}$
}

\subsection{Abstract}

Hurricanes are among the most costly natural hazards to impact buildings in coastal regions. Building roofs are designed using the wind load provisions of building codes and standards and, in the case of large buildings, wind tunnel tests. Wind permeable roof claddings like roof pavers are not well dealt with in many existing building codes and standards. The objective of this paper is to develop simple guidance in code format for design of loose-laid roof pavers. Large-scale experiments were performed to investigate the wind loading on concrete roof pavers on the flat roof of a low-rise building in Wall of Wind, a large-scale hurricane testing facility at Florida International University. They included wind blow-off tests and pressure measurements on the top and bottom surfaces of pavers. Based on the experimental results simplified guidelines have been developed for design of loose-laid roof pavers against wind uplift. The guidelines have been formatted so that use can be made of the existing information in codes and standards such as ASCE 7-10 pressure coefficients for components and

\footnotetext{
${ }^{\mathrm{d}} \mathrm{PhD}$ candidate, Civil and Environmental Engineering/International Hurricane Research Center, Florida International University, Miami, FL, USA, masgh002@,fiu.edu

${ }^{\mathrm{b}}$ Professor of Practice, Civil and Environmental Engineering/International Hurricane Research Center, Florida International University, Miami, FL, USA, peairwi@,fiu.edu

${ }^{c}$ Corresponding Author. Associate Professor, chowdhur@fiu.edu, Tel: (305) 348-0518
} 
cladding. The effects of pavers' edge-gap to spacer height ratio and parapet height as a ratio of building height are included in the guidelines as adjustment factors.

Keywords: Design guidelines; Roof pavers; Large-scale testing; Wind uplift

\subsection{Introduction}

It is clearly important that roofing materials be designed so that they can withstand the uplift forces that occur in strong winds. Some of the major losses that have occurred in hurricanes have been due to loss of roofing materials. Experience indicates that hurricane winds are well capable of ripping off materials such as tiles, shingles, roof pavers and gravel ballast. The building itself then becomes vulnerable to considerable additional damage through water infiltration and changes in internal pressure. As well, the wind-borne debris coming from the damaged roof often causes extensive additional damage to buildings downwind as it impacts them with high momentum.

Wind uplift of roof pavers is not only the result of the suction on their top surface, but also of the pressure on their underside for which no guidance is currently supplied in most wind codes. Therefore, for lack of better information, building designers will often make the simplifying assumption that the net uplift acting on a paver is the same as the exterior pressure specified in the building code. In reality a significant amount of pressure equalization occurs which tends to make this assumption quite conservative in many instances. On the other hand, the pressure equalization effect is subject to a number of influencing variables such as paver's location relative to a corner, paver size, parapet height, building height, gaps between pavers, and the stand-off distance of the pavers above the underlying roof surface. This has deterred the development of more specific guidance in codes. Interlocking and strapping systems are often used to improve the 
resistance of roof pavers, and they can be very effective. However failures do still occur and it will help in the design of such systems if better knowledge of the aerodynamic forces working on the pavers can be obtained.

The aerodynamic mechanisms that cause uplift are quite complex but in this paper guidance is developed in the form of relatively simple rules for the design of loose-laid roof pavers against uplift wind forces, rules that are amenable to use alongside or within building codes. A set of large-scale experiments was performed to study the wind loading mechanism of concrete roof pavers using the Wall of Wind (WOW) facility at Florida International University (FIU). Square concrete pavers, with $0.305 \mathrm{~m}$ side length and 2.5 $\mathrm{cm}$ thickness, were installed on a square portion of a flat roof of a low-rise building. These may be considered as $1 / 2$ scale models of typical $0.61 \mathrm{~m}$ square, $5.1 \mathrm{~cm}$ thick pavers. Both wind blow-off testing and pressure measurements were performed. The results are compared with estimates obtained from American Society of Civil Engineering (ASCE) 7-10 components and claddings exterior pressure coefficients. Guidelines are proposed for design of loose-laid roof pavers using ACSE 7-10 components and cladding exterior pressure coefficients taking into account the effects of different pavers' edge-gap to spacer height ratio, relative parapet height, and pressure equalization.

\subsection{Background}

Solid pavers are frequently used as ballast and walking surfaces on flat roofs and as decorative elements on terraces. It is necessary that they be capable of resisting uplift forces due to wind. A number of experimental and analytical studies are reported on wind loading and performance of loose laid roofing systems. The failure mechanisms were 
extensively studied by Kind and Wardlaw (1982) and a variety of wind tunnel experiments on small scale models have been performed by various researchers to investigate the wind loading of loose-laid roof paving system (Bienkiewicz and Sun, 1992, 1997; Irwin et al, 2012; Kind et al, 1987; Kind and Wardlaw, 1979). However, studies using full- and large-scale building models have been limited. Fu et al (2012) performed an experimental study to assess wind-induced pressures on full-scale loose concrete roof pavers using the 6-fan Wall of Wind, at FIU. Recently, Asghari Mooneghi et al (2014) performed a set of large scale experiments at 1:2 scale to investigate the wind loading mechanism of concrete roof pavers including wind blow-off tests and pressure measurements. The effect of the pavers' edge-gap to spacer height ratio and the parapet height as a fraction of building height were also explored. These studies demonstrated that the wind loading and failure mechanism of loose-laid roof pavers are of a complicated nature. However, several general conclusions can be drawn:

1. The paver's edge-gap to spacer height ratio affects the underside pressures such that the higher the ratio, the less the net uplift pressure on the paver. This may be regarded as increasing the failure wind speed (Asghari Mooneghi et al, 2014; Bienkiewicz and Sun, 1992, 1997).

2. The relative parapet height, defined as the ratio of the parapet height to the building height, affects the failure wind speed. For very low-heights parapets $\left(\sim \mathrm{h}_{\mathrm{p}} / \mathrm{H}<0.1\right)$, a reduction in the failure wind speed was observed as compared to zero-height parapet. However, for taller parapets, increasing the parapet height results in an increased failure wind speed (Asghari Mooneghi et al, 2014; Bienkiewicz and Sun, 1992; Kind, 1988; Kind et al, 1987). 
3. Increasing the level of turbulence in the approaching wind reduces the mean wind speed at failure (Bienkiewicz and Meroney, 1988).

4. Interlocking and strapping systems improve the wind performance of the roof pavers since the uplift loads tend to be shared across several pavers (Irwin et al, 2012; Kind et al, 1987)

The complex nature of the flows above and beneath such roofing systems have also been explored using numerical simulations. Amano et al (1988) proposed a simplified numerical model based on the unsteady Bernoulli equation with one value of pressure at each paver edge for obtaining the internal wind pressure distribution of roofing pavers under a known external pressure field. Correction terms were employed to take into account the effects of viscosity. The effect of gap between the pavers was also investigated. Kind et al (1988) proposed a correlation for predicting wind lift off speeds of loose laid insulation boards based on extensive wind tunnel testing results. The correlation accounts for the effects of building characteristics (low, intermediate or highrise building), parapet height, element weight per unit area and interlock effects. The tests of Kind et al (1988) were primarily for pavers laid directly on the roof with no spacers underneath. Gerhardt et al (1990) performed a set of experiments and calculations and developed an equation for calculating the failure wind speed based on the external pressure, the element size relative to smaller plan dimension of the building and the weight of the elements. Diagrams were provided to help choose the best possible solution when using these roofing systems. Sun and Bienkiewicz (1993) stated that the flows between and beneath the loose-laid pavers are very slow because of the boundary effects of the flow field, and should be treated as viscous. They employed Darcy's law to develop 
a numerical model for calculating the pressure distribution underneath roof pavers. In their model, the pressure distribution along paver edges was assumed piecewise linear. The experimental data and their numerical results show similar trends. This model was refined later to allow arbitrary pressure distribution along paver edges, and to take into account the interlock effects between pavers. This flow model is limited to the steady flow and was sufficient to estimate the mean pressure distribution for small stand-off distances between the roof surface and pavers and for low speeds of the flow, which means low Reynolds number. However, it may not be so applicable for a relatively high flow speed with high turbulence (Oh and Kopp, 2012). Kind (1994) proposed a numerical method based on Laplace's equation for predicting the underneath pressure distribution for loose laid roof pavers. It was assumed that inertia effects are negligible in the underelement flow and it was thought to be viscosity dominated. Also, the flow resistance in the element/roof deck interface plane was considered as uniform. With these assumptions the flow continuity equation reduces to the Laplace equation. The results were in reasonable agreement with measured pressure distributions in cases where the roof deck and the undersides of the elements were reasonably flat with uniform surface texture. The results are more likely to be applicable for pavers lying directly on the roof surface. Bofah et al (1996) proposed a theory for calculating the pressure distribution underneath roof pavers based on approximating the underneath flow by a two-dimensional laminar flow in a very shallow channel with a porous upper roof. Sinusoidal and uniform outer pressure distributions were investigated which were consistent with experimental results. Trung et al (2010) applied a method based on the Multiple Discharge Equations (MDE) as described in Oh et al (2007) to predict the underneath pressures of a porous sunshade 
roof cover from a known external pressure distribution. Computational results were compared with experiments performed on a 1:50 scale model of a low-rise building. The results of the computations were in good agreement with the experiments for $5 \%$ and $10 \%$ porosity ratios (ratio between the areas of orifices to the area of the sheet) and 4.7 $\mathrm{mm}$ height from the roof deck to the cover used in the experiments.

Previous experimental and numerical studies on the wind loading mechanism of loose-laid roofing systems like roof pavers, gravel ballast, green roofs, etc. have paved the way towards development of code specific models for design of such systems. However, many unanswered questions still remain in the current state of the art knowledge on this issue. For instance, there had been a number of studies to explain gravel scour action on ballasted roofs. For evaluating ballasted single-ply roof systems, the most detailed guidance referenced in the International Building Code (IBC) is ANSI/SPRI Standard RP-4 "Wind Design Standard for Ballasted Single-Ply Roofing Systems". A ballasted roof system is defined as one which is loose laid on the roof deck and is held in place by the weight of precast concrete pavers or stone aggregate. Based on the design wind speed, building height, parapet height, and exposure category, the designer can choose between three proposed systems or any other system which is demonstrated as equivalent. Pavers are placed mainly in the corner regions of the roof to increase the wind speed at which gravel scour begins to occur. Design tables in ANSI/SPRI Standard RP-4 are based on wind tunnel studies by Kind and Wardlaw (1977) and are supported by extensive field investigations which are applicable to building heights up to $45.72 \mathrm{~m}$., and parapet heights up to $1.83 \mathrm{~m}$. For the cases not covered in the standard, the user is referred to the work by Kind and Wardlaw (1977). 
The design tables are limited to $49.17 \mathrm{~m} / \mathrm{s}, 53.64 \mathrm{~m} / \mathrm{s}$, and $62.6 \mathrm{~m} / \mathrm{s} 3$-second gust wind zones and provide for the building height, parapet height, and exposure category. For parapet heights less than $0.3048 \mathrm{~m}$, the ballasted systems are limited to $22.86 \mathrm{~m}$. tall buildings.

In research aimed at codification of wind loading on porous claddings and covers over roofs which have a similar wind loading mechanism as roof pavers, Cheung and Melbourne (1986) and Cheung and Melbourne (1988) investigated the effect of porosity on wind loading on such systems. Reduction factors were proposed as a function of distance from the roof leading edge for different porosities and different internal volumes for a typical low-pitch roof cladding. Design wind loads could then be estimated from external pressure coefficients given in the existing building codes. Bienkiewicz and Meroney (1988) developed a rough design guideline for loose laid ballast pavers. The system failure condition was considered in terms of the failure wind speed and the wind loading parameters specified by the building code parameters (UBC, ANSI or ASCE 705 (Bienkiewicz and Endo, 2009)). This theory is limited to low buildings with rectangular flat roofs. The allowable building heights are given in the design guidelines in a tabular and/or graphic form for a range of design wind speeds and wind exposures Bienkiewicz and Meroney (1988).

Some codes and standards address the design of roof pavers systems. In the Netherlands code, NEN EN 1991-1-4/NA, a set of values for net pressure coefficients (difference between the external and underneath pressure coefficients; $C p_{n e t}=C p_{e}-C p_{i}$ ) is proposed for design of roofing tiles and pavers. These values were based on a number of experiments and full-scale studies on roof tiles on pitched roofs and roof pavers on flat 
roofs including those of Geurts (2000), who proposed equalization factors defined as $\mathrm{C}_{\mathrm{eq}}=\mathrm{C} p_{\text {net }} / \mathrm{Cp}_{\mathrm{e}}$ from full-scale measurements on roof tiles and roof pavers. The equalization factors are to be applied to the external pressure coefficients given in the Netherlands wind loading code. The proposed value of $\mathrm{C}_{\mathrm{eq}}$ for roof pavers with and without interlock were 0.25 and 0.6 , respectively. In the German Wind Code (DEUTSCHE NORM, 2001-03) design pressure coefficients are provided for building envelopes with permeable facades based on a study by Gerhardt and Janser (1995). In the Australian Standard for wind loads (AS 1170.2, 2011) reduction factors are given for estimating design wind loads on porous claddings. These factors depend on the cladding porosity and the horizontal distance from windward building edge. Other major international codes and standards for wind loads in USA and Canada (ASCE 7-10; NBCC) specify roof wind pressures for typical roof geometries but there are no specific provisions on how to apply such pressures to roofing elements such as tiles, shingles, and pavers.

Considering the complexity of the current numerical methods proposed in literature and lack of a systematic generic design guideline in ASCE 7 for determining the wind uplift resistance of roof pavers which takes into account the effect of pavers' edge gap to spacer height ratio, relative parapet height, and pressure equalization, this paper proposes a simplified yet reasonably accurate method for calculating the net uplift force of roofing systems from the existing external pressure coefficients in the current ASCE 7-10 standard. 


\subsection{Pressure Gradient Effects}

Multi-layer building envelopes, e.g. roof pavers are particularly sensitive not just to pressures but to spatial pressure gradients. Concrete roof pavers are usually placed on the roof with spacing above the roof deck and with gaps between the pavers. The pressure distribution produced by the wind flow over the outer surface of the roof produces secondary flows through the spaces between and underneath the paver elements. The so called pressure equalization occurs very quickly provided the space between the pavers and the roof deck below is not too large, typically in a small fraction of a second, because very small volumes of air exchange are needed to bring the underside pressure into equilibrium with the pressures around the paver perimeter. This phenomenon is controlled by the same physics as the internal pressure. However, in pressure equalization, much smaller volumes of air through many openings are involved. The pressure equalization effect greatly reduces the net uplift force on pavers in most areas of a roof. However, in areas of very high spatial gradients of pressure, such as those which occur under vortices near roof corners, significant net uplift pressures can still occur. Figure 1 illustrates the typical path of the vortices over a flat roof for cornering winds.
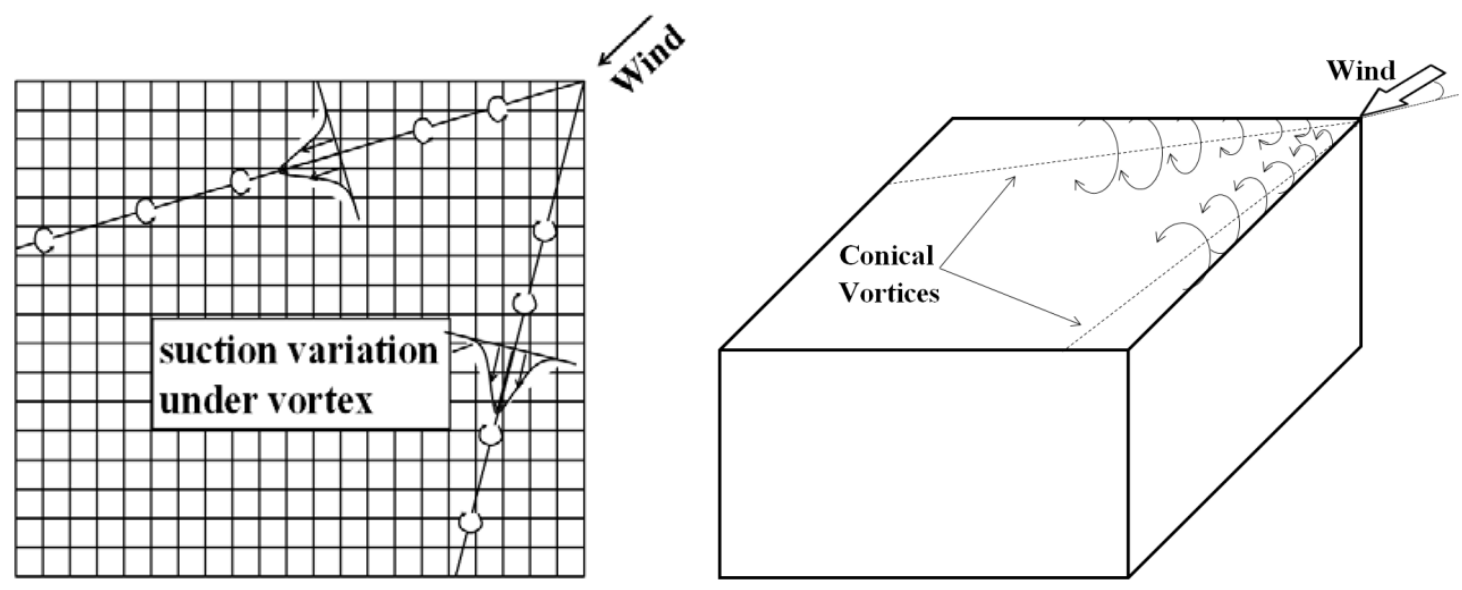
Figure 1. Conical vortices; Suction variation on roof under corner vortices

Along with the high suctions from the vortices there are also high velocities passing over the surface as the flow rotates rapidly about the vortex center. The vortex is analogous to a small tornado with axis approximately horizontal and with very high velocities near the vortex core. Thus not only are there high suctions tending to lift roofing material but also high tangential air speeds immediately adjacent to the roof surface, which are prone to penetrating under the edges of roofing elements and lifting them. It is very important to generate these vortices as part of the test to fully replicate these wind effects on a roof in a test. The bell shaped curves in Fig. 1 have greatest central suction near the corner and are very narrow there but as distance from the corner increases, the suction reduces and the width of the bell shape grows larger. The effect of these suction distributions on the roof will depend on the type of roof system being used and is clearly very different from a simple uniform pressure distribution. The diagram in Fig. 2 illustrates the general mechanism of uplift on roof pavers. The aerodynamic uplift force is the difference between the pressure on the lower surface of the paver, $P_{L}$ and the pressure on the upper surface, $P_{U}$ (Fig. 2). The pressure on the upper surface due to the presence of a corner vortex (solid curve) is negative (when measured relative to the static pressure in the surrounding air stream) and has a concentrated peak. The pressure on the lower surface is depicted by the broken curve and at the paver edge it is shown as being equal to that on the top surface at the paver edge. In practice, the top and bottom edge pressures do not always match exactly. The underneath pressure is dictated by the outer pressure distribution and the relative magnitude of the joint resistances compared to the under- 
element resistance which prevents a complete pressure equilibration between upper and lower surfaces of the element (Bofah et al, 1996, Gerhardt et al, 1990; Kind, 1994). Detailed measurements done by (Kind and Wardlaw, 1982) showed that the underneath pressure does tend to vary roughly linearly between the pressures at the paver edges as depicted in Fig. 2 (also discussed in Bofah et al (1996)). More precisely, it should satisfy the Laplace equation as explained by (Kind, 1994). It is only due to the sharp peak of the negative pressure under a vortex (between points A and B) that a net uplift occurs, signified by the large difference between the solid and broken curves. If the upper surface pressure does not have the peak then pressure equalization caused by flow around the edges of the paver results in smaller net uplift as shown by the small differences between the solid and dashed curves on the pavers outside of the zone between points A and B. But the impact of this highly depends on the size of the paver relative to the width of the corner vortex. If the paver is much larger than the width of the vortex then the impact is reduced since only a small fraction of the paver area is affected by the high suction. Also, if the paver is much smaller than the width of the vortex then, even if it is sitting in a high suction zone, the pressure equalization effect of the gaps at its edges substantially reduces the difference in pressure between top and bottom surfaces. If the paver and vortex widths are similar the net uplift will tend to be maximized. 


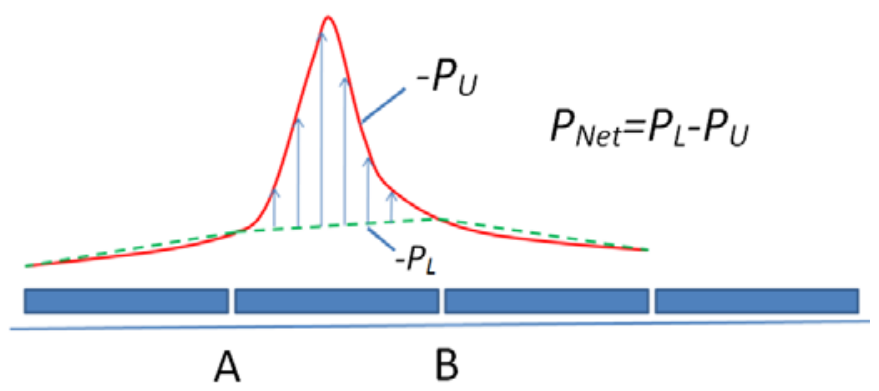

Figure 2. Pressure distributions on upper and lower surfaces of a roof paver

Interlocking and strapping systems are commonly used to improve the wind performance of roof pavers. In this case, the uplift force tends to be shared across several pavers. Figure 3 shows a strapping system running transverse to the axis of the vortex and connects to the center of each paver. The lift on the paver $\mathrm{AB}$ is now restrained not only by the weight of the paver $\mathrm{AB}$ but also by at least part of the weight of the adjacent pavers, on which there is little if any lift. The lift on the paver AB that is needed to both lift paver $\mathrm{AB}$ and also cause the adjacent pavers to rotate so that their edges at $\mathrm{A}$ and $\mathrm{B}$ become airborne, but not the farther edges, is about double that needed to lift the unconnected paver (Irwin et al, 2012). The lift required to cause the farther edges also to become airborne is about 3 times that for the unconnected paver. These considerations, along with the assumption that lift on real pavers varies approximately as wind velocity squared, lead to the expectation that strapping in the direction transverse to the line of the vortex will increase the lift off speed by a factor of approximately $\sqrt{2}=1.4$ to $\sqrt{3}=1.7$ (Irwin et al, 2012). 


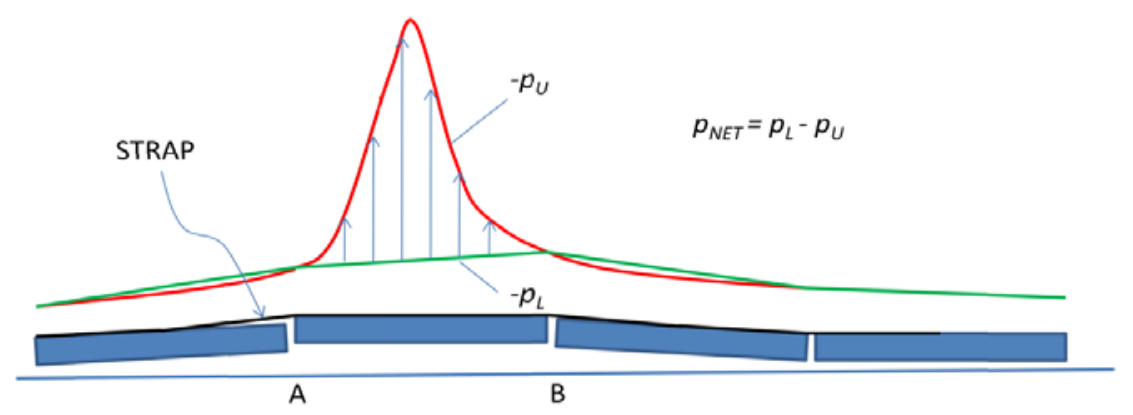

Figure 3. Straps running transverse to the axis of the vortex

At sufficient wind speeds the aerodynamic uplift force and/or the overturning moment on the element may become higher than the weight and/or the resisting moment due to gravity or other restraints, such as strapping, and lift off will occur. From this discussion it is concluded that parameters influencing the wind loading mechanism of roof pavers include paver size and weight, paver edge-gap to spacer height ratio, distance of the paver from the roof corner, and height of parapets.

\subsection{Description of the Experiments}

Large-scale (1:2) experiments have been reported by the authors in an earlier paper (Asghari Mooneghi et al, 2014). In this paper, additional results have been added in order to facilitate the development of design guidelines. Here only a brief description of the experiments is provided. For a full description the reader is referred to the previously referenced paper. The experiments were performed in the 12-fan Wall of Wind open jet facility at FIU which is able to generate up to a Category 5 Saffir-Simpson Scale hurricane wind speed that replicates a representative mean wind speed profile and the high frequency end of the turbulence spectrum. A set of triangular spires and floor 
roughness elements was used to generate appropriate turbulence and boundary layer characteristics (Fig. 4).

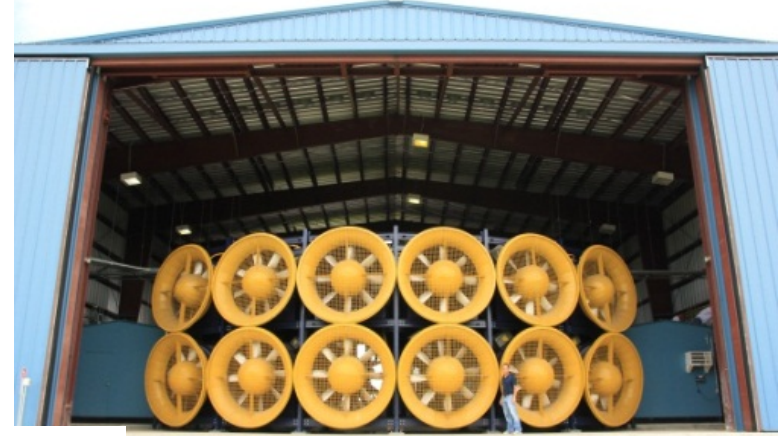

(a)

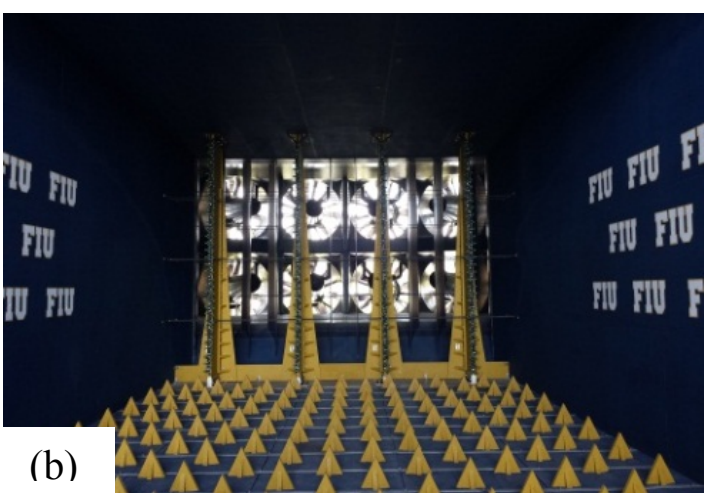

(b)

Figure 4. (a) Wall of Wind, Florida International University, (b) Spires and floor roughness elements

Figure 5 shows the comparison between the atmospheric boundary layer (ABL) full spectrum for suburban terrain as simulated in a boundary layer wind tunnel by $\mathrm{Fu}$ (2013) and the WOW partial spectrum. The dimensional Kaimal spectrum is also shown. Note that the high frequency portions of the WOW and wind tunnel spectra match satisfactorily and follow the $-5 / 3$ slope of the inertial sub-range. As noted by a number of researchers (Banks, 2011; Irwin, 2009; Kopp and Banks, 2013; Kumar and Stathopoulos, 1998; Melbourne, 1980; Richards et al, 2007; Saathoff and Melbourne, 1997; Tieleman, 2003; Yamada and Katsuchi, 2008), accurate simulation of high frequency turbulence is necessary for an adequate simulation of the separated flows on low-rise structures. Based on the fact that only the high frequency turbulence is adequately simulated at the WOW, the mean wind speed measured in WOW was estimated to be equivalent to approximately 0.21 second gust at full scale for the current set of experiments on pavers. The 
methodology for such estimation is a separate topic by itself and has been described in another paper which is currently under review.

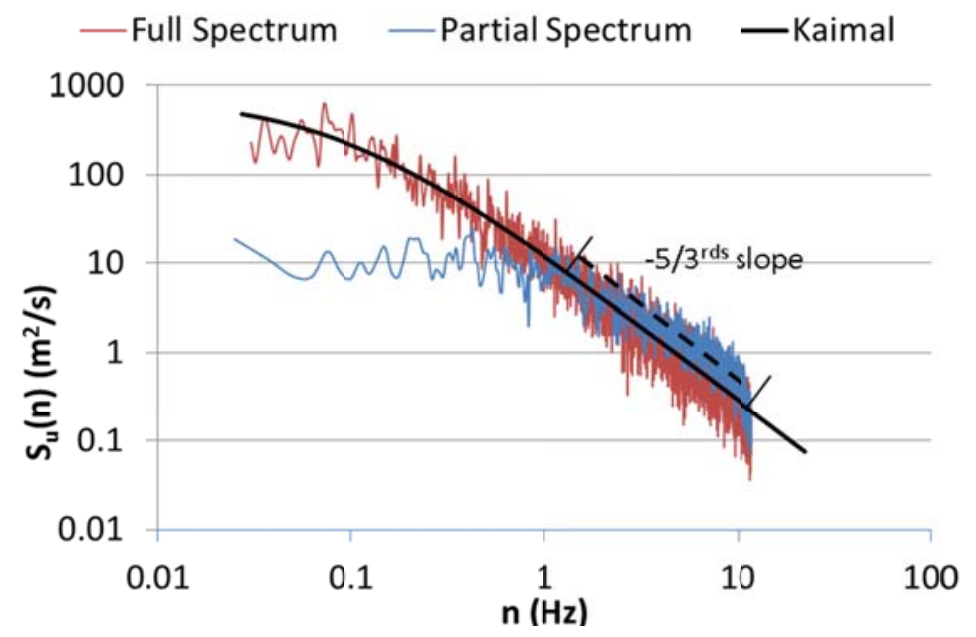

Figure 5. Comparison of ABL full spectrum for suburban terrain simulated in wind tunnel by $\mathrm{Fu}$ (2013), WOW partial spectrum and the Kaimal spectrum expressed at full scale

The mean wind speed and turbulence intensity profiles for suburban terrain are shown in Fig. 6 for $20.1 \mathrm{~m} / \mathrm{s}$ wind speed at $\mathrm{z}=2.6 \mathrm{~m}$ elevation (target power law coefficient was $\mathrm{a}=1 / 4)$.
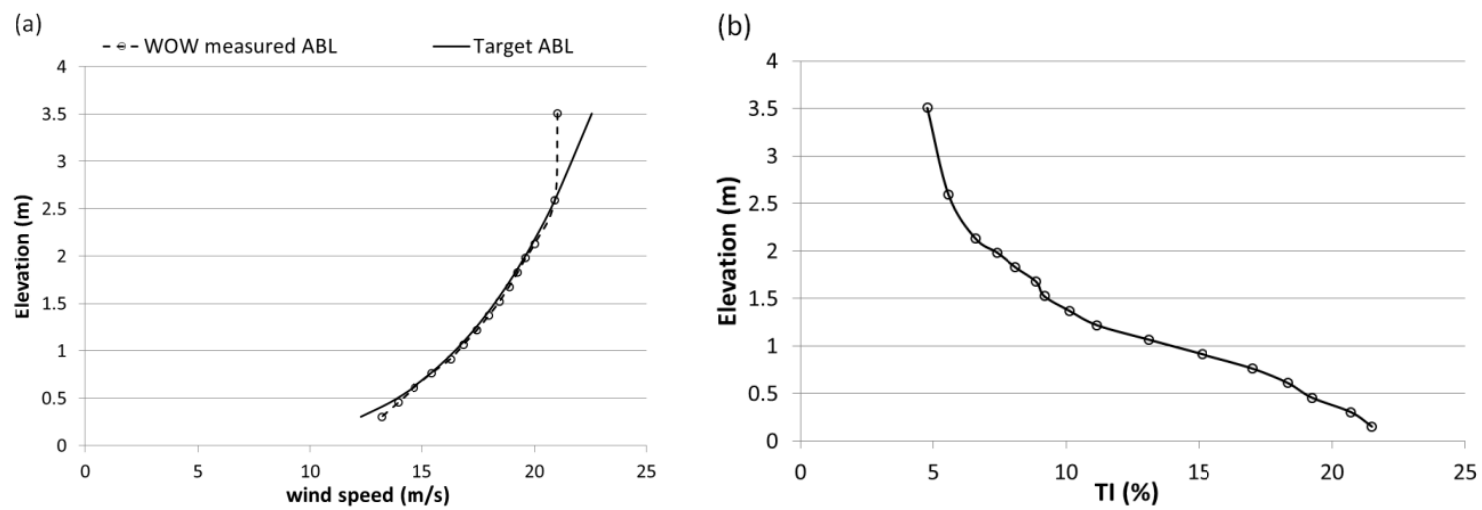

Figure 6. Simulated suburban terrain: (a) Atmospheric Boundary Layer (ABL) profile, (b) Turbulence intensity profile 
The dynamic similarity requirements for the tests and how they were satisfied have been described by (Asghari Mooneghi et al, 2014). The size of the 1:2 test building model was $3.35 \mathrm{~m}$ by $3.35 \mathrm{~m}$ in plan by $1.524 \mathrm{~m}$ high, representing at half scale a lowrise prototype building with height of $3.48 \mathrm{~m}$. The size of the test section was $6.1 \mathrm{~m}$ wide and $4.3 \mathrm{~m}$. high. The roof deck was made from plywood and was completely sealed and rigid. The rectangular sharp edged parapets on the building model were interchangeable which allowed the parapet height to be adjusted. There were no parapets on the leeward side of the building. This was done with the intent that the model roof could then be representative of the windward corner of a bigger roof structure on which the downwind parapets would not significantly influence flow over the upwind portions of the roof. Lin and Surry (1998) and Lin et al (1995) showed that, for low buildings which are large enough to have reattached flows on the roof, the distribution of pressure coefficients in the corner region is mainly dependent on the eave height, $H$, and not so much on the building plan dimensions for similar terrain conditions. Moreover, external pressure coefficients measured in the wind tunnel by Kopp et al (2005) on roof corners of a nearly flat building model were consistent with those measured on roof corners of flat roof lowrise building models with different plan aspect ratios (Ho et al, 2005; Pierre et al, 2005; Stathopoulos, 1982; Stathopoulos and Baskaran, 1988).

Both wind blow-off testing (i.e. blowing at sufficient speed to dislodge pavers) and pressure measurements were performed. For the wind blow-off tests, concrete pavers with a dimension of $0.305 \mathrm{~m}$ by $0.305 \mathrm{~m}$ by $2.54 \mathrm{~cm}$ thickness with weight per unit area of $535 \mathrm{~N} / \mathrm{m}^{2}$ were installed on the roof which can be considered as modeling typical 0.61 m square pavers at half-scale (Fig.7a). Pavers were numbered from 1 to 100 (Fig. 7b). 
Adjustable height pedestals were used to change the space between the paver and the roof deck $\left(\mathrm{H}_{\mathrm{s}}\right.$, Fig. $\left.7 \mathrm{c}\right)$. A constant $\mathrm{G}=3.175 \mathrm{~mm}$ space between adjacent pavers (Fig. $\left.7 \mathrm{c}\right)$ was maintained. For the pressure measurements, pavers with exactly the same dimensions as the concrete pavers $(0.305 \mathrm{~m} \times 0.305 \mathrm{~m} \times 2.54 \mathrm{~cm}$ thickness $)$ were made from Plexiglas which made it more convenient to install pressure taps on both upper and lower surfaces. The pressure tap layout can be found in Asghari Mooneghi et al (2014) (total of 447 pressure taps were used).

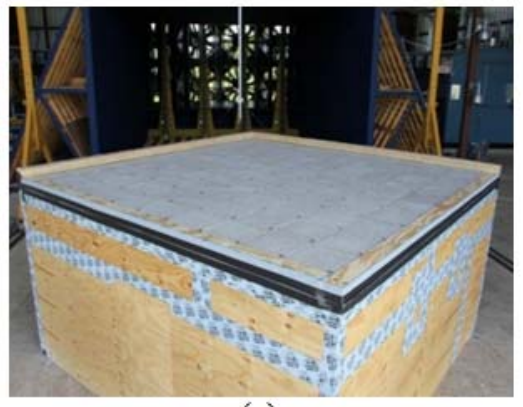

(a)

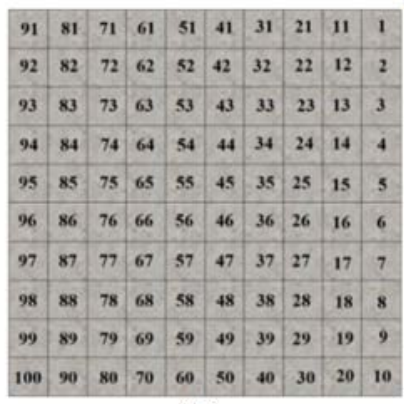

(b)

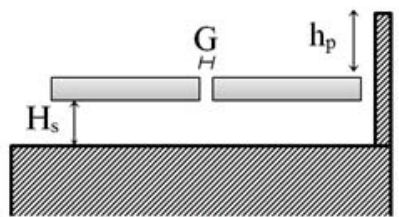

(c)

Figure 7. (a) Test building for wind liftoff tests, (b) Roof pavers numbering, (c) Geometrical parameter definition

A total of 13 experiments were carried out, including three wind blow-off tests and 10 pressure measurement tests. A summary of the parameters for each test is given in Table 1. Only one wind direction was tested, a quartering direction of $45^{\circ}$ relative to the roof edge. Based on past studies this wind direction was assessed to be the most critical orientation for generating high uplift under conical vortices on flat rectangular roofs (Holmes, 2007). The test procedure consisted of first conducting wind lift-off tests to find out the location where paver lift-off first occurred so that the pressure tap layout for the pressure measurements could be concentrated on the most sensitive pavers. The failure 
wind speeds measured at the roof height of the test model (1.524 $\mathrm{m}$ height) are reported in Table 2. After identifying the critical pavers and deciding on the pressure tap layout, the original pavers were replaced by the Plexiglas pavers with pressure taps. Pressure measurements were carried out at a wind speed of $18.5 \mathrm{~m} / \mathrm{s}$ which was below the failure speed of concrete pavers (but required some special measures to hold the Plexiglass pavers in place). Nine critical pavers were fitted with a total of 256 pressure taps to allow accurate measurements to be made of the pressure distribution on the top and bottom surfaces of the pavers. A 512 channel Scanivalve Corporation pressure scanning system was used for pressure measurements. Pressure data were acquired at a sampling frequency of $512 \mathrm{~Hz}$ for a period of three minutes. A transfer function was used to correct for tubing effects (Irwin et al, 1979).

Table 1. Test number and characteristics

\begin{tabular}{|lcc|}
\hline Test Number & $\mathbf{G} / \mathbf{H}_{\mathbf{s}}{ }^{*}$ & $\left(\mathbf{h}_{\mathbf{p}} / \mathbf{H}\right)_{\text {windward }}{ }^{* *}$ \\
\hline Wind Uplift 1 & 0.25 & 0.05 \\
Wind Uplift 2 & 0.083 & 0.05 \\
Wind Uplift 3 & 0.028 & 0.05 \\
Pressure 1-1 & 0.25 & 0.05 \\
Pressure 1-2 & 0.25 & 0.067 \\
Pressure 1-3 & 0.25 & 0.1 \\
Pressure 2-1 & 0.083 & 0.033 \\
Pressure 2-2 & 0.083 & 0.05 \\
Pressure 2-3 & 0.083 & 0.1 \\
Pressure 2-4 & 0.083 & 0.15 \\
Pressure 3-1 & 0.028 & 0 \\
Pressure 3-2 & 0.028 & 0.05 \\
Pressure 3-3 & 0.028 & 0.1 \\
\hline
\end{tabular}

* Constant $\mathrm{G}=3.175 \mathrm{~mm}$ for all tests

** Parapet height was measured from top of the pavers. Leeward building sides did not have any parapet. 
Table 2. Failure wind speed (Asghari Mooneghi et al, 2014)

\begin{tabular}{|c|c|}
\hline $\begin{array}{l}\text { Failure wind speed when wobbling started } \\
(\mathrm{m} / \mathrm{s})\end{array}$ & $\begin{array}{l}\text { Failure wind speed when 2 or 3 Pavers lifted } \\
\text { off }(\mathrm{m} / \mathrm{s})\end{array}$ \\
\hline 37.2 & 43 \\
34 & 37.3 \\
28 & 37 \\
\hline
\end{tabular}

\subsection{Data Analysis}

The mean pressure coefficient at any location was obtained from:

$$
C p_{\text {mean }}=\frac{P_{\text {mean }}}{\frac{1}{2} \rho U_{\text {mean }}^{2}}
$$

where $P_{\text {mean }}$ is the mean pressure, $\rho$ is the air density at the time of the test $(1.225$ $\mathrm{kg} / \mathrm{m}^{3}$ ) and $U$ is the mean wind speed measured at the building height of the test model $(1.524 \mathrm{~m})$.

The peak pressure coefficient was obtained from:

$$
C p_{\text {peak }}=\frac{P_{\text {peak }}}{\frac{1}{2} \rho U_{3 s}^{2}}
$$

where $P_{\text {peak }}$ is the peak pressure, and $U_{3 s}$ is the peak 3-s gust at the reference height obtained by performing moving averages. The Sadek and Simiu (2002) method was used to obtain statistics of pressure peaks from observed pressure time histories. Because estimates obtained from this approach are based on the entire information contained in the time series, they are more stable than estimates based on single observed peaks. For the evaluation of these estimated values $85 \%$ probability of non-exceedance was used. Data were low-pass filtered at $30 \mathrm{~Hz}$ (equivalent to $21 \mathrm{~Hz}$ at full scale). The net total pressure coefficient defined as the instantaneous difference between the external and the corresponding underneath pressure coefficient at the same location are: 


$$
C p_{\text {net }}(t)=C p_{\text {ext }}(t)-C p_{\text {int }}(t)
$$

The overall wind lift load, $L(t)$, acting on any single paver is obtained as:

$$
\begin{gathered}
L(t)=\frac{1}{2} \rho U^{2} \iint_{A_{\text {paver }}} C p_{\text {net }}(t, x, y) d A \\
C_{L}(t)=\frac{L(t)}{\frac{1}{2} \rho U^{2} A}
\end{gathered}
$$

where A is the surface area of the paver. The reduction in the net wind uplift can be expressed as:

$$
r=\frac{C_{L_{n e t}}}{C_{L_{e x t}}}
$$

It should be noted that the highest suction on the paver does not necessarily occur at the center of the paver. This means that even for cases where the total uplift force is less than the weight of the paver, the weight of the paver might not overcome the corresponding overturning moment. The overturning moment about a selected axis is obtained from:

$$
\begin{gathered}
M(t)=\frac{1}{2} \rho U^{2} \iint_{A_{\text {paver }}} C p_{\text {net }}(t, x, y) \times d(x, y) \times d A \\
C_{M}(t)=\frac{M(t)}{\frac{1}{2} \rho U^{2} A a}
\end{gathered}
$$

where $d(x, y)$ is the moment arm defined as the distance from the selected axis to each point on the paver (Fig. 8). Having the net lift, $L$, and moments $M_{x}$ and $\mathrm{M}_{\mathrm{y}}$, offsets of point of action of lift from the center are (Fig. 8):

$$
d_{y}=M_{x} / L ; \quad d_{x}=M_{y} / L
$$




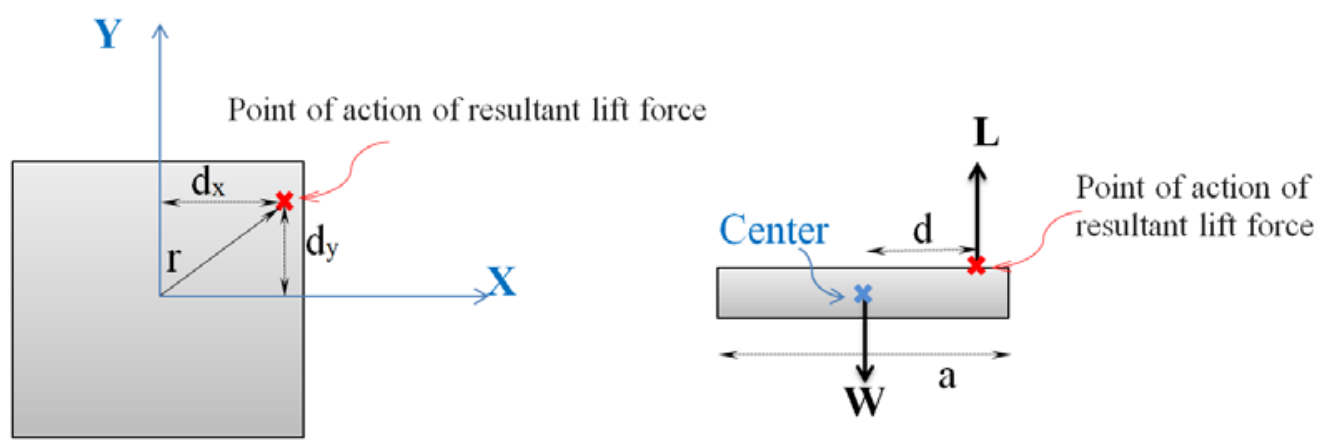

Figure 8. Definition of the point of action of the resultant lift force

The lift off takes place when the moment caused by the uplift force is equal to the moment from the paver weight, $W$. Therefore, the critical wind velocity $U_{C R I T}$ at which lift-off occurs is calculated from:

$$
\begin{gathered}
\frac{1}{2} \rho U_{C R I T}{ }^{2} C_{L} A\left(d+\frac{a}{2}\right)=W \times \frac{a}{2} \\
U_{C R I T}=\sqrt{\frac{a}{2\left(d+\frac{a}{2}\right)} \times \frac{W}{\frac{1}{2} \rho C_{L} A}} \quad\left(d \text { is the larger of } d_{x} \text { and } d_{y}\right)
\end{gathered}
$$

Therefore, if $C_{L}$ is known, the critical wind speed can be calculated. In this paper, three methods were examined to obtain the critical $C_{L}$ value:

Case I: Experiments: $C_{L}$ value is obtained from the large-scale pressure measurement experiments.

Case II: ASCE 7-10 components and claddings exterior pressure coefficients: The design wind pressures on buildings in the United States are determined using the ASCE 7-10 standard. It provides wind loads for the design of the Main Wind Force Resisting System (MWFRS), as well as Components and Cladding. These provisions cover buildings with common shapes, such as those with Flat, Gable, Hip, and Mono-slope roofs, under simple surrounding conditions. For the design of roof components and cladding, the roof is 
divided into rectangular shaped zones within which a constant pressure coefficient is specified. For permeable roof claddings such as loose-laid roof pavers, the ASCE standard currently does not provide specific guidance for estimating net wind uplift loads. However, a practice proposed for roof tiles (FPHLM, 2005, Volume II, p. 55) is to assume a zero underneath pressure coefficient and consider the exterior pressure coefficient as the net pressure coefficient. This approach is examined in this paper using ASCE 7-10 exterior pressure coefficient to determine the lift-off speed, i.e.

$$
U_{C R I T}=\sqrt{\frac{W}{\frac{1}{2} \rho C_{p_{\text {ext }}{ }^{A}}}}
$$

Case III: 1/3 Rule: In BRE (1985) it is stated that the magnitude of the net uplift coefficient was found empirically to be generally less than $1 / 3^{\text {rd }}$ of the magnitude of the peak negative external pressure coefficient on the upper surface of the paver. In other words as a rule of thumb, $C_{L} \leq-\frac{1}{3} C p_{\text {peak }}$. This is broadly in line with earlier findings of Kind and Wardlaw (1982). To examine this rule, $1 / 3^{\text {rd }}$ of the ASCE 7-10 peak exterior pressure coefficients for components and claddings is used to calculate the critical wind lift-off speed assuming that the net uplift acts at the paver's center (Eq. (12)).

The results from the wind lift-off experiments were compared with wind speeds calculated from the pressure measurements and different practices based on the ASCE 710 exterior pressure coefficients explained above. Code specific guidelines are then proposed for design of roof pavers which are more explained in the rest of the paper.

For the comparison of critical lift-off speed from different approach, one needs to pay attention to the fact that the same duration wind speeds be compared together. In this 
paper all the critical wind speeds are converted to $3 \mathrm{sec}$ gust speed for comparison purposes. The following section elaborates more this issue:

- Critical wind speeds obtained from ASCE 7-10 pressure coefficients (Case II and III) and peak lift coefficients from pressure measurements result in 3-sec full scale gust wind speed.

- As mentioned earlier, the critical lift-off speeds from the wind measurements are equivalent to $0.21 \mathrm{sec}$ gust and should be converted to a corresponding 3-sec full scale gust for comparison purposes.

- The mean pressure coefficient measured is to a good approximation a universal constant for any averaging time greater than about $0.21 \mathrm{~s}$. So if the pavers react to the $\Delta t$ second gust speed the lift-off speed $\mathrm{U}_{\Delta \mathrm{t}}$ can be calculated from Eq. (11). So the corresponding $3 \mathrm{sec}$ gust speed is

$$
U_{3 s e c}=\sqrt{\frac{a}{2\left(d+\frac{a}{2}\right)} \times \frac{W}{\frac{1}{2} \rho C_{L} A}} \times \frac{U_{3 s e c}}{U_{\Delta t}}
$$

It is not known in advance what averaging time the pavers react to except by hypothesizing various values and seeing what lines up best with the blow-off test results. So, various curves can be plotted for various assumed values of paver reaction time $\Delta t$.

The procedure for converting the wind speeds averaging time is explained in detail in Appendix A from which a conversion factor equal to $\frac{U_{3 s e c}}{U_{0.21 s e c}}=0.87$ was calculated for suburban terrain in Miami area at $\mathrm{z}=3.48 \mathrm{~m}$ (building height at full scale) . 


\subsection{Results and Discussion}

\subsubsection{Pressure measurements}

The reader is referred to the earlier paper by the authors for a detailed discussion about the external, underneath and net pressure coefficient contours and the failure mechanisms of roof pavers (Asghari Mooneghi et al, 2014). Mean and peak external pressure coefficients, mean underneath pressure coefficient and net mean pressure coefficients contours for the case of $\mathrm{G} / \mathrm{H}_{\mathrm{s}}=0.028$ and $\mathrm{h}_{\mathrm{p}} / \mathrm{H}=0$ i.e. no parapet case are given in Fig. 9 as an example.

The results of the tests show that pavers close to the edges and corners of the roof are subjected to the highest local negative pressures. These areas are under the conical vortices. As compared to external pressures the underneath pressures are lower in magnitude and show more uniformity. Pressure equalization reduces the net uplift force on the pavers. It should be noted that the peak values correspond to the estimated peak values for each tap during the test and do not happen simultaneously on all taps. In all tests, paver 21 was shown to be the most critical paver. So, in the rest of the paper, results are calculated for this paver. Table 3 shows the variations of the most negative mean and peak local $C_{p, e x t}$ values, $C_{\text {Lext }}, C_{\text {Lnet }}, C_{M x \text {,net }}$ and $C_{M y, n e t}$ on paver 21 with $\mathrm{G} / \mathrm{H}_{\mathrm{s}}$ and $\mathrm{h}_{\mathrm{p}} / \mathrm{H}$ ratios (Fig. 10). The $\mathrm{G} / \mathrm{H}_{\mathrm{s}}$ ratio affects the underside pressures such that the higher the ratio, the less the net pressure on the pavers. 

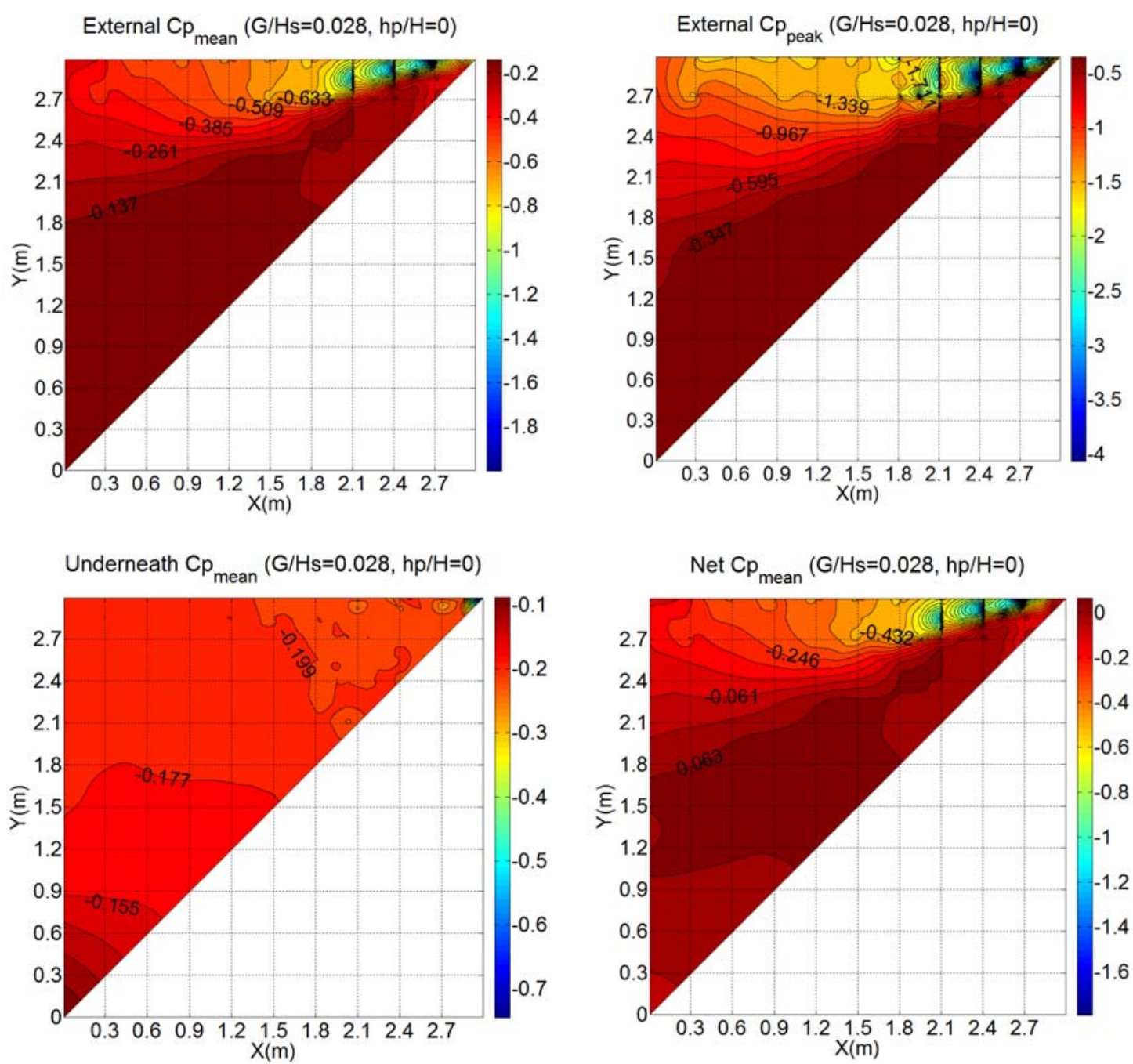

Figure 9. Pressure coefficient contours $\left(\mathrm{G} / \mathrm{H}_{\mathrm{s}}=0.028\right.$ and $\left.\mathrm{h}_{\mathrm{p}} / \mathrm{H}=0\right)$

The highest external single tap pressure coefficients and the external area averaged pressure coefficient $\left(C_{\text {Lext }}\right)$ observed on the most critical paver (paver 21) obtained for different cases (Table 3) were compared to component and cladding external pressure coefficients for roofs as given in ASCE 7-10. For gable roofs with slope $\theta \leq 7^{\circ}$ the largest external pressure coefficient for corner Zone 3 for tributary areas less than 0.9 $\mathrm{m}^{2}$ is given as -2.8 in Figure 30.4-2A (ASCE 7-10). The highest single tap peak suction coefficients observed in the present tests for all cases ranged from -4.1 for $\mathrm{h}_{\mathrm{p}} / \mathrm{H}=0$ and 
$\mathrm{G} / \mathrm{H}_{\mathrm{s}}=0.028$ to -2.05 for $\mathrm{h}_{\mathrm{p}} / \mathrm{H}=0.15$ and $\mathrm{G} / \mathrm{H}_{\mathrm{s}}=0.083$ in the critical paver zone. The highest peak external lift coefficients ranged from -1.44 for $\mathrm{h}_{\mathrm{p}} / \mathrm{H}=0.05$ and $\mathrm{G} / \mathrm{H}_{\mathrm{s}}=0.028$ to -1.19 for $h_{p} / H=0$ and $G / H_{s}=0.028$. The underneath pressure coefficients required for calculating the net pressure coefficients are not dealt with in ASCE 7-10.
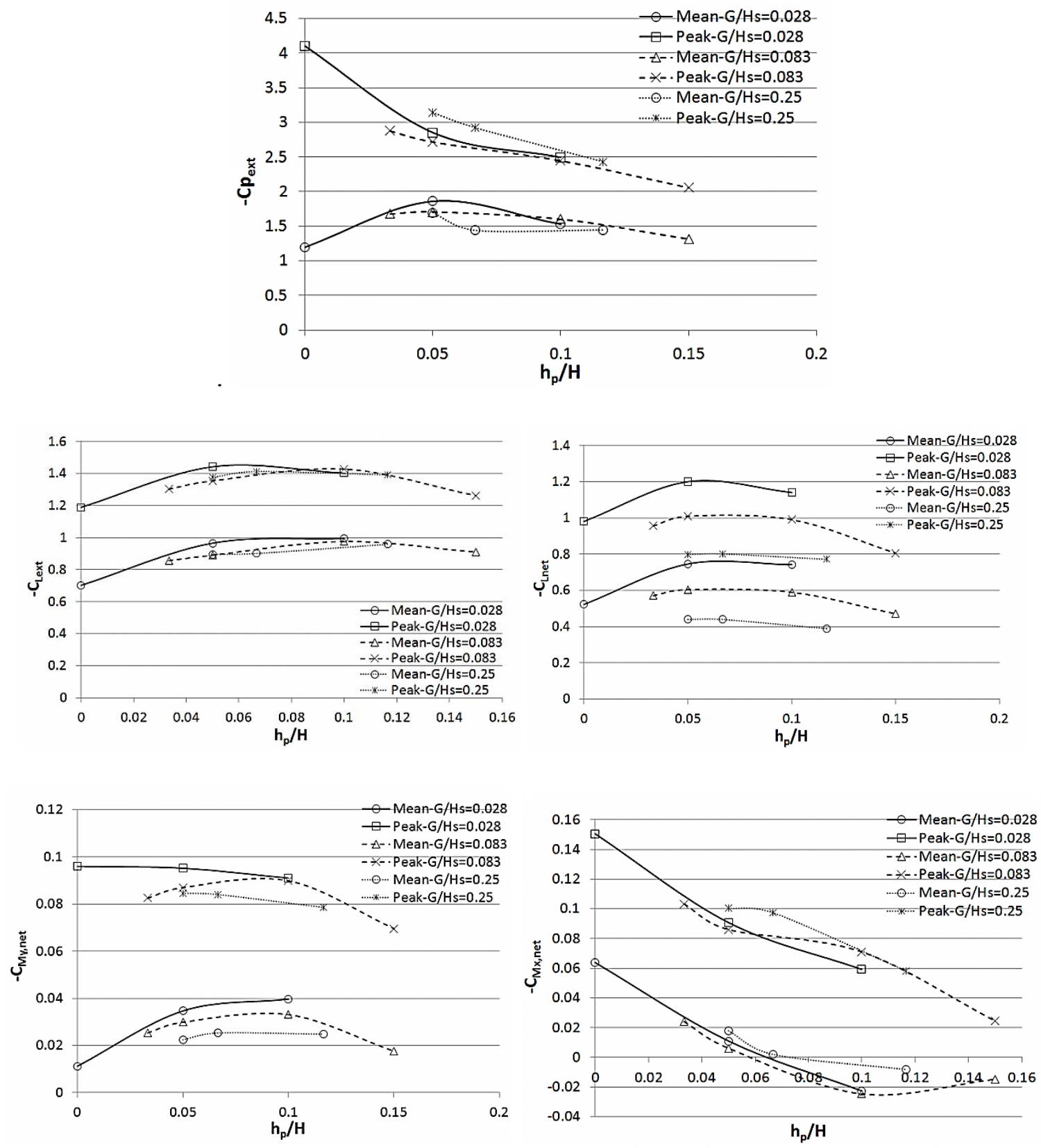

Figure 10. Highest local suction coefficients on the roof $C_{\text {Lext }}, C_{L n e t}, C_{M x, \text { net }}$ and $C_{M y, n e t}$ on paver 21 
The reduction factor defined as the ratio of the net lift coefficient to the external lift coefficient is plotted as a function of relative parapet height $\left(h_{p} / H\right)$ for different $G / H_{s}$ for paver 21 (Fig. 11).

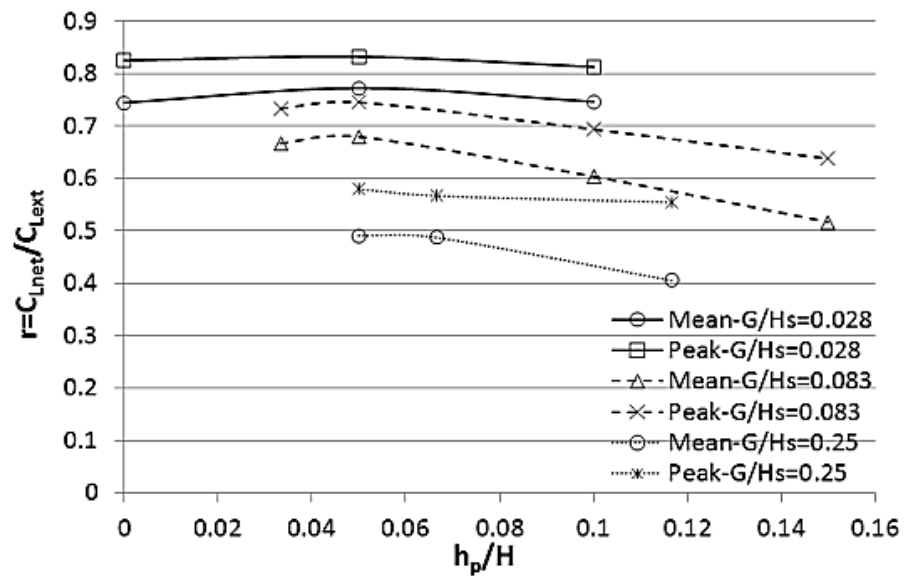

Figure 11. Reduction factor $r=C_{L_{n e t}} / C_{L \text { ext }}$

The results show that increasing the $\mathrm{G} / \mathrm{H}_{\mathrm{s}}$ ratio decreases the reduction factor. This means that the correlation between upper and lower surface pressures decreases with decreasing the $\mathrm{G} / \mathrm{H}_{\mathrm{s}}$ ratio. The reduction factor is not very sensitive to parapet height for $h_{p} / H$ less than about 0.1 . For $h_{p} / H$ ratios beyond 0.1 the reduction factor reduces gradually, i.e. improved performance of the pavers can be expected. 
Table 3. Most negative local pressure coefficient $C_{p, \text { ext }}, C_{\text {Lext }}, C_{\text {Lnet }}, C_{M x, \text { net }}$ and $C_{M y, n e t}$ on paver 21

\begin{tabular}{|c|c|c|c|c|c|c|c|c|c|c|c|}
\hline \multicolumn{2}{|c|}{ Test case } & \multicolumn{2}{|c|}{$\begin{array}{l}\text { Highest } C_{p, e x t} \text { read } \\
\text { on a tap (paver 21) }\end{array}$} & \multicolumn{2}{|c|}{$C_{\text {Lext }}$} & \multicolumn{2}{|c|}{$C_{\text {Lnet }}$} & \multicolumn{2}{|c|}{$C_{M x, n e t}$} & \multicolumn{2}{|c|}{$C_{M y, \text { net }}$} \\
\hline $\mathbf{G} / \mathbf{H}_{s}$ & $\mathbf{h}_{\mathrm{p}} / \mathbf{H}$ & Mean & Peak & Mean & Peak & Mean & Peak & Mean & Peak & Mean & Peak \\
\hline 0.25 & 0.05 & -1.70 & -3.14 & -0.89 & -1.38 & -0.44 & -0.80 & -0.02 & -0.10 & -0.02 & -0.08 \\
\hline 0.25 & 0.067 & -1.44 & -2.92 & -0.90 & -1.41 & -0.44 & -0.80 & 0.00 & -0.10 & -0.03 & -0.08 \\
\hline 0.25 & 0.1 & -1.45 & -2.43 & -0.96 & -1.39 & -0.39 & -0.77 & 0.01 & -0.06 & -0.02 & -0.08 \\
\hline 0.083 & 0.033 & -1.68 & -2.88 & -0.86 & -1.30 & -0.57 & -0.96 & -0.02 & -0.10 & -0.03 & -0.08 \\
\hline 0.083 & 0.05 & -1.71 & -2.71 & -0.89 & -1.35 & -0.60 & -1.01 & -0.01 & -0.09 & -0.03 & -0.09 \\
\hline 0.083 & 0.1 & -1.60 & -2.44 & -0.98 & -1.43 & -0.59 & -0.99 & 0.02 & -0.07 & -0.03 & -0.09 \\
\hline 0.083 & 0.15 & -1.31 & -2.05 & -0.91 & -1.26 & -0.47 & -0.81 & 0.01 & -0.02 & -0.02 & -0.07 \\
\hline 0.028 & 0 & -1.20 & -4.10 & -0.70 & -1.19 & -0.52 & -0.98 & -0.06 & -0.15 & -0.01 & -0.10 \\
\hline 0.028 & 0.05 & -1.86 & -2.85 & -0.97 & -1.44 & -0.75 & -1.20 & -0.01 & -0.09 & -0.03 & -0.10 \\
\hline 0.028 & 0.1 & -1.53 & -2.50 & -0.99 & -1.40 & -0.74 & -1.14 & 0.02 & -0.06 & -0.04 & -0.09 \\
\hline
\end{tabular}

\subsubsection{Critical wind speed calculations}

In order to see the overall effect of high local $\mathrm{Cp}$ values observed during pressure measurements on the failure wind speeds, the critical wind blow-off speeds obtained from wind blow-off tests (Table 2) are compared in Figs. 12 and 13 to the corresponding speeds calculated from pressure measurements using Eq. (11) for Paver 21 and to those obtained from methods explained in data analysis section. The values recorded for wind blow-off tests correspond to the cases when the wobbling of pavers started or the first failure was observed and are then multiplied by 0.87 factor to get the equivalent 3 -sec gust speed.

For the estimates based on ASCE 7-10 exterior pressures, Fig. 12, wind blow-off speed values are calculated using $\mathrm{GCp}=-2.8$ (external pressure coefficient in Zone 3 for $\mathrm{A}_{\mathrm{eff}}=0.09 \mathrm{~m}^{2} \leq 0.93 \mathrm{~m}^{2}$ ). For the limiting case of $\mathrm{G} / \mathrm{Hs} \sim$ zero (meaning a very large spacer height for a specific edge-gap between the pavers) one can assume that the underneath pressure needed would be similar to the internal pressure inside a building 
with a perforated roof. The underneath pressure coefficient for this case is calculated as the average of external pressure coefficients recorded at the center of all pavers using the following formula (Eq. 14).

$$
C_{p_{\text {int }}}(t)=\frac{1}{N}\left(\sum_{i=1}^{n=N} C_{p}(t)_{\text {ext }\left.\right|_{\text {center of paver } i}}\right)
$$

where $\mathrm{N}$ is the total number of pavers. The net lift coefficient was then calculated using Eq. (15)

$$
C_{L_{\text {net }}}(t)=C_{L_{\text {ext,on paver 21 }}}(t)-C_{L_{\text {int }}}(t)
$$

The measurements showed that wobbling of the pavers started at slightly lower speed than would be predicted purely on the basis of the mean $C_{\text {Lnet }}$ value combined with 3 second gust speed. This implies that some of the high frequency gust action occurring at shorter duration than 3 seconds was also necessary to initiate wobbling. However, assuming that the full gust speed, including all high frequency fluctuations, is required to start wobbling of the pavers would be on the conservative side. The results show that beyond a certain value of $\mathrm{H}_{\mathrm{s}}$ (i.e. for small $\mathrm{G} / \mathrm{H}_{\mathrm{s}}$ values) the pressures on the underneath can communicate very rapidly with other parts of the roof and further increases in $\mathrm{H}_{\mathrm{s}}$ do not make much difference. Once this point is reached there are no further decreases in lift-off velocity that are possible. The point where this situation is reached is around $\mathrm{G} / \mathrm{H}_{\mathrm{s}}$ $\sim 0.03\left(\mathrm{H}_{\mathrm{s}} / \mathrm{G} \sim 30\right)$. The critical wind blow-off speed calculated based on ASCE 7-10 exterior pressures coefficients alone is clearly conservative in comparison to the current experiments. 


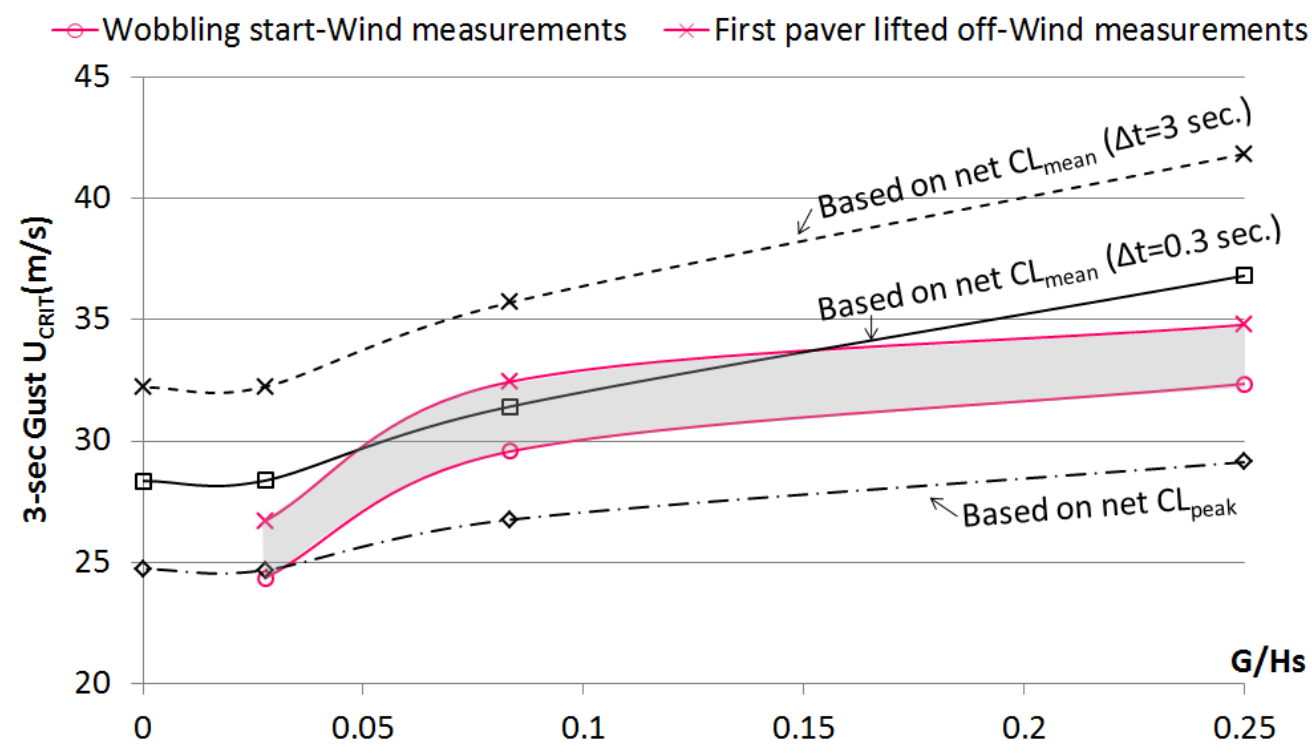

Figure 12. Comparison between wind lift-off speeds from wind blow-off tests and those obtained from pressure measurements

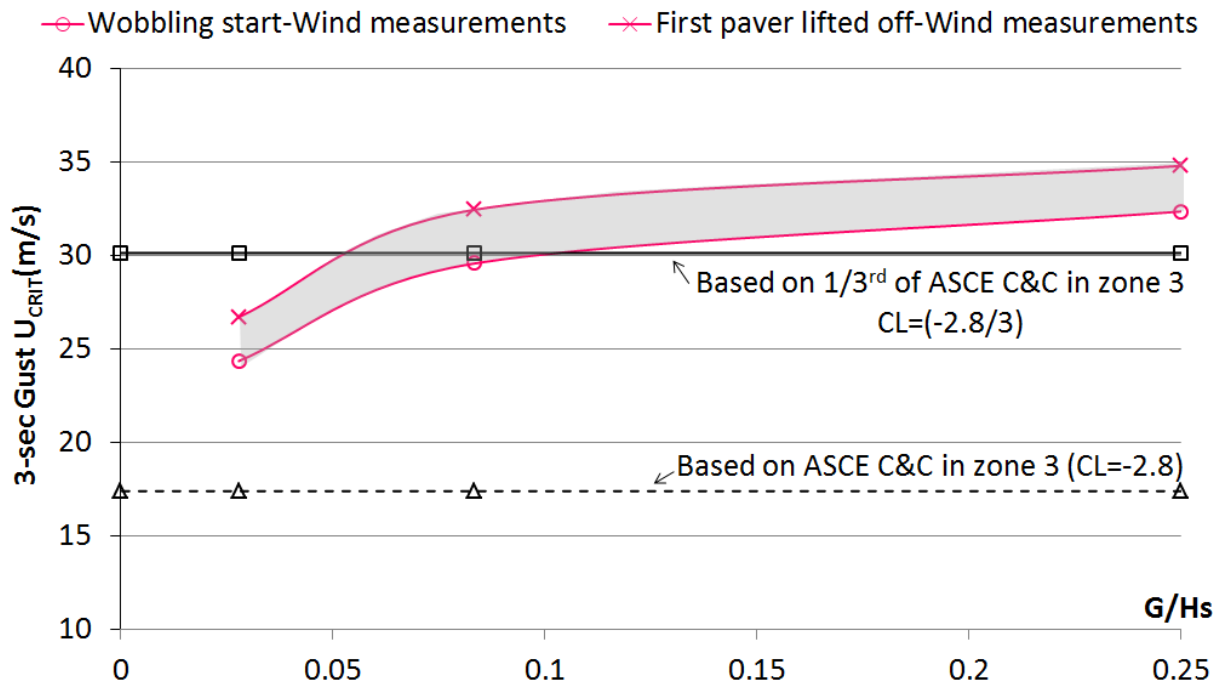

Figure 13. Comparison between wind lift-off speeds from wind blow-off tests and those obtained from a typical practice based on ASCE 7-10 exterior pressures on C\&C and $1 / 3^{\text {rd }}$ Rule

\subsubsection{Effect of connecting pavers}

There are various types of interlocking and strapping systems used to improve the wind performance of paving systems. The effect of a specific system has not been dealt 
with during the experiments in this study. However, guidance on the effectiveness of these systems can be obtained by evaluating the net uplift on groups of pavers rather than only one. The $C_{L_{n e t}}$ value is calculated for 6 different cases shown in Fig. 14 and compared to the highest $C_{L_{n e t}}$ value observed during the experiments on Paver 21 (Fig.15). In Fig. 14, the highlighted pavers were assumed to act as a single unit for the case of $\mathrm{G} / \mathrm{H}_{\mathrm{s}}=0.083$ and $\mathrm{h}_{\mathrm{p}} / \mathrm{H}=0.05$. The most critical paver is shown with an $\mathrm{X}$ mark.

The results illustrate the effect of connecting pavers together in reducing the net uplift force on the linked pavers as a unit. Based on the characteristics of the strapping or interlocking system in hand, different degrees of improvement can be expected. It should be noted that the surface pressure variation along the axis of the vortex varies much more slowly than in the transverse direction. So, strapping in the direction roughly parallel to the axis of the vortex is not expected to be as effective in restraining pavers from lift off as strapping in the transverse direction. If there is a high uplift on one paver the adjacent pavers in the direction along the vortex axis are likely to also experience significant uplift. Real strapping systems rarely align directly with the vortex axis or transverse to it. Therefore strapping in both orthogonal directions of a paving system is preferable.

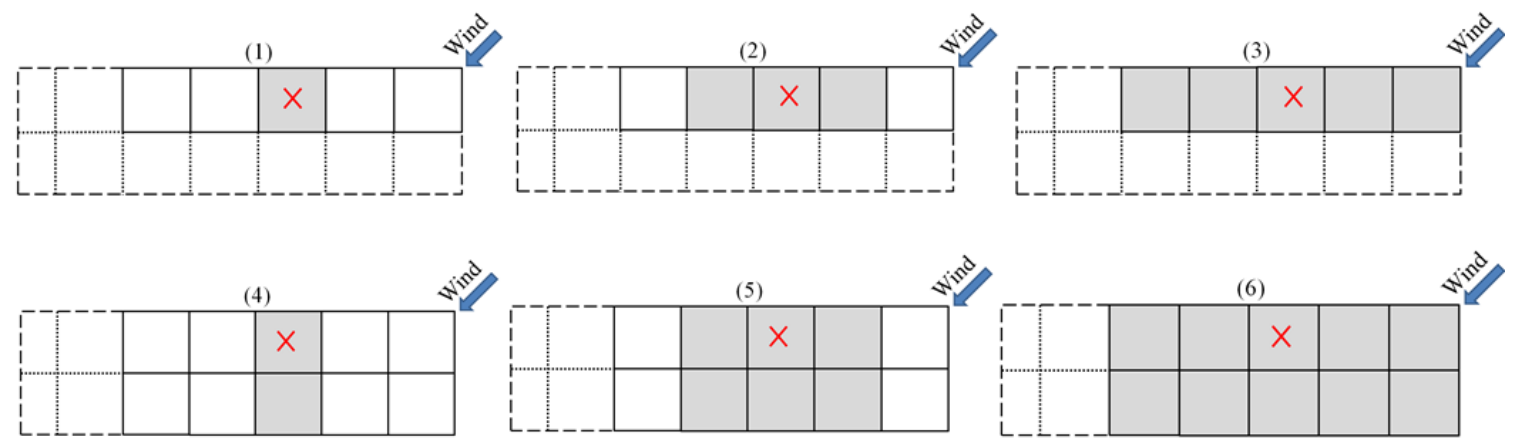

Figure 14. Interlocked pavers in different configurations 


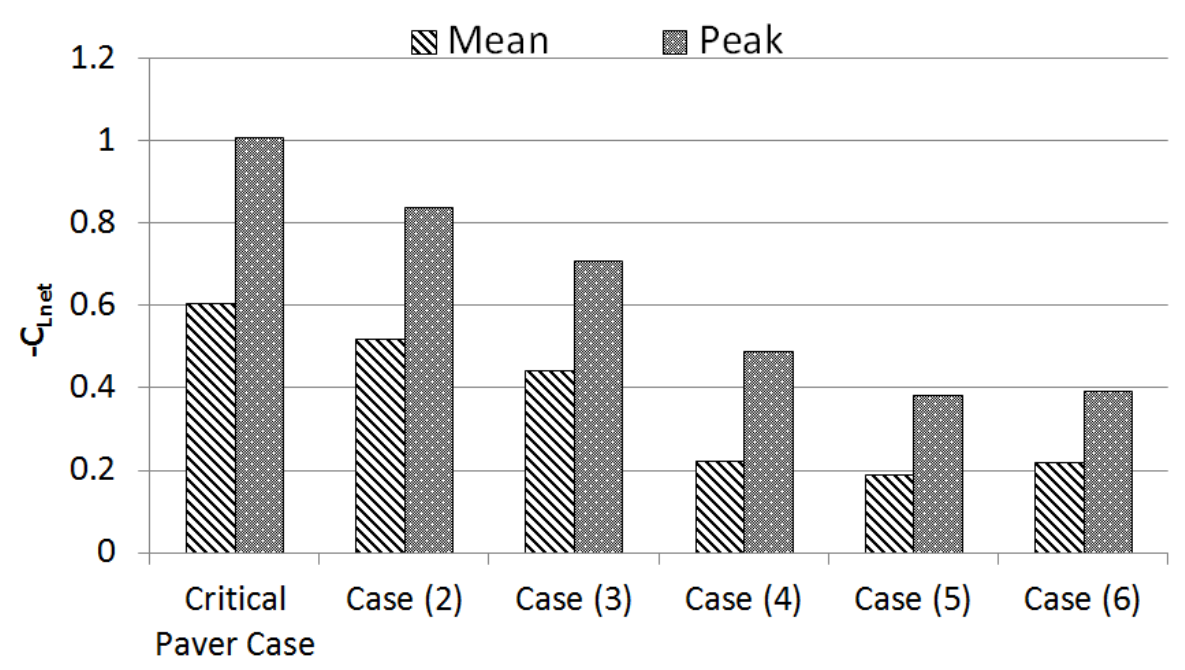

(1)

Figure 15. Comparison between $C_{L_{n e t}}$ values for different configurations defined in Fig. 14

\subsection{Proposed Guidelines}

Based on the results presented in the previous sections, the following equation is proposed for the design of loose-laid roof pavers.

$$
C_{L_{\text {net }}}=R_{1} \times R_{2} \times C_{p_{\text {ASCE 7-10,exterior,C\&C,Zone } 3}}
$$

where $R_{1}$ is a reduction factor for different gap ratios and $R_{2}$ is a reduction factor for different parapet heights. These are to be applied to the ASCE 7-10 exterior pressure coefficients for components and claddings in Zone 3. Here, Zone 3 in ASCE 7-10 is chosen as the worst case scenario for design of roof pavers as in many cases a single design will be used in all zones on the roof. However, $R_{1}$ in Eq. (16) can be modified to take into account the effects of location on the roof. Failure is defined here as the start of wobbling. $R_{1}$ and $R_{2}$ are to be calculated from the diagrams proposed in the following. The equivalent uplift force can then be calculated by multiplying Eq. (16) by the dynamic pressure at roof height. 


\subsubsection{Effect of $G / H_{s} \underline{\text { ratio }}$}

The reduction factor is defined as $C_{L_{n e t}} / C_{L_{e x t}}$ in which $C_{L_{\text {ext }}}$ is ASCE 7-10 exterior pressure coefficients for components and claddings in Zone 3 and $C_{L_{n e t}}$ values were calculated using the following formula in which failure is assumed to occur with the start of wobbling.

$$
U=\sqrt{\frac{W}{\frac{1}{2} \rho C_{L} A}} \rightarrow C_{L_{\text {estimated }}}=\frac{(W / A)}{\frac{1}{2} \rho U^{2} C R I T(\text { wobbling start from wind test })}
$$

The proposed reduction factor $R_{1}$ based on $\mathrm{G} / \mathrm{H}_{\mathrm{s}}$ ratio is plotted in Fig. 16. The value at $\mathrm{G} / \mathrm{H}_{\mathrm{s}} \sim 0$ comes from assuming $C_{L_{n e t}}=-2$ in which $C_{L_{e x t}}$ is assumed to be -2.8 (ASCE $\mathrm{C} \& \mathrm{C} \mathrm{Cp}$ in Zone 3) and $C_{L_{\text {int }}}=-0.8$ which is approximately calculated from averaging the external peak pressure coefficients on pavers $11,12,21,22,31$, and 32 . The $R_{1}$ factor changes an exterior pressure to a net pressure coefficient taking into account the effect of $\mathrm{G} / \mathrm{H}_{\mathrm{s}}$.

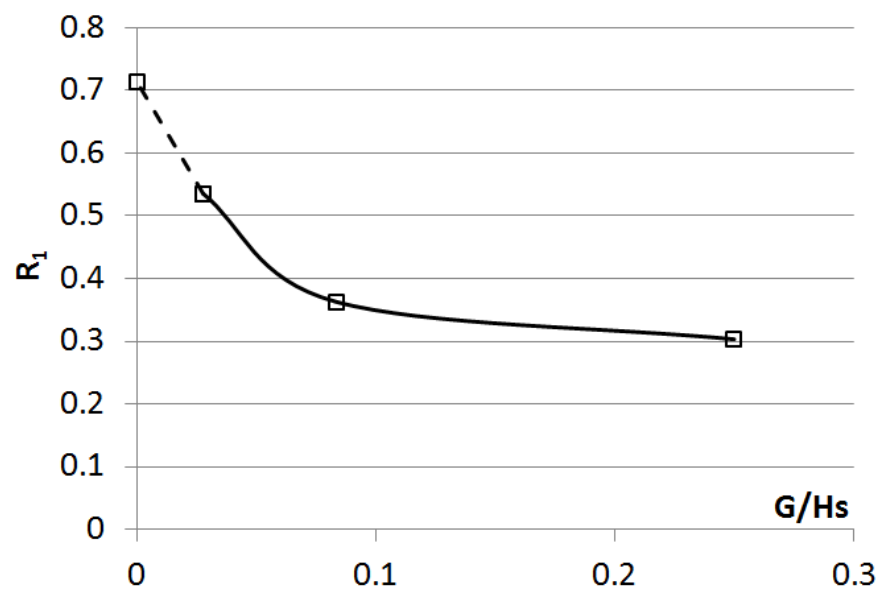

Figure 16. Reduction factor for different $\mathrm{G} / \mathrm{H}_{\mathrm{s}}$ ratios 


\subsubsection{Effect of parapet height}

$R_{2}$ reduction factor is proposed based on results presented in Fig. 11. For relative parapet height ratios less than 0.1 no reduction in the $C_{L}$ value is proposed (i.e. $R_{2}=1$ ). In ASCE 7-10 Figure 30.4-2A it is stated that the external pressure coefficients for Zone 3 can be reduced to the values in Zone 2 for parapets higher that $0.9144 \mathrm{~m}$. ( $3 \mathrm{ft}$.). This means about $36 \%$ reduction for $\mathrm{h}_{\mathrm{p}} / \mathrm{H}$ ratio of 0.3 and higher for the current experimental setup. This value is considered as the upper limit of the proposed reduction proposed in Fig. 17 (i.e. $h_{p} / H=0.3$ ). Kind et al (1987) proposed $h_{p} / H=0.1, h_{p} / H=0.02$ and $h_{p} / H=0.03$ for low, mid and high-rise buildings respectively, above which a somewhat rapid reduction in the worst suction values due to parapet was observed. As a matter of fact, application of the reduction factor in Fig. 17 for mid and high-rise buildings would be conservative.

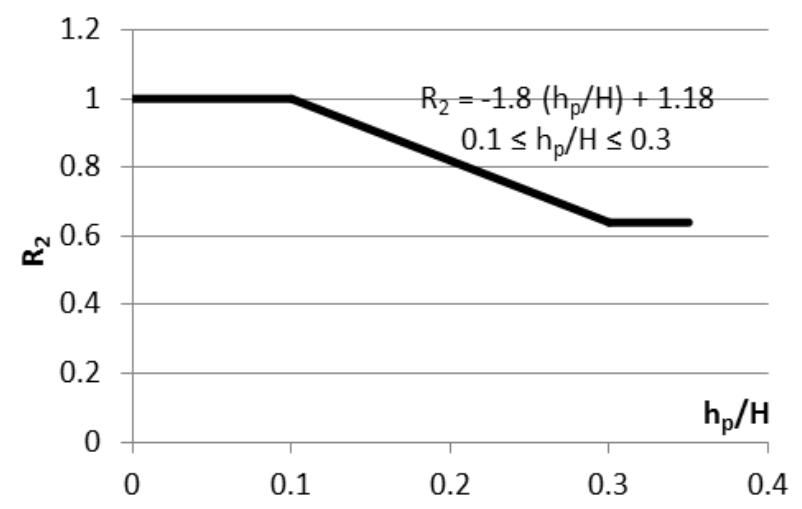

Figure 17. Reduction factor for different $h_{p} / H$ ratios

In Fig. 18 the proposed curve in Fig. 17 for $R_{2}$ reduction factor is compared to the experimental results presented previously in Fig. 11. The red and blue graphs are plotted by multiplying respectively the $R_{2}$ factor to the maximum of peak and mean reduction 
factor $r=C_{L_{n e t}} / C_{L_{\text {ext }}}$ obtained from experiments. This was done to make comparisons possible between the curves since due to pressure equalization effects, experimental reduction factor $r=C_{L_{n e t}} / C_{L_{e x t}}$ curves do not start at one as is the case for proposed $R_{2}$ reduction factor. Results show a good degree of agreement. In some cases (e.g. left graph in Fig. 18) the reduction due to parapet height from experiments $\left(r=C_{L_{n e t}} / C_{L_{\text {ext }}}\right)$ might start at $h_{p} / H$ ratios lower that the assumed $h_{p} / H=0.1$. However, $h_{p} / H=0.1$ and the corresponding curve proposed in Fig. 17 are based on results obtained from multiple experiments in order to have a universal curve. This value is also recommended in Kind et al (1987). It should be noted that the rate of decrease of reduction factor $r=$ $C_{L_{n e t}} / C_{L_{\text {ext }}}$ versus $\mathrm{h}_{\mathrm{p}} / \mathrm{H}$ obtained from experiments is in good agreement with the rate of decrease of proposed $R_{2}$ curve versus $\mathrm{h}_{\mathrm{p}} / \mathrm{H}$ (Fig.18).

Figure 19 shows the critical lift-off speeds from the measurements compared to values from the proposed guideline.

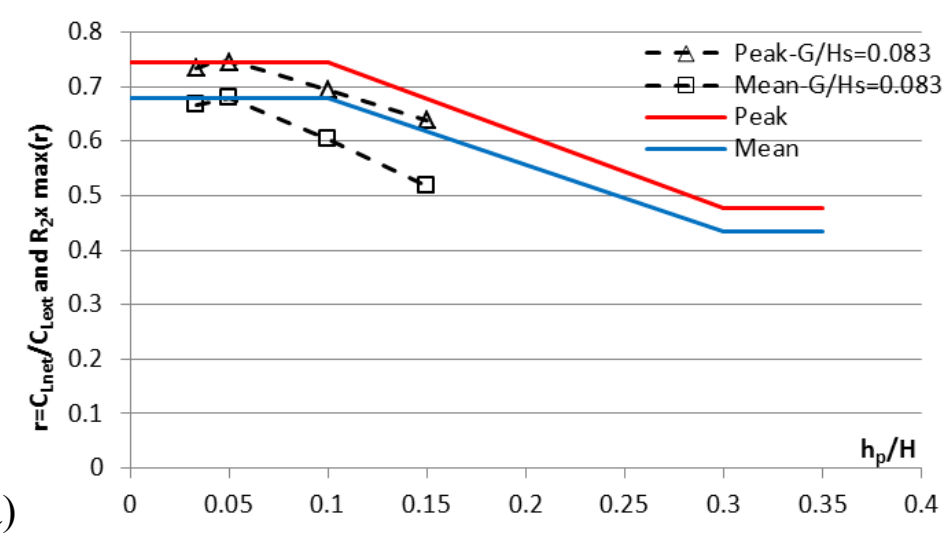




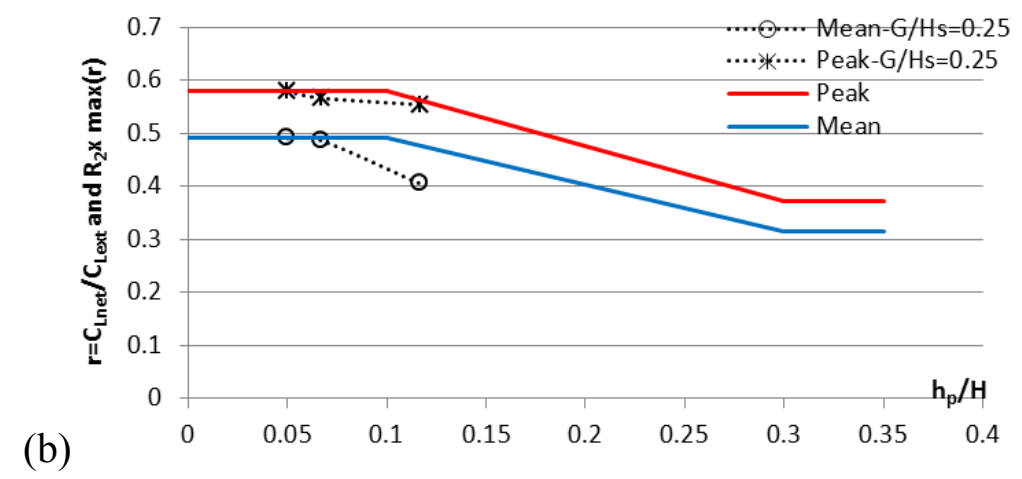

Figure 18. Comparison of proposed $R_{2}$ curve with $\mathrm{r}$ as a function of $\mathrm{h}_{\mathrm{p}} / \mathrm{H}$ : (a) $\mathrm{G} / \mathrm{H}_{\mathrm{s}}=0.083$, (b) $\mathrm{G} / \mathrm{H}_{\mathrm{s}}=0.25$

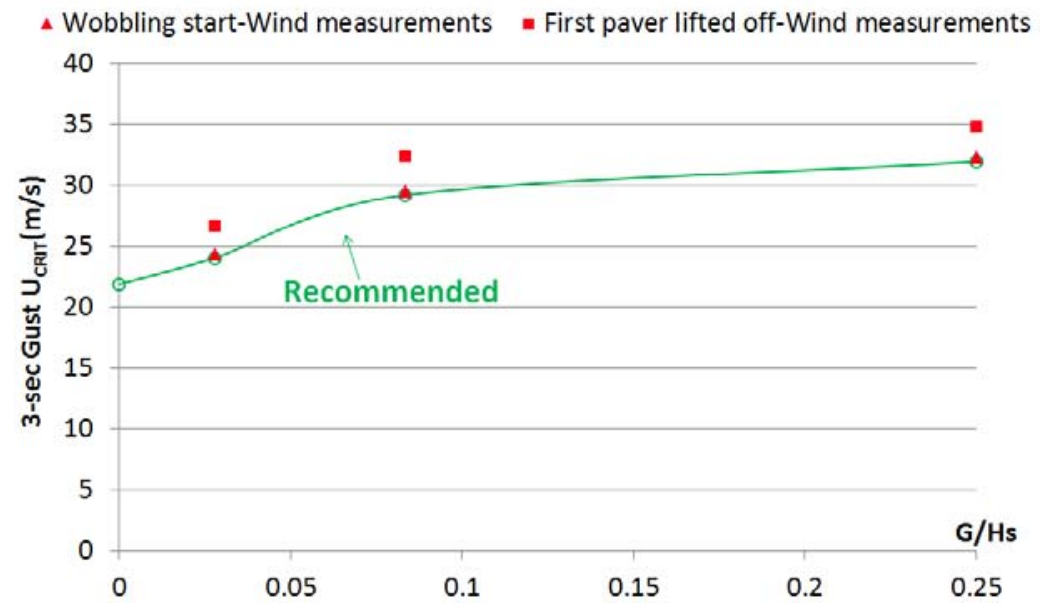

Figure 19. Critical wind speed vs. $\mathrm{G} / \mathrm{H}_{\mathrm{s}}\left(\mathrm{h}_{\mathrm{p}} / \mathrm{H}=0.05\right.$ for wind measurements $)$

\subsubsection{Applications and Special Notes}

1. The proposed guidelines were derived assuming a paver size of $0.305 \mathrm{~m}$ by $0.305 \mathrm{~m}$ by $2.54 \mathrm{~cm}$ thickness. This particular size was selected as it represents the most common paver size on typical flat roof low-rise buildings. The guidelines will probably work for pavers that have sizes close to the size tested. Future experiments are needed to investigate the applicability of the proposed guidelines for pavers with sizes and aspect ratios very different from the ones tested for the current work. 
2. The effect of building height has not been examined in this paper but, based on the results of Kind et al (1987), the results are expected to be conservative for mid and high-rise buildings.

3. The effect of paver size and geometry has not been evaluated in this paper. It is to be noted that the element sizes have an effect on the failure of non-interlocking roof pavers (Kind et al, 1987). Previous studies by Bienkiewicz and Sun (1997) indicated that square pavers are more wind-resistant than rectangular pavers.

4. The general effect of interlocking and strapping systems was investigated in this paper through the effect of load sharing mechanism between pavers. These systems are usually effective and improve the wind performance of roof pavers. The application of the proposed guidelines is primarily for loose-laid roof pavers without any interlocking or strapping system. However, some guidance of the effective reduction in lift-off forces can be drawn from the results in Figs. 14 and 15. For more precise results it is recommended to perform wind tunnel testing at large scale or full scale testing to find out the characteristics and wind performance of a specific interlocking or strapping system.

\subsection{Conclusions}

The objective of this paper was to develop simple guidance in code format for design of commonly used loose-laid roof pavers. A set of large-scale experiments was performed to investigate the wind loading on concrete roof pavers on the flat roof of a low-rise building. The experiments were performed in the Wall of Wind, a large-scale hurricane testing facility at Florida International University. Experiments included both wind blow-off tests and detailed pressure measurements on the top and bottom surfaces 
of the pavers. The general effect of interlocking and strapping systems was studied through the effect of load sharing mechanism between pavers. Based on the experimental results and review of literature, design guidelines are proposed for air-permeable looselaid roof pavers against wind uplift. The guidelines have been formatted so that use can be made of the existing information in codes and standards such as ASCE 7-10 on exterior pressures on components and cladding. The effects of pressure equalization, the paver's edge-gap to spacer height ratio and parapet height as a fraction of building height on the wind performance of roof pavers were investigated and are included in the guidelines as adjustment factors. The applications and limitations of the guidelines are discussed.

\subsection{Acknowledgements}

We would like to greatly thank the Tile Tech Company for providing us with concrete roof pavers and the pedestal system required for the wind destructive tests. This research was supported by the National Science Foundation (NSF) (NSF Award No. CMMI-1151003) and the Florida Division of Emergency Management (DEM). The help

received from the graduate research assistant, Ramtin Kargarmoakhar is gratefully acknowledged. The help offered by the Wall of Wind manager, Walter Conklin and the Research scientists, Roy Liu Marquis and James Erwin is also greatly appreciated.

\subsection{References}

Amano, T., Fujii, K., Tazaki, S., 1988. Wind loads on permeable roof-blocks in roof insulation systems. Journal of Wind Engineering \& Industrial Aerodynamics 29, 39-48.

ANSI/SPRI, RP-4, 2013. Wind design standard For ballasted single-ply roofing systems, Waltham, MA. 
AS 1170.2, 2011. Australian/New Zealand standard: structural design actions, Part 2: wind actions, Standards Australia/Standards New Zealand, Sydney, Australia.

ASCE 7-10, 2010. Minimum design loads for buildings and other structures, American Society of Civil Engineers, ASCE, Virginia.

Asghari Mooneghi, M., Irwin, P., Gan Chowdhury, A., 2014. Large-scale testing on wind uplift of roof pavers. Journal of wind engineering and industrial aerodynamics 128, 2236.

Banks, D., 2011. Measuring peak wind loads on solar power assemblies, in: Proceedings of the The 13th International Conference on Wind Engineering.

Bienkiewicz, B., Endo, M., 2009. Wind considerations for loose-laid and photovoltaic roofing systems, Structures Congress, Austin, Texas, pp. 2578-2587.

Bienkiewicz, B., Meroney, R.N., 1988. Wind effects on roof ballast pavers. Journal of engineering structures 114, 1250-1267.

Bienkiewicz, B., Sun, Y., 1992. Wind-tunnel study of wind loading on loose-laid roofing system. Journal of wind engineering and industrial aerodynamics 43, 1817-1828.

Bienkiewicz, B., Sun, Y., 1997. Wind loading and resistance of loose-laid roof paver systems. Journal of wind engineering and industrial aerodynamics 72, 401-410.

Bofah, K.K., Gerhardt, H.J., Kramer, C., 1996. Calculations of pressure equilibration underneath loose-laid, flow permeable roof insulation boards. Journal of wind engineering and industrial aerodynamics 59, 23-37.

Cheung, J.C.K., Melbourne, W.H., 1986. Wind loads on porous cladding, 9th Australasian Fluid Mechanics conference, Auckland, pp. 308-311.

Cheung, J.C.K., Melbourne, W.H., 1988. Wind loading on a porous roof. Journal of wind engineering and industrial aerodynamics 29, 19-28.

DEUTSCHE NORM, 2001-03. DIN 1055-4, Einwirkungen auf Tragwerke, Teil 4: Windlasten.

ESDU, 1985. Characteristics of atmospheric turbulence near the ground, Part II: Single point data for strong winds (Neutral Atmosphere), Engineering Sciences Data Unit Item 85020, London UK.

Fu, T.-C., 2013. Development of effective approaches to the large-scale aerodynamic testing of low-rise building, Civil Engineering. Florida International University. 
Fu, T.-C., Aly, A.M., Chowdhury, A.G., Bitsuamlak, G., Yeo, D., Simiu, E., 2012. A proposed technique for determining aerodynamic pressures on residential homes. Wind and Structures 15, 27-41.

Gerhardt, H.J., Janser, F., 1995. Windbelastung belufteter Fassadensysteme. Bauingenieur 70, 193-201.

Gerhardt, H.J., Kramer, C., Bofah, K.K., 1990. Wind loading on loosely laid pavers and insulation boards for flat roofs. Journal of Wind Engineering and Industrial Aerodynamics 36, 309-318.

Geurts, C.P.W., 2000. Wind loads on permeable roof covering products, Fourth Colloquium on Bluff Body Aerodynamics and Applications, Ruhr Universität Bochum, pp. 511-514.

Harris, R.I., Deaves, D.M., 1981. The Structure of Strong Winds, in: Proceedings of the CIRIA Conference. Published by the Construction Industry Research and Information Association, 6 Storey's Gate, London SW1P 3AU.

Ho, T.C.E., Surry, D., Morrish, D., Kopp, G.A., 2005. The UWO contribution to the NIST aerodynamic database for wind loads on low buildings: Part 1. Archiving format and basic aerodynamic data. Journal of wind engineering and industrial aerodynamics 93 , $1-30$.

Holmes, J.D., 2007. Wind loading of structures. Taylor \& Francis.

Irwin, P., 2009. Wind engineering research needs, building codes and project specific studies, in: Proceedings of the 11th Americas Conference on Wind Engineering.

Irwin, P., Cooper, K., Girard, R., 1979. Correction of distortion effects caused by tubing systems in measurements of fluctuating pressures. Journal of Wind Engineering and Industrial Aerodynamics 5, 93-107.

Irwin, P., Dragoiescu, C., Cicci, M., Thompson, G., 2012. Wind tunnel model studies of aerodynamic lifting of roof pavers, in: Proceedings of the Advances in Hurricane Engineering Conference, 496-505.

Kind, R.J., 1988. Worst suctions near edges of the flat roof tops with parapets. Journal of wind engineering and industrial aerodynamics 31, 251-264.

Kind, R.J., 1994. Predicting pressure distribution underneath loose laid roof cladding systems. Journal of Wind Engineering and Industrial Aerodynamics 51, 371-379.

Kind, R.J., Savage, M.G., Wardlaw, R.L., 1987. Further wind tunnel tests of loose-laid roofing systems. NRC. 
Kind, R.J., Savage, M.G., Wardlaw, R.L., 1988. Prediction of wind-induced failure of loose laid roof cladding systems. Journal of Wind Engineering and Industrial Aerodynamics 29, 29-37.

Kind, R.J., Wardlaw, R.L., 1977. The development of a procedure for the design of rooftops against gravel blow off and scour in high winds, Symposium on Roofing Technology, pp. 112-123.

Kind, R.J., Wardlaw, R.L., 1979. Model studies of the wind resistance of two loose-laid roof-insulation systems, LTR - LA- 234. National Research Council Canada.

Kind, R.J., Wardlaw, R.L., 1982. Failure mechanisms of loose laid roof insulation systems. Journal of wind engineering and industrial aerodynamics 9, 325-341.

Kopp, G.A., Banks, D., 2013. Use of the wind tunnel test method for obtaining design wind loads on roof-mounted solar arrays. Journal of structural engineering 139, 284-287.

Kopp, G.A., Surry, D., Mans, C., 2005. Wind effects of parapets on low buildings: Part 1. Basic aerodynamics and local loads. Journal of wind engineering and industrial aerodynamics $93,817-841$.

Kumar, K.S., Stathopoulos, T., 1998. Spectral density functions of wind pressures on various low building roof geometries. Wind and Structures 1, 203-223.

Lin, J.X., Surry, D., 1998. The variation of peak loads with tributary area near corners on flat low building roofs. Journal of wind engineering and industrial aerodynamics $77-78$, 185-196.

Lin, J.X., Surry, D., Tieleman, H.W., 1995. The distribution of pressure near roof corners of flat roof low buildings. Journal of Wind Engineering and Industrial Aerodynamics 56, $235-265$.

Melbourne, W.H., 1980. Turbulence effects on maximum surface pressures - a mechanism and possibility of reduction. Wind Engineering, 541-551.

NBCC, 1995. User's Guide-NBC 1995, Structural Commentaries (Part 4), National Research Council of Canada, Ottawa, Canada.

NEN EN 1991-1-4/NA, Eurocode: Actions on structures - General actions - Part 1.4: Wind actions.

Oh, J.H., Kopp, G.A., 2012. Pressure equalization and analytical solutions for pressures between double-layer envelopes, in: Proceedings of the 3rd American Association for Wind Engineering Workshop. 
Oh, J.H., Kopp, G.A., Inculet, D.R., 2007. The UWO contribution to the NIST aerodynamic database for wind loads on low buildings: Part 3. Internal pressures. Journal of Wind Engineering and Industrial Aerodynamics 95, 755-779.

Pierre, L.M.S., Kopp, G.A., Surry, D., Ho, T.C.E., 2005. The UWO contribution to the NIST aerodynamic database for wind loads on low buildings: Part 2. Comparison of data with wind load provisions. Journal of wind engineering and industrial aerodynamics 93 , 31-59.

Richards, P.J., Hoxey, R.P., Connell, B.D., Lander, D.P., 2007. Wind-tunnel modelling of the Silsoe Cube. Journal of wind engineering and industrial aerodynamics 95, 1384-1399.

Saathoff, P.J., Melbourne, W.H., 1997. Effects of free-stream turbulence on surface pressure fluctuation in a separation bubble. Journal Of Fluid Mechanics 337, 1-24.

Sadek, F., Simiu, E., 2002. Peak non-Gaussian wind effects for database-assisted lowrise building design. Journal of engineering Mechanics 128, 530-539.

Stathopoulos, T., 1982. Wind pressure on low buildings with parapets. Journal of the Structural Division 108, 2723-2736.

Stathopoulos, T., Baskaran, A., 1988. Turbulent wind loading on roofs with parapet configurations. Canadian Journal of Civil Engineering 29, 570-578.

Sun, Y., Bienkiewicz, B., 1993. Numerical simulation of pressure distributions underneath roofing paver systems. Journal of Wind Engineering and Industrial Aerodynamics 46-47, 517-526.

Tieleman, H.W., 2003. Wind tunnel simulation of wind loading on low-rise structures: a review. Journal of wind engineering and industrial aerodynamics 91, 1627-1649.

Trung, V., Tamura, Y., Yoshida, A., 2010. Numerical computation for lower surface pressures on a porous sunshade roof cover sheet, Fifth International Symposium on Computational Wind Engineering (CWE2010), Chapel Hill, North Carolina, USA.

Yamada, H., Katsuchi, H., 2008. Wind-tunnel study on effects of small-scale turbulence on flow patterns around rectangular cylinder, 4th International Colloquium on Bluff Bodies Aerodynamics \& Applications, Italy.

\subsection{Appendix}

\section{Procedure for Conversion of Wind Speed Averaging Time}

In order to convert a gust speed with a specific duration to another gust with a different duration, the following approach is taken from ESDU (1985) (Harris and 
Deaves (1981) Model). The mean wind speed in the atmospheric boundary layer can be calculated from the following equation:

$$
\frac{U}{u_{\tau}}=\frac{1}{k}\left[\ln \left(\frac{z}{z_{0}}\right)+a_{1} \frac{z}{h}+\left(1-\frac{a_{1}}{2}\right)\left(\frac{z}{h}\right)^{2}-\frac{4}{3}\left(\frac{z}{h}\right)^{3}+\frac{1}{4}\left(\frac{z}{h}\right)^{4}\right]
$$

where $\mathrm{k}$ is the Von Karman's constant equal to 0.4 and $a_{1}$ is a constant with the value 5.75. In this expression $\mathrm{f}$ is the Coriolis parameter given by:

$$
f=2 \Omega \sin (\varphi)
$$

were $\Omega=0.0000729$ is the angular velocity of the earth in radian per second, $\varphi$ is the latitude and $h$ is the boundary layer depth given by:

$$
h=\frac{u_{\tau}}{6 f}
$$

$u_{\tau}$ is the shear velocity. It can be quickly calculated using an iterative approach for a known gradient speed $U_{g}$ by guessing an initial value (e.g. $1.2 \mathrm{~m} / \mathrm{s}$ )

$$
u_{\tau, n}=\frac{k U_{g}}{\ln \frac{u_{\tau, n-1}}{z_{0} f}+1}
$$

were $u_{\tau, \mathrm{n}}$ is the nth iteration of $u_{\tau}$. Typically the iterative process converges very quickly. The relationship between the gust speed and the mean speed is:

$$
\frac{U_{g}}{U}=1+g I
$$

where $\mathrm{g}$ is a peak factor which depends on the gust duration and $I$ is the turbulence intensity. In order to calculate $g$, first another factor called $g^{\prime}$ is calculated from Davenport's original expression as:

$$
g^{\prime}=\sqrt{2 \ln \left(T_{0} v\left(\tau, T_{0}\right)\right)}+\frac{0.577}{\sqrt{2 \ln \left(T_{0} v\left(\tau, T_{0}\right)\right)}}
$$


$\mathrm{T}_{0}$ is the sampling period (e.g. one hour), $\tau$ is the duration of the running average for gust speed calculations (e.g. 3 seconds) and $v$ is "Cycling rate" which is calculated from the following expressions:

$$
\begin{aligned}
v\left(\tau, T_{0}=1 h r\right) & =\left(0.007+0.213\left(T_{u} / \tau\right)^{0.654}\right) / T_{u} \\
T_{u} & =3.13 z^{0.2} \text { seconds }
\end{aligned}
$$

Because of the running average process for measuring gusts of duration $\tau$ the turbulence spectrum is effectively low pass filtered. Therefore the spectrum being sampled to measure the peak gust is not the full spectrum of the intensity $I$. To correct for this the final peak factor $\mathrm{g}$ is computed from $g^{\prime}$ using the following equation:

$$
\begin{gathered}
g=g^{\prime}\left[1-0.193\left(\frac{T_{u}}{\tau}+0.1\right)^{-0.68}\right] \\
I=\frac{\sqrt{u^{2}}}{u_{\tau}} \frac{u_{\tau}}{U}
\end{gathered}
$$

$\frac{u_{\tau}}{U}$ can be obtained from the above and the $\frac{\sqrt{\mathrm{u}^{2}}}{u_{\tau}}$ is expressed as:

$$
\frac{\sqrt{u^{2}}}{u_{\tau}}=\frac{7.5 \eta\left(0.538+0.09 \ln \left(\frac{z}{z_{0}}\right)\right)^{16}}{1+0.156 \ln \left(u_{\tau} /\left(f z_{0}\right)\right)}
$$

where

$$
\eta=1-\frac{6 f z}{u_{\tau}}
$$

Using the above procedure for suburban terrain in Miami area at $\mathrm{z}=3.48 \mathrm{~m}$ (building height at full scale) results in final conversion factors of $\frac{U_{3 \sec }}{U_{0.21 s e c}}=0.87$ and $\frac{U_{3 s e c}}{U_{0.3 s e c}}=$ 0.88 . 


\section{CHAPTER VI}

SUMMARY AND CONCLUSIONS 


\section{CHAPTER VI}

\section{SUMMARY AND CONCLUSIONS}

This chapter summarizes the conclusions of this dissertation. The achievements in this dissertation are summarized into 2 parts: 1. A partial turbulence simulation methodology was successfully developed for predicting peak wind loads on small structures and building appurtenances. Pressure results obtained using large-scale models of the TTU and Silsoe building at WOW facility compared well to full-scale results. This showed the efficacy of the Partial Turbulence Simulation methodology. 2. Wind loading mechanisms of loose-laid roof pavers were investigated. The results of the experiments were used to propose design guidelines for roof pavers against wind uplift. The details are described in the following sections.

\subsection{Partial Turbulence Simulation}

Reliable wind load data can be obtained by first understanding the wind loading mechanism on structures and then developing flow simulation techniques for wind testing facilities. To this end, a method called Partial Turbulence Simulation (PTS) was developed for predicting peak wind loads on structures from large-scale testing in wind testing facilities. In large-scale testing which is most favorable for small structures and building appurtenances the ability to obtain a large enough turbulence integral scale in the laboratory is usually compromised by the limited dimensions of the wind tunnel. This means that in normal boundary layer wind tunnels it is not possible to simulate the low frequency end of the turbulence spectrum when using these larger model scales and only

the high frequency end of the turbulence spectrum can be simulated. In Chapter II, techniques and scaling requirements for large-scale testing in a facility with partial 
turbulence simulation were described in detail. A theoretical method was also developed to include the effects of deficient low frequency turbulence in post-test analysis. In this method, the turbulence is divided into two distinct statistical processes, one at high frequencies which can be simulated in the wind tunnel, and one at low frequencies which can be treated in a quasi-steady manner. The joint probability of load resulting from these two processes is derived, with one part coming from the wind tunnel data and the remainder from the assumed Gaussian behavior of the missing low frequency component. There are two versions for this method proposed in this dissertation. In the simplified version called PTS and described in Chapter II, just the effects of missing low frequency longitudinal turbulence are included in the post-test analysis which is believed to be the most important component of the turbulence. Comparison of the full-scale data on Silsoe cube with the results obtained from tests on a large-scale model of the Silsoe cube in the WoW facility at FIU for mean and peak pressure coefficients showed generally good agreement, particularly when the highest loads out of all wind directions were compared. Some differences were observed in the central area on the roof for non-governing wind directions, primarily quartering angles. This was due to the turbulence spectrum being slightly higher on the model at roof height and having a steeper vertical gradient. Another reason for this was considered to be due to ignoring the effects of low frequency fluctuations of lateral and vertical turbulence. To address the latter issue, the PTS method was extended in Chapter III to include the effects of low frequency lateral and vertical turbulence. In this version of the theory called in this dissertation 3DPTS, a number of tests are required at different wind tilt and azimuth angles in small angle increments. The efficacy of the method was assessed by comparing predicted mean and peak pressure 
coefficients derived from tests on large-scale models of the Silsoe Cube and TTU building models in the WOW facility with the corresponding available full-scale data. Results showed generally good agreement with full-scale data and improvements upon the PTS method on some taps in critical regions on the roof which are more sensitive to wind directional effects. It should be noted that while the present method was applied in the WoW facility, it is not limited in its application to this type of facility and is equally applicable to boundary layer wind tunnels in general. It also allows the use of considerably larger model scales than are possible in conventional testing, because it eliminates restrictions imposed by the achievable integral turbulence scales in the laboratory. The proposed theory substantially enhances the ability of existing wind testing facilities to make accurate predictions of full-scale behavior. It also allows for testing at higher Reynolds number and for improved spatial resolution of the pressure taps in high pressure zones.

\subsection{Wind Loading on Roof Pavers}

In order to implement the technical knowledge achieved from the experiments into engineering practices, the wind loading mechanisms of concrete roof pavers were investigated in this dissertation. Wind blow-off tests and pressure measurements were carried out on a square portion of a flat roof of a low-rise building. The experiments were performed in the WoW facility, at FIU. The effects of pavers' edge-gap to spacer height ratio and the influence of an edge parapet on net uplift pressures were also explored. Results showed that increasing the pavers' edge-gap to spacer height ratio improves the wind performance of the system. Parapets generally reduced the net uplift force on roof pavers. However, a certain relative parapet height in the range of $h_{p} / H=0.10$ to 0.15 
existed in which the uplift loads reach worst case values. The effects of resolution and layout of the pressure taps on the net uplift force and moment coefficients were also investigated and recommendations were made for the location and spacing of pressure taps needed to accurately resolve the uplift pressures. It was found that a larger number of taps than typically used in the past was needed for capturing the high local suctions. The general effect of interlocking and strapping systems was studied through the effect of load sharing mechanism between pavers. Based on the experimental results and review of literature, design guidelines were proposed for air-permeable loose-laid roof pavers against wind uplift. These guidelines have been formatted so that the user can utilize the existing information in codes and standards such as ASCE 7-10 on exterior pressures on components and cladding. These guidelines include the effects of pressure equalization, the paver's edge-gap to spacer height ratio and the parapet height as a fraction of building height as adjustment factors. The applications and limitations of the guidelines were discussed. 


\section{CHAPTER VII}

RECOMMENDATIONS FOR FUTURE RESEARCH 


\section{CHAPTER VII}

\section{RECOMMENDATIONS FOR FUTURE RESEARCH}

The objective of this dissertation was to comprehensively and persuasively investigate the wind loading mechanisms on building envelope and roofing systems, develop flow simulation techniques for large-scale wind testing in aerodynamic facilities from which reliable wind load data can be obtained, and implement the experimental results into engineering practices by developing code specific design guidelines. The recommendations for future research are described in the following sections.

\subsection{Partial Turbulence Simulation}

Future tests should be planned to refine the proposed partial turbulence simulation technique for a wider range of model scales. This is important for further validating the theory for a range of model scales and finding out its limitations. This will result in effective test protocols for large-scale wind testing which will be used to obtain benchmark aerodynamic data. These data are needed to validate or correct results of tests performed in conventional facilities and ultimately advance the state of the art knowledge of the aerodynamics and wind loading of low-rise buildings, building components and appurtenances.

\subsection{Non-stationary Gusts and Rapid Wind Directionality Change Effects}

Hurricane winds can exhibit strong occasional non-stationarities both in wind velocity and also direction which may have significant influence on wind loading. Similarly rapid changes occur in thunderstorm downbursts and tornadoes. The rapid changes in mean wind speed and direction raise questions about the applicability of conventional aerodynamic theories to evaluate effects of hurricanes, thunderstorms and 
tornadoes on structures. Therefore, information on aerodynamic effects of nonstationarities in the oncoming flow is desirable. Experiments should be performed on building models under the simulation of transient flows and compared with those obtained for steady winds. The partial turbulence simulation method can potentially be modified to include the non-stationary phenomena and their effects on structures.

\subsection{Design Guidelines for Roof Paving Systems}

In order to overcome the limitations of the proposed guidelines for design of roof pavers suggested in this dissertation, future experiment would be required to address the following issues:

1- Effects of building height

2- Effects of oncoming wind turbulence

2- Effects of shape of the roof pavers (plan aspect ratio, thickness and venting holes)

3- Design and investigate novel interlocking and strapping systems

Similar phenomena observed for the roof pavers affect other building envelope and roofing systems like roof tiles and shingles. The large-scale testing methods used in the present experiments are also applicable to other air-permeable roofing systems and provide new insights through accurately reproducing critical aerodynamic effects at fullscale, or close to full-scale Reynolds numbers. 
VITA

\section{MARYAM ASGHARI MOONEGHI}

Born, Tehran, Iran

2004-2008

B.Sc., Aerospace Engineering

Amirkabir University of Technology

Tehran, Iran

2008-2010

M.Sc., Aerospace Engineering (Structural)

Amirkabir University of Technology

Tehran, Iran

2010-2014

Research and Teaching Assistant

Florida International University

Miami, Florida

2012

M.Sc., Civil Engineering

Florida International University

Miami, Florida

$2010-2014$

$\mathrm{PhD}$, Civil Engineering

Florida International University

Miami, Florida

\section{PUBLICATIONS AND PRESENTATIONS}

Asghari Mooneghi, M., Irwin, P., Gan Chowdhury, A. (2015). Partial Turbulence Simulation Method for Predicting Peak Wind Loads on Small Structures and Building Appurtenances, Journal of Wind Engineering and Industrial Aerodynamics, under review.

Asghari Mooneghi, M., Irwin, P., Gan Chowdhury, A. (2015). Towards Guidelines for Design of Loose-Laid Roof Pavers for Wind Uplift, to be submitted to Wind and Structures.

Ovesy, H.R., Asghari Mooneghi, M., Kharazi, M. (2015). Post-Buckling Analysis of Delaminated Composite Plates Using a Novel Layerwise Theory, Accepted for Publication, Thin-Walled Structures.

Asghari Mooneghi, M., Irwin, P., Gan Chowdhury, A. (2014). Large-Scale Testing on Wind Uplift of Roof Pavers, Journal of Wind Engineering and Industrial Aerodynamics, 128: $22-36$. 
Kharazi, M., Ovesy, H.R., Asghari Mooneghi, M. (2014). Buckling Analysis of Delaminated Composite Plates Using a Novel Layerwise Theory, Thin-Walled Structures, 74: 246-254.

Asghari Mooneghi, M., Irwin, P., Gan Chowdhury, A. (June 2015). Partial Turbulence Simulation Method for Small Structures, 14th International Conference on Wind Engineering, Porto Alegre, Brazil, June 21-26, 2015.

Asghari Mooneghi, M., Irwin, P., Gan Chowdhury, A. (June 2015). Exploratory Studies on a Bilinear Aeroelastic Model for Tall Buildings, 14th International Conference on Wind Engineering, Porto Alegre, Brazil, June 21-26, 2015.

Filmon Habte, F., Asghari Mooneghi, M., Gan Chowdhury, A., Irwin, P. (June 2015). Full-Scale Testing to Evaluate the Performance of Standing Seam Metal Roofs Under Simulated Wind Loading, 14th International Conference on Wind Engineering, Porto Alegre, Brazil, June 21-26, 2015.

Richards, P., Asghari Mooneghi, M., Gan Chowdhury, A. (June 2015). Combing Directionally Narrow Band Wind Loading Data in order to Match Wide Band Full-scale Situations, 14th International Conference on Wind Engineering, Porto Alegre, Brazil, June 21-26, 2015.

Asghari Mooneghi, M., Irwin, P., Gan Chowdhury, A. (April 2015). Design Guidelines for Roof Pavers against Wind Uplift, Structures Congress, Portland, Oregon, April 2325, 2015.

Asghari Mooneghi, M., Irwin, P., Gan Chowdhury, A. (April 2014). Wind Uplift of Concrete Roof Pavers, Structures Congress, April 3-5, Boston, Massachusetts.

Asghari Mooneghi, M., Bitsuamlak, G. (October 2012). Aerodynamic Shape Optimization for High-rise Buildings, ATC-SEI Advances in Hurricane Engineering Conference, October 22-24, Miami, Florida.

Londono Lozano, J.G., Asghari, M.M.,Bitsuamlak, G.T. (June 2011). Optimal Wind Farm Turbine Placement and Selection, EMI 2011, June 2-4, North Eastern University, Boston, Massachusetts.

Ovesy, H.R., Kharazi, M., Asghari Mooneghi, M. (December 2010). Buckling Analysis of Composite Laminates with Through-The-Width Delamination Using a Novel Layerwise Theory, The 2nd International Conference on Composites: Characterization, Fabrication \& Application (CCFA-2), December 27- 30, Kish Island-Iran. 